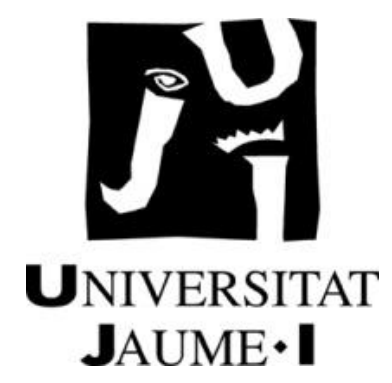

FACULTAD DE CIENCIAS DE LA SALUD DEPARTAMENTO DE PSICOLOGÍA BÁSICA, CLÍNICA Y PSICOBIOLOGÍA

\title{
NUEVOS ABORDAJES PARA EL TRATAMIENTO DE LA FIBROMIALGIA: UNA INTERVENCIÓN POSITIVA PARA LA PROMOCIÓN DEL OPTIMISMO MEDIANTE LA UTILIZACIÓN DE TICs
}

TESIS DOCTORAL

Presentada por:

Guadalupe Molinari

Dirigida por:

Dra. Cristina Botella Arbona

Dra. Azucena García-Palacios

Castellón, Abril 2017 



\section{Índice}

CAPÍTULO I Introducción General

CAPÍTULO II Development and pilot testing of a positive imagery intervention with online support in the treatment of fibromyalgia

CAPÍTULO III The power of visualization: back to the future for pain management in fibromyalgia syndrome

CAPÍTULO IV How and for whom does a 108 positive affect intervention work for fibromyalgia: An analysis of mediators and moderators

CAPÍTULO V Validación de instrumentos de medida utilizados en el estudio empírico

Psychometric properties of the General Self Efficacy-12 scale in Spanish: general and clinical population samples 
The contribution of future directed

thinking to affect dimensions:

differences in general and clinical

populations

Assessment of positive affect regulation:

validation of the Spanish version of the

Response to Positive Affect

questionnaire in clinical and general

samples

CAPÍTULO VI Discusión General

Referencias Bibliográficas

Anexos 


\section{Introducción general}

La fibromialgia (FM) es una enfermedad de etiología desconocida que se caracteriza por la presencia de dolor crónico generalizado acompañada de una gran variedad de síntomas somáticos, afectivos y cognitivos. Entre ellos, destacan la fatiga persistente, el sueño no reparador, la rigidez generalizada, los problemas de concentración y memoria, y los síntomas ansiosodepresivos (Rivera y cols., 2006). La prevalencia mundial de la FM está estimada en un 2,7\% y varía de acuerdo al país de estudio. En España, su prevalencia en población general se sitúa en un 2,4\% (Queiroz, 2013). Por sexos, la prevalencia entre los varones se estima en un $0,2 \%$, frente a un $4,2 \%$ en las mujeres, lo que supone una relación mujer:varón de 21:1. Según el estudio EPIFFAC realizado en España, el 84\% de los pacientes con FM tienen una o más enfermedades comórbidas: un 67\% tienen otras afecciones musculoesqueléticas, un 35\% sufre de trastornos psicológicos, un $27 \%$ de trastornos gastrointestinales, un $23,5 \%$ de trastornos cardiovasculares y un 19\% de trastornos endocrinológicos (Castells y cols., 2013).

Si bien esta enfermedad ha adquirido notoriedad en los últimos años, cuenta con 110 años de historia, y desde sus comienzos la FM se ha considerado una enfermedad controversial. La ausencia de patología orgánica específica demostrable, la gran heterogeneidad de síntomas (muchas veces compartidos con otros síndromes de dolor crónico) y el debate en torno a su especificidad diagnóstica, han ocasionado numerosos cuestionamientos a su reconocimiento como enfermedad y al establecimiento de sus criterios diagnósticos. Es por ello que aún hoy continúan en revisión 
(Wolfe y cols., 2011). Estas controversias han repercutido en el diagnóstico, evaluación y abordaje terapéutico de la FM.

En el período comprendido entre 1990 y 2010 las investigaciones científicas se dispararon, centrándose en el estudio de los mecanismos neurobiológicos de la FM, encontrando cada vez más un mayor número de síntomas asociados a la FM y diagnósticos comórbidos con otros síndromes como la fatiga crónica o el síndrome de colon irritable. Las evidencias de que se trataba de un síndrome que generaba un gran impacto psicosocial en la vida de las personas y que muchas de ellas presentaban además trastornos mentales asociados eran cada vez mayores.

\section{Más allá del modelo biopsicosocial del dolor}

La complejidad de la fibromialgia ocasiona que se recomiende que su abordaje sea también integral. En este sentido, los modelos bio-psicosociales del dolor son ampliamente aceptados (Flor y Turk, 2011). Éstos sostienen que para comprender la percepción y la respuesta de la persona al síndrome de dolor debemos tener en cuenta la interrelación entre factors biológicos, su estado psicológico y el contexto sociocultural en el que se encuentra (Gatchel, Peng, Peters, Fuchs y Turk, 2007). De esta manera, la experiencia de dolor es el resultado de la transmisión y modulación de la información sensitiva. Y este proceso será diferente para cada individuo, teniendo en cuenta su disposición genética, su historia de aprendizaje, su estado psicológico y su contexto sociocultural (ver Figura 1). 


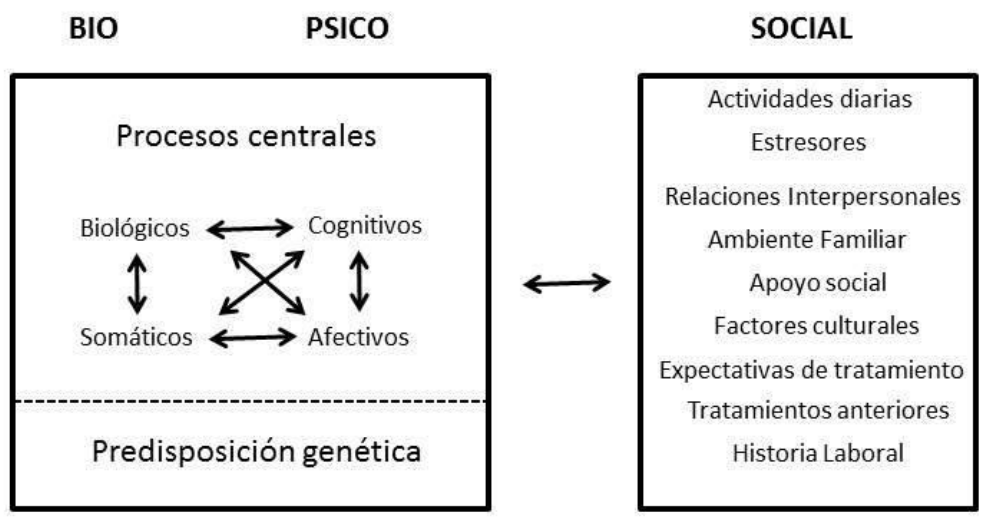

Figura 1. Modelo de los procesos biopsicosociales involucrados en la salud y enfermedad. Figura adaptada de Gatchel (2004)

Actualmente, se han propuesto nuevos modelos para entender los procesos involucrados en el fenómeno del dolor crónico (Jensen, Tan y Chua, 2015; Jensen, Ehde y Day, 2016). Esta propuesta se basa en el modelo de dos sistemas neurofisiológicos, de castigo y recompensa, de Jeffrey Gray (1990). De acuerdo a este modelo, el primer factor (BAS) es un sistema responsable de las conductas de acercamiento, y sus emociones (ej. Esperanza, alegría, entusiasmo) y cogniciones asociadas (ej. Autoeficacia). El segundo factor (BIS), por el contrario, es el sistema responsable de las conductas de evitación o inhibición, y sus emociones (ej. Ansiedad, depresión) y cogniciones asociadas (ej. Desesperanza). Estos dos sistemas se activan cuando, dentro de las condiciones ambientales, existe alguna señal de recompensa o castigo. Las señales de recompensa activarían el sistema BAS, mientras que las señales de castigo harían lo propio con el sistema BIS. En el caso del dolor, al tratarse de una experiencia aversiva para el individuo, 
activaría el sistema BIS, lo que generaría conductas como la inactividad o la interrupción de actividades que, a su vez, se asociarían a cogniciones negativas, como la catastrofización del dolor, y a emociones negativas como el miedo y la ansiedad. La experiencia de dolor, a su vez, podría tener un efecto indirecto (y negativo) en el sistema BAS, ocasionando un abandono de metas vitales y una inhibición de las respuestas cognitivas y emocionales positivas (Jensen, Ehde y Day, 2016).

A diferencia de los modelos biopsicosociales del dolor que hipotetizan una relación causal y muchas veces unidireccional entre los distintos factores, estos nuevos modelos de conceptualización del dolor crónico proponen relaciones de causalidad mutua, con factores que interaccionan y provocan cambios en otros, sin que ninguno de estos factores o sistemas sea el central (ver Figura 2). 


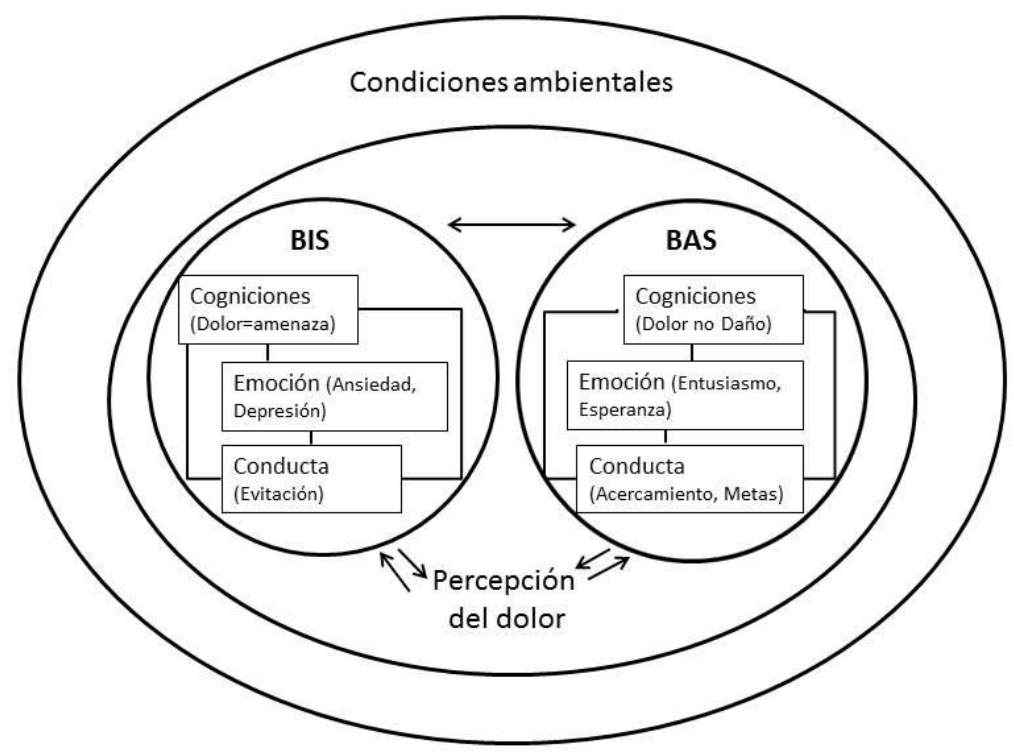

Figura 2. Modelo del BIS y BAS en dolor crónico. Figura adaptada de Jensen, Ehde y Day (2016)

En este sentido, desde un punto de vista clínico, los comportamientos, cogniciones y emociones asociadas al dolor son entendidos tanto como mecanismos de acción, así como resultados o consecuencias del dolor. Esto permite ampliar la mirada, no sólo a la hora de conceptualizar la experiencia de dolor, sino también en el abordaje terapéutico del mismo. Por ejemplo, hasta hace algunos años, los ensayos clínicos de dolor incluían medidas de sintomatología depresiva o ansiosa únicamente como medidas de resultados (Morley, Eccleston y Williams, 1999; Scascighini, Toma, Dober-Spielmann y Sprott, 2008). Sin embargo, siguiendo estos modelos, las emociones pueden entenderse también como agentes capaces de influenciar las conductas y los 
pensamientos asociados al dolor. Y en este punto, no sólo las emociones negativas, sino también las emociones positivas (Fredrickson, 2001).

\section{Más allá de las emociones negativas: importancia de los factores protectores}

En los últimos años, gracias a estas nuevas conceptualizaciones acerca de la experiencia de dolor, se ha empezado a estudiar la importancia de los factores protectores en pacientes con dolor crónico (Sturgeon y Zautra, 2010, 2013). Los factores psicológicos positivos como la aceptación del dolor, las emociones positivas y las estrategias adaptativas de afrontamiento influyen en el curso y en la experiencia de dolor.

El afecto positivo actúa amortiguando la experiencia de dolor a través de la reducción de la catastrofización del dolor (Hood, Pulvers, Carrillo, Merchant y Thomas, 2012) y ampliando el foco de atención y cognición hacia estímulos y experiencias no dolorosas (Finlan y Garland, 2015). Estudios recientes han encontrado una correlación negativa entre medidas de afecto positivo e intensidad del dolor en pacientes con FM (Finan, Zautra, Davis, 2009) y otros síndromes de dolor crónico (Tooyserkani, Besharat, Koochi, 2011; Zautra, Johnson y Davis, 2005). Asimismo, el afecto positivo se asocia a menores niveles de afecto negativo, especialmente en momentos de dolor intenso, y a menores niveles de depresión (Davis, Zautra y Smith, 2004; Strand y cols. 2006). Aunque son aún escasos, algunos estudios han explorado el rol del afecto positivo como moderador en la relación entre el dolor y algunos síntomas asociados. Thong, Tan y Jensen (2017) encontraron que aquellos participantes que tenían bajos niveles de 
afecto positivo evidenciaban correlaciones significativas entre la intensidad del dolor, el afecto negativo y niveles de depresión; mientras que aquellos participantes que manifestaban niveles elevados de afecto positivo, no mostraron correlaciones significativas entre dichas variables. Esto quiere decir que el afecto positivo parece actuar como "protector" frente al impacto del dolor.

Esta relación entre los niveles de afecto positivo y dolor parece variar en función del diagnóstico (Finan y Garland, 2015). Se ha demostrado que los pacientes con FM reportan mayor dolor y estrés diario que los pacientes con osteoatritis, y estas diferencias son explicadas por los niveles de afecto positivo. Además, los pacientes con FM presentan niveles de afecto positivo significativamente menores que los de pacientes con otras enfermedades reumatológicas (Zautra y cols., 2005). Estos déficits en el funcionamiento del afecto positivo en la FM también se han observado en estudios controlados de laboratorio mediante inducciones a través de imágenes positivas (Kamping, Bomba, Kanske, Diesch y Flor, 2013).

Otro de los factores protectores que se ha estudiado en relación al dolor crónico es el optimismo. El optimismo es entendido como una orientación hacia el futuro que se asocia a expectativas de resultados positivas (Carver, Scheier, Segerstrom, 2010). Si bien el optimismo es considerado un rasgo disposicional estable, muchos estudios sostienen la posibilidad de modificarlo en la edad adulta (Segerstrom, 2007). El optimismo ha sido relacionado con una menor sensibilidad al dolor, un mejor funcionamiento físico, una mayor adaptación al dolor y una reducción del malestar psicológico (Goodin y cols., 2013). Se ha demostrado que los 
individuos más optimistas son menos propensos a percibir las barreras que obstaculizan el camino hacia sus objetivos y, en los días que sienten más fatiga, son menos propensos a reducir su esfuerzo para alcanzar los mismos (Affleck y cols., 2001).

La percepción de autoeficacia en el manejo del dolor y sus consecuencias se ha caracterizado como un recurso psicológico protector y un factor de resiliencia asociado con la mejora de la función física en pacientes con dolor crónico (Edwards, Dworkin, Sullivan, Turk y Wasan, 2016). En un reciente meta-análisis, niveles bajos de autoeficacia en estos pacientes se asociaron a mayor incapacidad funcional, a un mayor número de problemas emocionales y mayor severidad del dolor (Jackson, Wang, Wang y Fan, 2014).

En síntesis, si bien la evidencia científica ha demostrado que los factores protectores positivos generan una serie de beneficios para los pacientes con dolor crónico, no existen en la actualidad prácticas empíricamente validadas que apunten directamente a aumentar los niveles de estas variables positivas. Por esta razón, es necesario el desarrollo y puesta a prueba de intervenciones que promuevan estos factores protectores que parecen resultar claves en la autogestión del dolor. Además, es necesario promover modelos que ayuden a entender cómo y para quiénes funcionarían estas intervenciones. 


\section{Nuevos abordajes terapéuticos para el tratamiento de la fibromialgia}

Como hemos señalado, la experiencia de dolor de estos pacientes es compleja e incluye factores conductuales, cognitivos y afectivos que afectan la calidad de vida de aquellos que la padecen. Por esta razón, los enfoques psicológicos han centrado sus esfuerzos en reducir la incapacidad generada por el dolor, el malestar emocional, y las estrategias de afrontamiento desadaptativas, más que buscar una reducción directa del dolor (Roditi y Robinson 2011). Las terapias cognitivo-comportamentales, la relajación, las intervenciones psicoeducativas, los tratamientos conductuales y los programas basados en mindfulness han demostrado ser efectivos en reducir los problemas de sueño, la depresión, el estado funcional y la catastrofización de los pacientes (Glombiewski y cols., 2010). Sin embargo, la evidencia de décadas de ensayos clínicos demuestra que los tamaños de efecto son modestos y sugiere que gran parte de la varianza de los resultados en los estudios sobre el tratamiento del dolor, y variables relacionadas con el dolor, sigue sin ser abordada en los tratamientos disponibles (Morley, Williams y Eccleston, 2013).

Normalmente, los enfoques terapéuticos son presentados a los pacientes dentro de un objetivo general orientado a disminuir las consecuencias negativas del dolor (Finan y Garland, 2015). Sin embargo, recientemente se han aplicado nuevas intervenciones clínicas para el manejo del dolor dirigidas a cambiar el enfoque de algunos paradigmas y a mejorar la eficacia de los tratamientos: 
(1) de aliviar y disminuir la manifestación de síntomas negativos a promover recursos de afrontamiento positivos para el dolor (Keefe y Wren, 2013).

(2) de las prácticas de salud tradicionales (ej. Terapia cara a cara ) a la inclusión de recursos de salud a través de las tecnologías de la información y de la comunicación (TICs) y de Internet.

En cuanto al primer punto, en el campo del dolor, el cambio de enfoque hacia el desarrollo de programas de tratamiento que promuevan factores positivos se hace evidente en los resultados de una reciente revisión sistemática de intervenciones psicológicas positivas en síndromes de dolor crónico (Iddon, Dickson y Unwin, 2016). En este trabajo se analizan 8 estudios (2 estudios cualitativos y 6 estudios cuantitativos) de los cuales todos excepto uno se desarrollaron a partir del año 2014. Esto indica la naturaleza emergente de esta área de investigación. En general, los estudios demuestran que estas intervenciones pueden ser beneficiosas en personas que sufren de dolor crónico, promoviendo mejoras en variables como el bienestar psicológico, la esperanza, auto-eficacia, felicidad y satisfacción con la vida. Las intervenciones psicológicas utilizadas así como los tamaños de efecto encontrados varían de acuerdo a los estudios, aunque suelen ser tamaños de efecto moderados. En cuanto al mantenimiento de los cambios a largo plazo, los resultados son mixtos (Simm, Iddon y Barker, 2014; Flink, Smeets, Bergbom y Peters, 2015; Muller y cols., 2016). Es importante tener en cuenta también que la mayoría de estos estudios no incluyeron un grupo control, y por lo tanto sus resultados deben analizarse con precaución. 
En cuanto al segundo punto, nuevas estrategias de intervención como los tratamientos basados en la evidencia aplicados a través de Internet, el uso de la realidad virtual y de aplicaciones para teléfonos inteligentes en los tratamientos son cada vez más frecuentes (Keogh, Rosser y Eccleston, 2010). Estas tecnologías ofrecen múltiples ventajas: reducen barreras para el acceso a servicios de salud, incrementan la eficiencia de los tratamientos y promueven el autocuidado (Mohr, Burns, Schueller, Clarke y Klinkman, 2013), un aspecto clave a tener en cuenta en condiciones crónicas. En pacientes con FM, la realidad virtual se ha utilizado cómo técnica de exposición frente al temor al movimiento y ha demostrado su eficacia para disminuir la catastrofización hacia el dolor (Morris, Louw, Grimmer y Meintjes, 2015). Asimismo, la realidad virtual se ha utilizado como una técnica adjunta a la terapia cognitivo comportamental para inducir relajación y promover la práctica del minfulness consiguiendo buenos resultados en la reducción del dolor, de la sintomatología depresiva y en la promoción de técnicas de afrontamiento más adaptativas (Botella y cols., 2013). Además, la realidad virtual se ha utilizado para la promoción de emociones positivas y motivación relacionada con actividades significativas (García-Palacios y cols., 2014). Es decir que las TICs también pueden ayudar a promover el funcionamiento positivo, mejorar el bienestar y fomentar la resiliencia en los invididuos. Cuando son utilizadas con este fin, se ha propuesto sean consideradas como Tecnologías Positivas (Botella, Baños y Guillén, 2017; Botella y cols., 2012; Riva, Baños, Botella, Mantovani y Gaggioli, 2016).

Aunque las actuales orientaciones en el manejo del dolor tienen como objetivo incorporar las TICs en la asistencia sanitaria y promover los factores 
protectores contra la experiencia del dolor, hasta la fecha, la investigación combinando estos esfuerzos en pacientes con dolor crónico es limitada (García-Palacios y cols., 2014, Herrero, García-Palacios, Castilla, Molinari y Botella, 2014).

\section{Mi Mejor Yo Posible: una propuesta de intervención}

Hasta hace poco, los efectos beneficiosos del optimismo sobre el dolor habían sido estudiados, fundamentalmente, a través de estudios correlacionales y de laboratorio (Goodin y Bulls, 2013). Sin embargo, para demostrar que los factores psicológicos positivos afectan de manera directa al dolor se necesitan estudios experimentales que incluyan intervenciones dirigidas a promover un funcionamiento positivo en pacientes que sufren de dolor.

Una de las intervenciones que más se ha utilizado con este propósito es Mi Mejor Yo Posible (King, 2001; Peters, Flink, Boersma, Linton, 2010). Esta intervención consiste en un ejercicio de escritura y visualización con el objetivo de que los participantes imaginen la mejor manera posible en que su vida se podría desarrollar en un futuro, teniendo en cuenta distintos ámbitos de vida: personal, profesional y social. Esta intervención ha sido utilizada en más de 30 estudios que han demostrado su eficacia para promover optimismo, aumentar el afecto positivo y el bienestar psicológico (Loveday, Lovell y Jones, 2016). Ha sido administrada a muestras diversas, incluyendo estudiantes, adultos, pacientes depresivos y pacientes con ideación suicida. Se ha mostrado eficaz al ser aplicada tanto de manera tradicional como 
online y los datos indican que repetir el ejercicio que se propone en la intervención podría aumentar su eficacia.

En el campo del dolor, la mayoría de los estudios que han utilizado esta intervención ha realizado ensayos experimentales controlados en entornos de laboratorio con procedimientos de inducción de dolor en participantes sanos (Hanssen, Peters, Vlaeyen, Meevissen y Vancleef, 2013; Hausmann, Parks, Youk y Kwoh, 2014, Boselie, Vancleef, Smeets y Peters, 2014). El ejercicio de Mi Mejor Yo Posible se ha mostrado eficaz para provocar un aumento en el optimismo que, a su vez, redujo la intensidad del dolor durante una tarea de inducción de dolor por frío (Hanssen y cols., 2013). Se ha demostrado que el optimismo elimina las dificultades inducidas por el dolor durante tareas ejecutivas (Boselie y cols., 2014). Además, las imágenes mentales han mostrado ser eficaces para el control del dolor en distintos grupos de personas con dolor crónico (Lewandowski, 2004) y en pacientes con FM (Fors, Sexton y Gotestam, 2002). Específicamente, las imágenes positivas han demostrado ser analgésicas ante el dolor (Alden, Dale y DeGood, 2001). Las imágenes mentales activan los sistemas cerebrales involucrados en el procesamiento de la información emocional, es por esto que las consecuencias emocionales son más potentes que ante la representación verbal de los eventos (Holmes y Matthews, 2005). La realización de ejercicios de visualización positiva tiene efectos sobre las creencias, las emociones y los comportamientos: puede aumentar la probabilidad percibida de que algo ocurra, prepararnos mejor para la acción al imaginar antes nuestros comportamientos, y aumentar el optimismo y expectativas positivas futuras (Holmes y Matthews, 2010). 
Uno de los primeros estudios en analizar la eficacia de un programa de intervención que incluía el ejercicio de Mi Mejor Yo Posible en pacientes clínicos con dolor crónico fue el trabajo de Flink y cols. (2015). En este estudio, cinco pacientes con dolor lumbar realizaron un tratamiento que incluía diversos ejercicios para promover factores positivos como la gratitud, el saboreo y el optimismo. Los resultados mostraron que tres de los cinco pacientes mostraron mejoras en la incapacidad causada por el dolor y en catastrofización hacia el dolor. No se observaron cambios significativos en las medidas de optimismo, pero se observó una tendencia de mejora en variables de bienestar psicológico. Sin embargo, no es posible analizar el efecto diferencial de cada uno de los ejercicios aplicados, así como los mecanismos de cambio de los mismos.

En el mayor estudio realizado hasta la fecha, aplicando intervenciones positivas en pacientes con dolor crónico, Muller y cols. (2016) aleatorizaron a 96 pacientes con diversas condiciones médicas (ej. Esclerosis múltiple, lesión de médula espinal, etc.) a dos grupos experimentales. A los participantes del grupo intervención se les asignaron cuatro actividades positivas personalizadas, entre las cuales se encontraban: Actos de bondad, Saboreo, Gratitud, Florecimiento, Optimismo (Mi Mejor Yo Posible), Apoyo Social y Perdón. Los participantes en el grupo control fueron instruidos a ser más atentos a su entorno y escribir sobre tres eventos específicos o actividades que hayan realizado en los últimos 7 días. Los participantes que recibieron la intervención positiva mostraron mejoras significativas en la intensidad e interferencia del dolor, en catastrofización hacia el dolor, depresión, satsifacción con la vida y afecto positivo. Si bien muchos de estos cambios se 
encontraron también en el grupo control, hubo diferencias significativas en intensidad del dolor en favor del grupo intervención. Muchos de estos efectos positivos se mantuvieron a los dos meses y medio después del tratamiento. Pero nuevamente en este estudio no es posible aislar los efectos específicos de cada uno de los ejercicios aplicados ni los mecanismos de acción de los mismos.

\section{Presentación de la tesis doctoral}

Teniendo en consideración la complejidad de la experiencia de dolor, la eficacia moderada de las intervenciones psicológicas aplicadas hasta el momento para el tratamiento del dolor crónico y la ausencia de evidencia científica acerca de los posibles mecanismos que permitan explicar cómo funcionan estas intervenciones, parece necesario un cambio de paradigma en el tratamiento del dolor (Morley y cols., 2013).

Con la inclusión de las intervenciones que promueven variables positivas en los protocolos de tratamiento se ha dado un primer paso en el desarrollo de un enfoque terapéutico dirigido a promover factores psicológicos protectores y así aumentar la eficacia de los tratamientos psicológicos. Sin embargo, los ejercicios psicológicos positivos específicos no han sido aislados y sometidos a prueba de forma específica en pacientes con dolor crónico (Finan y Garland, 2015). La gran mayoría de estas intervenciones han sido diseñadas y validadas en población general, y luego aplicadas en población clínica. Asimismo, a menudo éstas se presentan a los pacientes dentro de un enfoque dirigido a minimizar los aspectos negativos del dolor, o incluidas dentro de "paquetes de tratamiento" que incluyen 
varios componentes (Flink y cols., 2015, Muller y cols., 2016), por lo que es difícil analizar el papel específico que juegan las intervenciones dirigidas exclusivamente a promover aspectos positivos. Además, la relación causal entre variables psicológicas positivas, como el afecto positivo y el optimismo, y el dolor, así como los mecanismos subyacentes a esta relación, permanecen en gran medida sin respuesta. Por lo expuesto anteriormente, es necesario contar con intervenciones psicológicas específicas, que vinculen cambios psicológicos determinados a variables de resultado particulares (Morley y cols., 2013).

En vista de la importancia de contar con herramientas terapéuticas que puedan facilitar el manejo del dolor en pacientes con FM, y teniendo en consideración los alentadores resultados que se han obtenido hasta el momento mediante la incorporación de las TICs para aumentar la eficiencia de las intervenciones psicológicas en este grupo de pacientes (GarcíaPalacios y cols., 2014; Morris y cols., 2015), el objetivo de esta tesis doctoral ha sido desarrollar, implementar y someter a prueba la eficacia de una intervención psicológica apoyada en las TICs, orientada a la promoción del optimismo y del afecto positivo en pacientes con FM.

Esta tesis se plantea por tanto, abordar las cuestiones pendientes relativas al rol de las variables psicológicas positivas como factores protectores frente al dolor y en la promoción del bienestar en la experiencia de dolor. Específicamente, esta tesis tiene como objetivo responder a dos preguntas centrales de investigación: "¿Una intervención psicológica, exclusivamente basada en la promoción del afecto positivo y apoyada en TICs, es eficaz en la reducción del malestar sintomático y en la promoción del 
bienestar?". Y "¿Cuáles son los mecanismos subyacentes a la eficacia de esta intervención?: ¿cómo y para quién funciona?".

Con este propósito, se han realizado tres estudios principales: el primero es un estudio piloto centrado en el desarrollo y adaptación de la intervención psicológica orientada a promover emociones positivas (Mi Mejor Yo Posible) mediante el uso de TICs, y el análisis de su eficacia preliminar en una serie de casos clínicos de pacientes que sufren de FM; el segundo, analiza la eficacia de esta intervención psicológica que utiliza TICs y que incluye promoción de optimismo y afecto positivo, en un estudio controlado aleatorizado en pacientes que sufren de FM; en el tercer estudio, se analizan los moderadores y mediadores de la eficacia de esta intervención. Asimismo, se han realizado tres estudios complementarios que consisten en la validación al español de instrumentos de medida utilizados en la evaluación de las medidas de resultados principales vinculadas a la intervención.

Este trabajo se enmarca en una de las líneas de investigación que viene desarrollando desde hace varios años el grupo de investigación de la Dra. Botella, la Dra. García-Palacios y la Dra. Baños, de la Universidad Jaume I de Castellón y de la Universidad de Valencia, orientada a la aplicación de TICs (Realidad Virtual, Realidad Aumentada, Internet, dispositivos móviles, etc.) en el campo de la Psicología Clínica en general, así como en el área de la Psicología de la Salud en particular (por ejemplo, Botella et al., 2013; Herrero y cols., 2014, García-Palacios y cols., 2014).

La presente tesis doctoral adquiere un formato por compendio de publicaciones, incluyendo artículos indexados en reconocidas revistas de 
impacto y publicaciones científicas internacionales. En el momento de la redacción de esta tesis dos artículos estaban publicados y otros cuatro trabajos habían sido enviados a revistas de relevancia científica para su revisión y posterior aceptación. La tesis doctoral que se presenta se compone de cuatro capítulos que recogen cada uno de los artículos mencionados (Tabla 1). Aunque todos los capítulos están orientados al objetivo principal, cada uno de ellos cuenta con entidad propia, pudiendo ser leídos de manera independiente. Los coautores han manifestado su aceptación para que el doctorando presente el trabajo como tesis así como su renuncia expresa de presentarlo como parte de otra tesis doctoral.

De acuerdo con la normativa de estudios de doctorado regulados por el RD 99/2011 (que modifica el Real Decreto 1393/2007 de 29 de Octubre al que se inscribe la presente tesis doctoral) en la Universitat Jaume I, para las modalidades de Doctorado por compendio de publicaciones, los artículos científicos que dan cuerpo a esta tesis han sido redactados en lengua inglesa siendo el idioma habitual de comunicación científica. Han sido redactados en castellano la introducción general y la discusión general.

\title{
Tabla 1. Estudios científicos de la presente tesis doctoral
}

\author{
Capítulo II Development and pilot testing of a positive imagery \\ intervention with online support in the treatment of \\ fibromyalgia
}

Capítulo III The power of visualization: back to the future for pain management in fibromyalgia syndrome

Capítulo IV How and for whom does a positive affect intervention work for fibromyalgia: An analysis of mediators and moderators 


\begin{tabular}{ll}
\hline & Psychometric properties of the General Self \\
Efficacy-12 scale in Spanish: general and clinical \\
Capítulo V \\
population samples \\
The contribution of future directed thinking to \\
affect dimensions: differences in general and \\
clinical populations \\
Assessment of positive affect regulation: validation \\
of the Spanish version of the Response to Positive \\
Affect questionnaire in clinical and general samples \\
\hline
\end{tabular}

\section{Objetivos e hipótesis de la tesis doctoral}

El objetivo general de la presente tesis doctoral es diseñar, implementar y evaluar la eficacia y efectividad (aceptabilidad) de una intervención psicológica centrada en la promoción de emociones positivas que utiliza TICs y que se dirige a la promoción del bienestar psicológico en pacientes que sufren de fibromialgia.

En concreto, los objetivos específicos que se persiguen son:

- Diseñar y aplicar una intervención psicológica que utiliza TICs y que se dirige a la promoción del bienestar psicológico en pacientes que sufren de fibromialgia (Mi Mejor Yo).

- Explorar la utilidad de dicha intervención para inducir optimismo y afecto positivo en un grupo de pacientes con fibromialgia en un estudio piloto.

- Aportar datos acerca de la eficiencia (aceptación, utilidad percibida, viabilidad) de la intervención psicológica implementada (Mi Mejor Yo) 
- Evaluar la eficacia de la intervención en medidas de bienestar psicológico a corto (pre-post) y a largo plazo (seguimientos) en un ensayo clínico controlado en el que se compara la eficacia de Mi mejor Yo con la eficacia de una intervención control.

- Evaluar posibles moderadores y mediadores acerca de la eficacia de una intervención para promover optimismo y afecto positivo en pacientes con fibromialgia (Mi Mejor Yo).

Para la consecución de estos objetivos se han llevado a a cabo dos estudios empíricos, un estudio piloto y un ensayo clínico controlado.

Las hipótesis a contrastar en el estudio piloto son las siguientes:

Relacionadas con la utilidad de la intervención:

H1: Después de que los pacientes completen un mes de práctica de la intervención (Mi Mejor Yo) apoyada en TICs para inducir estados de ánimo positivos, se observará un aumento significativo en las emociones positivas y una disminución en las emociones negativas, así como un aumento en las expectativas de futuro positivas y una disminución de las negativas.

H2: Una vez finalizado el programa de intervención de Mi Mejor Yo, se observará un incremento significativo respecto a las puntuaciones preintervención en las medidas de optimismo y calidad de vida, así como una 
disminución en la sintomatología depresiva, las medidas de catastrofización, y estado emocional negativo.

H3: Los resultados obtenidos se mantendrán en los seguimientos realizados al mes y a los 3 meses.

Relacionadas con la aceptación de la intervención:

H4: Los pacientes otorgarán puntuaciones elevadas en aceptación y satisfacción con la intervención de Mi Mejor Yo y el uso de las TICs (utilidad, lógica, recomendación a terceros, agrado).

Las hipótesis a contrastar en el estudio controlado fueron las siguientes:

Relacionadas con la eficacia de la intervención de Mi Mejor Yo:

H1: Después de una sesión en la que los pacientes realicen la intervención de Mi Mejor Yo apoyada en TICs para inducir estados de ánimo positivos, se observará un aumento significativo en las emociones positivas y una disminución en las emociones negativas, así como un aumento en las expectativas de futuro positivas y una disminución de las negativas, y este cambio será significativamente mayor en el grupo intervención en comparación con el grupo control.

H2: Una vez finalizado el programa de intervención, se observará un incremento significativamente mayor respecto a las puntuaciones preintervención en las medidas de optimismo, afecto positivo, auto-eficacia y 
calidad de vida, así como una disminución en la sintomatología depresiva, las medidas de catastrofización, y afecto negativo, en la condición que reciba la intervención de Mi Mejor Yo en comparación con la condición control.

H3: Los resultados obtenidos en la condición de intervención de Mi Mejor Yo se mantendrán en los seguimientos realizados al mes y a los 3 meses, siendo este mantenimiento de los logros significativamente superior que en la condición control.

Relacionadas con los mecanismos subyacentes a la intervención:

H5: Los cambios del pre al post-intervención en afecto positivo y negativo, mediarán los efectos de la intervención de Mi Mejor Yo en la interferencia del dolor, los niveles de depresión, los niveles de autoeficacia y calidad de vida.

H6: Los cambios del pre al post-intervención en sintomatología depresiva mediarán los efectos de la intervención de Mi Mejor Yo en la interferencia del dolor, los niveles de autoeficacia y calidad de vida.

$\mathbf{H}_{7}$ : Los niveles iniciales de variables de resultado (interferencia del dolor, afecto, autoeficacia y calidad de vida), así como de las variables de proceso (estrategias de regulación emocional y rumiación), moderarán los efectos de la intervención de Mi Mejor Yo sobre los niveles de depresión. 


\section{Development and pilot testing of a positive}

\section{imagery intervention with online support in the}

\section{treatment of fibromyalgia}

Este capítulo ha sido aceptado para su publicación en la Revista Argentina de Clínica Psicológica. Autores: Molinari, G., Enrique, A., Herrero, R., FernándezLlanio Comella, N., Botella, C., y García-Palacios, A. (2017).

\section{Abstract}

Positive psychology interventions (PPI) represent a promising method to promote resources to better cope with pain. This study aims to describe the rationale for a PPI for fibromyalgia and outline a potential model by which a positive imagery exercise supported by Information and Communication technologies could lead to resilience in chronic pain. We present preliminary data of acceptability and feasibility of the Best Possible Self intervention with online support for clinical patients. In general, larger effect sizes and clinically significant change were found on measures of functional status and depression. An increment in quality of life was observed. This is the first study to provide preliminary evidence for the efficacy of a PPI in fibromyalgia using technologies to enhance self-management.

Keywords: Fibromyalgia; Positive psychology intervention; Best Possible Self; Pain resilience; Information and Communication technologies 


\section{Introduction}

If there is one syndrome that challenges diagnosis, treatment and prognosis is fibromyalgia syndrome (FMS). Heterogeneity in history, symptoms expression, comorbidity and treatment response have caused that in 30 years of research no pharmacological or nonpharmacological treatment has proven to be effective for all patients (Okifuji and Hare 2013).

FMS is a chronic musculoskeletal pain condition with unknown etiology, characterized by widespread pain, accompanied by fatigue, function disability, disturbed sleep, and affective disorders. In sum, pain experience in these patients is complex and involves behavioral, cognitive and affective factors that cause an impaired quality of life. For that reason, psychological approaches have concentrated their efforts in reducing pain-related disability, emotional distress, and maladaptative coping, rather than directly eliminating the locus of pain (Roditi and Robinson 2011). Cognitive behavioral therapies, relaxation, educational interventions, behavioral treatments, and mindfulness based programs, have proved to be effective in reducing sleep problems, depression, functional status and catastrophizing (Glombiewski et al. 2010). Therapeutic approaches are typically presented to patients within the general theme of minimizing negative appraisals of pain (Finan and Garland 2014). However, recently novel clinical interventions have been applied to pain management aiming to shift paradigms: (1) from alleviating and decreasing symptoms manifestations to promoting resources for coping with pain (Keefe and Wren 2013) and (2) from routine face to face health care practices, to the addition of e-health resources and information and communication technologies (ICTs), such as 
evidence based online interventions, virtual reality, and smartphone applications (Keogh et al. 2010). These technologies offer multiple advantages: reducing barriers to access health care andincreasing treatment efficiency and promoting self-management (Mohr et al. 2013), a core aspect in chronic conditions.

Positive psychological factors such as pain acceptance, positive emotions, and adaptative coping strategies, influence the course and experience of pain. Positive affect serve as a buffer to pain through the reduction in pain catastrophizing (Hood et al. 2012) and broadening the scope of attention and cognition to nonpainful stimuli and experiences (Finlan and Garland 2014). Optimism has been linked to lower pain sensitivity, better physical functioning and adjustment to pain, and less psychological distress and pain catastrophizing (Goodin et al. 2013). Until recently, the beneficial effects of optimism on pain have been studied mostly in correlational studies in clinical and laboratory settings (Goodin and Bulls 2013). To demonstrate that positive psychological factors causally affect pain, experimental studies that include direct interventions are needed.

Interventions aimed to promote positive psychological constructs have been developed in the positive psychology field. These positive psychology interventions (PPI) have proved to be effective in reducing depression and promoting subjective and psychological wellbeing (Sin and Lyubomirsky 2009). However, evidence from a recent meta-analysis shows that a substantial number of studies (17 of 39) have been tested in college students (Bolier et al. 2013). Moreover, in the field of pain, most of these interventions have been developed in controlled experimental lab research 
with pain inductions procedures (Hanssen et al. 2013; Boselie et al. 2014) or healthy participants (Hausmann et al. 2014), and have not been replicated in clinical populations.

For a PPI to be effective in increasing wellbeing is important not only the characteristics of the exercise but also the features of the person, known as person-activity fit (Lyubomirsky and Layous 2013). For that reason, we believe the positive psychology field is lacking of interventions specifically adapt and design for clinical populations. The aim of this study is to describe the adaptation and utilization of a PPI intervention, the Best Possible Self, with fibromyalgia patients. For this reason, we propose how a PPI could be combined with ICTs to provide a successful intervention for clinical patients. We describe a system developed by our team that includes narratives, sounds, and visual cues to focus patients' attention on the task and to potentiate the effects of the guided imagery exercise. Moreover, we present preliminary results of the intervention study with the Best Possible Self manipulation in a long term basis. To improve adherence, we gave patients access to a web-based platform and provide support through text messages twice a week. The level of acceptance and perceived utility as well as possible benefits of this intervention were also examined.

\section{Method}

Intervention rationale and development

Health psychology has benefited from positive psychology (Aspinwall and Tedeschi 2010). Moreover, recent models have been proposed to conceptualize how positive psychology constructs, such as positive affect and 
optimism, operate in the adaptation and self-management of chronic pain (Finan and Garland 2014). Taking into account this model, our aim was to develop an intervention for fibromyalgia patients with the intention to promote protective positive psychology factors to cope with pain. For this reason, we reviewed the PPI literature, including recent meta-analyses (Sin and Lyubomirsky 2009; Bolier et al. 2013), to identify validated exercises that target positive variables (e.g. hope, optimism, positive affect) that have been consistenly found to be related with pain.

Some of the conclussions of this review were that: (i) most of the interventions were addressed to college students or general population; (ii) individuals with psychosocial problems and who expected the intervention to make them happier benefited more from PPI's; (iii) in terms of design of the intervention, individual therapy was most effective, longer interventions were more likely to produce greater gains in wellbeing and have higher effect sizes, as well as studies involving referrals from a health care practitioner. Although these results are encouraging, most of these studies have small or medium effect sizes, and share a common barrier: adherence.

We consider PPI's as a first step into the development of a tailored therapeutic approach aimed to promote protective psychological factors. In this sense, specific positive psychology elements have not been extracted and tested in chronic pain patients (Finan and Garland 2014). Empirically supported psychosocial treatments often include interventions to enhance health but they are presented to patients as an approach directed to minimize negative appraisals of pain or in a "treatment package" (Flink et al. 
2015; Muller et al. 2016) that include several exercises, so it's difficult to analyze the specific role of PPI's.

For that reason, we propose a model (see Figure 1) by wich a PPI may lead to greater resilience in chronic pain. We selected an intervention to promote optimism considering that previous studies have demonstrated the beneficial effects of optimism in improving pain-related symptoms (e.g. lower pain sensitivity and less psychological distress). We chose a simple, wellaccepted and applicable intervention: the Best Possible Self (BPS) (Peters et al. 2010). It consists of a writing and guided imagery exercise that promotes positive future thinking by asking the patient to think about the best possible way that his life could turn out in 3 life domains: personal, relational, and professional. The BPS, compared to control, significantly increased optimism and positive affect in general population after a 2 weeks intervention (Meevissen et al. 2011). In the field of pain, the BPS has demonstrated that increasing optimism is effective in reducing pain intensity ratings during a cold pressor task (Hanssen et al. 2013). Moreover, it has proved that optimism abolishes pain-induced impairments in executive task performance (Boselie et al. 2014). Mental imagery has shown its efficacy for pain control in diverse chronic pain populations (Lewandowski 2004), and in fibromyalgia patients (Fors et al. 2002). Specifically, positive imagery has demonstrated greater pain analgesia (Alden et al. 2001). Mental imagery activates brain systems involved in processing emotional information therefore it has more powerful emotional consequences than does the verbal representation of events (Holmes and Matthews 2005, 2010). Deliberate engagement in positive future imagery has effects on beliefs, emotions and behaviors: it can 
enhanced the perceived likelihood of an event, increase optimism and positive future expectancies, and increase readiness for action of an imagined behavior. For fibromyalgia patients, this can be specially significant considering they report significantly lower positive affect than other rheumatology diseases (Zautra et al. 2005) and it has been demonstrated that more optimistic individuals were less likely to perceive goal barriers and, on days that they experienced more fatigue, they were less likely to reduce their effort in achieving their goals (Affleck et al. 2001).

Once the exercise was selected, we aimed to customize and adapt the BPS intervention to clinical patients. In terms of the design of a self-applied PPI, it was important not only to focus on efficacy but also in adherence. In this sense, ICTs offer the advantage of easy accessibility, personalized materials to enhance engagement and virtual support to promote motivation. We performed qualitative interviews with psychologists who are specialize in e-health interventions to define support duration and personalization, delivery method, design of the positive technology system to deliver the exercise and the online platform to access the material to practice the exercise. 


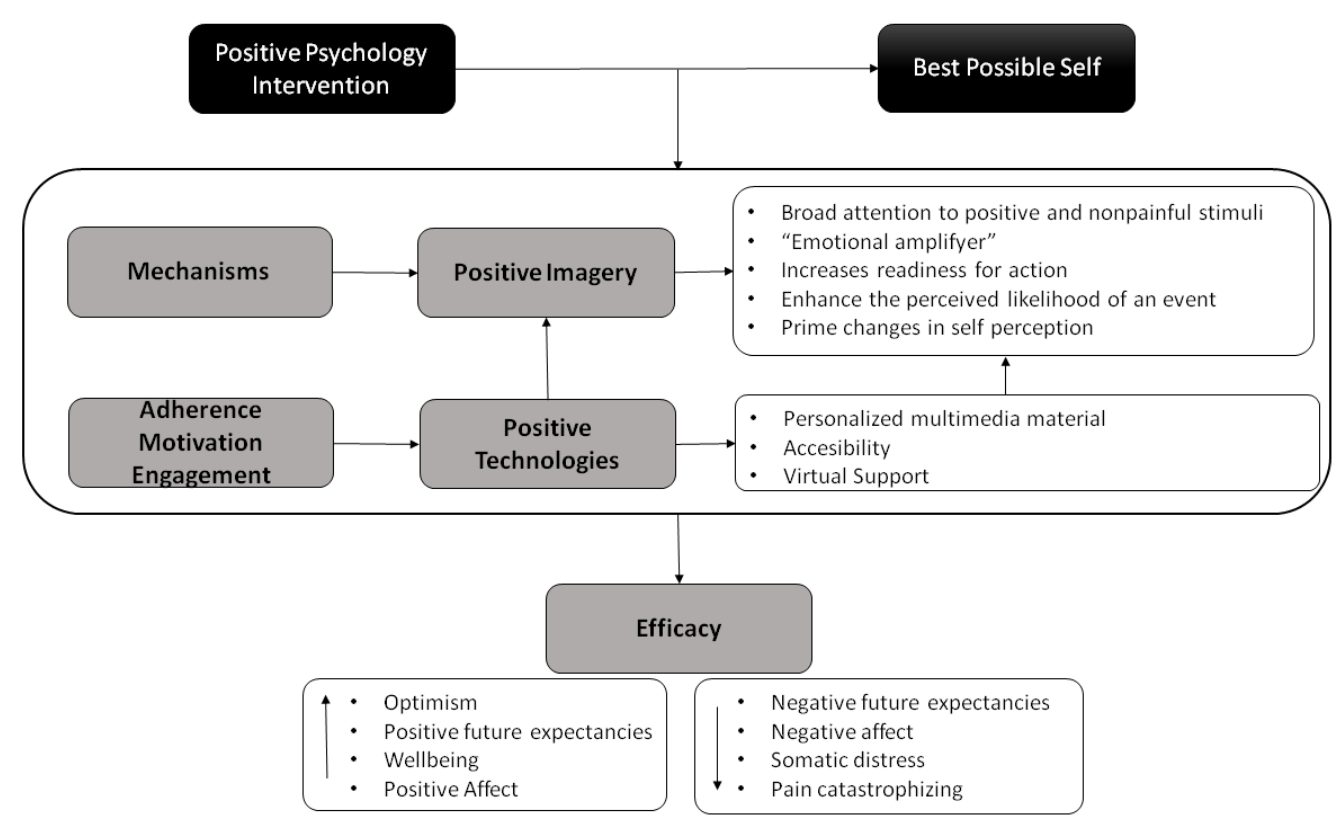

Figure 1. Model of the mechanisms and methods by which the Best Possible Self intervention could promote resilience and pain self-management

In terms of content of the BPS manual, we followed Meeviseen et al. (2011) instructions, with the exception that we included a health domain, specially relevant for this population. Due to the fact that longer interventions seem to produce greater gains in wellbeing and that the BPS manipulation has only been tested in a short term biasis, we included two follow-ups, at one month and at three months after completion of the intervention.

\section{Intervention supported by ICTs}

Patients were informed that they were participating in a study in order to measure "the power of visualization". Patients were asked to think of and write down all aspects that their future best possible self should 
encompass in personal, social, professional and health domains. To do so, patients used an interactive system called the Book of Life (see Figure 2a) (Baños et al. 2014). This system consists of a personal diary to promote positive narrative and a positive orientation towards the future. Moreover, multimedia resources (music, pictures, and videos) could be included to boost imagery. Patients were given 25 minutes to complete the exercise and 5 more minutes to visualize what they have just wrote. All patients were instructed to repeat the imagery exercise once a day at home over the next four weeks. In order to facilitate the practice, patients received access to an online platform called Emotional Therapy Online (TEO; Quero et al.2012). TEO is a completely open web-based system that allows the creation of personalized therapeutic material. Patients can access this material over the Internet using a personal password and visualize their personal diary with the narrative and multimedia they had selected at the lab session. At the end of the session, they can move around a virtual environment (they can choose a beach or a forest environment) to think about the session and their experience and continue visualizing their BPS (see Figure 2b). Finally, twice a week, SMS were sent to the patient's mobile phone with reminders to practice their exercise and reinforcements. 


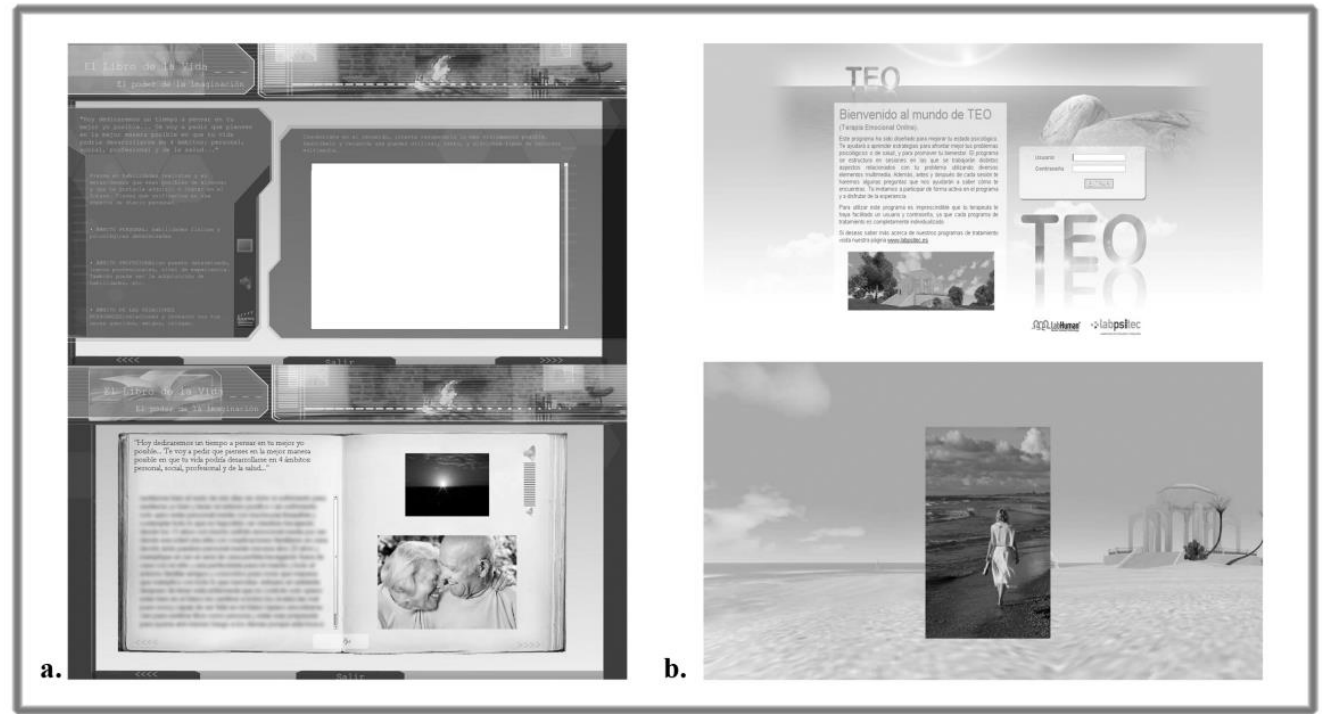

Figure 2. The Book of Life and TEO systems for the realization of the BPS manipulation.

\section{Participants}

Ten patients were referred by a rheumatologist from the Rheumatology Unit of Hospital Arnau of Vilanova. After the screening interviews, 7 patients were accepted into the study, and further assessments were conducted. All participants consented to this research protocol as approved by the Ethical committee at the University Jaume I.

\section{Measures}

Fibromyalgia Impact Questionnaire (FIQ-R; Esteve-Vives et al. 2007). The FIQ$\mathrm{R}$ is a 10 -item self-report questionnaire that measures the health status of patients with FMS assessing the interference of FMS in their daily life. The total score of the FIQ-R is calculated by adding 4 items. The first item focuses on the patient's ability to perform physical activities. The following two items require the patient to indicate the number of days in the past week they felt good and how many days of work he or she missed. The remaining item is 
composed by seven questions assessing the interference of pain to perform daily activities and other symptoms (pain, fatigue, morning tiredness, stiffness, anxiety, and depression) that are measured with a numerical rating scale (NRS).

Psychological distress was assessed by the Spanish version of the Brief Symptom Inventory (BSI; Ruipérez et al. 2001).

Depression. The Spanish version of the Beck Depression Inventory (BDI-II; Sanz et al.2005) is a 21-item self-report measure of cognitive, affective and somatic symptoms of depression. It is one of the most frequently used measures of depression in chronic pain patients. Its threshold for detecting depression varied according to the type of patients, suggesting the need for adjusting cut-off points to 22 to reduce the number of false-positives produced by the uneven item response of chronic pain patients (Poole et al. 2006). Therefore, we used this value as our cut-off.

Pain Catastrophizing. In the Pain Catastrohpizing Scale (PCS; Campayo et al. 2008) patient is ask to reflect on past painful experiences, and to indicate the degree to which they experienced each of 13 thoughts or feelings when experiencing pain, on 5-point scales from (0) not at all to (4) all the time. The PCS yields a total score and three subscale scores assessing rumination, magnification and helplessness. For the purpose of this study, we used the PCS total score.

Optimism and Future expectancies - The Life Orientation Test-revised (LOT-R; Otero et al. 1998) includes 10 items that assesses dispositional optimism. The Subjective Probability Task (SPT; MacLeod 1996, Molinari et al. in press) was used as a measure of positive (10 items) and negative (20 items) future 
expectancies. The SPT consists of 30 items scored on a 7-point Likert scale ranging from 1 (not at all likely to occur) to 7 (extremely likely to occur).

The Positive and Negative Affect Scale (PANAS; Sandin et al.1999) includes 20item evaluating positive and negative affect.

Quality of life. The Spanish version of the Quality of Life Index (QLI-Sp; Mezzich et al. 2000) consists of 10 items evaluating different dimensions of psychological well-being.

Acceptance and perceived usefulness. We used a satisfaction and acceptability scale (Borkovec and Nau 1972) to measure satisfaction with the BPS manipulation after completion of the intervention. The participants rated the items on a 0 to 10 scale where 0 was "not at all" and 10 was "completely." Also, patients were asked to rate the satisfaction and usefulness of each of the systems used, the frequency of applying the imagery exercise (number of sessions per week) and content of imagery.

\section{Procedure}

The rheumathologist of local public hospital gave general information about the studies and referred FMS patients interested in participating. All participants attended voluntarily and received no incentive. Patients had to fulfill the American College of Rheumatology criteria for primary FMS (Wolfe et al. 1990) and not present a severe psychiatric condition. Once the participants gave written informed consent to participate, a brief structured interview was conducted in order to assess pain history and treatments. Patients were assessed at baseline with the BSI. Patients took home the rest of the assessment protocol that had to be completed for the following lab session. In the following session, patients received a BPS manual and listened 
to the instructions through headphones to guarantee standardization and facilitate concentration (Meevissen et al. 2011). Next, the researcher presented to the patient the Book of life system and explained how to use it. After 25 min of writing about their BPS and selecting their images, music and videos, they performed the 5-min imagery exercise. Patients were told that they would receive an email giving them access to TEO to practice their exercise at home. The post intervention session took place at the university in the fourth week. The FIQ-R, measures of pain catastrophizing, anxiety and depression, positive and negative affect, future expectancies, optimism and quality of life, were administered. An interview was conducted in order to assess frequency of applying the imagery exercise and the acceptance and perceived utility of the intervention. At last, patients were asked to continue practicing their exercise and they were informed that they were going to be contacted at 1 and 3 month follow-ups. At follow-ups, patients completed the same questionnaires that at post intervention, except for the FIQ-R.

\section{Results}

\section{Baseline characteristics}

The seven patients were all women, had a mean age of 45 years old (range $=24-60, \mathrm{SD}=11$ ) and a mean disease duration of 9.8 years $(\mathrm{SD}=3.25)$. See Table 1 for each patient demographics and pain history. 
Table 1. Demographic characteristics

\begin{tabular}{|c|c|c|c|c|c|c|c|}
\hline & Age & $\begin{array}{l}\text { Marital } \\
\text { Status }\end{array}$ & Education & $\begin{array}{c}\text { Employme } \\
\text { nt }\end{array}$ & $\begin{array}{c}\text { Previous } \\
\text { treatment }\end{array}$ & Medication & Pain History \\
\hline FIB1 & 46 & Separated & $\begin{array}{l}\text { High } \\
\text { school }\end{array}$ & Unemployed & Yes & $\begin{array}{c}\text { Anxiolitics } \\
\text { Antidepressants } \\
\text { (SSRI) }\end{array}$ & $\begin{array}{l}\text { She has been suffering pain from the last } 12 \text { years. "It } \\
\text { was hard to live with pain, until I discover my } \\
\text { condition had a name". Now she feels some days she } \\
\text { can cope with her pain, and some days she can't. }\end{array}$ \\
\hline FIB2 & 49 & Married & $\begin{array}{l}\text { University } \\
\text { degree }\end{array}$ & $\begin{array}{l}\text { Active } \\
\text { worker }\end{array}$ & No & No & $\begin{array}{l}\text { She has been suffering pain from the last } 7 \text { years. She } \\
\text { received her diagnosis } 3 \text { years ago. She doesn't like } \\
\text { her job and feels she has no purpose in life. }\end{array}$ \\
\hline FIB3 & 48 & Married & $\begin{array}{l}\text { High } \\
\text { school }\end{array}$ & Unemployed & No & No & $\begin{array}{l}\text { She has been suffering pain from the last } 7 \text { years. "My } \\
\text { doctors, friends and family think my pain doesn't } \\
\text { exist". She's worried about the future. }\end{array}$ \\
\hline FIB4 & 60 & Separated & $\begin{array}{l}\text { High } \\
\text { school }\end{array}$ & Unemployed & Yes & Anxiolytics & $\begin{array}{l}\text { She has been suffering pain from the last } 10 \text { years } \\
\text { since menopause. Pain makes it difficult to perform } \\
\text { daily activities and it makes her feel "unconnected" to } \\
\text { her life and family. }\end{array}$ \\
\hline
\end{tabular}




\begin{tabular}{|c|c|c|c|c|c|c|c|}
\hline FIB5 & 48 & Married & $\begin{array}{l}\text { High } \\
\text { school }\end{array}$ & $\begin{array}{l}\text { Active } \\
\text { worker }\end{array}$ & No & Anxiolytics & $\begin{array}{l}\text { She has been suffering pain from the last } 15 \text { years. It } \\
\text { started on her leg and now it's worst on her knees. She } \\
\text { got her FM diagnosis two months ago. She feels } \\
\text { misunderstood by her doctors. }\end{array}$ \\
\hline FIB6 & 24 & Single & $\begin{array}{c}\text { University } \\
\text { degree }\end{array}$ & Student & Yes & Anxiolytics & $\begin{array}{l}\text { She has been suffering pain from the last } 6 \text { years since } \\
\text { a car accident She has back pain and problems } \\
\text { sleeping wich has increased in the last year. She feels } \\
\text { isolated and misunderstood. "I'm only } 24 \text {, how can I } \\
\text { continue with my life?" }\end{array}$ \\
\hline FIB7 & 40 & Married & $\begin{array}{c}\text { University } \\
\text { degree }\end{array}$ & $\begin{array}{l}\text { Active } \\
\text { worker }\end{array}$ & Yes & $\begin{array}{c}\text { Antidepressants } \\
\text { (SSRI) }\end{array}$ & $\begin{array}{l}\text { She have had pain problems all of her life, but received } \\
\text { the FM diagnosis } 8 \text { years ago. Most of the time she } \\
\text { feels without energy to do things she would like to do. }\end{array}$ \\
\hline
\end{tabular}


At baseline, all the patients had a severe impairment caused by fibromyalgia symptoms (FIQ-R Total Score $\geq 59$ ). In terms of psychological distress and symptomatology, scores on the General Disability Index showed a great psychological discomfort $(M=53.28 ; \quad S D=18.06)$ compared to normative data (Ruiperez et al. 2001).

\section{Outcome data}

Figures 3, 4 and 5 describe each client's raw data for outcomes at baseline, post-intervention, and 1 and 3-month follow-up assessments. In order to assess the clinical significance of the change resulted from the intervention, Clinical Significant Change (CSC) was calculated using Jacobson and Truax's Reliable Change Index (RCI, 1991). In the " $c$ " criterion, the posttest score has to be closer to the mean distribution of the functional population rather than the dysfunctional. When data was not available for functional population, we chose "a" criterion to decide when a patient had achieved a clinically significant improvement: the posttest score had to be two standard deviations in the direction of functionality above the mean for a dysfunctional population. Then we calculated the RCI to analyze the second condition to test the CSC, where an RCI equal to or greater than $|1.96|(p<$ .05) indicates a reliable change. To calculate the RCI, we used the posttest mean and the pretest mean of the result achieved for each patient, and the mean dysfunctional, the standard deviation and the stability reliability. We used data from the measures in chronic pain patients or in samples with mood disorders when it was not available. 

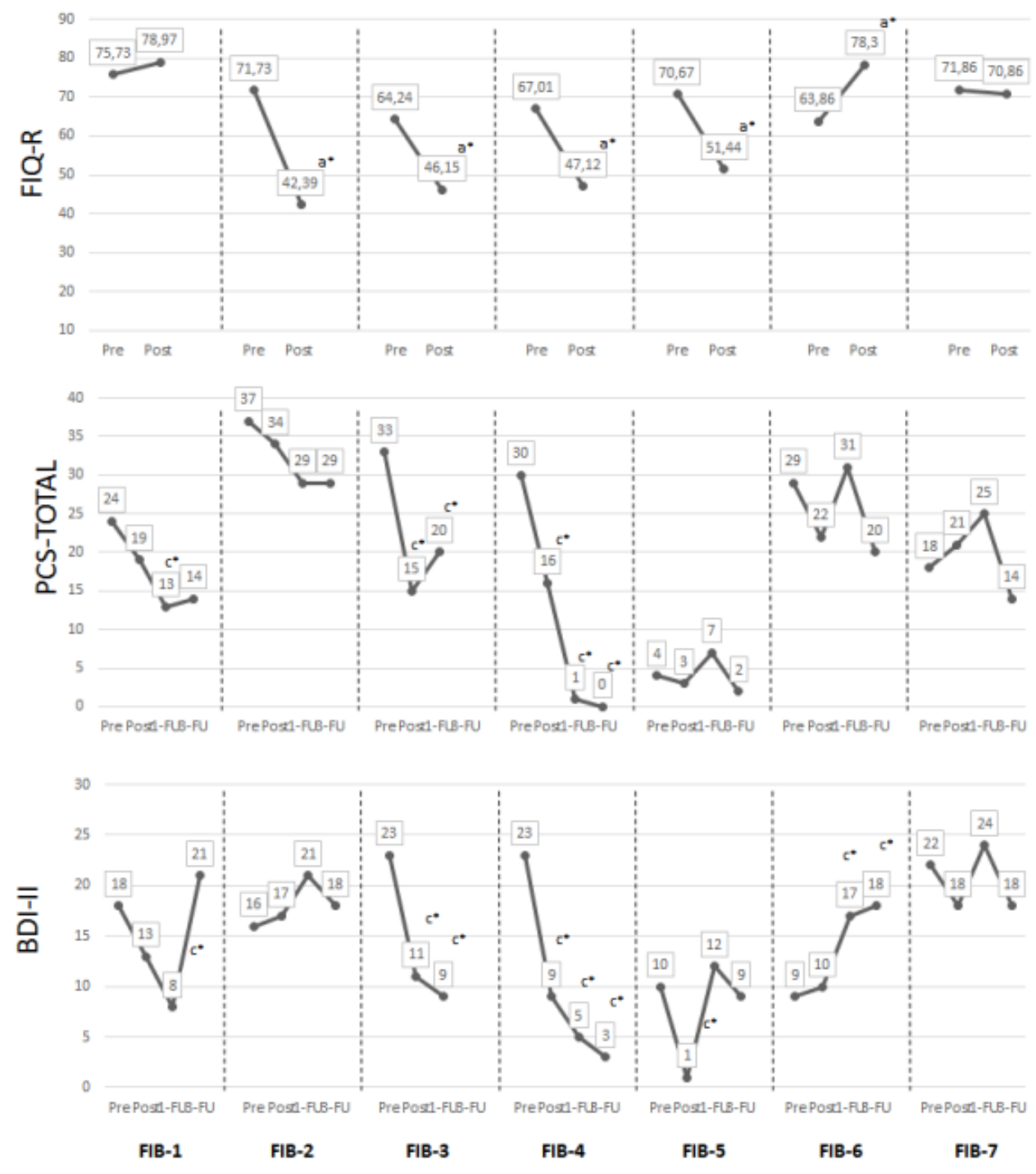

Figure 3. Raw data for each patient at pre, post, and follow-ups. Note. FIQ-R: Fibromyalgia Impact Questionnaire, PCS-TOTAL: Pain catastrohpizing scale, BDI-II: Beck Depression Inventory, OASIS: Overall Anxiety Severity and Impairment Scale. ${ }^{a^{*}}$ Clinically significant change. It is used the criterion A of the Jacobson and Truax's index (1991). ${ }^{*}$ Clinically significant change . It is use the criterion C of the Jacobson and Truax's index (1991). 


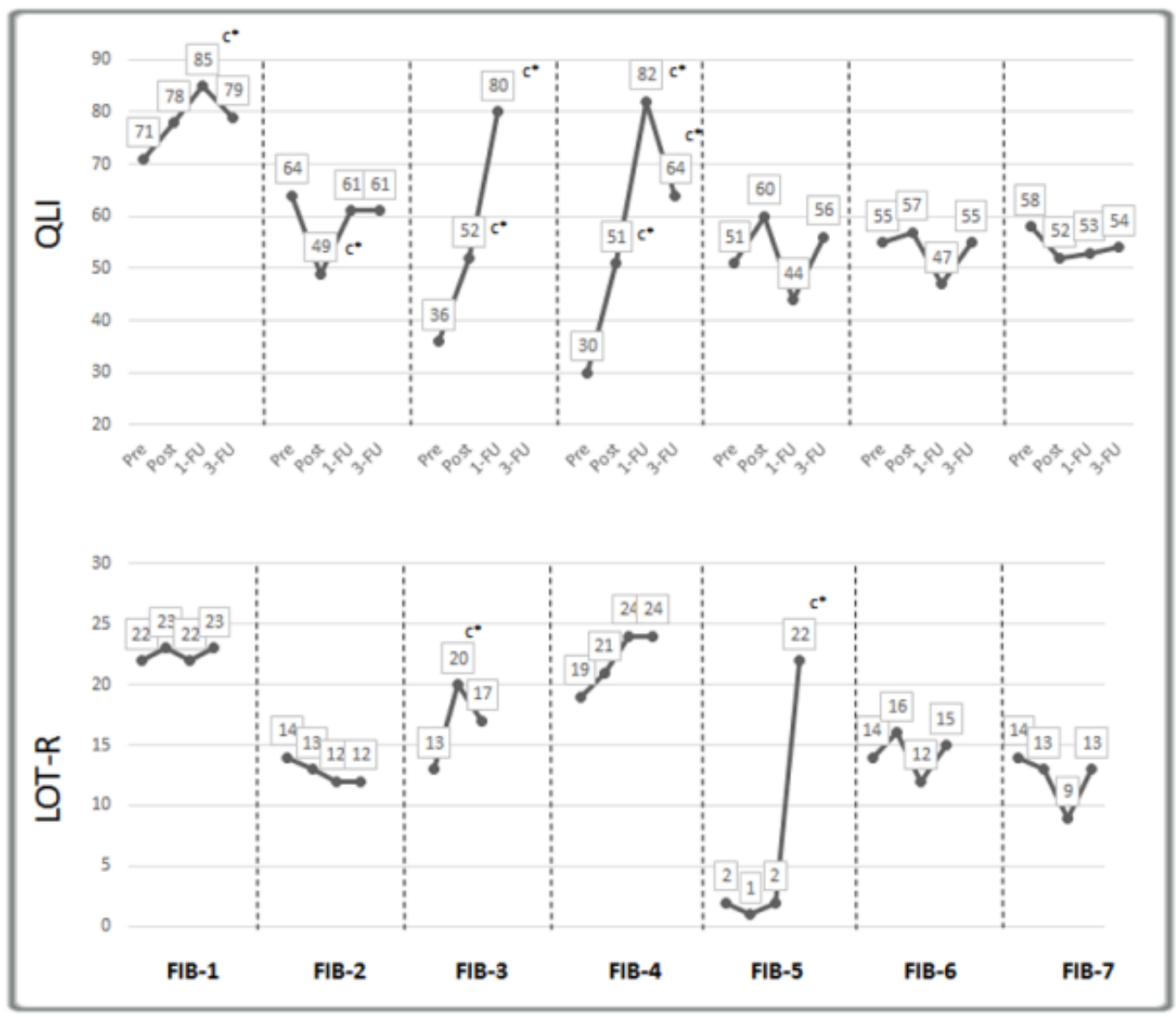

Figure 4. Raw data for each patient at pre, post, and follow-ups. Note. QLI: Quality of Life Index, LOT-R: Life Orientation Test. ${ }^{*}$ Clinically significant change. It is use the criterion C of the Jacobson and Truax's index (1991). 


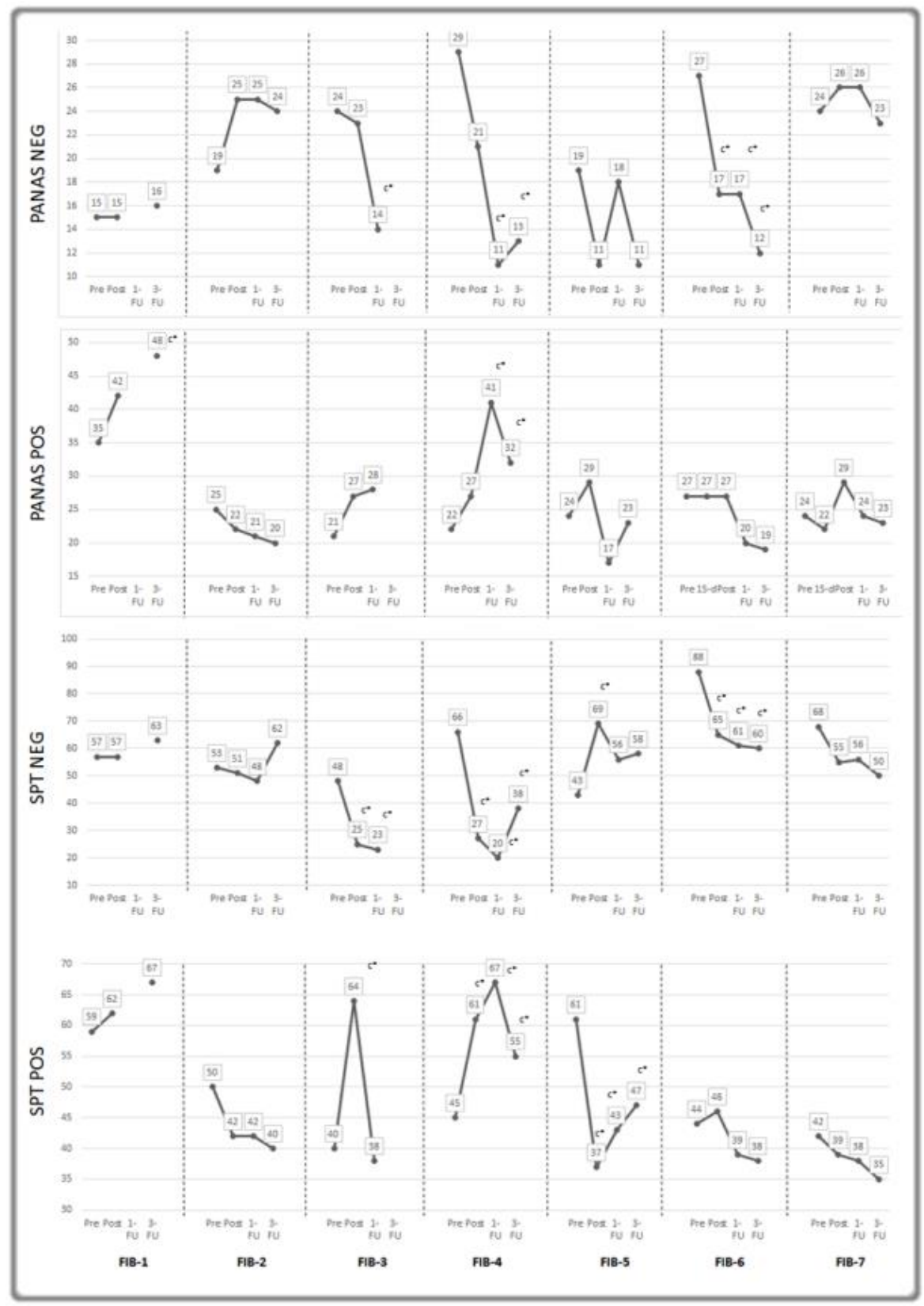

Figure 5. Raw data for each patient at pre, post, and follow-ups. Note. PANAS NEG: Negative affect schedule, PANAS POS: Positive affect schedule, SPT NEG: Negative expectations, SPT POS: Positive expectations. ${ }^{c^{*}}$ Clinically significant change . It is use the criterion C of the Jacobson and Truax's index (1991). 
The scores for the FIQ-R, showed a reduction from pre to post intervention in 5 of the 7 patients. Four of them achieved a reliable change according to the RCI. Scores in pain catastrophizing decreased at postintervention in 6 of the 7 patients. The most important result is that patients continued to improve in the follow-up period, achieving a higher reduction in negative thoughts and feelings associated with pain. Changes in this variable were reliable changes according to the RCI in patients 1,3 , and 4 .

There was a reduction in depression from pre to post-intervention in 5 of the 7 patients. Four of them achieved a reliable change. The decrease was more prominent in participants who scored above the scale's cutoff score for chronic pain: participants 3 and 4 . But also one of the patients with the lowest score at pretest had a drop of 9 points in the BDI-II at post intervention. One of the patients presented an increment on BDI scores that was a reliable change. However, only one of the patients scored above 22 at the 1 month follow-up and none of the patients had significant levels of depression at the 3 months follow-up.

Results indicated an increase in positive affect for 4 of the 7 patients at post intervention However, in only 2 of the patients these scores continued to increase from post intervention to follow-up and were reliable changes. Negative affect was reduced from pre to post-intervention in 4 of the 7 patients, and these results were maintained in the follow-up. Patients 3, 4 and 6 scored reliable changes.

Future expectancies showed mix results. On one hand, 4 of the 7 patients presented an increase in positive future expectancies at postintervention. Unexpectedly, patient 5 showed a reliable decrease in positive 
expectancies during the whole intervention. Only 3 patients achieved a reliable change in positive expectancies. On the other hand, 4 patients presented a score reduction in negative future expectancies at postintervention. One of the patients showed a significant increment in negative expectancies at post intervention but this was not maintain at follow-ups. At the 3-months follow-up, 3 of the patients showed a reduction of almost 20 points regarding their baseline level and achieved reliable changes.

Results for the LOT-R showed no change for almost all of the patients, with the exception of patients 3 and 5 that achieved a reliable change according to the RCI. Patient 5 (who had had the lowest score in this measure) achieved an important increase in optimism at the 3 months follow-up.

In terms of quality of life, 3 of the 7 patients improved from the pre to post-intervention. One of the patients showed a significant decrease in quality of life at post intervention but this was not maintain at follow-ups. Patients 3 and 4 duplicated their scores in this measure at follow-ups achieving a reliable change.

Table 2 describes the means, standard deviations, and effect sizes (Cohen 1988) from pre- to post-intervention, pre-intervention to 1 month follow up and pre-intervention to 3-months follow-up for each outcome. 
Table 2. Effect sizes (d) of outcomes

\begin{tabular}{|c|c|c|c|c|c|c|c|}
\hline & $\begin{array}{l}\text { Pre } \\
M(S D)\end{array}$ & $\begin{array}{l}\text { Post } \\
M(S D)\end{array}$ & $\begin{array}{l}\text { Follow up } 1 M \\
(S D)\end{array}$ & $\begin{array}{l}\text { Follow up } 3 \\
M(S D)\end{array}$ & $\begin{array}{l}\text { Pre to Post } \\
\text { intervention } d\end{array}$ & $\begin{array}{l}\text { Pre to Follow- } \\
\text { up } 1 d\end{array}$ & $\begin{array}{l}\text { Pre to Follow- } \\
\text { up } 3 d\end{array}$ \\
\hline FIQ-R & $69.3(4.39)$ & $59.32(16.07)$ & & & 1.98 & & \\
\hline PCS Total & 25 (11.11) & 18.57 (9.29) & 18 (11.39) & $13.17(10.93)$ & 0.50 & 0.55 & 0.90 \\
\hline BDI-II & $17.29(5.94)$ & $11.28(5.68)$ & $13.71(7.11)$ & $14.5(6.94)$ & 0.88 & 0.52 & 0.40 \\
\hline OASIS & $6(3.41)$ & $5(3.74)$ & $6.71(5.5)$ & $5.5(4.37)$ & 0.25 & -0.18 & 0.12 \\
\hline PANAS Pos & $25.43(4.65)$ & 29 (6.19) & $25.17(8.47)$ & $27.5(11.04)$ & -0.68 & 0.04 & -0.38 \\
\hline PANAS Neg & $22.86(5.24)$ & $19.71(5.56)$ & $18.5(5.96)$ & $16.5(5.68)$ & 0.52 & 0.70 & 1.02 \\
\hline SPT Pos & 48.71 (8.32) & $50.14(11.77)$ & $44.5(11.22)$ & $47(12.5)$ & -0.15 & 0.43 & 0.17 \\
\hline SPT Neg & $\begin{array}{l}60.43 \\
(15.13)\end{array}$ & $49.86(17.39)$ & $44(17.94)$ & $55.16(9.60)$ & 0.61 & 0.91 & 0.29 \\
\hline LOT-R & $14(6.24)$ & $15.28(7.41)$ & $14(7.64)$ & $18.17(5.42)$ & -0.18 & 0.0 & -0.57 \\
\hline QLI & $5.21(1.46)$ & $5.70(1)$ & $6.46(1.75)$ & $6.15(0.94)$ & -0.29 & -0.73 & -0.54 \\
\hline
\end{tabular}

Note. Effect size $(d)$ calculation from Cohen (1988) $d=0.2$ are regarded as a "small" effect size, $d=0.5$ as "medium,' and $d=0.8$ as "large". For the means and effect sizes, sample size at pre-treatment, post-treatment and 1 month follow-up was 7, with the exception of positive and negative emotions (PANAS) and future expectancies (SPT) which had data for 6 patients. At the 3 months follow-up, data was available for 6 patient 
During the intervention, patients practiced the imagery exercise from

1 to 4-5 times a week. At follow ups, in general, patients decreased the frequency of applying the exercise. Only one of them increased her practice. Patients expressed a high degree of satisfaction with the intervention and a very positive opinion of it's utility (see Table 3). Its average ratings for each question are shown in Table 4.

Table 3. Participant's opinions about the intervention

\begin{tabular}{ll}
\hline Participants & Opinions \\
\hline FIB1 & "During the exercise, I felt like pain was put it in a drawer. I found it \\
& pleasant. It's a pain patch. The pain remains but these days I'm \\
& taking it in a different manner". \\
FIB2 & "What I liked the most was that it forced me to take time for myself \\
& and ask me what were my goals and how could I make them a \\
& reality. But sometimes I was tired and it was exhausting to do it. I \\
& think anyone could benefit from this exercise, it's not necessary to \\
& suffer from FM. We all suffer "low seasons" and I think these \\
& exercises help you". \\
& "You think in something beautiful, something that you like. It \\
& relaxes you. I think that any person that needs to improve both \\
& physically and mentally could benefit from this exercise". \\
& "I have visualized myself being able to walk, meeting new people \\
that brought positive things to my life. I think it helped me to feel & better and let my mind rule over my body. I think it would be nice if \\
FIB4 & you could share your exercise with other people. When I couldn't \\
& use my computer, I did it on my mobile phone". \\
& "I thought in accessible goals, like improving the relationship with \\
& my daughter and the progress of my store. It helps your mind to \\
& overcome problems and pain. Medications don't do that. I liked \\
that it forced me to dedicate time to think in these things, which I & normally don't do". \\
& "I visualized how I want and hope my future will be: finishing \\
school, finding a job, being stable. I liked thinking that I could \\
achieve those goals, because I see them distant and difficult. \\
"I imagined myself more relaxed, I thought in being a good mother \\
to my children and that it's okay to make mistakes. The exercise \\
forces you to think positively about yourself, something that I \\
never do. It makes you to face you fears. At first, I was afraid to fail, \\
to get stuck in the past. I think it would be good to do it in groups \\
and with a therapist to lead the way".
\end{tabular}


Table 4. Utility and satisfaction with the intervention

$M(S D)$

To what extent were you satisfied with the

$6.71(2.29)$

imagery exercise you received?

To what extent would you recommend this

imagery exercise to a friend who has the

same problem?

To what extent do you think the imagery

$6.57(1.81)$

exercise has been helpful?

To what extent have you found this imagery

exercise aversive?

$1.71(2.98)$

\begin{tabular}{lcc}
\hline Positive Technologies & Satisfaction & Utility \\
& $M(S D)$ & $M(S D)$ \\
\hline The Book of Life & $7(1.73)$ & $7.57(1.9)$ \\
Emotional Therapy Online & $8.5(1.0)$ & $8.75(1.5)$ \\
SMS messages & $7.86(2.67)$ & $8(2.82)$ \\
Manual & $7(1.83)$ & $7.57(1.81)$ \\
Images & $6.86(1.95)$ & $7.29(2.29)$ \\
Audio quality & $7.43(1.9)$ & $7.57(1.9)$ \\
Videos & $7.50(2.07)$ & $7.67(2.06)$ \\
\hline
\end{tabular}

Note. Patients rated the items on a 0 to 10 scale where 0 was "not at all" and 10 was

"completely." 


\section{Discussion}

The aim of this study was to present a PPI intervention designed for clinical patients and preliminary test its efficacy in FMS patients. To our knowledge, it is the first study to test the BPS manipulation in FMS patients and using the benefits of technology to enhance intervention adherence and self-management.

Our results showed that the BPS imagery exercise led to a significant decreasedepression and impact of pain in functional status in fibromyalgia patients. For the FIQ-R, a change of $14 \%$ has been considered clinically relevant (Bennett et al. 2009). Patients achieved a reduction in the impairment caused by FM symptoms, showing changes in FIQ-R total scores ranged from $1.39 \%$ to $41 \%$., and 4 of the 7 patients achieved a reliable change. Reduction in depression scores were significant at post intervention and effect sizes were large. At the 3 months follow-up, none of the patients had a clinically significant level of depression. Pain catastrophizing showed a significant reduction at post-intervention but, moreover, it continued to disminish progressively until the 3 months follow-up. However, when employing the RCI only 3 of the patients showed a reliable change. Our results are in line with previous studies that experimentally induced pain and optimism, and found a reduction in situational and dimensional pain catastrophing in healthy participants (Boselie et al. 2014; Hanssen et al. 2013). Moreover, we extended previous findings by demonstrating that a BPS manipulation can have an effect on pain catastrophizing in chronic pain patients that have been suffering pain for approximately 10 years. These results are in line with previous studies reporting changes from $10 \%$ up to 
43\% (Jensen et al. 2001; Adams et al. 2007) in catastrophizing following psychological interventions. Our results showed that at the 3 months followup, patients presented a reduction from $22 \%$ up to $98 \%$ in PCS.

Regarding future expectancies, we found a significant reduction in negative expectancies at post-intervention that was maintained at follow-up. Four of the patients presented a reduction of 20 points in their baseline scores at the 3 months follow-up. Patients reported less negative affect from pre-intervention to post-intervention. The most relevant finding is that patients continued to improve in the follow-up, achieving a higher reduction in negative emotions, with large effect sizes. In terms of positive affect, patients reported more positive emotions although these results were not maintain at follow ups for most of the patients. Surprisingly, we found an increase in positive future expectancies that was reliable according to the RCI in only one of the patients. Taking into account previous BPS studies that, on the contrary, did not find any effect of induced optimism on negative affect (Sheldon and Lyubomirsky 2006; Peters et al. 2010; Meevissen et al. 2011), we found a significant effect on negative future expectancies and negative affect, but not in positive future expectancies and positive affect. It should be noticed that previous studies were perfomed on healthy subjects and these results could be explained due to differences in populations. Further studies in clinical samples should clarify these differences.

Dispositional optimism showed no significant change at post intervention and at 1 month follow-up. Only one of the patients achieved a reliable change. However, at the 3 months follow-up results demonstrated an increase in LOT-R scores, in patient FIB5 who had a change of 20 points with 
respect to her baseline levels. These results are in line with a recent study analyzing the nature of optimism (Eichner et al. 2014) and concluding that due to the dimensional characteristic of its structure, interventions aimed at increasing optimism should expect to gradually increment a more flexible and optimistic thinking. Another aspect worth mentioning is the fact that most of the studies using the BPS manipulation assumed changes in optimism, while actually they do not include the LOT-R as an outcome variable. One exception is the study by Flink et al. that include the LOT-R in a positive intervention protocol that incorporated the BPS. However, this study did not find changes in this measure at post intervention. Researchers that expect to apply positive psychology interventions (PPI) in a short term basis should consider the inclusion of different scales to examine optimism and include a long term design, specially for clinical populations. One of the key aspects of PPI is to promote well-being. Our results showed that patients that practiced their BPS imagery exercise reported an increased in their quality of life at post-intervention that was maintained at follow-ups.

Another aspect worth highlighting is the patients' acceptance of the use of technologies. Participants agreed that the use of The Book of Life helped them to visualize their exercise, and they considered TEO useful in practicing their exercise at home. In particular, they appreciated the SMS messages, which made it easier to remember to do the practice.

Our study has some limitations that should be considered. First, this is a pilot study and because of that we used a small and convenient sample. A more representative sample of FMS patients would allow the generalization of our findings. Another concern refers to our effect sizes. Although we found 
effect sizes that would be consider large by standars (Cohen 1988), because of the sample size, results should be interpreted with caution. Moreover, when employing a more strict methodological measure of change results where modest. Also, we did not include the FIQ-R at follow-ups, and it should be included in future studies in order to assess changes on health status and impact of FMS in a long term basis.

We believe our study makes an important contribution not only to PPI research but also to pain research, helping to understand how a PPI works in a special population, fibromyalgia patients, expanding its efficacy data in clinical populations and adding knowledge to the role that positive psychological factors have in pain experience. Also, our results add information of a good way to implement the BPS exercise integrating technologies into an existing healthcare delivery system. This initial pilot study encourages us to continue exploring the use of technology-based guided imagery interventions with this population and to conduct a randomized clinical trial to test its efficacy comparing to a control intervention. We think that management of this chronic pain condition needs to tailor multi-component interventions for the individual patient, taking into account new clinical interventions that address positive resources (Goodin and Bulls 2013), and understanding that if it is a chronic condition, selfmanagement is eventually a must. 


\section{References}

Adams, H., Ellis, T., Stanish, W.D., \& Sullivan, M. J. L. (2007). Psychosocial factors related to return to work following rehabilitation of whiplash injuries. Journal of Occupational Rehabilitation, 17, 305-315.

Affleck, G., Tennen, H., Zautra, A., Urrows, S., Abeles, M., Karoly, P. (2001). Women's pursuit of personal goals in daily life with fibromyalgia: a value-expectancy analysis. Journal of Consulting and Clinical Psychology, 69, 587-596.

Alden, A. L., Dale, J. A., \& DeGood, D. E. (2001). Interactive effects of the affect quality and directional focus of mental imagery on pain analgesia. Applied Psychophysiology and Biofeedback, 26, 117-126.

Aspinwal, L.G., \& Tedeschi, R.G. (2010a). The value of positive psychology for health psychology: Progress and pitfalls in examining the relation of positive phenomena to health. Annals of Behavioral Medicine, 39, 4-15.

Baños, R. M., Etchemendy, E., Farfallini, L., García-Palacios, A., Quero, S., \& Botella, C. (2014). EARTH of Well-Being System: A pilot study of an Information and Communication Technology-based positive psychology intervention. Journal of Positive Psychology, 9, 482-488.

Bennett, R. M., Bushmakin, A. G., Cappelleri, J. C., Zlateva, G., \& Sadosky, A. B. (2009). Minimal clinically important difference in the fibromyalgia impact questionnaire. Journal of Rheumatology, 36, 1304-1311.

Bolier, L., Haverman, M., Westerhof, G. J., Riper, H., Smit, F., \& Bohlmeijer, E. (2013). Positive psychology interventions: A meta-analysis of randomized controlled studies. BMC Public Health, 13, 119. 
Boselie, J. J., Vancleef, L. M., Smeets, T., \& Peters, M. L. (2014). Increasing optimism abolishes pain-induced impairments in executive task performance. Pain, 155, 334-340.

Borkovec, T. D., \& Nau, S. D. (1972). Credibility of analogue therapy rationales. Journal of Behavior Therapy and Experimental Psychiatry, 3, $257-260$.

Cohen, J. (1988). Statistical power analysis for the behavioral sciences, 2 nd ed. New Jersey: Lawrence Erlbaum.

Eichner, K. V., Kwon, P., \& Marcus, D. K. (2014). Optimists or optimistic? A taxometric study of optimism. Psychological Assessment, 26, 10561061.

Esteve-Vives, J., Rivera, J., Salvat, M. I., De Gracia, M., \& Alegre, C. (2007). Proposal for a consensus version of the fibromyalgia impact questionnaire for the Spanish population. Reumatología Clínica, 3, 2124.

Finan, P., \& Garland, E. (2015). The role of positive affect in pain and its treatment. Clinical Journal of Pain, 31, 177-187.

Flink, I. K., Smeets, E., Bergbom, S., Peters, M. L. (2015). Happy despite pain: a pilot study of a positive psychology intervention for patients with chronic pain. Scandinavian Journal of Pain, 7, 71-9.

Fors, E. A., Sexton, H., \& Götestam, K. G. (2002). The effect of guided imagery and amitriptyline on daily fibromyalgia pain: a prospective, randomized, controlled trial. Journal of Psychiatric Research, 36, 179187. 
García Campayo, J., Rodero, B., Alda, M., Sobradiel, N., Montero, J., \& Moreno, S. (2008). Validation of the Spanish version of the Pain Catastrophizing Scale in fibromyalgia. Medicina Clínica, 131, 487-492.

Glombiewski, J. A., Sawyer, A. T., Gutermann, J., Koenig, K., Rief, W., \& Hofmann, S. G. (2010). Psychological treatments for fibromyalgia: A meta-analysis. Pain, 151, 280-295.

Goodin, B. R., \& Bulls, H. W. (2013). Optimism and the experience of pain: benefits of seeing the glass as half full. Current Pain and Headache Reports, 17, 329-339.

Goodin, B. R., Glover, T. L., Sotolongo, A., King, C. D., Sibille, K. T., Herbert, M. S. et al. (2013). The association of greater dispositional optimism with less endogenous pain facilitation is indirectly transmitted through lower levels of pain catastrophizing. The Journal of Pain, 14(2), 12635.

Hanssen, M. M., Peters, M. L., Vlaeyen, J. W. S., Meevissen, Y. M. C., \& Vancleef, L. M. G. (2012). Optimism lowers pain: evidence of the causal status and underlying mechanisms. Pain, 154, 53-58.

Hausmann, L. R. M., Parks, A., Youk, A. O., \& Kwoh, C. K. (2014). Reduction of bodily pain in response to an online positive activities intervention. Journal of Pain, 15, 560-567.

Holmes E. A, \& Mathews A. (2005). Mental imagery and emotion: A special relationship? Emotion, 5, 489-97.

Holmes, E. A., \& Mathews, A. (2010). Mental imagery in emotion and emotional disorders. Clinical Psychology Review, 30, 349-362. 
Hood, A., Pulvers, K., Carrillo, J., Merchant, G., \& Thomas, M. (2012). Positive traits linked to less pain through lower pain catastrophizing. Personality and Individual Differences, 52, 401-405.

Jensen, M.P., Turner, J. A., \& Romano, J. M. (2001). Changes in beliefs, catastrophizing, and coping are associated with improvement in multidisciplinary pain treatment. Journal of Consulting and Clinical Psychology, 69, 655- 662.

Keefe, F.J., \& Wren, A. A. (2013). Optimism and pain: a positive move forward. Pain, 154, 7-8.

Keogh, E., Rosser, B. \& Eccleston, C. (2010). e-Health and chronic pain management: current status and developments. Pain, 151, 18-21.

Layous, K., Nelson, K. S., \& Lyubomirsky, S. (2012). What is the optimal way to deliver a positive activity intervention? The case of writing about one’s best possible selves. Journal of Happiness Studies, 14, 635-654.

Lewandowski, W. (2004). Patterning of pain and power with guided imagery. Nursing Science Quarterly, 17, 233-241.

Lyubomirsky, S., \& Layous, K. (2013). How do simple positive activities increase well-being? Current Directions in Psychological Science, 22, $57-62$.

MacLeod, A. K. (1996). Affect, emotional disorder, and future-directed thinking. Cognition \& Emotion, 10, 69-86.

Meevissen, Y. M., Peters, M. L., \& Alberts, H. J. (2011). Become more optimistic by imagining a best possible self: effects of a two week intervention. Journal of Behavior Therapy and Experimental Psychiatry, 42, 371-378. 
Mezzich, J. E., Ruipérez, M. A., Pérez, C., Yoon, G., Liu, J., Mahmud, S. (2000). The Spanish version of the quality of life index: presentation and validation. Journal of Nervous and Mental Disease, 188, 301-305.

Mohr, D. C., Burns, M. N., Schueller, S. M., Clarke, G., \& Klinkman, M. (2013). Behavioral intervention technologies: Evidence review and recommendations for future research. General Hospital Psychiatry, 35, 332-338.

Muller, R., Gertz, K. J., Molton, I. R., Terrill, A. L., Bombardier, C. H., Ehde, D. M.et al. (2016). Effects of a tailored positive psychology intervention on well-being and pain in individuals with chronic pain and a physical disability: a feasibility trial. Clinical Journal of Pain, 32, 32-44.

Norman, S. B., Cissell, S.H., Means-Christensen, A.J., \& Stein, M.B. (2006). Development and validation of an Overall Anxiety Severity and Impairment Scale (OASIS). Depression and anxiety, 23, 245-249.

Okifuji, A., \& Hare, B. D. (2013). Management of fibromyalgia syndrome: review of evidence. Pain and therapy, 2, 87-104.

Otero, J. M., Luengo, A., Romero, E., Gómez, J.A., \& Castro, C. (1998). Psicología de personalidad. Manual de prácticas. Barcelona: Ariel Practicum, 1998.

Peters, M. L., Flink, I. K., Boersma, K., Linton, S. J. (2010). Manipulating optimism: can imagining a best possible self be used to increase positive future expectancies? Journal of Positive Psychology, 5, 204211. 
Poole, H., Bramwell, R., Murphy, P. (2006). Factor structure of the Beck Depression Inventory-II in patients with chronic pain. Clinical Journal of Pain, 22, 790-98.

Quero, S., Molés, M., Pérez, M. A., Botella, C., \& Baños, R. M. (2012). An online emotional system to deliver homework assignments for treating adjustment disorders. Journal of CyberTherapy and Rehabilitation, 5, 115-116.

Roditi, D., \& Robinson, M. E. (2011). The role of psychological interventions in the management of patients with chronic pain. Psychology Research and Behavior Management, 4, 41-49. doi:10.2147/PRBM.S15375

Ruipérez, M. A., Ibáñez, M. I., Lorente, E., Moro, M., \& Ortet, G. (2001). Psychometric properties of the Spanish version of the BSI: contributions to the relationship between personality and psychotahology. European Journal of Psychological Assessment, 17, 241-250.

Sandin, B., Chorot, P., Lostao, L., Joiner, T. E., Santed, M. A., \& Valiente, R. M. (1999). Escalas PANAS de afecto positivo y negativo: Validación factorial y convergencia transcultural. Psicothema, 11, 37-51.

Sanz, J., García Vera, M. P., Espinosa, R., Fortin, M., Vázquez, C. (2005). Adaptación española del inventario para la depresión de Beck- II (BDIII): Propiedades psicométricas en pacientes con trastornos psicológicos. Clínica y Salud, 16, 121-142.

Sheldon, K. M., \& Lyubomirsky, S. (2006). How to increase and sustain positive emotion: the effects of expressing gratitude and visualizing best possible selves. Journal of Positive Psychology, 1, 73-82. 
Sin, N. L., \& Lyubomirsky, S. (2009). Enhancing well-being and alleviating depressive symptoms with Positive Psychology Interventions: A practice friendly meta-analysis. Journal of Clinical Psychology, 65, 467487.

Wolfe, F., Smythe, H. A., Yunus, M. B., Bennett, R. M., Bombardier, C., Goldenberg, D. L. et al. (1990). The American College of Rheumatology 1990 criteria for the classification of fibromyalgia: report of the Multicenter Criteria Committee. Arthritis and Rheumatism, 33, 160-72.

Zautra, A. J., Fasman, R., Reich, J. W., Harakas, P., Johnson, L. M., Olmsted, M. E. et al. (2005). Fibromyalgia: evidence for deficits in positive affect regulation. Psychosomatic Medicine, 67, 147-155. 


\section{The power of visualization: back to the future for pain management in fibromyalgia}

\section{syndrome}

Este capítulo ha sido enviado para su publicación a la revista Pain Medicine. Autores: Molinari, G., García-Palacios, A., Enrique, A., Roca P., FernándezLlanio Comella, N., y Botella, C. (submitted).

\section{Abstract}

Objective: Previous studies have demonstrated the effects of positive psychological factors on pain adjustment. Specifically, optimism has been linked to better physical functioning and less psychological distress. Until recently, these beneficial effects have mostly been examined in correlational studies or laboratory settings. The aim of this study is to test the efficacy of the Best Possible Self intervention using information and communication technologies with fibromyalgia patients.

Methods: Seventy-one patients were randomly allocated to the Best Possible Self intervention or a Daily Activities control condition. The Best Possible Self intervention used an interactive multimedia system with the support of an Internet platform to practice the guided imagery exercise online.

Results: Intent-to-treat analyses showed that, compared to the control condition, Best Possible Self patients showed significant improvements in depression, positive affect, and self-efficacy at post-intervention. Moreover, at 3-month follow-up, patients that received the intervention improved their 
optimism and negative affect significantly more than control condition participants.

Discussion: This study shows how a technology-supported intervention aimed at augmenting positive affect and promoting positive functioning works in the case of fibromyalgia, expanding the intervention's efficacy data in clinical populations and adding knowledge about the role that positive psychological factors play in pain experience. Moreover, it demonstrates the specific effects of the Best Possible Self intervention in order to incorporate this exercise in pain treatment protocols.

Keywords: fibromyalgia, treatment outcome, optimism, best possible self, selfefficacy 


\section{Introduction}

Fibromyalgia syndrome (FMS) is a chronic widespread pain condition characterized by fatigue, functional disability, disturbed sleep, cognitive impairment, and mood disorders [1]. Due to the heterogeneity in the presentation and severity of symptoms among patients, to date, no psychological or pharmacological treatment has been found to be effective for all patients. FMS patients take more medication, make six more yearly medical visits, and show a higher average of work days missed than the reference population [2]. FMS affects up to $3 \%$ of the population, and these data suggest annual incremental costs of up to approximately €12 billion for a population of 80 million for every year these patients are not treated [3].

FMS patients experience significantly low levels of quality of life that remain stable over time, even compared to other chronic pain disorders [4]. Comorbid depression is very common among FMS patients, with a lifetime prevalence of $62-86 \%$ [5], often accompanied by cognitive dysfunctions and pain catastrophizing, which lead to avoidance and withdrawal from daily life activities [6]. Approximately 35\% of patients report difficulties in performing common everyday activities [7].

In sum, pain experience in FMS is complex and multidimensional. Therefore, established guidelines recommend a multi-component approach [8]. Treatment options include pharmacotherapy (evidence-based treatment guidelines recommend four drug classes: anti-epileptic drugs, tricyclic antidepressants, selective serotonin reuptake inhibitors, and serotoninnorepinephrine reuptake inhibitors [9]; as well as aerobic exercise, relaxation, acupuncture, massage therapy, and psychological treatments. 
Psychological approaches comprise behavioral interventions, such as activity pacing or graded exposure to movement, combined with cognitive components (e.g. cognitive restructuring, problem-solving, and coping skills) $[10,11,12]$ and the use of mindfulness strategies and acceptance and commitment therapy skills [13]. These approaches have commonly focused on reducing negative emotions, cognitions, and maladaptive coping associated with pain [14].

Although psychological approaches have traditionally concentrated on reducing negative symptoms associated with pain, new developments in pain management emphasize the role of positive affect and positive adjustment factors in coping with pain (for a review, see [15]). In this regard, some empirically supported psychosocial treatments have included interventions to enhance positive factors, but they are presented to patients as an approach designed to minimize negative appraisals of pain or as part of a "treatment package" $[16,17,18]$ that includes several exercises. Therefore, the specific role of positive psychology interventions is difficult to analyze.

There is considerable variation in the combinations of treatment strategies across trials, and most of them report small to moderate effect sizes in reducing pain-related disability, emotional distress, and maladaptive coping [19]. However, in order to improve their efficacy and accessibility, a change in the design and implementation of pain treatments is needed [20]. In terms of theoretically-driven treatment models, treatment protocols combine several components, but with little evidence about merits of one combination of components over another or the rationale for including specific components [12]. Most of these treatment components have shown 
their efficacy in broader fields of research, but they have not been individually tested in people with chronic pain [21]. In this study, we focus on testing a single component designed to enhance positive affect and positive adjustment.

In the implementation of pain treatments, an important aspect is to promote self-management [22]. To do so, face to face applications could benefit from the integration of technologies to enhance self-management and extend the reach and feasibility of psychological interventions for chronic pain [23]. Recent meta-analyses and research studies provide evidence for the efficacy of Internet-based interventions [24, 25], virtual reality [26, 27, 28], and smartphone applications [29] in managing pain. These technologies reduce barriers to accessing health care, while decreasing costs, increasing treatment efficiency, and promoting self-management [30], a core aspect of chronic conditions. Technologies can also help to promote positive functioning, improve wellness, and foster strength and resilience in individuals. They are referred to as Positive Technologies [31, 32, 33].

Although current directions in pain management aim to incorporate ICTs in healthcare and promote protective factors against experiencing pain, to date, research combining these efforts in chronic pain patients is limited. Moreover, to our knowledge no study has tested a single positive intervention in a chronic pain population to analyze its isolated effect.

For these reasons, we adapted a positive future-thinking intervention using Information and Communication Technologies (ICTs) [34], the Best Possible Self (BPS), which combines positive imagery with goal setting in different self-domains. An ICT-based computerized system $[35,36]$ 
(Emotional Activities Related to Health, EARTH) supported by a web-based online platform [37] (Emotional Therapy Online, TEO) with a brief automated short message service (SMS) was developed to provide therapist support and encourage exercise practice in fibromyalgia patients. The aim of this study is to extend the findings of the pilot study and test the efficacy of the BPS intervention in fibromyalgia patients compared to an active control condition. To our knowledge, this is the first controlled study to test this intervention in fibromyalgia patients.

Taking into account previous results that demonstrated the efficacy of this intervention in general population $[38,39]$ and experimentally-induced pain $[40,41]$ samples, the first hypothesis is that FMS patients will present lower levels of negative expectations and negative affect and higher levels of positive affect and positive future expectations after a single session of the BPS intervention. The second and main hypothesis is that patients in the BPS condition will present lower levels of depression and negative affect and higher levels of positive affect and positive future expectations after the one month intervention, compared to patients in the daily activities condition. The third hypothesis is that patients in the BPS condition will report lower levels of pain catastrophizing and negative future expectations and higher levels of self-efficacy and quality of life, compared to patients in the control condition after the one month intervention. Finally, because there is a lack of empirical evidence about maintenance of changes after this intervention, we preliminary explored the long term effects of the BPS intervention at 1month and 3-months. 


\section{Materials and Method}

\section{Participants}

Participants were referred by a rheumatologist from the Rheumatology Unit of the Hospital Arnau of Vilanova. Inclusion criteria established that patients had to be diagnosed with FMS by a rheumatologist according to American College of Rheumatology criteria [42, 43]. Exclusion criteria were suffering from severe mental disorders such as schizophrenia, bipolar disorder, mental retardation, or substance abuse or dependence.

Sample size calculations were performed a priori using the statistical program $G^{*}$ Power (version 3.0.10 for Windows). Previous research found effect sizes ranging from medium to small $[16,34]$. In the analysis, we found that for an expected small effect size (0.2), with a $p<0.05$, an expected power of $0.95 \%$, and with a total of two groups and 4 measures, a sample size goal of 56 was large enough to provide reliable effect size estimates.

One hundred and fifteen participants were eligible, but 35 were not allocated to the conditions for several reasons (see flow diagram in Figure 1). The main reason for declining to participate was that the study involves coming to the University a few times to receive the intervention. Most of the patients depended on another family member to get around or presented mobility problems. The final sample comprised 71 participants with a diagnosis of FMS. The mean age of the sample was 51.08 years old $(S D=$ 10.54), ranging from 23 to 71 years, and the mean duration of suffering from pain was 13.1 years $(S D=10.07)$. All participants consented to the research protocol as approved by the Ethical committee at the University Jaume I. 


\section{Measures}

Demographic and pain-related information

A brief structured interview was conducted to assess demographic variables and pain duration. Self-reported psychological distress was assessed by the Spanish version of the Brief Symptom Inventory (BSI) [44, 45].

\section{Primary outcome measures}

Depression. The Beck Depression Inventory (BDI-II is a 21-item self-report measure of cognitive, affective, and somatic symptoms of depression. It presents good psychometric properties in the English and Spanish versions $[46,47]$.

The Positive and Negative Affect Scale (PANAS) includes two 10-item scales evaluating positive and negative affect. The rating scale ranges from: 1 'very slightly or not at all' to 5 'very much'. It has demonstrated both reliability and validity across cultures and languages, including Spanish [48, 49].

Optimism and Future expectancies. The Life Orientation Test-revised (LOT-R) includes 10 items (four are filler items) that assess dispositional optimism on a 5-point scale (1=disagree - 5=agree). For this study, the Spanish version was used [50, 51]. The Subjective Probability Task (SPT) was used as a measure of positive (10 items) and negative (20 items) future expectancies. The SPT consists of 30 items scored on a 7-point Likert scale ranging from 1 ('not at all likely to occur') to 7 ('extremely likely to occur'). For this study, our group performed a Spanish adaptation of the scale [52, 53].

\section{Secondary outcome measures}

Fibromyalgia Impact Questionnaire (FIQ-R). The FIQ-R is a 10-item self-report questionnaire that measures the health status of patients with FMS by 
assessing the interference FMS produces in their daily lives. It includes four sections that assess the patient's ability to perform daily and physical activities, his/her functional status, and other symptoms (pain, fatigue, morning tiredness, stiffness, anxiety, and depression). This instrument is widely used and has demonstrated good psychometric properties across cultures and languages, including Spanish $[54,55]$.

Pain Catastrophizing. On the Pain Catastrophizing Scale (PCS), the patient is asked to reflect on past painful experiences and indicate the degree to which s/he experiences each of 13 thoughts or feelings when experiencing pain, on 5-point scales ranging from (0) not at all to (4) all the time. The PCS yields a total score and three subscale scores assessing rumination, magnification, and helplessness. For the purpose of this study, we used the PCS total score $[56,57]$.

General Self Efficacy Scale-12 (GSES-12). This is a 12-item scale that evaluates perceived overall self-efficacy and three of its main aspects: initiative, persistence, and effort. All items are responded to on a 5-point scale ranging from 1 ('never happens to me') to 5 ('always happens to me'). For this study, we used the the Spanish version, which has shown good psychometric properties $[58,59]$.

Quality of life. The Spanish version of the Quality of Life Index (QLI-Sp) consists of 10 items evaluating different dimensions of psychological wellbeing: physical well-being, psychological/emotional well-being, self-care and independent functioning, occupational functioning, interpersonal functioning, social-emotional support, community and services support, personal fulfillment, and spiritual fulfillment $[60,61]$. 


\section{Design}

A single-blind randomized controlled trial with repeated measures (pre-intervention, post-session, post-intervention, 1-month follow-up, and 3month follow-up) and two conditions: Best Possible Self intervention (BPS) and the active control condition (Daily Activities, DA). The random assignment of the participants to the different experimental conditions was carried out by an independent researcher who had no knowledge about the study or the intervention received by the different groups. This investigator performed the randomized assignment according to a randomization list created by the Random Allocation Software, version 1.0. The study was registered in the United States National Institute of Health Registration System (http://www.clinicaltrials.gov) with Clinical Trials Registration Number: NCT02375061. https://clinicaltrials.gov/show/NCT02375061

\section{Data analyses}

A $t$ student and chi-square tests were performed to check for baseline differences between conditions. In order to improve the quality of the study, and following the CONSORT guidelines [62, 63, 64], Intent-To-Treat (ITT) analyses were carried out following Newman's guidelines [65] and using Maximum Likelihood (ML) estimation performed via Expectation Maximization imputation (EM). For the treatment of missing data, the procedure suggested by Hair and colleagues [66] was followed. First, the type of missing data was explored, concluding that construct-level data were missing and, thus, susceptible for imputation. Second, the quantity of missing values was analyzed, determining that none of the measures exceeds the recommended limits [67]. Third, a diagnosis of the random pattern of 
missing data was carried out with the Little MCAR test $\left(\chi^{2}(709)=686.26, p\right.$ >.05), concluding that missing data are completely random. Finally, Maximum Likelihood estimation (ML) was performed for the missing values, and sensitivity analysis compared the results of the completers to the estimated values. These sensitivity analyses showed that there was no chance of falling into biased estimations by using the ML estimation.

Three sets of analyses were carried out. First, to test our first hypothesis, we analyzed the single-session effects (pre-post session) through a 2x2 mixed ANOVA (with time as the within-subject variable and condition as the between-subject variable) to compare the effects of the intervention on affect and future expectations in the BPS and DA conditions. Second, to test our second and third hypothesis, we analyzed the efficacy of the selfapplied intervention from pre to post-intervention for each measure through a two-way mixed ANOVA. Finally, long-term effects of the BPS intervention were analyzed including the 1-month and 3-month follow-ups by carrying out a 2x4 mixed ANOVA for each measure (Pre, Post-intervention, 1-month follow-up, 3-month follow-up). All the assumptions for the ANOVAs performed were checked. In the case of mixed $2 \times 4$ ANOVAs, the degrees of freedom were corrected using Greenhouse-Geisser in those cases where the sphericity assumption was not fulfilled. Effect sizes (Cohen's $d$ ) [68] and confidence intervals were calculated for within-group and between-group changes, based on the pooled standard deviation. All statistical analyses were conducted using IBM SPSS Statistics 22. 


\section{Intervention}

BPS: Patients were asked to think of and write down all the aspects that their future best possible self should include in the personal, social, professional, and health domains. Patients used an interactive system called the Book of Life $[35,36]$. This application was used so that participants could write down and imagine their BPS and incorporate multimedia content as a personal diary to promote positive narrative and enrich visualization. Patients were given 20 minutes to complete the exercise, and the last 5 minutes were used to visualize what they had just written. In order for patients to practice the guided imagery at home, all the contents included by the participants in the "Book of Life" were exported to a web platform (Emotional Therapy Online, TE0) [37]. Please see Molinari et al. [34] for a complete description of the rationale and development of the technologysupported BPS system.

Daily Activities (DA): Patients were asked to think about and write down everything they had done in the past 24 hours. Participants in this condition were provided with a PowerPoint document to write the content of the exercise for 20 minutes and then visualize it as a power point presentation for the last 5 minutes.

In both conditions, during the whole intervention, participants received two short message services (SMS) per week with reminders to practice their exercise and reinforcements. Messages like: "Happiness is not a rational ideal, but rather one of imagination. Don't forget to continue to practice the imagination exercise! Thank you very much"; or "Hello! You're 
doing great! We encourage you to continue to practice the imagination exercise. Thank you very much", were sent in a randomized way.

\section{Procedure}

The rheumatologist at the local public hospital gave general information about the study and referred FMS patients who were interested in participating. All participants attended voluntarily and received no incentives. Once the participants had given their written informed consent to participate, a brief structured interview was conducted to assess pain history, treatments, and other diagnoses. Patients were assessed at baseline with the BSI. They took the rest of the assessment protocol home, and it had to be completed for the following lab session. In the following session, patients completed the SPT and the PANAS before performing the exercise. Then, participants in both conditions received a manual and listened to the instructions through headphones in order to guarantee standardization and facilitate concentration [39]. Next, the researcher presented the Book of life system to the BPS patients and explained how to use it. After 25 minutes of writing about their BPS and selecting their images, music and videos, they performed the 5-min imagery exercise. Patients were told that they would receive an email giving them access to $T E O$ to practice their exercise at home. Participants in the DA condition also performed the exercise on a computer using a PowerPoint presentation, and then they visualized it for 5 minutes. The post intervention session took place at the university in the fourth week. The measures of depression, positive and negative affect, future expectancies, optimism, pain catastrophizing, pain disability, anxiety, self-efficacy and quality of life were administered. An interview was conducted in order to 
assess the frequency with which the imagery exercise was applied, and the acceptance and perceived usefulness of the intervention. Finally, patients were asked to continue to practice their exercise, and they were informed that they were going to be contacted at 1-month and 3-month follow-ups. At the follow-ups, patients completed the same questionnaires as at postintervention.

\section{Results}

\section{Participants Flow}

One hundred and fifteen participants were contacted. After the screening interviews, 80 patients were accepted in the study and randomly allocated to the two experimental conditions: e-BPS, $n=40 ; D A, n=40$. Nine participants did not come back for a second session to return the assessment protocol and receive the allocated intervention. Thus, there were preintervention assessments for 38 participants in the e-BPS condition and for 33 participants in the DA condition. During the intervention program, there were 15 dropouts from the BPS group and 5 dropouts from the DA condition. At the 1-month follow-up, there were 5 dropouts from the BPS condition and 9 from the DA condition. Fifteen participants in the BPS group and 13 participants in the DA group completed the whole intervention (see Figure 1). 


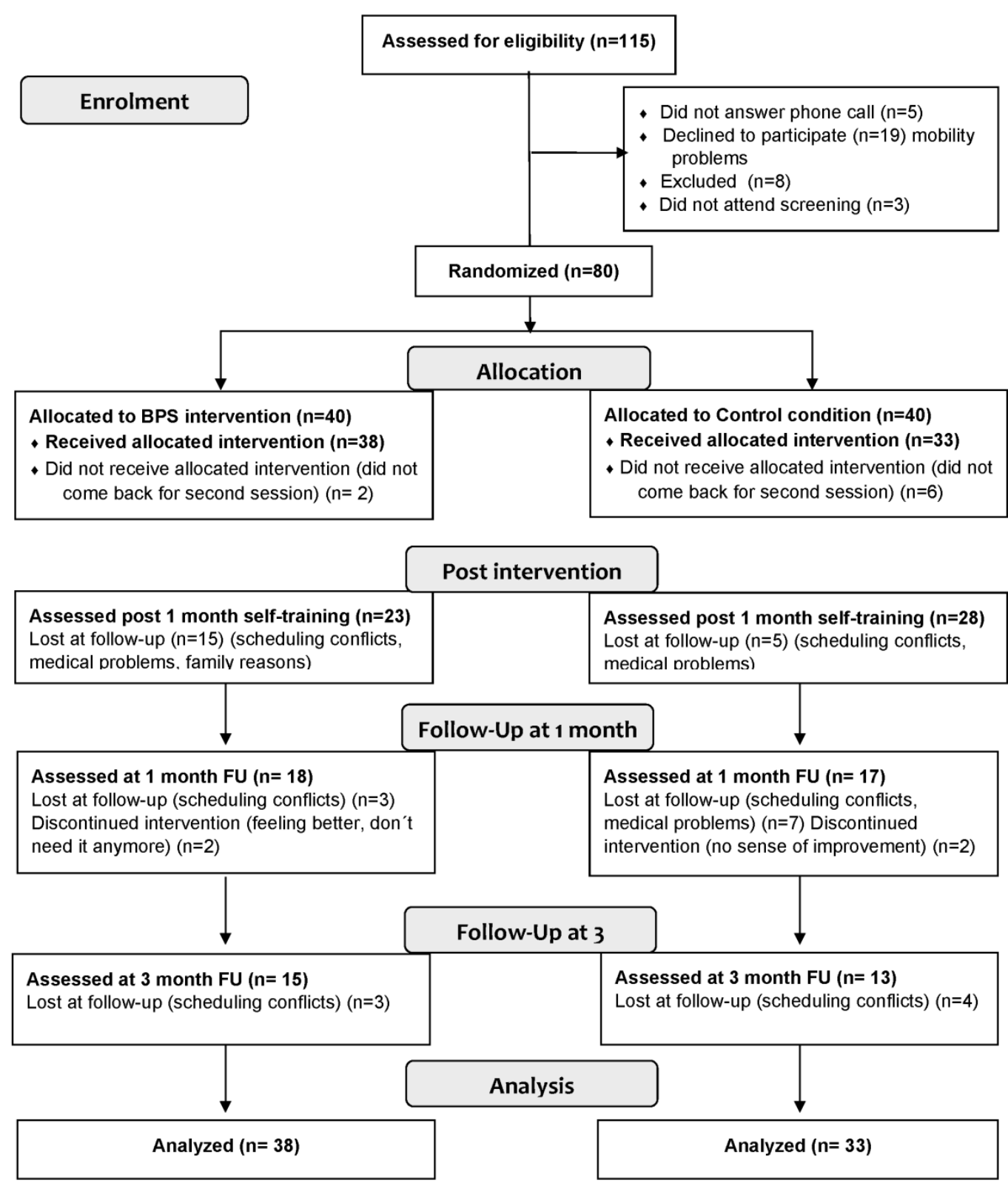

Figure 1. Participant's Flow Chart

\section{Pre intervention comparisons}

Chi-square tests showed no differences between the groups at pre-test in any

of the demographic variables: $\operatorname{sex}\left(\chi^{2}(1)=1.168 ; p=0.28\right)$; education $\left(\chi^{2}(3)\right.$

$=2.627 ; p=0.453)$; marital status $\left(\chi^{2}(3)=2.427 ; p=0.489\right)$; and occupation.

A student $t$ test revealed no differences between the groups regarding age $(t$ 
[69] $=-1.0 ; p=0.169)$ or years with pain $(t[67]=-0.61 ; p=0.543)$. Moreover, there were no statistically significant differences between the groups on any of the outcome variables, which indicated that the random assignment was successful.

\section{Baseline characteristics}

Patients were all women with a mean age of 51.08 years (range=23$71, S D=10.54)$ and a mean disease duration of 13.10 years $(S D=10.07)$. Most of the patients were married (71.8\%) and had a basic level of education (37.5\%). Eighty percent reported having received psychological treatment before. In terms of psychological distress and symptomatology, scores on the General Disability Index showed great psychological discomfort $(\bar{X}=70.87$; $S D=32.36)$.

\section{Intervention effects}

\section{Pre-post-session effects (Single-session effects)}

Regarding the first hypothesis of the study, to analyze single-session effects, we conducted a $2 \times 2$ analysis of variance ANOVA of the SPT and PANAS questionnaires. There was no significant interaction effect for the ANOVA on post-session changes in scores for any of the measures. Results showed significant time effects for the SPT-NEG $\left(F_{(1,69)}=33.18, p<.01, \eta^{2}\right.$ partial $=.32)$ and $\operatorname{PA}\left(F_{(1,69)}=18.66, p<.01, \eta^{2}\right.$ partial $\left.=.21\right)$. The post-hoc comparisons of the "moment of measurement" variable revealed statistically significant reductions in SPT-NEG between the pre-session and post-session in both conditions $(p<.001)$. In PA, increases in positive affect at post session were only significant in the BPS group $(p<.001)$. Figure 2 shows the graph of the changes in scores for both conditions. A moderate effect size was found for 
the BPS condition on the SPT-NEG ( $d=-.45 ; 95 \%$ CI $[.21, .68])$ and PA $(d=.47$; 95\% CI [-.76, -.18]). For the control condition, a small effect size was found for PA $(d=.29 ; 95 \%$ CI $[-.53,-.05])$ and SPT-NEG $(d=-.33 ; 95 \%$ CI $[.14, .52])$.

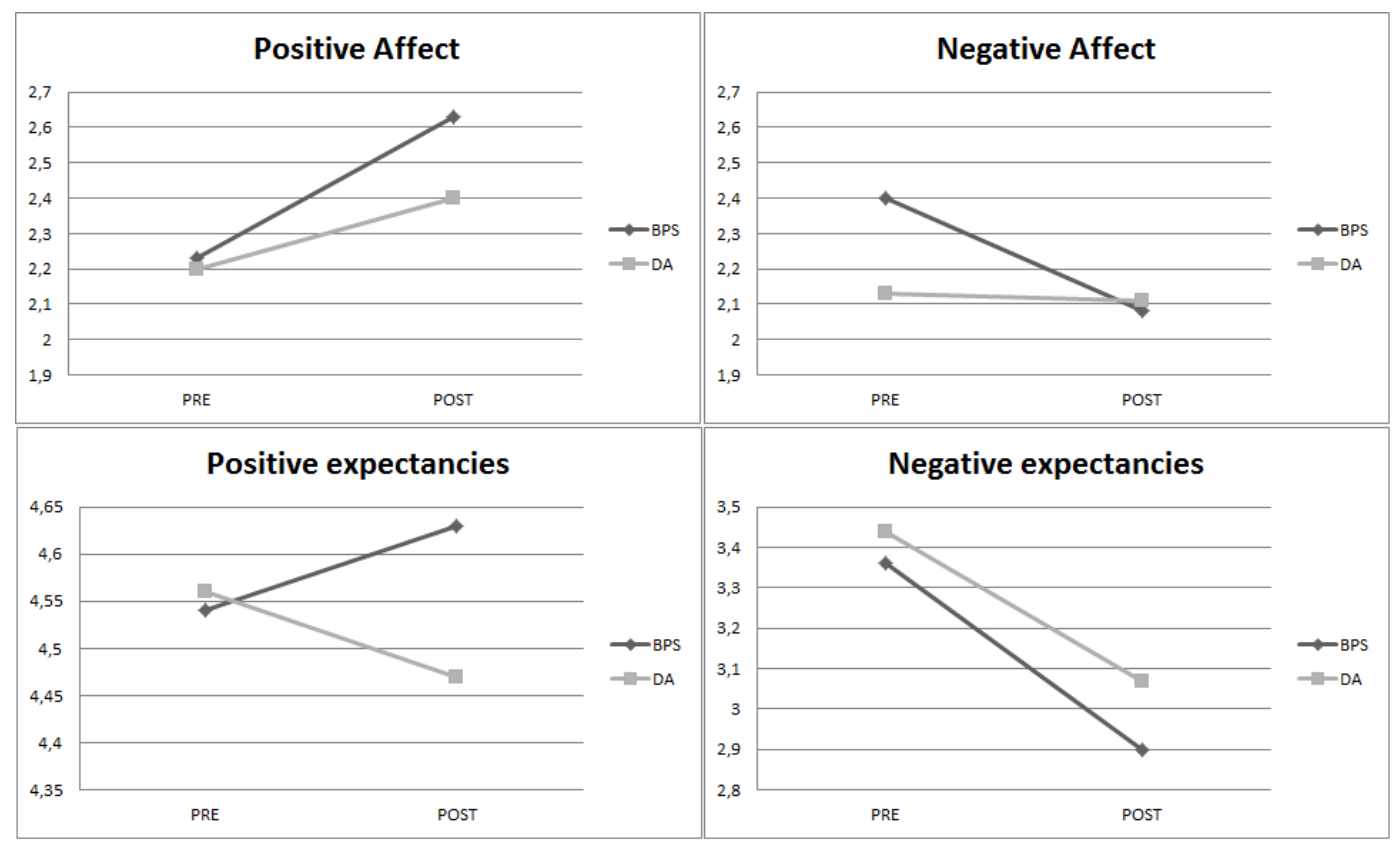

Figure 2. Changes pre-post session

\section{Pre-post intervention effects}

In order to test the main hypothesis of the study, to explore the effects produced by the two intervention modalities (BPS vs DA) during one month of self-application with online support, a series of mixed ANOVAs on all outcome measures were conducted.

Primary outcome measures

Analysis revealed a significant Group x Time interaction on the BDI-II $\left(F_{(1,69)}=7.34, p<.05, \eta^{2}\right.$ partial $\left.=.10\right)$. Post-hoc comparisons of the interaction effect revealed that the BPS group significantly reduced their BDI scores at post-intervention $(p<.005)$, a difference that was not found in the control 
group. No effect of the group factor was found $\left(F_{(1,69)}=1.08, p=.30\right)$. Also, the main effect of time was not statistically significant $\left(F_{(1,69)}=2.60, p=.11\right)$.

Regarding the interaction effects on future expectancies, no significant differences were found on the LOT-R $\left(F_{(1,69)}=2.86, p=.09\right)$; neither on the $\operatorname{SPT}-\mathrm{P}\left(F_{(1,69)}=.55, p=.46\right)$; or the SPT-N $\left(F_{(1,69)}=1.97, p=.16\right)$. No effect of the group factor was found on the LOT-R $\left(F_{(1,69)}=.04, p=.84\right)$; neither on the SPT-P $\left(F_{(1,69)}=.07, p=.78\right)$; or the SPT-N $\left(F_{(1,69)}=1.35, p=.25\right)$. The analysis revealed a significant time effect on the LOT-R $\left(F_{(1,69)}=5.02, p<.05, \eta^{2}\right.$ partial $=$ $.07)$, and the SPT-NEG $\left(F_{(1,69)}=5.22, p<.05, \eta^{2}\right.$ partial $\left.=.07\right)$, indicating a significant increase in optimism and a reduction in negative expectancies from pre to post intervention. Although the interaction effect is not statistically significant, post-hoc analysis of the interaction for the LOT-R and SPT-NEG variables shows that the differences between pre-post are only significant for the intervention group $(p<.01)$, but not for the control group ( $p>.05)$. A significant Group x Time interaction was found on PA, indicating larger increases in positive affect in the BPS condition, compared to the DA condition at post-intervention $\left(F_{(1,69)}=5.53, p<.05, \eta^{2}\right.$ partial $\left.=.07\right)$. In addition, regarding the interaction effect, a trend toward significance was found on NA $\left(F_{(1,69)}=3.53, p=.06, \eta^{2}\right.$ partial $\left.=.04\right)$. Post-hoc comparisons revealed that the increases in positive affect and reductions in negative affect between pre and post-intervention are significant for the intervention group $(p<.05)$, but not for the control group ( $p>.05)$. No effect of the group factor was found for PA $\left(F_{(1,69)}=1.04, p=.31\right)$; or NA $\left(F_{(1,69)}=.01, p=.90\right)$. There was a significant main effect of time on $\operatorname{PA}\left(F_{(1,69)}=4.16, p<.05, \eta^{2}\right.$ partial $\left.=.06\right)$, indicating significant pre to post-intervention increments in positive affect. 
The analysis revealed a significant Group x Time interaction on the GSES-12 $\left(F_{(1,69)}=9.32, p<.01, \eta^{2}\right.$ partial $\left.=.12\right)$, indicating larger increases in selfefficacy in the BPS condition compared to the DA condition at postintervention. No significant effect was found for the group factor on the GSES$12\left(F_{(1,69)}=.12, p=.73\right)$; and the main effect of time was not significant either $\left(F_{(1,69)}=.07, p=.73\right)$. Regarding the FIQ-R, the effects of the Group $\mathrm{x}$ Time interaction were not significant $\left(F_{(1,69)}=.09, p=.76\right)$, indicating that participants in the BPS group did not differ significantly from the DA group on pain functioning at post intervention. Moreover, no significant effect of the group factor was found $\left(F_{(1,69)}=.29, p=.59\right)$. The effects of time on the FIQ-R were not significant either $\left(F_{(1,69)}=.01, p=.98\right)$. No interaction effects were found on the PCS $\left(F_{(1,69)}=.31, p=.58\right)$; or the QLI $\left(F_{(1,69)}=1.45, p=.23\right)$. In addition, the effects of the group factor were not significant on the PCS $F_{(1,}$ $\left.{ }_{69)}=1.15, p=.28\right)$; or the QLI $\left(F_{(1,69)}=.24, p=.62\right)$. But there was a significant main effect of time on the PCS $\left(F_{(1,69)}=17.69, p<.01, \eta^{2}\right.$ partial $\left.=.20\right)$, indicating significant pre to post-intervention decreases in pain catastrophizing; and on the QLI $\left(F_{(1,69)}=7.37, p<.05, \eta^{2}\right.$ partial $\left.=.20\right)$, indicating significant pre to postintervention increases in quality of life. Although the interaction effect is not statistically significant, post-hoc analysis of the interaction for the QLI show that the differences between pre and post-intervention are only significant for the intervention group $(p<.01)$, but not for the control group $(p>.05)$. The descriptive statistics, effect sizes and confidence intervals are presented in Table 1. 
Table 1. Means, standard deviations, effect sizes, and coefficient intervals for changes from pre to post intervention according to condition $(n=71)$

\section{Best Possible Self}

\begin{tabular}{|c|c|c|c|c|c|c|}
\hline $\begin{array}{c}\text { Pre } \\
\text { M (SD) }\end{array}$ & $\begin{array}{c}\text { Post } \\
\text { M (SD) }\end{array}$ & $\begin{array}{l}\text { Within-group } \\
\text { effect size, } \\
d[95 \% \mathrm{CI}]\end{array}$ & $\begin{array}{c}\text { Pre } \\
\text { M (SD) }\end{array}$ & $\begin{array}{c}\text { Post } \\
\text { M (SD) }\end{array}$ & $\begin{array}{c}\text { Within- } \\
\text { group effect } \\
\text { size, } \\
d[95 \% \mathrm{CI}]\end{array}$ & $\begin{array}{c}\text { Between-group } \\
\text { effect size, } \\
d[95 \% \mathrm{CI}]\end{array}$ \\
\hline
\end{tabular}

\section{Primary outcome measures}

\begin{tabular}{|c|c|c|c|c|c|c|c|}
\hline BDI-II & $\begin{array}{c}23.13 \\
(11.18)\end{array}$ & $\begin{array}{c}19.14 \\
(11.75)\end{array}$ & $-.35^{* *}[.13, .57]$ & $23.24(9.47)$ & $24.25(12.27)$ & $.10[-.34, .13]$ & $-.42[-.89, .05]$ \\
\hline LOT & $18.61(3.95)$ & $20.1(4.86)$ & $.37[-.76, .02]$ & $19.51(4.11)$ & $19.78(4.89)$ & $.06[-.42, .29]$ & $.06[-.40, .53]$ \\
\hline SPT-POS & $4.54(1.02)$ & $4.44(.99)$ & $.10[-.23, .43]$ & $4.56(1.14)$ & $4.29(1.2)$ & $-.23[-.04, .50]$ & $.13[-.33, .60]$ \\
\hline SPT-NEG & $3.36(1)$ & $2.73(1.62)$ & $-.62^{* *}[.22,1.01]$ & $3.44(1.08)$ & $3.29(1.6)$ & $.14[-.22, .49]$ & $-.34[-.81, .13]$ \\
\hline PA & $2.23(.81)$ & $2.5(.78)$ & $.33^{* *}[-.56,-.10]$ & $2.2(.68)$ & $2.18(.79)$ & $-.03[-.21, .27]$ & $.40[-.07, .87]$ \\
\hline NA & $2.4(.84)$ & $2.01(1.06)$ & $-.45^{* *}[.07, .84]$ & $2.13(.81)$ & $2.23(1.0)$ & $.12[-.52, .28]$ & $-.21[-.68, .26]$ \\
\hline
\end{tabular}




\section{Secondary outcome measures}

\begin{tabular}{cccccccc}
\hline FIQ-R & $64.94(15.72)$ & $64.46(17.04)$ & $-.03[-.26, .32]$ & $66.25(13.2)$ & $66.82(17.62)$ & $.04[-.35, .26]$ & $-.13[-.60, .33]$ \\
PCS & $26(14.24)$ & $21.45(13)$ &.$- .31^{* *}[-\mathbf{1 4}, .49]$ & $28.75(13.57)$ & $25.26(13.16)$ & $-.25^{* *}[\mathbf{0 , . 5}]$ & $-.29[-.75, .18]$ \\
GSES & $41.08(8.47)$ & $43.01(7.44)$ & $.22[-.45,0]$ & $42.57(7.36)$ & $40.27(8.76)$ & $-.31^{* *}[.03, .58]$ & $.33[-.13, .81]$ \\
QLI & $48.81(15.81)$ & $54.01(15.06)$ &. $\mathbf{. 3 2}^{* *}[-.56,-.09]$ & $48.76(13.71)$ & $50.76(16.07)$ & $\mathbf{. 3 2} 2^{* *}[-.59,-.05]$ & $.21[-.26, .67]$
\end{tabular}

Note. BDI-II= Beck Depression Inventory; LOT-R= Life Orientation Test; SPT-POS and SPT-NEG= positive and negative future expectations; PA and NA, positive and negative affect scale; FIQ-R=Fibromyalgia Impact Questionnaire; PCS= Pain Catastrophizing Scale; GSES= General self-efficacy total scale, QLI= Quality of Life Inventory. Effect size $(d)$ calculation from Cohen [68] $d=0.2$ are regarded as a "small" effect size, $d=0.5$ as "medium,' and $d=0.8$ as "large". ${ }^{* *} p<.01$ 


\section{Follow-up effects of the self-applied intervention}

In order to preliminary explore if effects of the self-applied intervention were sustainably effective, a series of mixed ANOVAs were conducted including 1-month and 3-month follow-ups.

Primary outcome measures

Regarding changes at the follow-ups, the analysis revealed no interaction effects on the BDI-II $\left(F_{(2.17,150.12)}=1.99, p=.12\right)$. No statistically significant main effect of the group factor was found $\left(F_{(2.17,150.12)}=1.47, p\right.$ $=.23)$. There was a significant time effect on the BDI-II $\left(F_{(2.17,150.12)}=20.5\right.$ $p<.01, \eta^{2}$ partial $=.31$ ), indicating that a change occurred in the scores over time. The post-hoc comparisons of the "moment of measurement" variable revealed statistically significant differences between the pre-intervention and 1-month and 3-month follow-ups $(p<.001)$; and between the postintervention and the 1-month and 3-month follow-ups $(p<.001)$. Although the interaction effect is not statistically significant, post-hoc analysis of the interaction for the BDI-II show that the differences between pre and postintervention $(p<.01)$, pre and 1-month $(p<.001)$ and 3-month follow-ups $(p<.001)$, post-intervention and the 1-month and 3-month follow-ups, are significant for the intervention group $(p<.05)$. For the control group, differences between pre and 1-month follow-up $(p<.05)$, and between postintervention and 1-month $(p<.001)$ and 3-months follow-ups $(p<.01)$ are significant. No statistically significant effects were observed in the other combinations.

A significant Group $\mathrm{x}$ Time interaction was found on the LOT-R, indicating larger increases in optimism in the BPS condition compared to the 
DA condition at follow-ups $\left(F_{(1,69)}=2.62, p<.05, \eta^{2}\right.$ partial $\left.=.04\right)$. Post-hoc analysis of the interaction for the LOT-R show that the differences between pre and post-intervention in optimism $(p<.05)$, and between pre and 3 month follow-up ( $p<.001 ; d=.91,95 \%$ CI $[-1.36, .46])$, are significant for the intervention group but not for the control group $(p=1)$. No statistically significant main effect of the group factor was found $\left(F_{(1,69)}=1.09, p=.29\right)$. There was a significant main effect of time on the LOT-R $\left(F_{(1,69)}=3.38, p<.05\right.$, $\eta^{2}$ partial $=.05$ ). The post-hoc comparisons of the "moment of measurement" revealed statistically significant differences between pre-intervention and 3month follow-up $(p<.05)$. No significant interaction effects of Group x Time were found on the SPT-P $\left(F_{(1,69)}=0.49, p=.69\right)$, or the SPT-N $\left(F_{(1,69)}=1.23\right.$, $p=.29$ ). Although the interaction effect is not statistically significant, post-hoc analysis of the interaction for the SPT-N show that the differences between pre and post-intervention $(p<.05)$, pre and 1 -month $(p<.01)$ and 3 -month follow-ups $(p<.001)$ are significant for the intervention group. For the control group, only differences between pre and 3-month follow-up $(p<.01)$ are significant. Moreover, no effect of the group factor was found on SPT-P $\left(F_{(1}\right.$, $\left.{ }_{69)}=.36, p=.55\right)$, or the SPT-N $\left(F_{(1,69)}=1.28, p=.26\right)$. There was a significant main effect of time on the SPT-P $\left(F_{(1,69)}=6.61, p<.001, \eta^{2}\right.$ partial $\left.=.09\right)$; and the $\operatorname{SPT}-\mathrm{N}\left(F_{(1,69)}=9.33, p<.001, \eta^{2}\right.$ partial $\left.=.12\right)$, indicating significant changes in future expectations over time. The post-hoc analysis of the "moment of measurement" revealed statistically significant differences in positive expectancies between pre-intervention and 1-month follow-up $(p<.001)$; and between post-intervention and 1 -month follow-up $(p<.05)$. In terms of negative expectancies, statistically significant differences were found 
between pre-intervention and the 1-month and 3-month follow-ups $(p<.001)$; and between the first and last follow-ups $(p<.05)$. No statistically significant effects were observed in the other combinations.

No significant Group x Time interaction on PA was found $\left(F_{(1,69)}=\right.$ $2.09, p=.10)$. No effect of the group factor was found on PA $\left(F_{(1,69)}=1.87\right.$, $p=.18)$. The effects of time were not significant either $\left(F_{(1,69)}=2.31, p=.07\right)$. Regarding NA, a significant interaction effect was found $\left(F_{(1,69)}=2.75, p<.05\right.$, $\eta^{2}$ partial $\left.=.04\right)$, indicating larger decreases in negative affect in the BPS condition compared to the DA condition at the follow-ups. Post-hoc analysis of the interaction for NA show that the differences between pre and 1-month follow-up $(p<.05)$, and between pre and 3-month follow-up $(p<.001)$, are significant for the intervention group but not for the control group $(p=1)$. No effect of the group factor was found on NA $\left(F_{(1,69)}=0.53, p=.47\right)$. The effects of time were not significant either $\left(F_{(1,69)}=1.98, p=.13\right)$.

Secondary outcome measures

Regarding the interaction effects, the ANOVA revealed no significant effects on the GSES-12 $\left(F_{(1,69)}=2.52, p=.07\right)$. No effect of the group factor was found on the GSES-12 $\left(F_{(1,69)}=.45, p=.51\right)$. The effects of time were not significant either $\left(F_{(1,69)}=1.98, p=.13\right)$.

Regarding the FIQ-R, the effects of the Group $\mathrm{x}$ Time interaction were not significant $\left(F_{(1,69)}=.37, p=.77\right)$. No effect of the group factor was found on the FIQ-R $\left(F_{(1,69)}=.82, p=.37\right)$. However, the analysis revealed a significant time effect on the FIQ-R $\left(F_{(1,69)}=4.68, p<.05, \eta^{2}\right.$ partial $\left.=.06\right)$, indicating that an improvement in pain functioning was achieved at followups. The post-hoc analysis of the "moment of measurement" revealed 
statistically significant differences between pre-treatment and 3-month follow-up $(p<.05)$ and between the 1-month and 3-month follow-ups $(p<.05)$. No interaction effects were found on the PCS $\left(F_{(1,69)}=.65, p=.58\right)$; or the QLI $\left(F_{(1,69)}=1.92, p=13\right)$. In addition, the effects of the group factor on the PCS were not significant $\left(F_{(1,69)}=2.12, p=.15\right)$; or the QLI $\left(F_{(1,69)}=1.40, p=.24\right)$. The analysis revealed a significant time effect on the PCS $\left(F_{(1,69)}=24.99\right.$, $p<.01, \eta^{2}$ partial $=.27$ ), indicating significant decreases in pain catastrophizing over time; and on the QLI $\left(F_{(1,69)}=8.80, p<.001, \eta^{2}\right.$ partial $\left.=.11\right)$, indicating significant increases in quality of life. The post-hoc comparisons of the "moment of measurement" revealed statistically significant differences in pain catastrophizing between pre-intervention and the 1-month and 3-month follow-ups $(p<.001)$; between post-intervention and the 3-month follow-up $(p<.001) ;$ and between the 1-month and 3-month follow-ups $(p<.001)$. In terms of quality of life, significant differences in time were found between pre-intervention and 1-month follow-up $(p<.001)$; pre-intervention and 3month follow-up $(p<.05)$, and post-intervention and 1-month follow-up $(p<.05)$. Although the interaction effect is not statistically significant, posthoc analysis of the interaction for the QLI show that the differences between pre and post-intervention $(p<.05)$, pre and 1-month $(p<.001)$ and 3-month follow-ups $(p<.01)$ are only significant for the intervention group. The descriptive statistics, effect sizes and confidence intervals are presented in Table 2 . 
Table 2 presents the means, standard deviations, effect sizes, and coefficient intervals for changes at follow-ups according to condition $(n=71)$

Best Possible Self

\begin{tabular}{|c|c|c|c|c|c|c|c|}
\hline & \multicolumn{2}{|c|}{ Best Possible Self } & \multicolumn{4}{|c|}{ Daily Activities } & \multirow[b]{2}{*}{$\begin{array}{c}\text { From Pre to } 3 \\
\text { FU Between- } \\
\text { group effect } \\
\text { size, } \\
d[95 \% \mathrm{CI}]\end{array}$} \\
\hline & $\begin{array}{c}1 \text { FU } \\
\text { M (SD) }\end{array}$ & $\begin{array}{c}3 \text { FU } \\
\text { M (SD) }\end{array}$ & $\begin{array}{c}\text { From Pre to } 3 \\
\text { FU Within- } \\
\text { group effect } \\
\text { size, } \\
d[95 \% \mathrm{CI}]\end{array}$ & $\begin{array}{c}1 \text { FU } \\
\text { M (SD) }\end{array}$ & $\begin{array}{c}3 \text { FU } \\
\text { M (SD) }\end{array}$ & $\begin{array}{c}\text { From Pre to } 3 \\
\text { FU Within- } \\
\text { group effect } \\
\text { size, } \\
d[95 \% \mathrm{CI}]\end{array}$ & \\
\hline \multicolumn{8}{|c|}{ Primary outcome measures } \\
\hline BDI-II & $15.82(11.06)$ & $14.15(9.57)$ & $-.79^{* *}[.35,1.22]$ & $17.88(12.08)$ & $18.05(12.06)$ & $-.54^{* *}[.19, .88]$ & $-.42[-.89, .05]$ \\
\hline LOT & $20.5(5.57)$ & $22.29(5.56)$ & $.91^{* *}[-1.36, .46]$ & $19.55(5.65)$ & $19.69(5.07)$ & $.04[-.46, .37]$ & $.06[-.40, .53]$ \\
\hline SPT-POS & $4.18(1.1)$ & $4.33(1.34)$ & $.20[-.09, .50]$ & $3.94(1.02)$ & $4.13(1.3)$ & $-.37^{* *}[.07, .66]$ & $.13[-.33, .60]$ \\
\hline SPT-NEG & $2.88(1.1)$ & $2.61(0.79)$ & $-.73^{* *}[.37,1.10]$ & $3.1(1.09)$ & $2.8(.93)$ & $-.58^{* *}[.16,1]$ & $-.34[-.81, .13]$ \\
\hline PA & $2.56(.84)$ & $2.48(.92)$ & $.30^{* *}[-.57,-.03]$ & $2.22(.76)$ & $2.23(.81)$ & $.04[-.24, .16]$ & $.40[-.07, .87]$ \\
\hline NA & $2.03(.58)$ & $1.92(.61)$ & $-.56^{* *}[.26, .86]$ & $2.32(.82)$ & $2.09(.60)$ & $-.05[-.30, .39]$ & $-.21[-.68, .26]$ \\
\hline
\end{tabular}

\section{Daily Activities}




\begin{tabular}{cccccccc}
\hline \multicolumn{7}{c}{ Secondary outcome measures } \\
\hline FIQ-R & $65.96(14.95)$ & $60.44(12.33)$ & $-.28[-.03, .60]$ & $70.95(18.22)$ & $62.15(15.10)$ &.$- .30^{* *}[.02, .58]$ & $-.13[-.60, .33]$ \\
PCS & $19.42(12.26)$ & $17.17(12.65)$ & $-.61^{* *}[.35, .86]$ & $24.59(11.65)$ & $21.86(11.15)$ &.$- .50^{* *}[.25, .74]$ & $-.29[-.76, .18]$ \\
GSES & $42.32(8.12)$ & $43.10(8.96)$ & $.23[-.59, .12]$ & $41.37(7.90)$ & $40.92(7.79)$ & $-.22[-.20, .64]$ & $.33[-.13, .81]$ \\
QLI & $58.61(15.29)$ & $56.68(14.64)$ &. $\mathbf{4 9 *}[-.78,-.19]$ & $53.41(16.46)$ & $50.19(14.38)$ & $.09[-.39, .22]$ & $.21[-.26, .67]$ \\
\hline
\end{tabular}

Note. 1 FU= 1 month follow-up; 3 FU= 3 month follow-up; BDI-II= Beck Depression Inventory; LOT-R= Life Orientation Test; SPT-POS and SPT-NEG= positive and negative future expectations; PA and NA, positive and negative affect scale; FIQ-R=Fibromyalgia Impact Questionnaire; PCS= Pain Catastrophizing Scale; GSES= General self-efficacy total scale, QLI= Quality of Life Inventory. Effect size $(d)$ calculation from Cohen [68] $d=0.2$ are regarded as a "small" effect size, $d=0.5$ as "medium,' and $d=0.8$ as "large". ${ }^{* *} p<.01$ 


\section{Discussion}

The aim of this study was to test the efficacy of a positive future thinking intervention in a randomized controlled trial with FMS patients. To our knowledge, this is the first study to test the specificity of the BPS manipulation in FMS patients using the benefits of technology to enhance intervention adherence and self-management.

Regarding the single-session effects, the BPS intervention and the daily activities exercise both produced significant decreases in negative expectations and increases in positive affect. However, increases in positive affect at post-session were only significant in the BPS condition. Positive effects of thinking and writing about daily activities could be explained by the fact that reflecting about the events that happened during the day could generate a higher level of awareness of activity goals. Thus, it could act as a simple behavioral activation exercise. This exercise was chosen as the control condition because it was selected in several similar studies [38, 39, 69]. Furthermore, it is possible that the significant time effects were due to the placebo effect or "expectation inductions" [70]. Informing patients about and emphasizing the positive intended and expected outcomes could have optimized the exercise's effectiveness. Moreover, the selected imagery intervention was brief, but cognitively challenging for FMS patients. More practice time may be required to obtain substantial effects of the BPS, as suggested in a recent meta-analysis of the effects of imagery interventions on pain [71]. 
For this reason, for one month, patients self-applied both exercises at home counting only with online support. The results showed that, on the primary outcome measures, compared to an active control condition, the daily imagery of the BPS exercise led to a significant decrease in depression and negative affect and an increase in positive affect. These results are in line with the findings of Pietrowsky and Mikutta [72], who showed that, after practicing the BPS, depressive patients decreased their BDI levels. Unlike previous BPS studies that did not find any interaction effect of induced optimism on negative affect, compared to a control condition $[38,39,69,73]$, we found a significant effect on negative affect. Moreover, these changes were maintained at the follow-ups. Changes in positive affect suggest that both exercises had beneficial effects in terms of augmenting positive mood, but it increased significantly more in the BPS intervention group. For fibromyalgia patients, this can be especially significant, considering that they report significantly lower positive affect than patients with other rheumatology diseases [74]. In fibromyalgia, affect balance styles have been shown to be predictive of psychiatric comorbidity, pain severity, and functional status [75], especially the Depressive affect balance style (high negative affect/low positive affect). A Healthy style (low negative affect/high positive affect) was associated with lower symptoms of depression, anxiety and pain-related outcomes.

Interestingly, even though the BPS intervention primarily targeted future expectancies, we found no interaction effects on the SPT-POS or the SPT-NEG. Expectancies for negative outcomes 
decreased significantly after both the BPS and the control intervention, but this reduction was only significant in the BPS group. A significant increase in optimism levels was found at follow-ups in the BPS condition compared to the control group. The BPS exercise is a brief and focal intervention. Due to the dimensional and trait nature of optimism [76], interventions aimed at increasing optimism should expect to gradually achieve more flexible and optimistic thinking. Moreover, it should be noted that previous studies that found changes in future expectancies were performed on healthy subjects and these differences could be explained by differences in populations [38, 39, 69]. Further studies in different clinical samples should clarify these discrepancies.

On the secondary outcome measures, analyses revealed a significant interaction effect on self-efficacy. In this case, post intervention effects showed the specificity of the BPS intervention. It seems that the visualization of positive future goals helped patients to increase their belief in their ability to perform specific behaviors [77]. It is difficult for FMS sufferers to set goals related to activities that are positive and meaningful for them. Fear of movement, fatigue, low mood, and pain get in the way of their willingness to perform the activities, causing avoidance activity patterns and low motivation and persistence [78]. In the current study, we extended previous findings by demonstrating that a BPS manipulation can have an effect on selfefficacy in chronic pain patients who have been experiencing pain for approximately 10 years. This is important because a recent meta- 
analysis indicated that self-efficacy has significant associations with impairment, affective distress, and pain severity in chronic pain samples, and it represents an important protective factor for subsequent adjustment [79]. Moreover, self-efficacy has been characterized as a protective psychological resource and a resilience factor associated with improved physical function in patients with chronic pain [80].

Although pain was not a primary outcome measure in this study, pain disability, as measured by the Fibromyalgia Impact questionnaire, showed reductions at follow-ups in both conditions. Current directions in chronic pain treatments suggest that reductions in pain may not be requirements for decreasing distress and promoting better functioning [81]. This could be especially important in interventions aimed at augmenting positive affect and promoting positive functioning, where the focus of the intervention is on teaching patients skills to help them live a meaningful life in spite of their pain. Both exercises were effective in reducing pain catastrophizing and increasing quality of life, although changes in quality of life from pre-intervention to follow-ups were only significant in the BPS group. These findings are in line with previous studies that experimentally induced pain and optimism and found a reduction in situational and dimensional pain catastrophizing in healthy participants $[40,41]$. Although previous BPS studies have not included quality of life as an outcome measure, these results suggest that positive imagery is capable of improving the functional status in 
fibromyalgia, coinciding with guided imagery studies for rheumatic diseases that found improvements in psychological well-being [82, 83].

Even though the results from this study are promising, several limitations should be mentioned. First, the sample size was small, and this study needs to be replicated with larger samples. Moreover, it is important to note that the efficacy of the technologies was not compared to a condition without technologies, which means that we are unable to know the differential role of the technology in the implementation of the BPS exercise. In light of the results obtained in this study, an important point to highlight is the effect produced by the control condition, the Daily Activities exercise. Patients from both conditions received the same description of the study, which stated that performing the exercise could have a positive influence on their mood. This instruction could have influenced the results. It has been demonstrated that expectancies about treatment outcomes can enhance or reduce the analgesic effects of active interventions [70]. However, the information was extracted from other studies in which expectations had no effect on the results $[39,69]$. Furthermore, thinking and writing about daily activities could have acted as a behavioral activation intervention, and this could have positively influenced the participants' mood. Furthermore, the control condition focused on the last 24 hours, unlike the BPS exercise, which is oriented toward the future. These patients often express thoughts about fear of the future and hopelessness about what the future may bring [84], and so thinking about the future might be a very challenging activity for them. 
Although the role of positive factors as a buffer for the disabling effects of chronic pain has been widely studied, the positive psychology components of treatment approaches for chronic pain had not previously been extracted and tested [15]. We believe our study makes an important contribution to pain research, helping to understand how a positive psychology intervention supported by technologies works in fibromyalgia patients, expanding its efficacy data in clinical populations and adding knowledge about the role of positive psychological factors in the pain experience. Moreover, our findings show the specific effects of the Best Possible Self intervention, helping to draw conclusions about the usefulness of incorporating this exercise in treatment protocols.

Thus, a larger question remains about how interventions aimed at augmenting positive affect and promoting positive functioning work, and which mechanisms act as facilitators of change. Should we place a primary emphasis in treatment on positive factors as a pathway to improving chronic pain symptoms? Should we first alleviate distress symptoms in order to achieve changes in positive functioning measures? Future investigations should determine what specific mechanisms in interventions promote positive factors, and whether effect sizes can be improved. Psychological intervention therapies for chronic pain are often complex and address different therapeutic targets. Perhaps it is time to take a step back and design and test particular interventions to produce changes in specific variables, and then include them in treatment protocols. 


\section{Acknowledgements}

This study was funded in part by the Ministry of Economy, Industry and Competitiveness (PSI2014-54172-R), the Excellence in Research Program PROMETEO II (Generalitat Valenciana. Conselleria de Educación, 2013/003), Plan de Promoción de la Investigación 2013, Universitat Jaume I (P11B2013-66), and by the CIBER of Physiopathology of Obesity Nutrition, an initiative of ISCIII (ISCII CB06 03/0052).

\section{References}

1. Robinson RL, Kroenke K, Mease P, Williams DA, Chen Y, D’Souza D, Wohlreich M, McCarberg B. Burden of illness and treatment patterns for patients with fibromyalgia. Pain Med 2012; 13: 136676.

2. Sicras-Mainar A, Rejas J, Navarro R, Blanca M, Morcillo A, Larios R, Velasco S, Villarroya C. Treating patients with fibromyalgia in primary care settings under routine medical practice: a claim database cost and burden of illness study. Arthritis Res Ther 2009; 11: R54.

3. Spaeth M. Epidemiology, costs, and the economic burden of fibromyalgia. Arthritis Res Ther 2009; 11: 2.

4. Häuser W, Ablin J, Fitzcharles MA, Littlejohn G, Luciano JV, Usui C, Walitt B. Fibromyalgia. Nat Rev Dis Primers 2015; 1: 15022.

5. Aliciati A, Sgiarovello P, Atzeni F, Sarzi-Puttini P. Psychiatric problems in fibromyalgia: clinical and neurobiological links 
between mood disorders and fibromyalgia. Reumatismo 2012; 64: 268-74.

6. Edwards RR, Bingham CO, 3rd, Bathon J, Haythornthwaite, JA. Catastrophizing and pain in arthritis, fibromyalgia, and other rheumatic diseases. Arthritis Rheum 2006; 55: 325-32.

7. Smith HS, Harris RE, Clauw DJ. Fibromyalgia. In: Benzon HT, Raja SN, Molly RE, Liu SS, Fishman SM, eds. Essentials of pain medicine. 3rd ed. Philadelphia: Elsevier, 2011: 345-50.

8. Chinn S, Caldwell W, Gritsenko K. Fibromyalgia Pathogenesis and Treatment Options Update. Curr Pain Headache Rep 2016; 20: 25.

9. Halpern R, Shah SN, Cappelleri JC, Masters ET, Clair A. Evaluating guideline-recommended pain medication use among patients with newly diagnosed fibromyalgia. Pain Pract 2015; 16: 1027-39.

10. Roditi D, Robinson ME. The role of psychological interventions in the management of patients with chronic pain. Psychol Res Behav Manag 2011; 4: 41-9.

11. Kaiser RS, Mooreville M, Kannan K. Psychological interventions for the management of chronic pain: a review of current evidence. Curr Pain Headache Rep 2015; 19: 43.

12. Morley S, Williams A. New developments in the psychological management of chronic pain. Can J Psychiatry 2015; 60: 168-75.

13. Theadom A, Cropley M, Smith HE, Feigin VL, McPherson K. Mind and body therapy for fibromyalgia. Cochrane Database Syst Rev 2015; 9: CD001980. 
14. Glombiewski JA, Sawyer AT, Gutermann J, Koenig K, Rief W, Hofmann SG. Psychological treatments for fibromyalgia: A metaanalysis. Pain 2010; 151: 280-95.

15. Finan PH, Garland EL. The role of positive affect in pain and its treatment. Clin J Pain 2015; 31: 177-87.

16. Flink IK, Smeets E, Bergbom S, Peters ML. Happy despite pain: a pilot study of a positive psychology intervention for patients with chronic pain. Scand J Pain 2015; 7: 71-9.

17. Hausmann LRM, Parks A, Youk AO, Kwoh CK. Reduction of bodily pain in response to an online positive activities intervention. J Pain 2014; 15: 560-67.

18. Muller R, Gertz KJ, Molton IR, Terrill AL, Bombardier CH, Ehde DM, Jensen MP. Effects of a tailored positive psychology intervention on well-being and pain in individuals with chronic pain and a physical disability: a feasibility trial. Clin J Pain 2016; 32: 32-44.

19. Macfarlane GJ, Kronisch C, Dean LE, Atzeni F, Häuser W, Fluß E, Choy E, Kosek E, Amris K, Branco J, Dincer F, Leino-Arjas P, Longley K, McCarthy GM, Makri S, Perrot S, Sarzi-Puttini P, Taylor A, Jones GT. EULAR revised recommendations for the management of fibromyalgia. Ann Rheum Dis 2017; 76: 318-28.

20. Morley SJ, Williams A, Eccleston, C. Examining the evidence about psychological treatments for chronic pain: time for a paradigm shift? Pain 2013; 154: 1929-31.

21. Hassett AL, Finan $\mathrm{PH}$. The role of resilience in the clinical management of chronic pain. Curr Pain Headache Rep 2016; 20 : 39. 
22. Du S, Yuan C, Xiao X, Chu J, Qiu Y, Qian H. Self-management programs for chronic musculoskeletal pain conditions: a systematic review and meta-analysis. Patient Educ Couns 2011; 85: 299-310.

23. Heapy AA, Higgins DM, Cervone D, Wandner L, Fenton BT, Kerns RD. A systematic review of technology-assisted self-management interventions for chronic pain: Looking across treatment modalities. Clin J Pain 2015; 31: 470-92.

24. Bender JL, Radhakrishnan A, Diorio C, Englesakis M, Jadad AR. Can pain be managed through the Internet? A systematic review of randomized controlled trials. Pain 2011; 152: 1740-50.

25. Dear BF, Titov N, Perry KN, Johnston L, Wootton BM, Terides MD, Rapee RM, Hudson JL. The Pain Course: a randomised controlled trial of a clinician-guided Internet-delivered cognitive behaviour therapy program for managing chronic pain and emotional wellbeing. Pain 2013; 154: 942-50.

26. Sulea C, Soomro A, Boyd C, Wiederhold BK. Pain Management in Virtual Reality: A Comprehensive Research Chart. Cyberpsychol Behav Soc Netw 2014; 17: 402-13.

27. Herrero R, Castilla D, Vizcaíno Y, Molinari G, García-Palacios A, Botella C. Avances en el tratamiento psicológico de la fibromialgia: el uso de la realidad virtual para la inducción de emociones positivas y la promoción de la activación comportamental. Un estudio piloto. Rev Argent Clin Psic 2013; 22: 111-20. 
28. Herrero R, García-Palacios A, Castilla D, Molinari G, Botella C. Virtual Reality for the Induction of Positive Emotions in the Treatment of Fibromyalgia: A Pilot Study over Acceptability, Satisfaction, and the Effect of Virtual Reality on Mood. Cyberpsychol Behav Soc Netw 2014, 17: 379-84.

29. Lalloo C, Jibb LA, Rivera J, Agarwal A, Stinson JN. "There's a Pain App for That": Review of Patient-targeted Smartphone Applications for Pain Management. Clin J Pain 2015; 31: 557-63.

30. Mohr DC, Burns MN, Schueller SM, Clarke G, Klinkman M. Behavioral intervention technologies: Evidence review and recommendations for future research. Gen Hosp Psychiatry 2013; 35: 332-38.

31. Botella C, Riva G, Gaggioli A, Wiederhold BK, Alcaniz M, Baños RM. The present and future of positive technologies. Cyberpsychol Behav Soc Netw 2012; 15: 78-84.

32. Riva G, Baños RM, Botella C, Mantovani F, Gaggioli A. Transforming Experience: The Potential of Augmented Reality and Virtual Reality for Enhancing Personal and Clinical Change. Front Psychiatry 2016; 7: 164.

33. Fleming TM, de Beurs D, Khazaal Y, Gaggioli A, Riva G, Botella C, Baños RM, Aschieri F, Bavin L, Kleiboer A, Merry S, Lau H, Riper H. Maximizing the impact of e-therapy and serious gaming: Time for a paradigm shift. Front Psychiatry 2016; 7: 65.

34. Molinari G, Enrique Roig A, Herrero R, Fernández-Llanio Comella N, Botella C, García Palacios A. Development and pilot testing of a 
positive imagery intervention with online support in the treatment of fibromyalgia. Rev Argent Clin Psic 2017. (In press.)

35. Baños RM, Etchemendy E, Farfallini L, García-Palacios A, Quero S, Botella C. EARTH of well-being system: A pilot study of an information and communication technology-based positive psychology intervention. J Posit Psychol 2014; 9: 482-88.

36. Botella C, Baños RM, Etchemendy E, García-Palacios A, Alcañiz M. Psychological countermeasures in manned space missions: "EARTH" system for the mars-500 project. Comput Human Behav 2016; 55: 898-908.

37. Quero S, Molés M, Pérez MA, Botella C, Baños RM. An online emotional system to deliver homework assignments for treating adjustment disorders. J Cyber Ther Rehabil 2012; 5: 115-16.

38. Peters ML, Flink IK, Boersma K, Linton SJ. Manipulating optimism: can imagining a best possible self be used to increase positive future expectancies? J Posit Psychol 2010; 5: 204-11.

39. Meevissen YM, Peters ML, Alberts HJ. Become more optimistic by imagining a best possible self: effects of a two week intervention. $J$ Behav Ther Exp Psychiatry 2011; 42: 371-78.

40. Hanssen MM, Peters ML, Vlaeyen JWS, Meevissen YMC, Vancleef LMG. Optimism lowers pain: evidence of the causal status and underlying mechanisms. Pain 2012; 154: 53-8.

41. Boselie JJ, Vancleef LM, Smeets T, Peters ML. Increasing optimism abolishes pain-induced impairments in executive task performance. Pain 2014; 155: 334-40. 
42. Wolfe F, Smythe HA, Yunus MB, Bennett RM, Bombardier C, Goldenberg DL, Tugwell P, Campbell SM, Abeles M, Clark P, et al. The American College of Rheumatology 1990 Criteria for the Classification of Fibromyalgia. Report of the Multicenter Criteria Committee. Arthritis Rheum 1990; 33:160-72.

43. Wolfe F, Clauw DJ, Fitzcharles MA, Goldenberg DL, Häuser W, Katz RS, Mease P, Russell AS, Russell IJ, Winfield JB. Fibromyalgia criteria and severity scales for clinical and epidemiological studies: a modification of the ACR Preliminary Diagnostic Criteria for Fibromyalgia. J Rheumatol 2011; 38:1113-22.

44. Derogatis LR. Brief Symptom Inventory. Baltimore: Clinical Psychometric Research, 1975.

45. Ruipérez MA, Ibáñez MI, Lorente E, Moro M, Ortet G. Psychometric properties of the Spanish version of the BSI: contributions to the relationship between personality and psychotahology. Eur $J$ Psychol Assess 2001; 17: 241-50.

46. Beck AT, Steer RA, Brown GK. Manual for the Beck Depression Inventory-II. San Antonio, TX: Psychological Corporation, 1996.

47. Sanz J, García Vera MP, Espinosa R, Fortin M, Vázquez C. Adaptación española del inventario para la depresión de Beck-II (BDI-II): Propiedades psicométricas en pacientes con trastornos psicológicos. Clin Salud 2005; 16: 121-42.

48. Watson D, Clark LA, Tellegen A. Development and validation of brief measures of positive and negative affect: the PANAS scales. $J$ Pers Soc Psychol 1988; 54: 1063-70. 
49. Sandin B, Chorot P, Lostao L, Joiner TE, Santed MA, Valiente RM. Escalas PANAS de afecto positivo y negativo: Validación factorial y convergencia transcultural. Psicothema 1999; 11: 37-51.

50. Scheier MF, Carver CS, Bridges MW. Distinguishing optimism from neuroticism (and trait anxiety, self-mastery, and self-esteem): A reevaluation of the Life Orientation Test. J Pers Soc Psychol 1994; 67: 1063-78.

51. Otero JM, Luengo A, Romero E, Gómez JA, Castro C. Psicología de personalidad. Manual de prácticas. Barcelona: Ariel Practicum, 1998.

52. MacLeod AK. Affect, emotional disorder, and future-directed thinking. Cogn Emot 1996; 10: 69-86.

53. Molinari G, Dragomir-Davis AM, Enrique A, García-Palacios A, Baños RM, Botella C. The contribution of future-directed thinking to affect dimensions: differences in general and clinical populations. (In press.)

54. Burckhardt CS, Clark SR, Bennett RM. The fibromyalgia impact questionnaire: development and validation. J Rheumatol 1991; 18: 728-33.

55. Esteve-Vives J, Rivera J, Salvat MI, de Gracia Blanco M, de Miquel CA. Proposal of a consensual version of the Fibromyalgia Impact Questionnaire (FIQ) for the Spanish population. Reumatol Clin 2007; 3:21-4.

56. Sullivan MJL, Bishop S, Pivik J. The Pain Catastrophizing Scale: Development and validation. Psychol Assess 1995, 7: 524-32. 
57. García Campayo J, Rodero B, Alda M, Sobradiel N, Montero J, Moreno S. Validation of the Spanish version of the Pain Catastrophizing Scale in fibromyalgia. Med Clin 2008; 131: 487-92.

58. Bosscher RJ, Smit JH. Confirmatory factor analysis of the General Self Efficacy Scale. Behav Res Ther 1998; 36: 339-43.

59. Herrero R, Espinoza M, Molinari G, Etchemendy E, Garcia-Palacios A, Botella C, Baños RM. Psychometric properties of the General Self Efficacy-12 Scale in Spanish: general and clinical population samples. Compr Psychiatry 2014; 55: 1738-43.

60. Mezzich JE, Schmolke MM. An introduction to ethics and quality of life in comprehensive psychiatric diagnosis. Psychopath 1999; 32: 119-20.

61. Mezzich JE, Ruipérez MA, Pérez C, Yoon G, Liu J, Mahmud S. The Spanish version of the quality of life index: presentation and validation. J Nerv Ment Dis 2000; 188: 301-5.

62. Moher D, Schulz KF, Altman DG, Group C. The CONSORT statement: revised recommendations for improving the quality of reports of parallel-group randomized trials. J Am Podiatr Med Assoc 2001; 91: 437-42.

63. Moher D, Hopewell S, Schulz KF, Montori V, Gotzsche PC, Devereaux PJ, et al. CONSORT 2010 Explanation and Elaboration: Updated guidelines for reporting parallel group randomised trials. J Clin Epidemiol 2010; 63: e1-37. 
64. Eysenbach G, Group CE. CONSORT-EHEALTH: improving and standardizing evaluation reports of Web-based and mobile health interventions. J Med Internet Res 2011; 13: e126.

65. Newman DA. Missing data: Five practical guidelines. Organ Res Methods [Internet]. 2014; 17: 372-411. Available from: http://www.sagepublications.com

66. Hair JF, Black WC, Babin BJ, Anderson RE. Multivariate data analysis (7th Ed.). River, NJ: Pearson-Prentice Hall. International Edition, 2014.

67. Arias RM, Chacón JC, Castellanos MA. Análisis de datos en Psicología y Ciencias de la Salud (Vol I). Madrid: EOS Instituto de Orientación Psicológica; 2015.

68. Cohen J. Statistical power analysis for the behavioral sciences, 2nd ed. New Jersey: Lawrence Erlbaum; 1988.

69. Sheldon KM, Lyubomirsky S. How to increase and sustain positive emotion: the effects of expressing gratitude and visualizing best possible selves. J Posit Psychol 2006; 1: 73-82.

70. Peerdeman KJ, Van laarhoven AI, Peters ML, Evers AW. An integrative review of the influence of expectancies on pain. Front. Psychol 2016; 7: 1270.

71. Peerdeman KJ, van Laarhoven AI, Keij SM, Vase L, Rovers MM, Peters ML, Evers AW. Relieving patients' pain with expectation interventions: a meta-analysis. Pain 2016; 157: 1179-91. 
72. Pietrowsky R, Mikutta J. Effects of positive psychology interventions in depressive patients: a randomized control study. Psychology 2012; 3: 1067-73.

73. Renner F, Schwarz P, Peters ML, Huibers MJ. Effects of a best possible self mental imagery exercise on mood and dysfunctional attitudes. Psychiatry Res 2014; 215: 105-10.

74. Zautra AJ, Fasman R, Reich JW, Harakas P, Johnson LM, Olmsted ME, Davis MC. Fibromyalgia: evidence for deficits in positive affect regulation. Psychosom Med 2005; 67:147-55.

75. Toussaint LL, Vincent A, McAllister SJ, Oh TH, Hassett AL. A Comparison of Fibromyalgia Symptoms in Patients with Healthy versus Depressive, Low and Reactive Affect Balance Styles. Scand J Pain 2014; 5:161-66.

76. Eichner KV, Kwon P, Marcus DK. Optimists or optimistic? A taxometric study of optimism. Psychol Assess 2014; 26: 1056-61.

77. Bandura A. Self-efficacy: Toward a unifying theory of behavioral change. Psychol Rev 1977; 84: 191-215.

78. Esteve R, Ramírez-Maestre C, Peters ML, Serrano-Ibáñez ER, RuízPárraga GT, López-Martínez AE. Development and initial validation of the Activity Patterns Scale in patients with chronic pain. J Pain 2016; 17: 451-61.

79. Wang Y, Fan H. Self-efficacy and chronic pain outcomes: a metaanalytic review. J Pain 2014; 15: 800-14. 
80. Edwards RR, Dworkin RH, Sullivan MD, Turk DC, Wasan AD. The Role of Psychosocial Processes in the Development and Maintenance of Chronic Pain. J Pain 2016; 17: 70-92

81. Vowles KE, Witkiewitz K, Levell J, Sowden G, Ashworth J. Are reductions in pain intensity and pain-related distress necessary? An analysis of within-treatment change trajectories in relation to improved functioning following interdisciplinary acceptance and commitment therapy for adults with chronic pain. J Consult Clin Psychol 2017; 85:87-98.

82. Menzies V, Taylor AG, Bourguignon C. Effects of guided imagery on outcomes of pain, functional status, and self-efficacy in persons diagnosed with fibromyalgia. J Altern Complement Med 2006; 12: 23-30.

83. Giacobbi PR, Stabler M, Stewart J, Jaeschke AM, Siebert JL, Kelley GA. Guided Imagery for Arthritis and other Rheumatic Diseases: A Systematic Review of Randomized Controlled Trials. Pain Manag Nurs 2015; 16: 792-803.

84. Sallinen M, Kukkurainen ML, Peltokallio L. Finally heard, believed and accepted-peer support in the narratives of women with fibromyalgia. Patient Educ Couns 2011; 85: 126-30. 


\section{How and for whom does a positive affect}

\section{intervention work for fibromyalgia: An}

\section{analysis of mediators and moderators}

Este capítulo ha sido enviado para su publicación en The Journal of Pain. Autores: Molinari, G., Miragall, M., Enrique, A., Botella, C., Baños, R. M. y García-Palacios, A. (submitted).

\section{Abstract}

Psychological Interventions designed to augment positive affect and foster positive functioning are a promising way to promote resources to better cope with pain. However, few studies have addressed the efficacy of positive affect interventions in chronic pain populations and which patients can benefit more from them. The aim of the present study was to identify mediators and moderators of a positive affect intervention for fibromyalgia patients. We used data from a previous RCT that examined changes in pain disability, depression, self-efficacy, and quality of life after the Best Possible Self intervention. Mediation analysis showed that depression mediated changes in pain interference. Positive and negative affect were significant mediators of depression and quality of life. No significant mediators were found for changes in self-efficacy. Moderation analysis showed that patients with low and moderate baseline levels of self-efficacy benefited more from the intervention. Emotion regulation strategies of negative and positive 
affect and rumination also moderated intervention effects. To our knowledge, this is the first study to analyze mechanisms and patient characteristics associated with the response to positive pain management interventions in fibromyalgia patients.

Perspective: This study provides experimental evidence about mediators and moderators of a positive affect intervention for fibromyalgia syndrome. This knowledge may improve our understanding of mechanisms of change in treatment outcomes and allow a better match between patient characteristics and chronic pain interventions.

Keywords: Fibromyalgia, positive affect, treatment moderators, treatment mediators 


\section{Introduction}

Psychological interventions designed to increase positive affect and foment positive functioning are a promising way to promote resources to better cope with pain ${ }^{18,23}$. The role of positive factors, such as positive affect, may differ across chronic pain disorders ${ }^{13}$. These interventions could be especially relevant for Fibromyalgia syndrome (FMS), a chronic musculoskeletal pain condition characterized by daily pain and stress and associated with lower levels of positive affect than other rheumatoid arthritis conditions ${ }^{53}$. However, there is still a lack of studies about how positive psychology interventions work in FMS and which patients can benefit most from them.

Research on moderators and mediators of treatment efficacy in FMS has mostly focused on Cognitive Behavior Therapy (CBT). FMS patients with a large number of pain behaviors might receive greater benefit from operant therapy, whereas those with a high level of affective distress would benefit more from $\mathrm{CBT}^{27,44}$. These results suggest that moderators depend on the treatment administered and, thus, can be used for treatment allocation. In a randomized controlled trial of web-based Acceptance and Commitment Therapy, low psychological wellbeing at baseline moderated treatment effects. Furthermore, higher pain interference, depression, and anxiety, and lower levels of emotional well-being predicted higher pain interference in daily life six months later ${ }^{46}$.

Cognitive styles have been associated with poorer FMS symptoms and treatment outcomes. Higher rumination correlates with 
higher levels of depression, anxiety and perceived stress, and lower levels of optimism and control ${ }^{30}$. In addition, early-treatment changes in pain catastrophizing predicted final treatment pain outcomes, even when controlling for depression ${ }^{6,7}$.

There is evidence that the way people with fibromyalgia regulate their emotions may be relevant to their pain and adjustment ${ }^{48}$. Although little is known about whether emotion regulation strategies affect the response to psychological interventions for pain, there is evidence that in women with FMS who experience their emotions intensely, emotion expression is associated with less impact of fibromyalgia ${ }^{16}$. Moreover, FMS patients had significantly more difficulty in identifying feelings, compared to controls, and alexithymia moderated the relationship between anxiety and pain catastrophizing, and between anxiety and fear of pain ${ }^{31}$.

In terms of treatment mediators, self-efficacy had unique effects beyond perceived control over pain, catastrophizing, disability beliefs, and harm in chronic pain patients ${ }^{47}$. In FMS patients, research on within-day relations among sleep quality, affect, and activity interference found that pain and positive affect mediated the relationship between sleep quality and activity interference. Positive affect was a stronger mediator than pain, and negative affect was not a significant mediator, showing that boosting positive affect could serve as a buffer against pain disability ${ }^{26}$.

Many questions remain about the therapeutic mediating and moderating processes underlying mechanisms of change in FMS 
treatment ${ }^{49}$. The aim of the present study was to identify mediators and moderators of a positive affect intervention for FMS patients. We used data from a previous study that examined changes in depression, positive and negative affect, pain disability, and quality of life after the Best Possible Self (BPS) intervention. The primary objective was to test the hypothesis that pre- to post-intervention changes in positive and negative affect mediated the effects of the BPS intervention on subsequent pain disability, depression, self-efficacy, and quality of life. Moreover, we tested whether changes in depression also mediated the effects of the BPS on pain interference, self-efficacy, and quality of life. This approach coincides with recent chronic pain models proposing that affect can be an outcome variable as well as a causal agent that influences behavior and cognition ${ }^{24}$. A second objective was to determine whether patients' baseline characteristics moderated the positive intervention effects on the primary outcome. We examined whether initial levels of outcome variables (pain disability, affect, selfefficacy, and quality of life), as well as process variables (emotion regulation strategies and rumination), influenced the effects of the BPS on depression.

\section{Methods}

\section{Participants and procedure}

The study sample comes from the original sample in the RCT on the efficacy of a positive psychology intervention for FMS patients (Molinari, García-Palacios, Enrique, Roca, Fernández-Llanio Comella, \& 
Botella, submitted). All participants consented to the research protocol approved by the Ethical committee at Jaume I University.

Participants were referred by a rheumatologist from the Rheumatology Unit of Arnau of Vilanova Hospital. Study inclusion criteria were: (a) 18 years or older; (b) diagnosis of FMS by a rheumatologist and in accordance with American College of Rheumatology criteria51. Exclusion criteria were: (c) severe mental disorder; (d) substance abuse or dependence; (e) unwillingness or inability to come to the University at least once. Participants had to come to the University for a brief structured interview and an initial assessment. Then, they were allocated to the BPS condition or to the control condition, the Daily Activities (DA). In the following lab session, patients received the instructions to perform the exercises using Information and Communication technologies (ICTs). Participants followed a 4-week, self-applied intervention with online support. The post-intervention session took place at the university one month from baseline.

The total sample comprised 71 participants with a diagnosis of FMS. The mean age of the sample was 51.08 years old $(S D=10.54)$, ranging from 23 to 71 , and the mean time suffering from pain was 13.1 years $(S D=10.07)$.

Intervention supported by ICTs

Patients were informed that they were participating in a study to measure "the power of visualization" and received an instruction manual ${ }^{32}$. In the BPS condition, patients were asked to think of and 
write down all the aspects that their future best possible self should encompass in four domains: personal, social, professional, and health domains. To perform the exercise, patients used a system, the Book of life ${ }^{1,34}$, which includes narratives, sounds, and visual cues to focus patients' attention on the task and strengthen the effects of the guided imagery exercise. As a personal diary, patients reflected on their best possible self for 20 minutes. To continue the visualization at home, patients had access to a web-platform, Emotional Therapy Online ${ }^{37}$. In the DA condition, using a PowerPoint presentation, participants had to write down and visualize what they had done in the last 24 hours. In both conditions, patients were advised to practice their exercise every day, or at least 3 times a week. They received two short messages (SMS) a week with minimal support and reminders to practice their exercise.

\section{Measures}

Fibromyalgia Impact Questionnaire (FIQ-R ${ }^{3}$ ). The FIQ-R is a 10 -item, self-report questionnaire that measures the health status of patients with FMS by assessing the interference of FMS in their daily life. The total score on the FIQ-R is calculated by adding the scores on four items. The first item focuses on the patient's ability to perform physical activities. The following two items ask the patient to indicate the number of days in the past week s/he felt good and how many days of work s/he had missed. The remaining item is composed of seven questions assessing the interference of pain in performing daily activities, as well as other symptoms (pain, fatigue, morning tiredness, 
stiffness, anxiety, and depression), measured with a numerical rating scale (NRS). Ranges of severity of the impact of FM using the FIQ-R total score (0-100) have been established: $<39$ (low impact), $\geq 39$ to $<59$ (moderate impact), $\geq 59$ (severe impact). This instrument has been validated for the assessment of fibromyalgia in several languages, including Spanish ${ }^{11}$.

The Beck Depression Inventory $\left(\mathrm{BDI}-\mathrm{II}^{2}\right)$ is a 21 -item, self-report measure of cognitive, affective, and somatic symptoms of depression. For this study, we used the Spanish version, which has demonstrated good psychometric properties, similar to the English version ${ }^{41}$.

Quality of life Index. The Spanish version of the Quality of Life Index $\left(\mathrm{QLI}-\mathrm{Sp}^{33}\right)$ consists of 10 items that evaluate different dimensions of psychological well-being.

General Self Efficacy Scale-12 (GSES-124). This is a 12-item scale that evaluates perceived overall self-efficacy and three of its main aspects: initiative, persistence, and effort. All items are responded to on a 5point scale ranging from 1 ('never happens to me') to 5 ('always happens to me'). For this study, we used the Spanish version, which has shown good psychometric properties ${ }^{20}$.

The Positive and Negative Affect Scale (PANAS ${ }^{50}$ ) includes 20 items that evaluate positive and negative affect. The range for each scale (10 items on each) is from 10 to 50 . The Spanish version has demonstrated good validity and reliability ${ }^{40}$. 
The Ruminative Responses Scale (RRS ${ }^{36}$ ) consists of 22 items that assess a ruminative response style, consisting of an excessive focus on causes and consequences of depressive symptoms. For the purpose of this study, we used the total score of the Spanish version of this questionnaire, which has shown good internal consistency, factorial validity, and test-retest reliability ${ }^{21}$.

Responses to Positive Affect Questionnaire (RPA ${ }^{12}$ ) is a 17-item scale that assesses responses to positive affective states. The original measure consists of three factor-analytically derived subscales: Selffocused positive rumination, Emotion-focused positive rumination, and Dampening. Whereas the first two strategies attempt to enhance or maintain positive mood once it is experienced, the dampening strategy focuses on decreasing or eliminating the intensity and duration of positive affect. We used the Spanish version of this questionnaire, validated by our group, which has shown good psychometric properties (Molinari, Etchemendy, Herrero, Espinoza, Paniagua, Feldman, GarcíaPalacios, Baños, \& Botella, submitted).

Difficulties in Emotion Regulation Scale $\left(D_{E R S}{ }^{17}\right.$ ) is a questionnaire that assesses clinically relevant difficulties in emotion regulation. The Spanish version includes 28 items and has five factors: Non-acceptance of Emotional Responses, Difficulties Engaging in Goal-Directed Behavior, Lack of Emotional Control, Lack of Emotional Awareness, and Lack of Emotion Clarity. The scale has demonstrated good internal consistency and test-retest reliability 22 . 
Statistical analyses

All statistical analyses were conducted using the SPSS for Windows, version 20. To assess the difference between the two conditions (intervention versus control) for baseline variables (years suffering from pain, BDI-II, FIQ, QLI, GSES-12, PANAS, DERS, RPA, and RRS), Student's unpaired t-tests were performed.

Changes in BDI-II, FIQ, QLI, GSES-12, PANAS (+), and PANAS (-) were calculated using pre-intervention and post-intervention scores $($ Change $=$ Post-intervention score - Pre-intervention score $)$. Negative values for changes in the BDI-II, PANAS (-), and FIQ reflect improvements in depressive symptomatology, negative affect, and interference of FMS, respectively. By contrast, positive values for changes in the QLI, GSES-12, and PANAS (+) reflect improvements in quality of life, self-efficacy, and positive affect, respectively.

Moderation analyses were carried out to examine whether the relationship between the condition (intervention versus control) and the change in the primary outcome, BDI-II, was moderated by the scores on the FIQ, PANAS (-) and (+), QLI, GSES-12, DERS subscales, RPA subscales, and RRS. The procedure described by Hayes ${ }^{19}$ was performed using the macro PROCESS for SPSS, version 2.15, choosing "model 1". Regression coefficients are reported in unstandardized form as $b$-values. Tests of significance $(p<.05)$ or a confidence interval (not including zero) in the interaction answered the question about whether the effect of condition on change in BDI-II was moderated by other variables. Intervention condition was coded as "1", and control 
condition was coded as " 2 ", and so a positive relationship between condition and change in BDI-II meant that patients who received the intervention showed greater improvements in depressive symptomatology. Conditional effects of condition on change in BDI-II at values of the moderator (mean and \pm 1 standard deviation) were estimated with the "pick-a-point" approach (or analysis of simple slopes). Consequently, $-1 S D$ from the mean represents a "low" level, the mean represents a "moderate" level, and $+1 S D$ from the mean represents a "high" level of each moderator.

Parallel multiple mediator analyses were performed using "model 4" from the macro PROCESS to test whether: a) the effect of condition on change in FIQ was mediated by the change in PANAS (-), PANAS (+), and BDI-II (FIQ model); b) the effect of condition on change in QLI was mediated by the change in PANAS (-), PANAS (+), and BDI-II (QLI model); b) the effect of condition on change in GSES-12 was mediated by the change in PANAS (-), PANAS (+), and BDI-II (GSES-12 model); and d) the effect of condition on change in BDI-II was mediated by the change in PANAS (-), PANAS $(+)$, and BDI-II (BDI-II model). Biascorrected bootstrap 95\% confidence intervals (CIs) based on 5,000 samples were used to assess the specific and total indirect effects. CI that did not include the zero value indicated a significant indirect effect, meaning that the effect of the predictor variable on the outcome variable was mediated by another variable. Pairwise comparisons between specific indirect effects were carried out to test whether one 
indirect effect was statistically different from another through the confidence interval.

\section{Results}

\section{Previous checks: Differences at baseline}

No differences were found in terms of years suffering from pain, BDI-II, FIQ, QLI, GSES-12, PANAS (+), PANAS (-), DERS subscales, RPA subscales, and RRS, except for the DERS subscale called "Lack of Emotion Clarity". Table 1 shows the difference in baseline variables in both conditions.

\section{Moderation analysis of the effect of the condition on the change in} BDI-II by FIQ, QLI, GSES-12, PANAS, DERS, RPA, and RRS.

Moderation analyses showed that the effect of the condition on the change in BDI-II was moderated by GSES-12, Difficulties Engaging in Goal-Directed Behavior (DERS), Emotion-focused positive rumination (RPA), and Rumination (RRS) scores at baseline, but not by FIQ, $F(1,43)$ $=0.90, p=.347 ;$ QIL, $F(1,43)=3.35, p=.074 ;$ PANAS $(+), F(1,42)=2.01$, $p=.163 ;$ PANAS $(-), F(1,42)=1.91, p=.175$; Lack of Emotional Awareness (DERS), $F(1,43)=1.53, p=.223$; Lack of Emotion Clarity (DERS), $F(1,43)=0.33, p=.566 ;$ Non-acceptance of Emotional Responses (DERS), $F(1,43)=1.42, p=.241$; Lack of emotional control (DERS), $F(1,43)=4.02, p=.051$; Dampening (RPA), $F(1,37)=1.15, p=$ .290; or Self-focused positive rumination (RPA), $F(1,37)=0.61, p=.441$. In the following subsections, the results of the significant moderation analyses are shown in detail (see Table 2 and Figure 1). 
- Self-efficacy (GSES-12). The overall model explained $23.78 \%$ of the variance in change in BDI-II, and it was significant, $F(3,43)=3.54, p=$ .022. The interaction between condition and self-efficacy at baseline was significant, $F(1,43)=4.12, p=.049$, meaning that self-efficacy at baseline was a moderator of the effect of the condition on the change in BDI-II, accounting for $6.63 \%$ of the variance. Analysis of simple slopes showed that there was a positive significant relationship between condition and change in BDI-II when self-efficacy was "low", $b=12.44$, $95 \%$ CI $[3.96,20.91], t=2.94, p=.005$, and "moderate", $b=7.25,95 \%$ CI $[2.20,12.30], t=2.90, p=.006$. Patients in the intervention condition with low and moderate levels of self-efficacy at baseline achieved greater improvements in depressive symptomatology.

- Difficulties Engaging in Goal-Directed Behavior (DERS). The overall model explained $27.19 \%$ of the variance in change in BDI-II, and it was significant, $F(3,43)=3.87, p=.016$. The interaction between condition and Difficulties Engaging in Goal-Directed Behavior at baseline was significant, $F(1,43)=5.84, p=.020$, meaning that the Difficulties Engaging in Goal-Directed Behavior at baseline was a moderator of the effect of the condition on the change in BDI-II, accounting for $11.00 \%$ of the variance. Analysis of simple slopes showed that there was a positive significant relationship between condition and change in BDI-II when Difficulties Engaging in Goal-Directed Behavior was "moderate", $b=$ $6.83,95 \%$ CI $[1.85,11.81], t=2.77, p=.008$, and "high", $b=13.09,95 \%$ CI $[5.07,21.10], t=3.29, p=.002$. Patients in the intervention condition with moderate and high levels of Difficulties Engaging in Goal-Directed 
Behavior at baseline achieved greater improvements in depressive symptomatology.

- Emotion-focused positive rumination (RPA). The overall model explained $28.59 \%$ of the variance in change in BDI-II, and it was significant, $F(3,37)=7.43, p<.001$. The interaction between condition and emotion-focused positive rumination at baseline was significant, $F(1,37)=6.90, p=.013$, meaning that emotion-focused positive rumination at baseline was a moderator of the effect of the condition on the change in BDI-II, accounting for $13.06 \%$ of the variance. Analysis of simple slopes showed that there was a positive significant relationship between condition and change in BDI-II when emotion-focused positive rumination was "low", $b=14.35,95 \%$ CI [7.94, 20.76], $t=4.54, p<.001$, and "moderate", $b=7.10,95 \%$ CI [1.36, 12.85], $t=2.51, p=.017$. Patients in the intervention condition with low and moderate levels of emotion-focused positive rumination at baseline achieved greater improvements in depressive symptomatology.

- Rumination (RRS). The overall model explained $21.30 \%$ of the variance in change in BDI-II, and it was significant, $F(3,43)=4.43, p=$ .008. The interaction between condition and rumination at baseline was significant, $F(1,43)=4.85, p=.033$, meaning that rumination at baseline was a moderator of the effect of the condition on the change in BDI-II, accounting for $5.95 \%$ of the variance. Analysis of simple slopes showed that there was a positive significant relationship between condition and change in BDI-II when rumination was "moderate", $b=7.13,95 \%$ CI [1.91, 12.35], $t=2.75, p=.009$, and "high", $b=11.90,95 \%$ CI [4.80, 
19.01], $t=3.38, p=.002$. Patients in the intervention condition with moderate and high levels of rumination at baseline achieved greater improvements in depressive symptomatology.

\section{Parallel Multiple Mediation analysis: FIQ, QLI, GSES-12, and BDI-II model.}

- FIQ model. The total indirect effect was significant, implying that the change in PANAS (+), PANAS (-), and BDI-II collectively mediates the relationship between condition and change in FIQ. However, an examination of the specific indirect effects indicates that only the change in BDI-II was a mediator of the effect of condition on the change in FIQ, meaning that participants in the intervention condition had greater improvements in depressive symptomatology than participants in the control condition, and participants who had greater improvements in depressive symptomatology had greater improvements in interference of FMS. There was no evidence that the condition influenced the change in FIQ, regardless of its effect on the change in BDI-II. Figure 2 and Table 3 show the results of the multiple parallel mediation in detail.

- QLI model. The total indirect effect was significant, implying that the change in PANAS (+), PANAS (-), and BDI-II collectively mediates the relationship between condition and change in QLI. However, an examination of the specific indirect effects indicates that only the changes in PANAS (+) and PANAS (-) are mediators of the effect of condition on the change in QLI, which means that participants in the 
intervention condition had greater improvements in positive and negative affect than participants in the control condition, and participants who had greater improvements in positive and negative affect had greater improvements in QLI. Pairwise contrasts showed that the indirect effect of PANAS (-) on change in QLI was significantly larger than the indirect effect through BDI-II. Nevertheless, the condition influenced the change in QLI, regardless of its effect on the change in PANAS (+) and PANAS (-) (see Figure 2 and Table 3).

- GSES-12 model. Although the total indirect effect was significant, an examination of the specific indirect effects indicates that changes in PANAS (+), PANAS (-), and BDI-II were not mediators of the effect of condition on the change in GSES-12. There was also no evidence that the condition influenced the change in GSES-12, regardless of its effect on the change in PANAS (+), PANAS (-), and BDI-II. (see Figure 2 and Table 3).

- BDI-II model. The total indirect effect was significant, implying that the changes in PANAS $(+)$ and PANAS $(-)$ collectively mediate the relationship between condition and change in BDI-II. Furthermore, an examination of the specific indirect effects showed that both PANAS (+) and PANAS (-) were mediators of the effect of condition on the change in BDI-II. Pairwise contrasts showed that the indirect effect of PANAS $(+)$ on change in BDI-II was not different from the indirect effect through PANAS (-). There was no evidence that the condition influenced the change in BDI-II, regardless of its effect on the change in PANAS (+) and PANAS (-) (see Figure 2 and Table 3). 
Table 1. Descriptive statistics of years suffering from pain, BDI-II, FIQ, QLI, GSES-12, PANAS, DERS, RPA, RRS at baseline in Intervention and Control conditions.

\begin{tabular}{|c|c|c|c|c|}
\hline & $\begin{array}{c}\text { Intervention } \\
(n=21)^{b} \\
M(S D)\end{array}$ & $\begin{array}{c}\text { Control } \\
(n=26) \\
M(S D) \\
\end{array}$ & $t$ value & $\boldsymbol{p}^{\mathrm{a}}$ \\
\hline $\begin{array}{l}\text { Years suffering } \\
\text { from pain }\end{array}$ & $11.81(7.11)$ & $14.96(11.55)$ & $t(45)=-1.09$ & .280 \\
\hline BDI-II & $25.48(10.51)$ & $22.12(10.07)$ & $t(45)=1.12$ & .270 \\
\hline FIQ & $67.82(12.29)$ & $65.22(14.11)$ & $t(45)=0.66$ & .510 \\
\hline QLI & 48.33 (13.88) & $49.08(14.54)$ & $t(45)=-0.18$ & .860 \\
\hline GSES-12 & $40.67(6.00)$ & $43.19(7.61)$ & $t(45)=-1.24$ & .221 \\
\hline \multicolumn{5}{|l|}{ PANAS } \\
\hline Positive & $2.04(0.61)$ & $2.25(0.71)$ & $t(44)=-1.04$ & .302 \\
\hline Negative & $2.43(0.67)$ & $2.06(0.81)$ & $t(44)=1.62$ & .113 \\
\hline \multicolumn{5}{|l|}{ DERS } \\
\hline $\begin{array}{l}\text { Lack of Emotional } \\
\text { Awareness }\end{array}$ & $11.10(4.23)$ & $8.96(4.21)$ & $t(45)=1.72$ & .092 \\
\hline $\begin{array}{l}\text { Lack of Emotional } \\
\text { Clarity }\end{array}$ & $9.76(3.60)$ & 7.81 (2.99) & $t(45)=2.03$ & .048 \\
\hline $\begin{array}{l}\text { Non-acceptance } \\
\text { of Emotional } \\
\text { Responses }\end{array}$ & $21.33(9.65)$ & $16.58(7.61)$ & $t(45)=1.89$ & .065 \\
\hline $\begin{array}{l}\text { Difficulties } \\
\text { Engaging in Goals }\end{array}$ & $13.76(4.95)$ & $12.62(4.12)$ & $t(45)=0.87$ & .390 \\
\hline $\begin{array}{l}\text { Lack of emotional } \\
\text { control }\end{array}$ & $20.95(9.51)$ & $20.54(8.49)$ & $t(45)=0.16$ & .876 \\
\hline \multicolumn{5}{|l|}{ RPA } \\
\hline Dampening & $16.50(6.35)$ & $18.48(6.46)$ & $t(39)=-0.98$ & .333 \\
\hline $\begin{array}{l}\text { Emotion-focused } \\
\text { positive } \\
\text { rumination }\end{array}$ & $13.94(4.24)$ & $13.04(4.86)$ & $t(39)=0.62$ & .537 \\
\hline $\begin{array}{l}\text { Self-focused } \\
\text { positive } \\
\text { rumination }\end{array}$ & $7.00(3.41)$ & 7.39 (3.29) & $t(39)=-0.37$ & .712 \\
\hline RRS & $49.29(12.53)$ & 48.69 (15.29) & $t(45)=0.14$ & .887 \\
\hline
\end{tabular}

Note. BDI-II=Beck Depression Inventory-II; FIQ= Fibromyalgia Impact Questionnaire; QLI= Quality of life Index; GSES-12 = General Self-efficacy scale; PANAS = Positive and Negative Affective Schedule; DERS = Difficulties in Emotion Regulation Scale; RPA = Responses to Positive Affect Questionnaire; RRS = Ruminative Responses Scale. ${ }^{a} p$ and t-values are results for the test comparing Intervention and Control conditions. $b$ Due to missing values, the analyses for PANAS were carried out with $n=20$ (Intervention condition), and the analyses for RPA were performed with $n=18$ (Intervention condition) and $n=23$ (Control condition). 
Table 2. Linear model of predictors of change in BDI-II.

\begin{tabular}{|c|c|c|c|c|}
\hline & $b$ & SE & $t$ & $p$ \\
\hline \multicolumn{5}{|l|}{ Self-efficacy (GSES-12) } \\
\hline Constant & $-0.92[-3.44,1.60]$ & 1.25 & -0.74 & .465 \\
\hline Self-efficacy (centered) & $-0.12[-0.48,0.23]$ & 0.18 & -0.70 & .491 \\
\hline Condition (centered) & $7.25[2.20,12.30]$ & 2.50 & 2.90 & .006 \\
\hline Condition X Self-efficacy & $-0.74[-1.48,-0.00]$ & 0.37 & -2.09 & .049 \\
\hline \multicolumn{5}{|l|}{$\begin{array}{l}\text { Difficulties Engaging in Goals } \\
\text { (DERS) }\end{array}$} \\
\hline Constant & $-0.99[-3.49,1.52]$ & 1.24 & -0.80 & .431 \\
\hline $\begin{array}{l}\text { Difficulties Engaging in Goals } \\
\text { (centered) }\end{array}$ & $-0.12[-0.71,0.47]$ & 0.29 & -0.42 & .680 \\
\hline Condition (centered) & $6.83[1.85,11.81]$ & 2.47 & 2.77 & .008 \\
\hline $\begin{array}{l}\text { Condition X Difficulties } \\
\text { Engaging in Goals }\end{array}$ & $1.39[0.23,2.55]$ & 0.58 & 2.42 & .020 \\
\hline \multicolumn{5}{|l|}{$\begin{array}{l}\text { Emotion-focused positive } \\
\text { rumination (RPA) }\end{array}$} \\
\hline Constant & $-1.60[-4.42,1.23]$ & 1.39 & -1.15 & .260 \\
\hline Emotion-focused (centered) & $-0.18[-0.78,0.42]$ & 0.30 & -0.61 & .548 \\
\hline Condition (centered) & $7.10[1.36,12.85]$ & 2.83 & 2.51 & .017 \\
\hline $\begin{array}{l}\text { Condition X Emotion- } \\
\text { focused }\end{array}$ & $-1.59[-2.82,-0.36]$ & 0.61 & -2.63 & .013 \\
\hline \multicolumn{5}{|l|}{ Rumination (RRS) } \\
\hline Constant & $-1.33[-3.91,1.24]$ & 1.28 & -1.04 & .302 \\
\hline Rumination (centered) & $0.02[-0.13,0.17]$ & 0.07 & 0.22 & .831 \\
\hline Condition (centered) & $7.13[1.91,12.35]$ & 2.59 & 2.75 & .009 \\
\hline Condition X Rumination & $0.34[0.03,0.65]$ & 0.16 & 2.20 & .033 \\
\hline
\end{tabular}

Note. GSES-12 = General Self-efficacy scale; DERS = Difficulties in Emotion Regulation Scale; RPA = Responses to Positive Affect Questionnaire; RRS = Ruminative Responses Scale; $\mathrm{SE}=$ Standard error. 
Figure 1. Simple slopes graph of the regressions of condition on change in BDI-II at three levels of the moderator variables (low, moderate, and high).
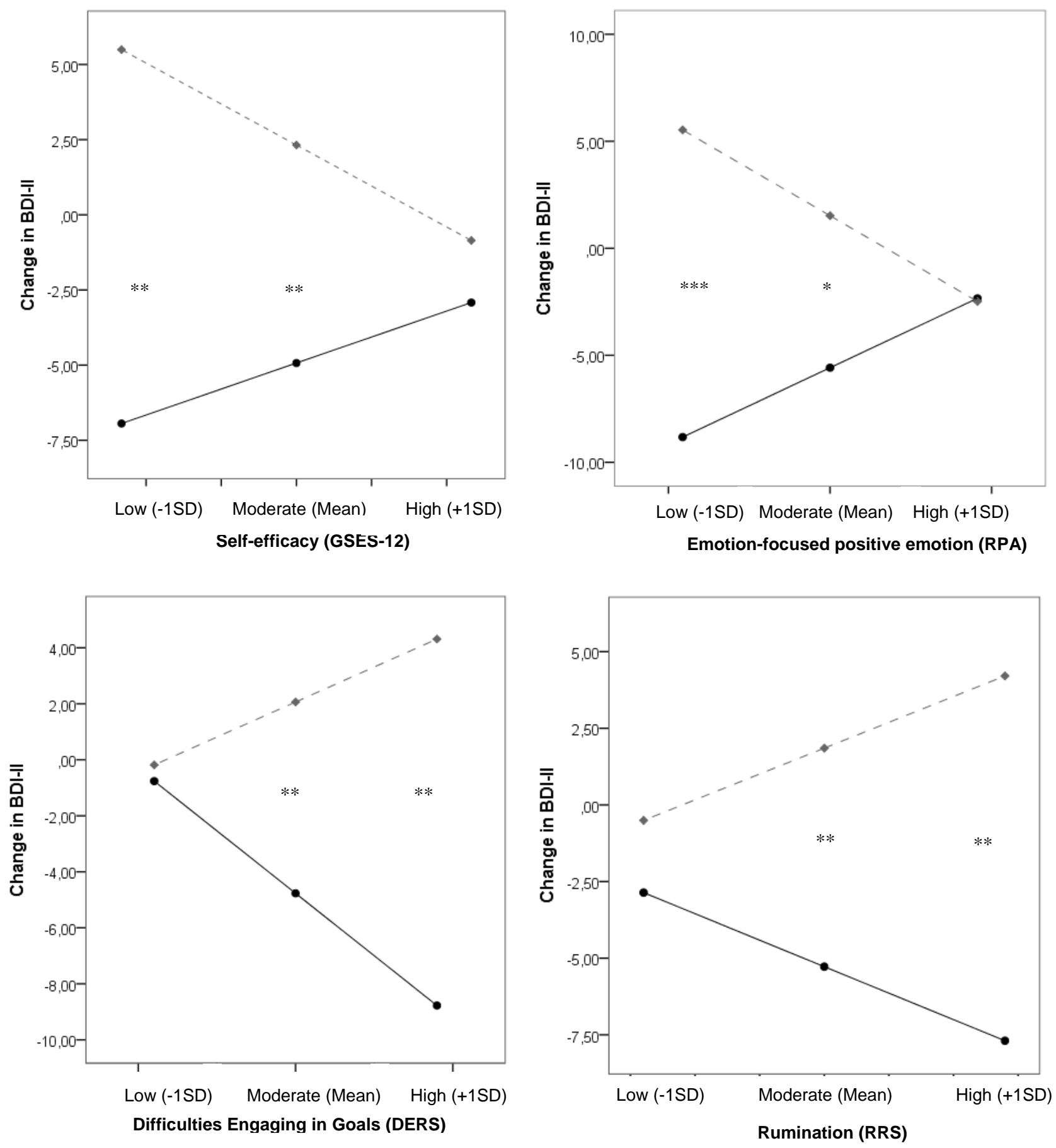

Note. ${ }^{* * *} p<.001 ;{ }^{* *} p<.01 ;{ }^{*} p<.05$. 
Figure 2. Multiple mediation of FIQ, QLI, GSES-12 and BDI-II models.
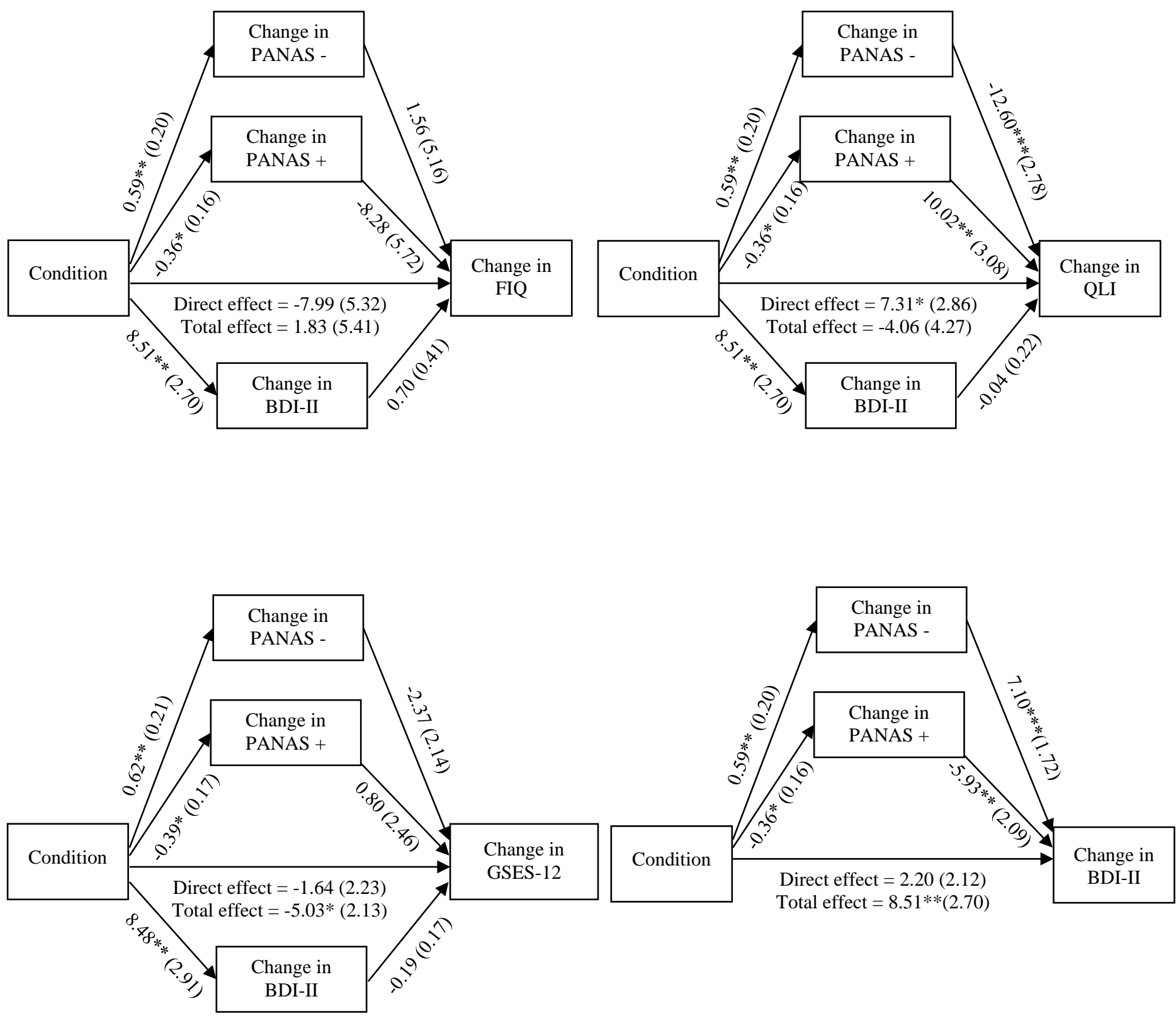

Note. All coefficients represent unstandardized regression coefficients (and standard errors in parenthesis). ${ }^{*} p<.05{ }^{* *} p<.01 ;{ }^{* * *} p<.001$. Due to missing values, mediation analyses were carried out with $n=40$. BDI-II = Beck Depression Inventory-II; FIQ = Fibromyalgia Impact Questionnaire; QLI = Quality of life Index; PANAS = Positive and Negative Affective Schedule; GSES-12 = General Self-Efficacy Scale. 
Table 3. Coefficients, Standard errors (SE), and Confidence intervals (CI) of the Parallel Multiple Mediation for each model.

\begin{tabular}{|c|c|c|c|c|c|c|c|c|}
\hline & \multicolumn{2}{|c|}{ FIQ model } & \multicolumn{2}{|c|}{ QLI model } & \multicolumn{2}{|c|}{ GSES-12 model } & \multicolumn{2}{|c|}{ BDI-II model } \\
\hline & $\begin{array}{c}\text { Coefficients } \\
(S E)\end{array}$ & $95 \% \mathrm{CI}$ & $\begin{array}{c}\text { Coefficients } \\
(S E)\end{array}$ & $95 \% \mathrm{CI}$ & $\begin{array}{c}\text { Coefficients } \\
(S E)\end{array}$ & $95 \% \mathrm{CI}$ & $\begin{array}{l}\text { Coefficients } \\
(S E)\end{array}$ & $95 \% \mathrm{CI}$ \\
\hline \multicolumn{9}{|l|}{ Indirect effects } \\
\hline Total indirect effect & $9.81(4.60)$ & {$[2.18,20.45]$} & $\begin{array}{l}-11.37 \\
(3.78)\end{array}$ & {$[-19.35,-4.58]$} & $-3.39(1.48)$ & {$[-6.86,-$} & $6.31(2.39)$ & {$[2.10,11.46]$} \\
\hline Specific change in BDI-II & $5.95(4.09)$ & {$[0.57,17.41]$} & $-0.36(2.50)$ & {$[-7.26,2.61]$} & $-1.60(1.44)$ & {$[-5.04,0.44]$} & - & - \\
\hline $\begin{array}{l}\text { Specific change in PANAS } \\
(+)\end{array}$ & $2.94(2.43)$ & {$[-0.23,10.61]$} & $-3.56(1.66)$ & {$[-7.69,-0.82]$} & $-0.31(1.18)$ & {$[-3.95,0.88]$} & $2.11(1.42)$ & {$[0.25,6.13]$} \\
\hline Specific change in PANAS $(-)$ & $0.92(3.29)$ & {$[-4.99,8.32]$} & $-7.46(2.78)$ & {$[-14.37,-2.89]$} & $-1.48(1.54)$ & {$[-5.61,0.69]$} & $4.20(1.76)$ & {$[1.35,8.28]$} \\
\hline \multicolumn{9}{|l|}{ Contrasts } \\
\hline BDI-II - PANAS (+) & $3.00(5.32)$ & {$[-6.67,14.98]$} & $3.20(3.11)$ & {$[-2.24,9.68]$} & $1.29(2.21)$ & {$[-4.95,3.19]$} & - & - \\
\hline BDI-II - PANAS (-) & $5.02(6.42)$ & {$[-5.84,20.49]$} & $7.10(4.05)$ & {$[0.23,15.91]$} & $0.12(2.60)$ & {$[-4.73,5.19]$} & - & - \\
\hline PANAS (+) - PANAS (-) & $2.02(3.10)$ & {$[-3.49,9.28]$} & $3.89(3.13)$ & {$[-2.03,10.32]$} & $1.17(1.91)$ & {$[-1.98,6.12]$} & $-2.09(2.13)$ & {$[-6.57,1.81]$} \\
\hline
\end{tabular}

Note. FIQ = Fibromyalgia Impact Questionnaire; QLI = Quality of life Index; GSES-12 = General Self-Efficacy Scale; BDI-II = Beck Depression Inventory-II; PANAS = Positive and Negative Affective Schedule; SE = Standard error. 


\section{Discussion}

This study investigated the mechanisms of change in an intervention designed to increase positive affect and promote positive functioning in FMS patients, and it examined which patients may benefit more from them. To our knowledge, this is the first study to analyze how the Best Possible Self intervention, as a positive affect intervention, works in FMS.

First, four mediation models were tested, taking into account four primary outcomes studied in most pain treatments: pain disability, depression, self-efficacy, and quality of life. Regarding pain disability, an analysis of the specific indirect effects showed that only changes in depression mediated the improvements in interference of FMS, measured by the FIQ. Participants who practiced the guided imagery exercise obtained greater improvements in depressive symptomatology than participants in the control condition, and they also had greater improvements in pain impairment. There was no evidence that the condition influenced the change in FIQ independently from its effect on the change in BDI-II. This is an important finding as it implies that changes in emotional functioning are necessary in order to achieve changes in functional status, coinciding with results from a study showing that stress mediated the relationship between an online CBT intervention and pain severity in chronic pain patients ${ }^{8}$. In addition, the finding that negative and positive affect were not direct mediators of pain disability has also been observed in previous research assessing the association between trait positive affect and pain severity ${ }^{14,43}$. These results suggest that, although positive and negative affect contribute to 
the pain function, this relationship may be complex and not directly observable with traditional pain measures ${ }^{18}$.

Regarding depression, changes in positive and negative affect were mediators of the effect of the BPS intervention on changes in the BDI-II. There was no evidence that the condition influenced the change in BDI-II, independently from its effect on the change in positive and negative affect. This means that participants who received the BPS intervention had greater reductions in negative affect and increases in positive affect than the control condition, and this led to reductions in depressive symptomatology. These findings confirm the distinct effects of negative and positive affect on depression in pain syndromes. Previous correlational studies found that associations between pain intensity and negative affect and between pain intensity and depressive symptoms were moderated by positive affect ${ }^{45}$. Chronic pain patients with low positive affect showed strong associations among pain intensity, depression, and negative affect, whereas patients with high positive affect showed non-significant associations among pain intensity, depression, and negative affect. These results coincide with those from another study showing a positive association between positive and negative affect and goal representations. These representations facilitate goal pursuit and are related to depression levels ${ }^{25,35}$. The importance of our study is that it is one of the first studies to causally confirm positive affect as a significant buffer between pain and pain-related outcomes ${ }^{38}$.

Regarding quality of life, negative affect and positive affect emerged as mediators of the effect of the BPS intervention on quality of life. Patients in this condition had greater improvements in positive and negative affect than 
participants in the control condition, and participants who had greater improvements in positive and negative affect had greater improvements in QLI. Research has demonstrated that negative and positive affect were distinct affective responses to coping in patients with rheumatoid arthritis, and that both affective states were necessary to understand the disease effects on quality of life. Patients with higher pain and limitations from rheumatoid arthritis had higher levels of maladaptive coping, and this was associated with lower positive affect and higher negative affect ${ }^{52}$. However, it should be noted that practicing the imagery exercise influenced the change in QLI, regardless of its effect on the change in positive and negative affect. This means that the BPS intervention was able to significantly improve quality of life in FMS patients, independently from changes in positive and negative affect. Changes in quality of life in FMS may be explained by a complex set of factors that are not merely reduced to negative and positive affect.

Finally, in terms of self-efficacy, changes in positive affect, negative affect, or depression were not mediators of the effect of condition on the change in GSES-12. In this regard, although self-efficacy is a primary outcome in different types of pain treatments ${ }^{42}$, questions remain about what specific intervention components lead to changes in self-efficacy. Future studies should address these questions, including factors such as intervention dosage, frequency of practice, and motivation.

A second objective was to determine whether initial levels of outcome variables (pain disability, affect, self-efficacy, and quality of life), as well as process variables (emotion regulation strategies, and rumination), influenced the effects of the BPS intervention on depression. In terms of outcome 
variables, moderation analysis revealed that no baseline levels of pain impairment, positive and negative affect, or quality of life had a significant effect on the outcome. However, patients with low and moderate levels of self-efficacy at baseline who received the BPS intervention achieved greater improvements in depressive symptomatology. Previous studies analyzing the relationships between baseline clinical and psychological variables related to treatment response reached the conclusion that no clear demographic or clinical variable predicts improvement after CBT Internetbased pain management programs ${ }^{8,9}$. To our knowledge, no previous study has analyzed moderators of change in an intervention to promote positive functioning. One exception is a study that analyzed the effects of an ACT online intervention for chronic pain ${ }^{46}$, finding that ACT may not produce effective changes in pain interference in patients with low levels of autonomy and environmental mastery. Our results differ from these findings because, in our study, FMS patients with low and moderate self-efficacy at baseline benefited more from the BPS intervention. First, it should be noted that ACT is a complex intervention that cannot be considered merely a positive affect intervention. Second, ACT was applied online, which may have influenced the results. Results from our study are promising, as the main absence of moderators may indicate that a positive affect intervention is effective for a wide variety of FMS patients. Furthermore, FMS patients are characterized by low levels of self-efficacy compared to other rheumatoid diseases, and so the BPS intervention may be especially suitable for them.

In terms of process variables, moderation analysis revealed that patients with moderate and high levels of Difficulties Engaging in Goal- 
Directed Behavior at baseline achieved greater improvements in depressive symptomatology after practicing the BPS intervention. This means that patients who have problems concentrating and accomplishing tasks while experiencing negative emotions benefit more from the positive-guided imagery exercise. Having to practice the positive thinking task seems to help patients to regulate their negative mood. Furthermore, patients with low and moderate levels of emotion-focused positive rumination at baseline who received the intervention achieved greater improvements in depressive symptomatology. Emotion-focused positive rumination is an adaptive emotion regulation strategy that implies focusing on positive affective sensations in order to increase positive affect ${ }^{12}$. In this regard, practicing the guided-imagery exercise seemed to act as a facilitator to enhance positive affect in patients who did not tend to respond to positive affective states with strategies targeting positive affect. In addition, patients in the intervention condition with moderate and high levels of rumination at baseline achieved greater improvements in depressive symptomatology. Rumination is a repetitive process where individuals focus their attention on the content, causes, and consequences of affective states and symptoms ${ }^{29}$. Rumination about negative emotions is associated with the onset and course of depression, anxiety, and poorer coping styles in FMS ${ }^{30}$. More importantly, the ruminative style is persistent, even when depressive symptomatology improves ${ }^{5}$. Therefore, we believe this intervention could help patients with a ruminative style to change their focus of attention from negative content (e.g, pain, daily stress) to positive content. These results contribute to the understanding of emotion regulation strategies in the association between 
induced positive affect and depression in chronic pain patients. Our findings suggest that future research on pain would benefit from measuring responses to both negative and positive affect regulation mechanisms. Moreover, the present study extends previous studies on moderators of change in pain treatments by including emotion regulation strategies as clinical predictors.

This study has a number of limitations that should be considered. First, the sample size is small. Therefore, our study needs to be replicated with larger samples. Moreover, it would be necessary to test whether other positive affect interventions find similar mediator and moderator variables. The question of whether all positive affect interventions work in a similar way in chronic pain patients is still an understudied topic. Regarding assessment methods, relying on the use of self-report measures of pain, affect, and emotion regulation processes could have influenced the results of the present study. In addition, evaluating emotion regulation with self-report measures can be difficult, especially for patients with limited introspection abilities $^{28}$. Future research should address these limitations by including different assessment methods. Although we were able to identify the contribution of negative and positive affect to depression and quality of life in FMS patients, future studies should address the question of whether it is important to first address negative affect and then promote positive affect, or if it is best to focus on positive factors to buffer pain-related symptoms. In this regard, ecological momentary assessment and interventions can be a useful tool to measure daily variations and analyze casual relationships between these variables ${ }^{39}$. 
In summary, this study extends previous findings about patient characteristics associated with the response to pain management interventions. Moreover, it presents evidence about how and who may benefit more from an intervention aimed at augmenting positive affect and promoting positive functioning in FMS patients. Traditionally, these efforts have focused on responses to CBT treatments ${ }^{10}$. More research is needed to advance our understanding of the therapeutic mechanisms involved in psychological interventions for chronic pain management.

From biopsychosocial models of pain ${ }^{15}$ to current models of behavioral and inhibition systems related to pain ${ }^{24}$, they all state the importance of psychosocial factors in the maintenance of chronic pain. The relationships among cognitive, affective, and behavioral variables and pain appear to be more complex than originally thought, with behaviors, thoughts and emotions as causal agents, but also as outcomes in pain interventions. Moreover, these interactions may be modulated by individual differences. To understand these multifaceted interactions, chronic pain interventions need to target and assess these different variables associated with pain, including positive factors and emotion regulation strategies, in order to enhance the psychological management of chronic pain.

\section{References}

1. Baños RM, Etchemendy E, Farfallini L, García-Palacios A, Quero S, Botella C: EARTH of well-being system: A pilot study of an information and communication technology-based positive psychology intervention. J Posit Psychol 9: 482-488, 2014. 
2. Beck AT, Steer RA, Brown GK. Manual for the Beck Depression InventoryII. San Antonio, TX: Psychological Corporation, 1996.

3. Bennett R, Friend R, Jones KD, Ward R, Han BK, Ross RL: The revised Fibromyalgia Impact Questionnaire (FIQR): validation and psychometric properties. Arthritis Res Ther 11:R120, 2009.

4. Bosscher RJ, Smit JH: Confirmatory factor analysis of the General Self Efficacy Scale. Behav Res Ther 36: 339-43, 1998.

5. Brinker JK, Dozois DJ: Ruminative thought style and depressed mood. J Clin Psychol 65: 1-19, 2009.

6. Burns JW, Glenn B, Bruehl S, Harden RN, Lofland K: Cognitive factors influence outcome following multidisciplinary chronic pain treatment: a replication and extension of a cross-lagged panel analysis. Behav Res Ther 41:1163-1182, 2003.

7. Campbell CM, McCauley L, Bounds SC, Mathur VA, Conn L, Simango M, Edwards RR, Fontaine KR: Changes in pain catastrophizing predict later changes in fibromyalgia clinical and experimental pain report: crosslagged panel analyses of dispositional and situational catastrophizing. Arthritis Res Ther 14: R231, 2012. doi:10.1186/ar4073.

8. DasMahapatra P, Chiauzzi E, Pujol LM, Los C, Trudeau KJ: Mediators and Moderators of Chronic Pain Outcomes in an Online Self-Management $\begin{array}{llll}\text { Program. } & \text { Clin } \quad \text { J } & \text { Pain }\end{array}$ doi:10.1097/AJP.0000000000000125.

9. Dear BF, Gandy M, Karin E, Ricciardi T, Langman N, Staples LG, Fogliati VJ, Sharpe L, McLellan LF, Titov N: The Pain Course: exploring predictors 
of clinical response to an Internet-delivered pain management program. Pain 157: 2257-2268, 2016. doi: 10.1097/j.pain.0000000000000639.

10. Ehde DM, Dillworth TM, Turner JA: Cognitive-behavioral therapy for individuals with chronic pain: efficacy, innovations, and directions for research. Am Psychol 69:153-166, 2014. doi: 10.1037/a0035747.

11. Esteve-Vives J, Rivera J, Salvat MI, de Gracia Blanco M, de Miquel CA: Proposal of a consensual version of the Fibromyalgia Impact Questionnaire (FIQ) for the Spanish population. Reumatol Clin 3:21-24, 2007.

12. Feldman GC, Joormann J, Johnson SL: Responses to Positive Affect: A SelfReport Measure of Rumination and Dampening. Cognit Ther Res 32: 507525, 2008. doi:10.1007/s10608-006-9083-0.

13. Finan PH, Garland EL: The role of positive affect in pain and its treatment. Clin J Pain 31: 177-187, 2015.

14. Finan PH, Quartana PJ, Smith MT: Positive and negative affect dimensions in chronic knee osteoarthritis: effects on clinical and laboratory pain. Psychosom Med 75: 463-470, 2013.

15. Flor H, Turk DC (eds): Chronic pain: an integrated biobehavioral approach. Seattle, IASP Press, 2011.

16. Geenen R, van Ooijen-van der Linden L, Lumley MA, Bijlsma JW, van Middendorp H: The match-mismatch model of emotion processing styles and emotion regulation strategies in fibromyalgia. Psychosom Res 72:4550, 2012. doi: 10.1016/j.jpsychores.2011.09.004.

17. Gratz KL, Roemer L: Multidimensional Assessment of Emotion Regulation and Dysregulation: Development, Factor Structure, and Initial Validation 
of the Difficulties in Emotion Regulation Scale. J Psychopathol Behav Assess 26: 41, 2004. doi:10.1023/B:JOBA.0000007455.08539.94

18. Hassett AL, Finan PH: The role of resilience in the clinical management of chronic pain. Curr Pain Headache Rep 20: 39, 2016. doi: 10.1007/s11916-016-0567-7.

19. Hayes AF. Introduction to mediation, moderation, and conditional process analysis: A regression-based approach. Guilford Press, 2013.

20. Herrero R, Espinoza M, Molinari G, Etchemendy E, Garcia-Palacios A, Botella C, Baños RM: Psychometric properties of the General Self Efficacy-12 Scale in Spanish: general and clinical population samples. Compr Psychiatry 55: 1738-1743, 2014.

21. Hervás G: Adaptación al castellano de un instrumento para evaluar el estilo rumiativo: La Escala de Respuestas Rumiativas [Spanish adaptation of an instrument to assess ruminative style: Ruminative responses scale]. Revista de Psicopatología y Psicología Clínica, 13: 111121, 2008.

22. Hervás G, Jódar R: Adaptación al castellano de la Escala de dificultades en la regulación emocional. Clin Salud 19: 139-156, 2008.

23. Iddon JE, Dickson JM, Unwin J: Positive Psychological Interventions and Chronic Non-Cancer Pain: A Systematic Review of the Literature. Int J Appl Posit Psychol (2016). doi:10.1007/s41042-016-0003-6

24. Jensen MP, Ehde DM, Day MA: The Behavioral Activation and Inhibition Systems. Implications for understanding and treating chronic pain. J Pain 17: 529.e1-529.e18, 2016. doi: 10.1016/j.jpain.2016.02.001 
25. Karoly P, Ruehlman LS: Goal cognition and its clinical implications: Development and preliminary validation of four motivational assessment instruments. Assessment 2: 113-129, 1995.

26. Kothari DJ, Davis MC, Yeung EW, Tennen HA: Positive affect and pain. Pain 156: 540-6, 2015.

27. Kröner-Herwig B: Chronic pain syndromes and their treatment by psychological interventions. Curr Opin Psychiatry 22: 200-204, 2009.

28. Lumley MA, Cohen JL, Borszcz GS, Cano A, Radcliffe AM, Porter LS, Schubiner H, Keefe FJ: Pain and Emotion: A Biopsychosocial Review of Recent Research. Clin Psychol 67: 942-968, 2011. doi:10.1002/jclp.20816

29. Lyubomirsky S, Nolen-Hoeksema S: Effects of self-focused rumination on negative thinking and interpersonal problem solving. J Pers Soc Psychol 69:176-190, 1995.

30. Malin K, Littlejohn GO: Rumination modulates stress and other psychological processes in fibromyalgia. Eur J Rheumatol 2: 143-148, 2015.doi.org/10.5152/eurjrheum.2015.0005

31. Martínez MP, Sánchez AI, Miró E, Lami MJ, Prados G, Morales A: Relationships between physical symptoms, emotional distress, and pain appraisal in fibromyalgia: the moderator effect of alexithymia. J Psychol 149:115-40, 2015. doi: 10.1080/00223980.2013.844673.

32. Meevissen YM, Peters ML, Alberts HJ: Become more optimistic by imagining a best possible self: effects of a two week intervention. J Behav Ther Exp Psychiatry 42: 371-78, 2011. 
33. Mezzich JE, Ruipérez MA, Pérez C, Yoon G, Liu J, Mahmud S: The Spanish version of the quality of life index: presentation and validation. J Nerv Ment Dis 188: 301-5, 2000.

34. Molinari G, Enrique Roig A, Herrero R, Fernández-Llanio Comella N, Botella C, García Palacios A. Development and pilot testing of a positive imagery intervention with online support in the treatment of fibromyalgia. Rev Argent Clin Psic 2017. (In press.)

35. Mun CJ, Karoly P, Okun MA, Kim H, Tennen H: Affect, work-goal schemas, and work-goal striving among adults with chronic pain: a multilevel structural equation analysis. J Behav Med 39: 288-299, 2016. doi: 10.1007/s10865-015-9696-4.

36. Nolen-Hoeksema S, Morrow J: A prospective study of depression and post-traumatic stress symptoms following a natural disaster: The 1989 Loma Prieta Earthquake. J Pers Soc Psychol 61, 115-121, 1991.

37. Quero S, Molés M, Pérez MA, Botella C, Baños RM: An online emotional system to deliver homework assignments for treating adjustment disorders. J Cyber Ther Rehabil 5: 115-116, 2012.

38. Reme SE: Positive affect could reduce the impact of pain. Scand J Pain 14: 89-90, 2017.

39. Salaffi F, Sarzi-Puttini P, Atzeni F: How to measure chronic pain: New concepts. Best Pract Res Clin Rheumatol 29:164-86, 2015. doi: 10.1016/j.berh.2015.04.023.

40. Sandin B, Chorot P, Lostao L, Joiner TE, Santed MA, Valiente RM: Escalas PANAS de afecto positivo y negativo: Validación factorial y convergencia transcultural. Psicothema 11: 37-51, 1999. 
41. Sanz J, García Vera MP, Espinosa R, Fortin M, Vázquez C: Adaptación española del inventario para la depresión de Beck-II (BDI-II): Propiedades psicométricas en pacientes con trastornos psicológicos. Clin Salud 16: 121-42, 2005.

42. Somers TJ, Wren AA, Shelby RA: The Context of Pain in Arthritis: Selfefficacy for Managing Pain and Other Symptoms. Curr Pain Headache Rep 16: 502-508, 2012. doi:10.1007/s11916-012-0298-3.

43. Strand EB, Kerns RD, Christie A, Haavik-Nilsen K, Klokkerud M, Finset A: Higher levels of pain readiness to change and more positive affect reduce pain reports-a weekly assessment study on arthritis patients. Pain 127: 204-213, 2007.

44. Thieme K, Turk DC, Flor H: Responder criteria for operant and cognitivebehavioral treatment of fibromyalgia syndrome. Arthritis Rheum 57: 830-836, 2007.

45. Thong ISK, Tan G, Jensen MP: The buffering role of positive affect on the association between pain intensity and pain related outcomes. Scand J Pain 14: 91-97, 2017.

46. Trompetter HR, Bohlmeijer ET, Lamers SM, Schreurs KM: Positive Psychological Wellbeing Is Required for Online Self-Help Acceptance and Commitment Therapy for Chronic Pain to be Effective. Front Psychol 7: 353, 2016. doi: 10.3389/fpsyg.2016.00353.

47. Turner JA, Holtzman S, Mancl L: Mediators, moderators, and predictors of therapeutic change in cognitive-behavioral therapy for chronic pain. Pain 127: 276-286, 2007. 
48. van Middendorp H, Lumley MA, Moerbeek M, Jacobs JW, Bijlsma JW, Geenen R: Effects of anger and anger regulation styles on pain in daily life of women with fibromyalgia: a diary study. Eur J Pain 14: 176-182, 2010. doi: 10.1016/j.ejpain.2009.03.007.

49. Van Houdenhove B, Luyten P: Customizing treatment of chronic fatigue syndrome and fibromyalgia: the role of perpetuating factors. Psychosomatics 49:470-477, 2008. doi: 10.1176/appi.psy.49.6.470

50. Watson D, Clark LA, Tellegen A: Development and validation of brief measures of positive and negative affect: the PANAS scales. J Pers Soc Psychol 54: 1063-1070, 1988.

51. Wolfe F, Clauw DJ, Fitzcharles MA, Goldenberg DL, Häuser W, Katz RS, Mease P, Russell AS, Russell IJ, Winfield JB: Fibromyalgia criteria and severity scales for clinical and epidemiological studies: a modification of the ACR Preliminary Diagnostic Criteria for Fibromyalgia. J Rheumatol 38: 1113-1122, 2011.

52. Zautra AJ, Burleson MH, Smith CA, Blalock SJ, Wallston KA, DeVellis RF, DeVellis BM, Smith TW: Arthritis and perceptions of quality of life: an examination of positive and negative affect in rheumatoid arthritis patients. Health Psychol 14: 399-408, 1995.

53. Zautra AJ, Fasman R, Reich JW, Harakas P, Johnson LM, Olmsted ME, Davis MC: Fibromyalgia: evidence for deficits in positive affect regulation. Psychosom Med 67: 147-155, 2005. 


\section{Validación de instrumentos de medida utilizados en el estudio empírico}

Los trabajos que se incluyen a continuación han sido desarrollados de manera transversal al desarrollo de la intervención estudiada, con el objetivo de validar la utilización de las medidas de resultado principales en el idioma español y en población clínica.

\section{Psychometric properties of the General Self Efficacy-}

\section{2 scale in Spanish: general and clinical population}

\section{samples}

Este artículo ha sido publicado en la Revista Comprehensive Psychiatry. Autores: Herrero, R., Espinoza, M., Molinari, G., Etchemendy, E., GarcíaPalacios, A, Botella, C., y Baños, R. M. (2014).

\section{Abstract}

The General Self Efficacy Scale (GSES-12) is a short version of the Sherer's Self-Efficacy Scale, and evaluates a general dimension and three aspects of self-efficacy: initiative, persistence and effort. The aim of this study is to explore the factorial structure, reliability, and criterion validity of the Spanish adaptation of the GSES-12 in general and clinical populations. The sample was composed of 714 volunteers (332 from the clinical population). Results of the principal components analysis yielded a 3-factor structure that was 
later confirmed through Confirmatory Factor Analysis. Moreover, this study shows good internal consistency and test-retest values, and differences in self-efficacy scores between the clinical and non-clinical groups. The present study demonstrates that the Spanish version of the GSES-12 is a valid and reliable measure, and it adds relevant information to the debate about the dimensional structure of general self-efficacy.

Keywords: general self-efficacy, psychometric properties, reliability, validity. 


\section{Introduction}

Self-efficacy expectations imply the belief that one is able to perform a specific behavior. These beliefs affect the decision to initiate an action, the amount of effort people will invest, and how long they will persist in this behavior when difficulties appear ${ }^{1} 2$ making a considerable contribution to motivation and performance ${ }^{3}$. Some authors have proposed a 'general' selfefficacy dimension, conceptualized as a generalized belief about one's competence to perform across a variety of situations ${ }^{4,5}$. It is important to notice that the construct of general self-efficacy have been questioned, based on the argument that could not differ from other self-evaluative constructs, like self-esteem ${ }^{6,7,8}$. Nevertheless, results are mixed, considering the fact that there are data supporting the distinction between general self-efficacy and other related constructs ${ }^{4}, 6$, 9. Therefore, the general self-efficacy beliefs predict behavioral differences between individuals, suggesting their relevance to understand psychotherapy outcomes, so having adequate instruments to measure them will be important.

One of the available measures to assess the general self-efficacy dimension is Sherer's Self-Efficacy Scale (GSES) ${ }^{10}$. This self-report is composed of 30 items divided into 2 subscales: general and social selfefficacy. The scale has been translated into different languages ${ }^{11}$ 12. For example, López-Torrecillas, García, Cañadas, Ramírez and de la Fuente (2006) ${ }^{13}$ translated the scale into Spanish, and they also proposed a 2-factor model ('general' and 'social' self-efficacy). They detected significant differences between clinical and nonclinical samples, pointing out the usefulness of this scale in clinical contexts. Other authors have also offered 
some evidence of discriminant validity ${ }^{14}$ and of the relationship between selfefficacy and psychotherapy outcomes ${ }^{15,} 16$. The conceptualization of general self-efficacy as a unitary construct and the multifactorial structure of the GSES has been a highly controversial issue ${ }^{6}$. Woodruff and Cashman ${ }^{17}$ found a factorial structure different from Sherer et al.'s original proposal ${ }^{10}$, but consistent with the conceptual framework. These authors obtained a 5-factor model, maintaining the 2 original areas ('general' and 'social' self-efficacy), but including 3 sub-areas for the former (magnitude, strength and competence) and 2 sub-areas for the latter (competence and strength).

Although the original version of the scale was composed by two different subscales, Sherer et al. pointed out that the general self-efficacy subscale appears to be more useful than the social self-efficacy subscale to assess self-efficacy expectations ${ }^{10}$, 18. In this sense, several authors focused their studies only on the general self-efficacy subscale using its 17-items independently. Regarding this scale, Bosscher and Smit ${ }^{19,20}$ offered a modified 12-item version (GSES-12) that was initially tested on elderly people. They excluded 5 items from the original subscale because they showed low itemtest correlations and ambiguous wording. Items are answered on a 5-point Likert scale ranging from 1 ('never happens to me') to 5 ('always happens to $m e$ ), where high scores indicate high self-efficacy. The GSES-12 has been used in several studies with different samples (elderly people, depression, abused women, etc. $)^{21,22,23}$ applied factor analytic techniques and confirmed the factor structure found by Woodruff and Cashman ${ }^{17}$. They suggested that the data best fit a model with 3 correlated factors (initiative, effort, persistence) and one higher-order factor (general self-efficacy) ${ }^{19}$. 
Other scales have been developed to assess general self-efficacy, such as the General Perceived Self-Efficacy Scale (GPSES) ${ }^{24}$ or the New General SelfEfficacy Scale (NGES) ${ }^{6}$. Although these scales were designed to improve the weaknesses associated with the original GSES, Scherbaum et al. (2006) ${ }^{5}$ considered that the three scales (GPSES, NGSE, and GSES) offer comparable information and work better for individuals with average or below average levels of general self-efficacy. Scherbaum et al. ${ }^{5}$ also stated that all 3 scales fit a one-dimensional model better.

Therefore, taking into consideration that general self-efficacy is a concept associated with mental health, well-being and also an important mechanism of change in clinical outcomes, the aim of this study is to evaluate and disseminate the psychometric properties of the GSES-1220 in a Spanish adult sample including general and clinical populations. Although, there is a Spanish validation of the GSES ${ }^{13}$ that evaluated the psychometric properties of the original scale, improved versions of this scale were not validated in Spanish population. Besides, López-Torrecillas et al. ${ }^{13}$ assessed the original factor structure, without analyzing other proposed models. For that reason, this paper seeks to present psychometric data of a new version of the GSES and contribute to the debate of its structure.

\section{Material and methods}

\section{Participants}

The sample was composed of 714 Spanish volunteers (554 women, 160 men), 382 participants (269 women, 113 men) from the general population, and 332 participants (285 women, 47 men) from the clinical 
population who were attending two clinical services (Psychological Support Service at Universitat Jaume I -SAP-, and Previ Clinical Psychology Center) (see Table 1 for demographic characteristics). Participants from the general population (GP) belonged to the university community (students and relatives). Participants from the clinical population (CP) were individuals seeking treatment for psychological disorders (total=179; anxiety disorders= 72; adjustment disorders $=39$; personality disorders $=28$; $\operatorname{mood}$ disorders $=$ 21 and eating disorders $=18$ ) or emotional problems related to medical conditions (total=154; fibromyalgia= 123 and cancer=31).

Table 1. Demographic characteristics of general and clinical samples

\begin{tabular}{|c|c|c|c|c|}
\hline & & $\mathbf{C P}$ & GP & TS \\
\hline Age & & $\begin{array}{l}37.86 \\
\text { (SD 12.73) }\end{array}$ & $\begin{array}{l}27.05 \\
\text { (SD 9.55) }\end{array}$ & $\begin{array}{l}31.92 \\
(S D 12.33)\end{array}$ \\
\hline \multirow[t]{2}{*}{ Sex } & Male & $\begin{array}{l}47 \\
(14.2 \%)\end{array}$ & $\begin{array}{l}113 \\
(29.6 \%)\end{array}$ & $\begin{array}{l}160 \\
(22.4 \%)\end{array}$ \\
\hline & Female & $\begin{array}{l}285 \\
(85.8 \%)\end{array}$ & $\begin{array}{l}269 \\
(70.4 \%)\end{array}$ & $\begin{array}{l}554 \\
(77.6 \%)\end{array}$ \\
\hline \multirow[t]{3}{*}{$\begin{array}{l}\text { Educational } \\
\text { Level }\end{array}$} & Elementary & $\begin{array}{l}95 \\
(28.6 \%)\end{array}$ & $\begin{array}{l}30 \\
(7.9 \%)\end{array}$ & $\begin{array}{l}125 \\
(17.5 \%)\end{array}$ \\
\hline & High school & $\begin{array}{l}121 \\
(36.4 \%)\end{array}$ & $\begin{array}{l}111 \\
(29 \%)\end{array}$ & $\begin{array}{l}232 \\
(32.5 \%)\end{array}$ \\
\hline & University degree & $116(35 \%)$ & $241(63 \%)$ & $357(50 \%)$ \\
\hline \multirow[t]{4}{*}{ Marital Status } & Single & $139(41.9 \%)$ & $251(65.7 \%)$ & $390(54.6 \%)$ \\
\hline & $\begin{array}{l}\text { Married/ } \\
\text { Living } \\
\text { partner }\end{array}$ & $146(44 \%)$ & $88(23 \%)$ & $234(32.7 \%)$ \\
\hline & Separated & $39(11.7 \%)$ & $41(10.7 \%)$ & $80(11.2 \%)$ \\
\hline & Widow & $8(2.4 \%)$ & $2(0.5 \%)$ & $10(1.4 \%)$ \\
\hline
\end{tabular}

Note. $C P=$ clinical population; $G P=$ general population; $T S=$ total sample; $S D=$ standard deviation. 


\section{Translation of the GSES-12}

Permission to translate and use the GSES-12 was obtained from the original authors ${ }^{10}$. First, a native Spanish speaker who was aware of the objective of the GSES-12 translated it into Spanish. Then, a bilingual (Spanish-English) speaker who was not familiar with the GSES performed a back-translation. No discrepancies between the two versions were found.

\section{Measures}

General Self Efficacy Scale-12 (GSES-12) ${ }^{20}$. This scale has 3 factors: Initiative (willingness to initiate behavior), Effort (willingness to make an effort to complete the behavior), and Persistence (persevering to complete the task in the face of adversity). Internal consistency of the original scale was 0.64 for initiative, 0.63 for effort, and 0.64 for persistence. The total scale obtained a Cronbach's $\alpha$ of 0.69 .

Beck Depression Inventory II (BDI-II) ${ }^{25}$, 26. This inventory includes 21 items evaluating cognitive, behavioral, affective and somatic symptoms of depression. In the current sample, Cronbach's $\alpha$ was 0.89 .

State and Trait Anxiety Inventory (STAI) ${ }^{27,28}$. It is a self-administered questionnaire containing 40 items divided into 2 subscales that evaluate anxiety as trait and state. In the current sample, Cronbach's $\alpha$ were 0.90 for state and 0.64 for trait.

Rosenberg Self-esteem Scale (RSES) ${ }^{29}$, 30. This self-report instrument includes 10 items that evaluate self-esteem, self-worth, acceptability and confidence. Cronbach's $\alpha$ for this sample was 0.66 . 
Positive And Negative Affect Schedule (PANAS) ${ }^{31,32}$. This instrument includes 20 items that assess two dimensions of affect: positive and negative. Cronbach's $\alpha$ were 0.89 for positive affect and 0.82 for negative affect.

Life Orientation Test-revised (LOT-R $)^{33}$, 34. This instrument is used to assess generalized optimism, and it includes 10 items to be responded to on a 5point scale. Cronbach's $\alpha$ was 0.56 .

Quality of Life Index (QLI-Sp) ${ }^{35}$. It consists of 10 items that evaluate perceived well-being in different areas (physical, psychological/emotional, occupational functioning, interpersonal functioning, among others). Cronbach's $\alpha$ was 0.89 .

\section{Procedure}

The corresponding ethical committees approved the study and all participants provided voluntary and informed written consent. No specific inclusion and exclusion criteria were established, and no incentive was offered for participation.

Participants from the GP were recruited from the university community (students and relatives). The assessment protocol was applied collectively for students and individually for their relatives. Before the questionnaires were administered, demographic data were collected. Regarding participants from the $\mathrm{CP}$, people seeking treatment at SAP and at Previ Center were invited to participate. They filled out all the instruments individually in an assessment session. 
In order to evaluate test-retest reliability, the sample was contacted one month after the first administration of the GSES-12 and asked to complete it again, but only a total of 84 participants completed the retests.

\section{Data analysis}

The total sample $(\mathrm{N}=714)$ was randomly divided into two independent samples using SPSS, one for exploratory factor analysis (EFA; $n=$ 349) and one for confirmatory factor analysis (CFA; $n=365$ ). No statistical differences were found in the demographic characteristics of the two samples.

EFA was performed with SPSS software, version 20 (SPSS Inc., Chicago, Illinois). The suitability of the data for EFA was assessed using the Kaiser-Meyer-Olkin (KMO) and Bartlett sphericity tests. Additionally, the kurtosis and skewness of the items were analyzed to verify their normal distribution. A principal components analysis with Oblimin rotation was performed. CFA was performed on the second subsample to test the model in the EFA, using the EQS program, version 6.1. The following recommended goodness-of-fit indices were used: a corrected Satorra-Bentler chi-square (SB $\chi 2$ ), the Robust Comparative Fit Index (RCFI), and the Root Mean Squared Error of Approximation (RMSEA) with its confidence interval (90\% CI).

The descriptive statistics for the GSES-12 were calculated for the entire sample and for sample type (GP vs. CP), sex and age. Internal consistency and split half-reliability of the Spanish GSES-12 were assessed. In addition, the temporal stability of the data and the discriminant and convergent validity were also calculated, using correlation coefficients with 
measures of depression, anxiety, self-esteem, positive and negative affect, optimism, and quality of life.

\section{Results}

\section{Exploratory Factor Analysis}

Regarding the distribution of items in the GSES-12, it is worth mentioning that the univariate normality of data, determined by the asymmetry and kurtosis of the items, showed that asymmetry values ranged from -0.374 to 1.170 and kurtosis values from -0.997 to 1.731 . Considering that the KMO index was 0.89 and Bartlett's test ( $\chi 2$ value) of sphericity was $1587.69(p<0.00)$, the data were suitable for an EFA conducted with the first randomly extracted subsample. A principal axis factor analysis of the GSES12 items yielded 3 factors that were confirmed by a visual inspection of the scree-plot. Together, these factors accounted for $62.54 \%$ of the total variance. Inspection of the direct Oblimin rotation solution showed factors to be reasonable representations of the original GSES-12 subscales: Persistence (F1), Effort (F2) and Initiative (F3). As Table 2 shows, all the factor loadings were above 0.3 , and no items cross-loaded into other factors. The three subscales had moderate positive correlations with each other (see Table 2). The structure was equivalent to the one proposed by Bosscher and Smit ${ }^{19}$, and it was submitted to a CFA. 
Table 2. Pearson Correlations between factors and with the total score

\begin{tabular}{lllll}
\hline & Initiative & Effort & Persistence & Total \\
\hline Initiative & 1 & & & \\
Effort & $0.447^{* *}$ & 1 & & \\
Persistence & $0.595^{* *}$ & $0.400^{* *}$ & 1 & 1 \\
Total & $0.795^{* *}$ & $0.804^{* *}$ & $0.817^{* *}$ & \\
\hline Note. ${ }^{* *} \mathrm{p}<.01$ & & &
\end{tabular}

\section{Confirmatory Factor Analysis}

CFA was used to test the 3 competing models: a model with a unifactorial structure (model 1), a model containing 3 uncorrelated firstorder factors (model 2), and a model containing 3 related first-order factors with one higher-order factor (model 3). This latter model agrees with our previous EFA analysis. As there was evidence of multivariate non-normality in the data (Mardia $=40.1774)$, the Robust Maximum Likelihood estimation method was used. Research has proposed a two-index criterion for assessing the adequacy of model fit: RCFI and RMSEA ${ }^{36}$.

Model 1 showed poor fit indices $\left[\mathrm{sbX}^{2}=354.0782 ; \mathrm{df}=54 ;(\mathrm{p}<0.001)\right.$; $\mathrm{RCFI}=0.703 ;$ RMSEA $=0.124 ; 90 \% \mathrm{CI}=.111-.136]$, while models 2 and 3 seemed to fit the data well. The $\mathrm{X}^{2}$ was significant in both models (model 2: $\mathrm{X}^{2}$ $(d f=54)=260.0832, p<0.00$; model 3: $\operatorname{sbX}^{2}=75.2713 ; d f=51(p<0.01)$. The RMSEA showed a better fit for model 3 (RMSEA $=.036$ 90\% CI= .016-053) than for model 2 (RMSEA =.103; 90\% CI=0.90-0.115). The RCFI confirmed a better fit of model $3(\mathrm{RCFI}=0.976)$ than model $2(\mathrm{RCFI}=0.796)$. The fit was 
consistently better for the higher-order model than for the other two models tested. Table 3 shows item-scale correlations for the EFA and CFA of the first validation study for the GSES-12 in the Spanish language.

Table 3. Mean and SD for items, sub-scales, total score and final factor solution of the Spanish GSES-12

\begin{tabular}{|c|c|c|c|c|c|}
\hline \multirow[t]{3}{*}{ Items } & \multirow{3}{*}{$\begin{array}{l}\text { Mean } \\
\text { (SD) }\end{array}$} & \multirow{3}{*}{$\begin{array}{l}\text { Initiative } \\
\text { F3 }\end{array}$} & \multicolumn{2}{|l|}{ EFA } & \multirow[t]{3}{*}{ CFA } \\
\hline & & & Effort & Persistence & \\
\hline & & & F2 & F1 & \\
\hline Item 1 & $3.98(.90)$ & .780 & -.230 & .280 & .750 \\
\hline Item 2 & $4.05(.95)$ & .844 & -.140 & .149 & .792 \\
\hline Item 3 & $4.00(.93)$ & .713 & -.194 & .341 & .824 \\
\hline Item 4 & $3.37(1.05)$ & .035 & .676 & -.313 & .475 \\
\hline Item 5 & $3.51(1.08)$ & -.300 & .669 & -.290 & .694 \\
\hline Item 6 & $3.12(1.15)$ & -.294 & .716 & .001 & .671 \\
\hline Item 7 & $3.26(1.14)$ & -.054 & .736 & -.117 & .575 \\
\hline Item 8 & $2.81(1.22)$ & -.386 & .645 & -.148 & .668 \\
\hline Item 9 & $3.89(.96)$ & .084 & -.075 & .777 & .514 \\
\hline Item 10 & $4.00(1.06)$ & .295 & -.184 & .747 & .782 \\
\hline Item 11 & $3.64(1.04)$ & .206 & -.196 & .687 & .771 \\
\hline Item 12 & $3.61(1.18)$ & .370 & -.262 & .611 & .782 \\
\hline Initiative & $12.01(2.39)$ & & & & \\
\hline Effort & $16.10(4.08)$ & & & & \\
\hline Persistence & $15.14(3.34)$ & & & & \\
\hline Total & $43.23(7.96)$ & & & & \\
\hline
\end{tabular}




\section{Descriptive statistics}

Table 3 shows the means and standard deviations of the Spanish GSES-12 items and factors obtained in the entire sample. The means and standard deviation values of the GSES subscales obtained in the subsamples of population, sex and age are displayed in Tables 4 and 5. Significant differences in all self-efficacy scores were found between the GP and CP subsamples. GP showed more willingness to initiate, invest effort and use persistence in completing a task in the face of adversity than CP. Moreover, persistence and total score showed a medium-high effect size (see Table 4). No significant differences were found between men's and women's scores (Initiative: $t=0.388, p=0.698$; Effort: $t=0.860, p=0.390$; Persistence: $t=1.427$, $p=0.154$; and Total: $t=1.190, p=0.234$ ) or between age groups on the total score and on the different subscales (Initiative: $f=0.751, p=0.522$; Effort: $f=$ 0.697, $p=0.554$; Persistence: $f=0.542, p=0.654$; and Total: $f=0.728, p=0.536$ ).

Table 4. Descriptive statistics of the subscales and total score of the Spanish GSES-12 regarding population

\begin{tabular}{lllll}
\hline Population & $\begin{array}{l}\text { GP } \\
\text { Mean(SD) }\end{array}$ & $\begin{array}{l}\text { CP } \\
\text { Mean(SD) }\end{array}$ & Cohen`s $\boldsymbol{t}$ \\
\hline Initiative & $12.32(1.89)$ & $11.65(2.82)$ & $3.803^{* *}$ & -0.279 \\
Effort & $16.94(3.66)$ & $15.11(4.32)$ & $6.104^{* *}$ & -0.457 \\
Persistence & $16.10(2.55)$ & $14.04(3.76)$ & $8.639^{* *}$ & $\mathbf{- 0 . 6 4 1}$ \\
Total & $45.37(6.55)$ & $40.80(8.77)$ & $8.001^{* *}$ & $\mathbf{- 0 . 5 9 5}$ \\
\hline Note. SD= standard deviation; Cohen $(1988)^{37}$ defined $d=0.2$ as a 'small' effect size, $d=0.5$ & & \\
as 'medium,' and $d=0.8$ as 'large';** $p<.01$ (bilateral)
\end{tabular}


Table 5. Descriptive statistics of the subscales and total score of the Spanish GSES-12 regarding sex and age

\begin{tabular}{lllll}
\hline & $\begin{array}{l}\text { Initiative } \\
\text { Mean(SD) }\end{array}$ & $\begin{array}{l}\text { Effort } \\
\text { Mean(SD) }\end{array}$ & $\begin{array}{l}\text { Persistence } \\
\text { Mean(SD) }\end{array}$ & $\begin{array}{l}\text { Total } \\
\text { Mean(SD) }\end{array}$ \\
\hline Sex & & & & \\
Male & $12.10(2.14)$ & $16.38(3.88$ & $15.50(3.07)$ & $43.98(7.36)$ \\
Female & $12.02(2.40)$ & $16.06(4.09)$ & $15.06(3.37)$ & $43.12(8.00)$ \\
\hline Age & & & & \\
$16-25$ & $11.98(2.24)$ & $15.99(3.95)$ & $15.22(3.16)$ & $43.19(7.75)$ \\
$25-35$ & $12.02(2.25)$ & $16.17(4.05)$ & $15.04(3.46)$ & $43.24(8.16)$ \\
$35-50$ & $12.23(2.52)$ & $16.70(4.03)$ & $15.31(3.33)$ & $44.18(7.91)$ \\
$50-65$ & $11.90(2.75)$ & $15.63(4.48)$ & $14.80(3.57)$ & $42.34(7.96)$ \\
\hline Note. SD= standard deviation. & & &
\end{tabular}

\section{Reliability: Internal consistency and test-retest}

The internal consistency coefficients for the subscales varied from excellent to good (Initiative= 0.83; Effort=0.77; Persistence $=0.80$; and Total=0.86) . The present data offer higher Cronbach's alpha coefficients for the three subscales than those from Bosscher and Smit's ${ }^{19}$ study. Additionally, splithalf reliability was calculated. GSES-12 items were randomly divided into two, showing an acceptable coefficient (0.88). With regard to time stability, the results indicate good test-retest reliability over a 1-month period $($ Initiative $=0.67 ;$ Effort $=0.74 ;$ Persistence $=0.84 ;$ and Total $=0.84)$. 


\section{Correlation analyses}

Correlation coefficients are summarized in Table 6. GSES-12 subscales were strongly associated with all the measurements, and negatively and significantly correlated with depression, anxiety (both state and trait) and negative affect. Positive and relevant correlations were found between the GSES-12 subscales and self-esteem, positive affect and quality of life. Optimism was only significantly correlated with Persistence.

Table 6. Correlation of Spanish GSES and measures of depression, anxiety, positive and negative affect, and quality of life.

\begin{tabular}{lcccccccc}
\hline & BDI & $\begin{array}{c}\text { STAI- } \\
\text { T }\end{array}$ & $\begin{array}{c}\text { STAI- } \\
\text { S }\end{array}$ & RSES & PA & NA & $\begin{array}{c}\text { LOT- } \\
\text { R }\end{array}$ & QLI \\
& & & & & & & & \\
\hline Initiative & $-.364^{* *}$ & $-.485^{* *}$ & $-.348^{* *}$ & $.411^{* *}$ & $.354^{* *}$ & $-.316^{* *}$ & .117 & $.354^{* *}$ \\
Effort & $-.197^{* *}$ & $-.385^{* *}$ & $-.304^{* *}$ & $.643^{* *}$ & $.502^{* *}$ & $-.308^{* *}$ & .058 & $.287^{* *}$ \\
Persistence & $-.502^{* *}$ & $-.539^{* *}$ & $-.493^{* *}$ & $.547^{* *}$ & $.547^{* *}$ & $-.514^{* *}$ & $.239^{* *}$ & $.489^{* *}$ \\
Total & $-.437^{* *}$ & $-.558^{* *}$ & $-.476^{* *}$ & $.656^{* *}$ & $.589^{* *}$ & $-.460^{* *}$ & .163 & $.470^{* *}$ \\
\hline
\end{tabular}

Note. BDI= Beck depression inventory; STAI-S/T, state trait anxiety inventory; RSES Rosenberg self-esteem scale; PA, positive and NA negative affect scale; LOT-R, list of optimism-revised; QLI, quality of life-Spanish; ${ }^{* *} p<.01 ;{ }^{*} p<.05$ (bilateral).

\section{Discussion}

The purpose of the present study was to explore the psychometric properties and factorial structure of the GSES-12 in a Spanish adult sample that included clinical and general populations.

Findings support the original 3-factor structure with one higher-order factor. The three-factor model obtained here suggests that 'initiative', 'effort' 
and 'persistence' are valid indicators of beliefs about one's competence. Results support the model proposed by Bosscher and Smit ${ }^{19}$ and the idea of an underlying construct of general self-efficacy, but they diverge from Scherbaum et al. $^{5}$, who found that the three general self-efficacy scales (GPSES, NGSE, and GSES) have a unidimensional model. However, it is important to note that the sample in that study was composed only of university students, and they filled out the original version of the scale (17 items). We would like to highlight that the label of 'persistence' could require further revision, and we propose renaming it as 'competence', since the content of this subscale seems to be more related to beliefs about the perception of one's own ability, and this term could describe the content of the items better.

Regarding the internal consistency, the values obtained were higher than those reported in the original version. The scale also showed moderate to high time stability indexes. This is the first study to analyze the test-retest reliability of the GSES-12, and the data support general self-efficacy as a stable construct.

When exploring differences according to sample type (GP vs. CP), sex, and age, there were only significant differences for groups. CP scored significantly lower than GP on the total score and the three subscales, and persistence was the scale with the biggest effect size. These results are quite relevant for the clinical use of the scale, as they support the idea that selfefficacy could be a key component in psychopathology and possibly in treatment response. 
Regarding criterion validity, significant correlations were found between the GSES-12 subscales and measures of depression, anxiety, selfesteem, positive and negative affect, optimism, and quality of life. These results are in line with previous studies that assessed the relationship between general self-efficacy, anxiety, depression, and self-esteem ${ }^{13,22}$.

The only dimension that did not correlate with all the GSES-12 subscales was optimism, which only correlated with Persistence, and this correlation was moderate. This finding supports the multidimensionality of the self-efficacy concept, suggested also by Bosscher and Smit ${ }^{19}$, and adds evidence to previous studies about the relationship between optimism and behavioral aspects such as persistence and coping 38 , 39. However, prior literature has also shown a positive and significant correlation between optimism and general self-efficacy (using the GSES) ${ }^{40}$, and Schweizer and $K^{\circ} \mathrm{ch}^{41}$ proposed that general self-efficacy could be a component of general optimism. According to the present results, optimism is only related to a facet of selfefficacy, but it has been highlighted that LOT-R obtained a low internal consistency value $(0.56)$ in our study. Therefore, more studies are needed in order to corroborate this finding.

This study presents limitations that should be taken into account. The first is the heterogeneous composition of the $\mathrm{CP}$, as participants with different psychological disorders were included, and the different psychopathologies and severity levels were not considered. The second limitation is that the GP included mainly university students. Further research should examine whether our results could be generalized to other samples. 
Moreover, taking into account the good psychometric properties of Chen's scale (NGSES) ${ }^{6}$ and the good results obtained in the present study with the GSES-12, it would be interesting for future studies to compare these two scales in general and clinical populations. Given that they have different factor structures, a comparison could help to specify the differential usefulness of each.

\section{Conclusions}

In conclusion, the present study demonstrates that the Spanish version of the GSES-12 is a valid and reliable measure for assessing general self-efficacy in general and clinical populations. Furthermore, it adds relevant information to the debate about the dimensional structure of general self-efficacy. Our results confirm the three dimensional structure of the GSES-12 proposed by Bosscher and Smit 19. Findings showed that there is sufficient evidence to support the construct validity of the scale. Furthermore, internal consistency and test-retest correlation were good, supporting the reliability of the Spanish version of the scale and its use in clinical and general Spanish populations.

\section{Acknowledgements}

This study was funded in part by the Spanish Ministry of Education, Culture and Sport, Projects ACTIOBE (PSI2011-25767), Excellence in Research Program PROMETEO II (Generalitat Valenciana. Conselleria de Educación, 2013/003) and 'CIBER of Physiopathology of Obesity Nutrition, an initiative of ISCIII (ISC III CB06 03/0052). 


\section{References}

1. Bandura A. Self-efficacy: Toward a Unifying Theory of Behavioral Change. Psychol Rev 1977; 84(2):191-215.

2. Bandura A. Self-Efficacy Mechanism in Human Agency. Am Psychol 1982; 37(2):122-147.

3. Bandura A, Locke E. Negative Self-Efficacy and Goal Effects Revisited. J Appl Psychol 2003; 88(1):87-99.

4. Judge T, Erez A, Bono J. The power of being positive: the relation between positive self-concept and job performance. Hum Perform 1998; 11(2/3):167-187.

5. Scherbaum C, Cohen-Charash Y, Kern M. Measuring General Self-Efficacy: A Comparison of Three Measures Using Item Response Theory. Educ Psychol Meas 2006; 66(6):1047-1063.

6. Chen G, Gully S, Eden D. Validation of a New General Self-Efficacy Scale. Organ Res Meth 2001; 4(1):62-83.

7. Judge T, Erez A, Bono J, Thoresen C. Are Measures of Self-Esteem, Neuroticism, Locus of Control, and Generalized Self-Efficacy Indicators of a Common Core Construct? J Pers Soc Psychol 2002; 83(3):693-710.

8. Stanley K, Murphy M. A comparison of general self-efficacy with selfesteem. Genet Soc Gen Psychol Monogr 1997; 123(1):79-99.

9. Chen G, Gully S, Eden D. General self-efficacy and self-esteem: toward theoretical and empirical distinction between correlated self-evaluations. $J$ Organ Behav 2004; 25(3):375-395. 
10. Sherer M, Maddux J, Mercandante B, Prentice-Dunn S, Jacobs B, Rogers R. The Self-Efficacy Scale: Construction and Validation. Psychol Rep 1982; 51:663-671.

11. Matto SK, Malhotra R. Self-efficacy Scale: Hindi translation and factor structure. Indian J Clin Psychol 1998; 25:154-158.

12. Yildirim F, Ilhan IO. The validity and reliability of the General SelfEfficacy scale Turkish form. Turk Psikiyatri Derg 2010; 21(4):301-308.

13. López-Torrecillas F, García J, Cañadas G, Ramírez I, De la Fuente E. Validity of Self-Efficacy Scale Scores for a Spanish Sample. Psychol Rep 2006; 98(2):437-450.

14. Laserna J, Castillo A, Peláez E, Navío L, Torres C, Rueda S, ... Pérez M. Alteraciones emocionales y variables moduladoras en familiarescuidadores de enfermos de Alzheimer. Psicol Conductual 1997; 5(3):365375.

15. Eden D, Aviram A. Self-Efficacy Training to Speed Reemployment: Helping People to Help Themselves. J Appl Psychol 1993; 78(3):352-360.

16. Sadowski C, Long C, Jenkins L. Does Substance Abuse Treatment Have Self-Schematic Effects? J Psychol 1993; 127(3):323-327.

17. Woodruff S, Cashman J. Task, Domain, and General Efficacy: A Reexamination of the Self-Efficacy Scale. Psychol Rep 1993; 72(2):423432.

18. Sherer M, Adams C. Construct Validation of the Self-Efficacy Scale. Psychol Rep 1983; 53(3):899-902.

19. Bosscher R, Smit J. Confirmatory factor analysis of the General SelfEfficacy Scale. Behav Res Ther 1998; 36(3):339-343. 
20. Bosscher R, Smit J, Kempen G. Algemene competentieverwachtingen bij ouderen: Een onderzoek naar de psychometrische kenmerken van de algemene competentieschaal. Ned Tijdschr Psychol 1997; 52(6):239-248.

21. Galenkamp H, Huisman M, Braam A, Deeg D. Estimates of prospective change in self-rated health in older people were biased owing to potential recalibration response shift. J Clin Epidemiol 2012; 65(9):978-988.

22. Jonker I, Sijbrandij M, Wolf J. Toward Needs Profiles of Shelter-Based Abused Women: Latent Class Approach. Psychol Women Q 2012; 36(1):3853.

23. Steunenberg B, Beekman A, Deeg D, Kerkhof A. Personality predicts recurrence of late-life depression. J Affect Disord 2010; 123(1):164-172.

24. Schwarzer R, Jerusalem M. Generalized Self-Efficacy scale. In Weinman J, Wright S. Johnston M, editors. Measures in health psychology: A user's portfolio. Causal and control beliefs. Windsor, UK: NFER-NELSON; 1995.

25. Beck AT, Steer RA, Brown GK. Manual for the beck depression inventory. The Psychological Corporation. San Antonio, TX; 1996.

26. Sanz J, Navarro ME, Vázquez C. Adaptación española del Inventario para la depresión de Beck-II (BDI-II): Propiedades psicométricas en estudiantes universitarios. Anal modif conducta 2003; 29(124):239-288.

27. Spielberger CD, Gorsuch R, Lushene RE Manual for the state-trait inventory. Consulting Psychologists, Palo Alto, California; 1970.

28. Seisdedos N. Cuestionario de ansiedad estado-rasgo. Adaptación española. Madrid: TEA; 1988. 
29. Baños RM, Guillén V. Psychometric characteristics in normal and social phobic samples for a Spanish version of the Rosenberg self-esteem scale. Psychol Rep 2000; 87(1):269-274.

30. Rosenberg, M. Society and the adolescent self-image. Princeton, NJ: Princeton University Press; 1965.

31. Watson D, Clark LA, Tellegen A. Development and validation of brief measures of positive and negative affect: the PANAS scales. J Pers Soc Psychol 1988; 54(6):1063.

32. Sandin B, Chorot P, Lostao L, Joiner TE, Santed MA, Valiente RM. Escalas PANAS de afecto positive y negative: Validación factorial y convergencia transcultural. Psicothema 1999; 11(9):37-51.

33. Perczek R, Carver CS, Price AA, Pozo-Kaderman C. Coping, mood, and aspects of personality in Spanish translation and evidence of convergence with English versions. J Pers Assess 2000; 74(1):63-87.

34. Scheier MF, Carver CS, Bridges MW. Distinguishing optimism from neuroticism (and trait anxiety, self-mastery, and self-esteem): a reevaluation of the Life Orientation Test. J Pers Soc Psychol 1994; 67(6):1063.

35. Mezzich JE, Ruipérez MA, Pérez C, Yoon G, Liu J, \& Mahmud S. The Spanish version of the quality of life index: presentation and validation. $J$ Nerv Ment Dis 2000; 188(5): 301-305.

36. $\mathrm{Hu} \mathrm{LT}$, Bentler PM. Cutoff criteria for fit indexes in covariance structure analysis: Conventional criteria versus new alternatives. Struct Equ Modeling 1999; 6(1):1-55. 
37. Cohen, J. (1988) Statistical power analysis for the behavioral sciences, 2nd ed. Hillsdale, NJ: Lawrence Earlbaum Associates.

38. Scheier MF, Carver CS. Optimism, coping, and health: assessment and implications of generalized outcome expectancies. Health psychol 1985; 4(3):219.

39. Solberg Nes L, Segerstrom SC. Dispositional optimism and coping: A meta-analytical review. Pers Soc Psychol Rev 2006; 10(3):235-251

40. Luszczynska A, Gutiérrez-Doña B, Schwarzer R. General self-efficacy in various domains of human functioning: Evidence from five countries. Int J Psychol 2005; 40(2):80-89.

41. Schweizer K, Koch W. The assessment of components of optimism by POSO-E. Pers Individ Dif 2001; 31(5):563-574 


\section{The contribution of future directed thinking to affect}

\section{dimensions: differences in general and clinical}

\section{populations}

Este artículo ha sido enviado para su publicación en The Journal of Psychology. Autores: Molinari, G., Dragomir-Davis, A. M., Enrique A, GarcíaPalacios A, Baños RM y Botella C. (submitted).

\section{Abstract}

Future-directed thinking is a core feature of mental disorders. Recent attempts were made to integrate dimensions of affect and cognition in the conceptualization of depression and anxiety. The present study seeks to explore a two-system cognitive-affective view in general and clinical populations and to determine the role of future expectancies in the prediction of positive and negative affect. 427 healthy volunteers and 203 clinical patients completed measures of affect, worry, hopelessness, anxiety, depression, and future expectancies. To explore the structure of cognitiveaffective correlates in depression and anxiety, all measures were subjected to an exploratory factor analysis (EFA). Regression analyses were conducted to determine which cognitive variables were predictive of high negative affect and low positive affect. The EFA yielded a negative and a positive affect factor, although the factorial structure differed for the two populations. Regression analysis showed that future expectancies were significant predictors of low positive affect and high negative affect in both populations. Differences were found in the clinical sample, as for patients 
with eating disorders the absence of positive expectancies was the only predictor of low positive affect. These findings have implications for the treatment of psychological disorders, reflecting the necessity to target changes in future expectancies.

Keywords: Future-directed thinking, Affect, Subjective Probability Task, Anxiety, Depression, Validation 


\section{Introduction}

Future-directed thinking represents a key characteristic of human behavior, motivating and driving people through virtually all the actions in the pursuit of their goals. As a core cognitive feature implicated in anxiety and depression, future-directed thinking received great attention, especially in the context of the cognitive theory of emotional disorders (Beck, 1976). One component of Beck's cognitive theory is the cognitive content-specificity hypothesis, which states that depression and anxiety are each characterized by unique cognitive content, with depression being characterized by pessimistic and self-critical cognitions, and anxiety by cognitions related to potential harm or danger (Clark \& Beck, 1989). Although the cognitive content-specificity hypothesis has been well-supported (e.g., Clark, Beck, \& Brown, 1989), more recent studies indicate that anxious cognitive content does not discriminate well between depression and anxiety (Beck \& Perkins, 2001; Beck, Perkins, Holder, Robbins, Gray, \& Allison, 2001). Another existing model that explains the shared and unique emotional features of depression and anxiety is the tripartite model of depression and anxiety (Clark \& Watson, 1991; Clark, Watson, \& Mineka, 1994; Watson, Clark, \& Carey, 1988; Watson \& Tellegen, 1985). The tripartite model argues that depression and anxiety are both characterized by increased levels of negative affect (NA), but that depression can be distinguished from anxiety by the presence of low positive affect (PA) and anxiety can be distinguished from depression by the presence of physiological hyperarousal.

More recently, attempts have been made to integrate these two models that explain the shared and unique emotional and cognitive features 
of depression and anxiety. However, in a study integrating the cognitive and emotional correlates of anxiety and depression, Beck and colleagues emphasized the inconsistency resulting from merging these two models: multiple studies found that anxious cognitive content is correlated with high NA, and according to the tripartite model, NA is a shared feature of depression and anxiety. This results in an inconsistency with the cognitive content-specificity hypothesis, which states that anxious cognitive content should be a unique feature of anxiety (Beck \& Perkins, 2001; Beck, Perkins, Holder, Robbins, Gray, \& Allison, 2001). Therefore, Beck and colleagues suggest that worry and hopelessness are more clearly linked to NA and PA, respectively, compared to more heterogeneous/global anxious and depressive cognitive content. More specifically, they suggest that worry is a cognitive correlate of high NA, and that hopelessness is a cognitive correlate of low PA. Consequently, worry and high NA are shared with both depression and anxiety, while hopelessness and low PA are characteristic only for depression and discriminate between depression and anxiety.

Similarly, MacLeod, Byrne, and Valentine (1996) explored the cognitive-affective correlates of depression and anxiety, including also a more specific aspect of cognition - future-directed thinking. The authors described positive and negative future-directed thinking within a broader cognitive-affective framework in order to conceptualize depression and anxiety. This framework consists of two distinct cognitive-affective systems that integrate dimensions of affect, orientations to the future, and specific future expectancies. According to MacLeod et al. (1996), there is a negative affect system consisting of negative affect (NA), worry, and negative 
expectancies for the future (NE), and a positive affect system consisting of positive affect (PA), low levels of hopelessness, and positive expectancies for the future (PE). In this study conducted with a student sample, both anxiety and depression have been associated with the negative affect system, while only depression has been associated with the positive affect system. Indeed, multiple studies have shown that future-directed thinking plays an important role in psychological disorders, and moreover that specific patterns of futuredirected thinking are linked to particular disorders: while anxiety disorders have been associated with an increased expectancy for negative future events, depression has been associated with both a decreased expectancy for positive future events and an increased expectancy for negative future events (MacLeod \& Byrne, 1996; MacLeod et al., 1996; MacLeod, Rose, \& Williams, 1993; Miranda, Fontes, \& Marroquín, 2008; Miranda \& Mennin, 2007).

Given their important role in the psychopathology of emotional disorders, biases in positive and negative future-directed thinking are often targeted in the treatment of these disorders, and studies are showing that interventions focusing on such cognitive biases can be efficacious (e.g., interventions focusing on generating alternative solutions may increase the expectancy for positive future events; exposure-based interventions challenge patients' expectancies, by providing opportunities to test and modify these expectancies) (Miloyan, Pachana, \& Suddendorf, 2013; Rief, Glombiewski, Gollwitzer, Schubo, Schwarting, \& Thorwart, 2015). Understanding the different patterns of future-directed thinking and affect associated with anxiety and depression is therefore crucial for the effective treatment of these disorders. 
The present study is a further attempt to integrate the cognitive and affective correlates of anxiety and depression, including a more specific set of cognitions related to the future (PE and NE), as did MacLeod and colleagues (1996). However, the sample used in MacLeod et al.'s study was composed of students, while in the present study the sample of participants was recruited from both general and clinical populations. Therefore, the present study sought to explore the structure of cognitive-affective correlates in depression and anxiety and to test the two-system view proposed by MacLeod et al. (1996), using both general and clinical Spanish-speaking populations. We hypothesized that the results for the general sample will resemble the ones obtained by MacLeod et al. in the student sample: their exploratory factor analysis revealed a negative affect factor consisting of NA, worry, anxiety, depression, and NE, and a positive affect factor consisting of PA, depression, hopelessness and PE. Although our analysis of the cognitive-affective correlates in the clinical sample is largely exploratory, we expect a higher loading of depression on the positive affect factor than the one obtained by MacLeod and colleagues, given that depression has a strong component of reduced PA. We also expect that NE will cluster with NA, worry, anxiety, and depression, and PE will cluster with PA, hopelessness (low levels), and depression (low levels).

We also wanted to explore the cognitive correlates of NA and PA and to compare the predictive ability of PE, NE, worry, and hopelessness, in the same line with Beck and colleagues' study (Beck et al., 2001). NE and PE are specific cognitions concerning the future that can be viewed as components of worry and hopelessness, respectively. By examining PE and NE in relation 
with affect, we hope to shed more light on the cognitive correlates of high NA and low PA. More specifically, we expected NE and PE to make unique contributions in predicting NA and PA, respectively, in addition to worry and hopelessness.

In order to test these hypotheses, our first aim was to validate the Spanish version of the measure to assess future-directed thinking, the Subjective Probability Task (SPT; MacLeod et al., 1996). The SPT assesses the tendency of having specific positive and negative future expectancies and since its development different adaptations of this instrument have been used in research (e.g., Hanssen, Peters, Vlaeyen, Meevissen, \& Vancleef, 2013; Stöber, 2000); in addition to being used in research on future-directed thinking in depression and anxiety, the SPT is also currently being employed to measure changes following a positive activity intervention aimed at increasing PE for the future (Meevissen, Peters, \& Alberts, 2011; Peters, Flink, Boersma, \& Linton, 2010). However, the SPT has been validated only in English-speaking samples and has been used only with student populations (MacLeod et al., 1996; Meevissen et al., 2011; Peters et al., 2010), which limits the generalizability of the results. This study hypothesized that the Spanish version of the SPT (from now on S-SPT) will yield the same factor structure as the original version, showing good psychometric properties. We also expected to find significant differences between general and clinical samples in PE and NE. 


\section{Method}

\section{Participants and procedure}

Total sample was composed of 630 participants. All participants were native Spanish speakers (82.5\% having Spanish nationality and $17.5 \%$ having Argentinean nationality). Among the participants, $9.2 \%$ had completed elementary studies; $22.5 \%$ had completed high school; $63.5 \%$ had completed university studies; and $4.8 \%$ did not indicate their educational level. The general population (GP) subsample consisted of 427 volunteers $(67.4 \%$ women, mean age 25.8 years). The clinical subsample (CP) consisted of 203 participants (88.2\% women, mean age 33 years) seeking treatment for anxiety and mood disorders (42.4\%) eating and personality disorders (40.9\%), and fibromyalgia (16.7\%). The participants with anxiety, mood, eating, and personality disorders were diagnosed by a clinical psychologist using diagnostic interviews: Anxiety Disorders Interview Schedule (ADIS-IV; Di Nardo, Brown, \& Barlow, 1994); Structured Clinical Interview for DSM-IV (SCID-I; First, Spitzer, Gibbon, \& Williams, 1996; SCID-II; First, Gibbon, Spitzer, Williams, \& Benjamin, 1997). The participants with fibromyalgia were diagnosed by a rheumatologist following the American College of Rheumatology criteria (Wolfe et al., 1990).

The corresponding ethical committees approved the study and all participants signed an informed-consent form and completed the measures either in paper-and-pencil format or online. No incentive was offered for participation and there were no other exclusion criteria.

To test the construct validity of the S-SPT, the total sample of 630 was randomly split into Sample A $(n=289)$ that was subjected to an exploratory 
factor analysis (EFA) and Sample B $(n=341)$ that was used to test models using confirmatory factor analysis (CFA). All statistical analyses were performed with SPSS software, version 20, and EQS program, version 6.1. Independent Samples T-Tests were conducted for all the measures used in the study, in order to examine the differences between general and clinical samples. To evaluate test-retest reliability, 78 (40 from GP and 38 from CP) participants were asked to complete the S-SPT one month after the first administration. In order to explore the structure of cognitive-affective correlates in depression and anxiety, all measures were subjected to a principal axis factoring EFA, using the entire sample $(n=630)$. The EFA was conducted separately for the general and clinical samples. Lastly, we conducted four regression analyses to determine which cognitive variables were predictive of high NA and low PA in general and clinical populations. In each analysis, all the variables were entered simultaneously into the regression equation.

\section{Translation of the SPT}

Permission to validate the SPT was granted by the original authors. A native Spanish speaker translated the items from English to Spanish. Then, a Spanish-English bilingual speaker who was not familiar with the SPT performed a back-translation from Spanish to English. No discrepancies between the two versions were found (see the S-SPT in Table 1).

\section{Measures}

Positive and negative affect

Affect was measured using the Spanish version of the Positive and Negative Affect Schedule (PANAS; Sandín, Chorot, Lostao, Joiner, Santed \& 
Valiente, 1999). The PANAS consists of two subscales, one measuring PA and one measuring NA. Each subscale consists of 10 items, which are scored on a 5-point Likert scale ranging from 1 (very slightly or not at all) to 5 (extremely). The PANAS subscales have been shown to have good internal and test-retest reliability (Watson, Clark, \& Tellegen, 1988). The internal consistency coefficients found for the PANAS subscales in the present study were .90 for NA and .92 for PA.

Worry

The Spanish version of the Penn State Worry Questionnaire (PSWQ; Sandín, Chorot, Valiente \& Lostao, 2009) was used to measure worry. The PSWQ assesses self-reported trait worry through 16 items scored on a 5point Likert scale ranging from 1 (not at all typical of me) to 5 (very typical of me). Of the 16 items composing the scale, 11 of them are negatively phrased and 5 are positively phrased. The PSWQ has been shown to have good psychometric properties (Meyer, Miller, Metzger, \& Borkovec, 1990). The internal consistency coefficient found for the PSWQ in the present study was .93.

\section{Hopelessness}

The Spanish version of the Beck Hopelessness Scale (BHS; Aguilar, Hidalgo, Cano, López, Campillo \& Hernández, 1995) was used to assess levels of hopelessness of the participants. The BHS consists of 20 true-false items that measure generalized negative expectancies about the future. Of the 20 items, eleven are negatively phrased and 9 are positively phrased. The BHS has also been shown to have good psychometric properties (Beck, Weissman, 
Lester \& Trexler, 1974). The internal consistency coefficient found for the BHS in the present study was .85.

Anxiety

Anxiety was measured with a Spanish version (adapted by our research group) of the Overall Anxiety Severity and Impairment Scale (OASIS; Norman, Hami Cissell, Means-Christensen \& Stein, 2006). OASIS is a brief instrument consisting of 5 items that measure the frequency and severity of anxiety, as well as the level of avoidance and work/school/home and social interference that anxiety produces. OASIS has likewise been found to have good psychometric properties (Norman et al., 2006). The internal consistency coefficient found for the OASIS in the present study was .90 .

Depression

Depression was measured with a Spanish version (adapted by our research group) of the Overall Depression Severity and Impairment Scale (ODSIS; Bentley, Gallagher, Carl \& Barlow, 2014). Like OASIS, ODSIS is a brief instrument consisting of 5 items that measure the frequency and severity of depression, as well as the level of avoidance and work/school/home and social interference that depression produces. ODSIS has been found to have good psychometric properties (Bentley et al., 2014). The internal consistency coefficient found for the ODSIS in the present study was .95.

\section{Future expectancies}

The Subjective Probability Task (SPT; MacLeod et al., 1996) was used as a measure of positive and negative future expectancies. The SPT consists of 30 items rated on a 7-point Likert scale on which participants have to estimate the probability of each item happening to them in the future, from 1 
(not at all likely to occur) to 7 (extremely likely to occur). The SPT is divided into two subscales: one consists of 20 items referring to negative outcomes (e.g. "You will have a serious disagreement with a good friend") and another one consists of 10 items referring to positive outcomes (e.g. "You will make good and lasting friendships"). Each of these subscales produces an independent score, with the score for the negative expectancies subscale varying from a minimum of 20 to a maximum of 140 , and the score for the positive expectancies subscale varying from a minimum of 10 to a maximum of 70. The SPT has been shown to have good internal consistency, with the authors reporting coefficients of .90 for the negative items and .86 for the positive items. The two subscales also showed good discriminant validity (MacLeod et al., 1996). The internal consistency coefficients found for the SPT subscales in the present study were .93 for negative expectancies and .87 for positive expectancies.

\section{Results}

\section{Validation of the S-SPT}

Exploratory Factor Analysis

The results obtained from the Kaiser-Meyer-Olkin test of sampling adequacy (KMO) (0.931) and Bartlett's test of sphericity was significant $\left(x^{2}\right.$ $(435)=4683.60, p<.00)$, indicating that the data were suitable for an EFA. The normal distribution of data was determined by the asymmetry (range from -1.233 to 1.427 ) and kurtosis (range from -1.114 to 1.582 ) values. In order to determine the number of factors to retain, a parallel analysis test (Horn, 1965) was conducted, confirmed by a visual inspection of the scree 
plot. Both methods suggested the extraction of two factors. A maximum likelihood factor analysis using an oblimin rotation yielded two factors that accounted for $48.71 \%$ of the total variance. The inspection of the oblimin rotation solution showed the factors to be accurate representations of the two original subscales of the SPT (see Table 1). The two factors were negatively correlated $(r=-.30)$. As Table 1 shows, all factor loadings were above .30 , and no items cross-loaded into the other factor.

\section{Table 1. Factor loadings of EFA and CFA for the S-SPT}

\begin{tabular}{|c|c|c|}
\hline & F1 & F2 \\
\hline 1. Tendrá un serio desacuerdo con un buen amigo & $.50(.52)$ & .17 \\
\hline 2. Las personas le admirarán & -.03 & $.66(.54)$ \\
\hline 3. Tendrá problemas de salud & $.52(.52)$ & -.07 \\
\hline 4. Tomará una decisión de la que se arrepentirá & $.75(.66)$ & .05 \\
\hline 5. Se sentirá incomprendido & $.69(.64)$ & .03 \\
\hline 6. Tendrá mucha energía y entusiasmo & -.04 & $.70(.72)$ \\
\hline 7. Le irá bien en las actividades que realice & -.02 & $.78(.74)$ \\
\hline 8. Le culparán por cosas que han salido mal & $.70(.65)$ & .01 \\
\hline 9. Logrará las cosas que se ha propuesto & -.09 & $.81(.80)$ \\
\hline 10. Será víctima de un delito & $.63(.46)$ & .24 \\
\hline 11. Alguien cercano a usted le rechazará & $.78(.68)$ & .04 \\
\hline 12. Las cosas no resultarán como había esperado & $.72(.67)$ & -.05 \\
\hline 13. No le gustará a los demás & $.69(.77)$ & -.09 \\
\hline 14. Estará en forma y gozará de buena salud & -.15 & $.56(.63)$ \\
\hline 15. La gente pensará que es monótono y aburrido & $.57(.68)$ & -.14 \\
\hline 16. Tendrá muchos buenos momentos con amigos & -.12 & $.59(.58)$ \\
\hline 17. Podrá soportar fácilmente la presión & -.05 & $.61(.55)$ \\
\hline 18. La gente pensará que es un fracaso & $.58(.77)$ & -.28 \\
\hline $\begin{array}{l}\text { 19. Su mente estará muy alerta y centrada en sus } \\
\text { objetivos }\end{array}$ & .20 & $.41(.45)$ \\
\hline 20. Sus amigos le excluirán & $.56(.71)$ & -.16 \\
\hline 21. Tendrá un accidente & $.68(.55)$ & .16 \\
\hline 22. Cometerá muchos errores & $.71(.69)$ & -.03 \\
\hline 23. Irá muy atrasado en su trabajo & $.56(.68)$ & -.15 \\
\hline 24. No podrá confiar en nadie & $.54(.62)$ & -.14 \\
\hline 25. Se sentirá cansado y apático & $.53(.67)$ & -.27 \\
\hline
\end{tabular}




\begin{tabular}{lcc}
\hline 26. Hará amistades buenas y duraderas & -.12 & $\mathbf{. 6 1}(.56)$ \\
27. La gente se burlará de usted &. $\mathbf{6 6}(.79)$ & -.19 \\
28. Decepcionará a una persona cercana & $.76(.71)$ & -.03 \\
29. Le gustará a las personas que conozca & -.03 & $\mathbf{. 6 6}(.61)$ \\
30. No podrá sobrellevar sus responsabilidades & $.38(.58)$ & -.24 \\
\hline
\end{tabular}

Note. Factor loadings of .30 or above are shown in bold. Factor loadings of CFA are shown in brackets. Factor $1=$ Negative Expectancies; Factor $2=$ Positive Expectancies. Positive items are shown in italics

\section{Confirmatory Factor Analysis}

Taking into account the results from the EFA, a CFA with the Robust Maximum Likelihood estimation method was used. This model agrees with our previous EFA analysis and with the original version of the questionnaire. The following recommended goodness-of-fit indices were used: a corrected Satorra-Bentler chi-square (S-B $\chi 2$ ), the Robust Comparative Fit Index (CFI), and the Root Mean Squared Error of Approximation (RMSEA) with its confidence interval $(90 \% \mathrm{CI})$. The fit indices indicated that the two-factor structure of the SPT was a good representation of the data: $\left(\operatorname{sb} \chi^{2}=\right.$ 1316.7365; $\mathrm{df}=405 ;(\mathrm{p}<0.001) ; \mathrm{CFI}=0.94 ; \mathrm{RMSEA}=0.08 ; 90 \% \mathrm{CI}=.07-.08)$.

\section{Reliability: Internal Consistency and Test-Retest}

The internal consistency coefficients of the two SPT subscales were excellent (NE $\alpha=.93$, and PE $\alpha=.87$ ). Results indicate good test-retest reliability $(\mathrm{NE}=.88, \mathrm{PE}=.83$ for the $\mathrm{GP} ; \mathrm{NE}=.80, \mathrm{PE}=.74$ for the $\mathrm{CP})$.

\section{Correlation Analyses}

Correlation coefficients for all the measures are presented in Table 2. Measures of NA, worry, hopelessness, anxiety, and depression correlated 
positively with the NE subscale, and negatively with the PE subscale; PA correlated negatively with the $\mathrm{NE}$ subscale, and positively with the $\mathrm{PE}$ subscale.

Table 2. Correlations between the S-SPT and measures of affect, worry, hopelessness, anxiety, and depression in a non-clinical population $(n=427$, above the diagonal) and clinical population $(n=203$, below the diagonal).

\begin{tabular}{|c|c|c|c|c|c|c|c|c|}
\hline & $\begin{array}{r}\text { SPT- } \\
\text { NE }\end{array}$ & $\begin{array}{r}\text { SPT- } \\
\text { PE }\end{array}$ & $\begin{array}{r}\text { PANAS- } \\
\mathbf{N}\end{array}$ & $\begin{array}{r}\text { PANAS- } \\
\text { P }\end{array}$ & PSWQ & BHS & OASIS & ODSIS \\
\hline SPT-NE & - & -.31 & .57 & -.35 & .37 & .57 & .49 & .52 \\
\hline SPT-PE & -.49 & - & -.37 & .70 & -.26 & -.58 & -.28 & -.36 \\
\hline $\begin{array}{l}\text { PANAS- } \\
\mathbf{N}\end{array}$ & .58 & -.40 & - & -.28 & .62 & .46 & .64 & .53 \\
\hline $\begin{array}{l}\text { PANAS- } \\
\text { P }\end{array}$ & -.42 & .66 & -.34 & - & -.30 & -.57 & -.32 & -.41 \\
\hline PSWQ & .28 & -.25 & .53 & -.27 & - & .32 & .56 & .37 \\
\hline BHS & .72 & -.69 & .55 & -.59 & .33 & - & .41 & .48 \\
\hline OASIS & .51 & -.41 & .62 & -.30 & .39 & .38 & - & .65 \\
\hline ODSIS & .58 & -.57 & .61 & -.46 & .31 & .50 & .72 & - \\
\hline
\end{tabular}

Note. All correlations are significant at $p<.01$.

SPT-NE = Subjective Probability Task-Negative Expectancies; SPT-PE = Subjective Probability Task-Positive Expectancies; PANAS-N = Positive and Negative Affect ScheduleNegative Affect; PANAS-P = Positive and Negative Affect Schedule-Positive Affect; PSWQ = Penn State Worry Questionnaire; BHS = Beck Hopelessness Scale; OASIS = Overall Anxiety Severity and Impairment Scale; ODSIS = Overall Depression Severity and Impairment Scale.

\section{Descriptive Statistics}

Table 3 shows the means and standard deviations of all the measures included in the study for each of the subsamples of the population (i.e., general and clinical). As expected, significant differences have been observed 
between the GP and $\mathrm{CP}$ samples regarding both $\mathrm{NE}$ and $\mathrm{PE}$, with the $\mathrm{CP}$ sample holding less PE and more NE. While the effect size found for the NE subscale was small to medium $(t(621)=-4.39, p<.001, d=-.36)$, the effect size found for the PE subscale was medium to large $(t(621)=9.80, p<.001, d$ $=.82$ ). Also, significant differences regarding all the other measures were found between GP and CP subsamples.

Table 3. Descriptive statistics for all the measures for general and clinical populations

\begin{tabular}{lcccc}
\hline & GP & CP & t & $\boldsymbol{d}$ \\
& $\mathbf{M}(\mathbf{S D})$ & $\mathbf{M}(\mathbf{S D})$ & & \\
\hline SPT-NE & $60.70(19.74)$ & $68.75(24.42)$ & $-4.39^{* *}$ & -0.36 \\
SPT-PE & $50.40(8.78)$ & $42.41(10.63)$ & $9.80^{* *}$ & 0.82 \\
PANAS-N & $19.85(7.45)$ & $25.34(8.30)$ & $-7.66^{* *}$ & -0.70 \\
PANAS-P & $33.08(7.27)$ & $25.32(8.60)$ & $10.83^{* *}$ & 0.97 \\
PSWQ & $52.17(13.21)$ & $60.92(11.68)$ & $-6.14^{* *}$ & -0.70 \\
BHS & $4.31(3.35)$ & $8.22(5.67)$ & $-6.29^{* *}$ & -0.84 \\
OASIS & $4.77(3.94)$ & $9.47(4.86)$ & $-11.44^{* *}$ & -1.06 \\
ODSIS & $3.15(3.95)$ & $7.32(5.35)$ & $-8.49^{* *}$ & -0.89
\end{tabular}

Note. $\mathrm{M}=$ mean; $\mathrm{SD}=$ standard deviation; $\mathrm{GP}=$ general population; $\mathrm{CP}=$ clinical population; ${ }^{* *} p<.001 ;{ }^{*} p<.05$. SPT-NE = Subjective Probability Task-Negative Expectancies; SPT-PE = Subjective Probability Task-Positive Expectancies; PANAS-P = Positive and Negative Affect Schedule-Positive Affect; PANAS-N = Positive and Negative Affect Schedule-Negative Affect; PSWQ = Penn State Worry Questionnaire; BHS = Beck Hopelessness Scale; OASIS = Overall Anxiety Severity and Impairment Scale; ODSIS = Overall Depression Severity and Impairment Scale.

Cohen (1988) defines $d=0.2$ as a "small" effect size, $d=0.5$ as "medium," and $d=0.8$ as "large. 
Exploratory Factor Analysis - Cognitive-Affective Correlates of Depression and Anxiety

All the measures used in the study were subsequently subjected to a principal axis factoring analysis using oblimin rotation, separately for the GP and $\mathrm{CP}$ (Table 4). In order to determine the number of factors to retain, a parallel analysis test (Horn, 1965) was conducted, confirmed by a visual inspection of the scree plot. Both methods suggested the extraction of two factors, consistent with previous results (MacLeod et al., 1996). First, the analysis for the GP produced one large factor and another factor with an eigenvalue above one, explaining together $70.5 \%$ of the variance. The first factor, a negative affect factor (NA-GP), had positive loadings from NA, worry, anxiety, depression, and negative expectancies. The second factor, a positive affect factor (PA-GP), had positive loadings from PA and positive expectancies and a negative loading from hopelessness. The two factors were negatively correlated $(r=-.54)$.

Similarly, the analysis for the CP produced one large factor and another factor with an eigenvalue above one, explaining together $71.1 \%$ of the variance. The first factor had positive loadings from hopelessness, depression, and NE, and negative loadings from PA and PE. The second factor had positive loadings from NA, worry, anxiety, and depression. For these reasons, we named the factors Lack of Positive Affect (LPA-CP), and Negative Affect (NA-CP), respectively. Generally, this factorial structure is the inverse of the one found for the GP. LPA-CP behaves as the inverse of factor PA-GP; however, depression and NE did not load on PA-GP, but did load on the LPACP. NA-CP mirrors NA-GP regarding all loadings, except for the NE, which 
failed to load on the NA-CP. The two factors found for the CP were positively correlated $(r=.62)$.

Table 4. Principal Axis Oblimin Rotated Solution and Factor Loadings for Affect, Cognition, Depression, and Anxiety Measures

\begin{tabular}{lrrrr}
\hline & \multicolumn{2}{c}{ GP } & \multicolumn{2}{c}{ CP } \\
\cline { 2 - 5 } & NA-GP & PA-GP & LPA-CP & NA-CP \\
& $(54.3 \%)$ & $(16.2 \%)$ & $(56.8 \%)$ & $(14.3 \%)$ \\
\hline PANAS-N & .80 & -.05 & .04 &. $\mathbf{8 5}$ \\
PANAS-P & -.04 & .79 & -.86 & .12 \\
PSWQ & .72 & .02 & -.03 & .53 \\
BHS & .24 & -.60 & .79 & .08 \\
OASIS & .95 & .12 & -.02 &. $\mathbf{8 2}$ \\
ODSIS &. $\mathbf{6 9}$ & -.05 &. $\mathbf{3 1}$ &. $\mathbf{5 6}$ \\
SPT-NE & .55 & -.22 &. $\mathbf{6 0}$ & .24 \\
SPT-PE & .10 &. $\mathbf{9 0}$ & -.82 & -.04
\end{tabular}

Note. Factor loadings of .30 or above are shown in bold. GP = General Population; $\mathrm{CP}=$ Clinical Population. NA = Negative Affect factor; PA = Positive Affect factor; LPA = Lack of Positive Affect. PANAS-N = Positive and Negative Affect Schedule-Negative Affect; PANAS-P $=$ Positive and Negative Affect Schedule-Positive Affect; PSWQ = Penn State Worry Questionnaire; BHS = Beck Hopelessness Scale; OASIS = Overall Anxiety Severity and Impairment Scale; ODSIS = Overall Depression Severity and Impairment Scale; SPT-NE = Subjective Probability Task-Negative Expectancies; SPT-PE = Subjective Probability TaskPositive Expectancies.

Prediction of Positive and Negative Affect

First, the PSWQ, BHS, PE, and NE were used to predict NA scores. In the general sample, the overall prediction of NA was significant, explaining $52 \%$ of the variance in NA scores $\left(R=.73, \mathrm{~F}_{(4,109)}=30.18, \mathrm{p}<.001\right)$. An examination of the individual predictors showed that the PSWQ $(\beta=.44, \mathrm{p}<$ $.001)$ and the $\mathrm{NE}(\beta=.31, \mathrm{p}<.001)$ made unique contributions to the prediction of NA. In the clinical sample, the explained variance of this model was $48 \%\left(R=.71, \mathrm{~F}_{(4,90)}=21.8, \mathrm{p}<.001\right)$, the PSWQ being the unique 
significant predictor of NA scores $(\beta=.42, \mathrm{p}<.001)$. Second, the cognitive variables were entered to predict PA scores. In the general sample, the overall prediction of PA was significant, explaining 55\% of the variance in PA scores $\left(R=.75, \mathrm{~F}_{(4,109)}=34.6, \mathrm{p}<.001\right)$. An examination of the individual predictors showed that the PE $(\beta=.56, \mathrm{p}<.001)$ and the BHS $(\beta=-.18, \mathrm{p}<$ .005) made unique contributions to the prediction of PA. In the clinical sample, the explained variance of this model was $52 \%\left(R=.74, \mathrm{~F}_{(4,90)}=25.87\right.$, $p<.001)$, the PE being the unique significant predictor of PA scores $(\beta=.55$, $\mathrm{p}<.001$ ). Examining more closely at these differences, we divided the clinical sample in two groups: patients suffering from anxiety and mood disorders, and those suffering from eating and personality disorders. We found differences in the prediction of PA. In the subsample of anxiety and mood disorders, the explained variance of the PA model was $60 \%\left(R=.77, \mathrm{~F}_{(4,47)}=\right.$ 16.26, $\mathrm{p}<.001)$, the PE $(\beta=.49, \mathrm{p}<.001)$ and the BHS $(\beta=-.32, \mathrm{p}<.005)$ being significant predictors. However, in the subsample of eating and personality disorders, the explained variance was $47 \%\left(R=.68, \mathrm{~F}_{(4,40)}=7.9, \mathrm{p}<.001\right), \mathrm{PE}$ being the unique significant predictor of PA scores $(\beta=.64, \mathrm{p}<.001)$.

The results of these regression analyses demonstrated that NE and PE have unique relationships with NA and PA, respectively. Moreover, regarding PA in clinical populations, although BHS and PE share a significant proportion of variance, PE had a unique relationship with PA, specially in the eating and personality disorders subsample. These results add information to the relationship between low PA and hopelessness and high NA with worry, incorporating into this framework the important role of future expectancies. 


\section{Discussion}

The present study aimed to further examine the cognitive-affective structure in depression and anxiety in general and clinical populations, and to explore the cognitive correlates of NA and PA. To do so, first we sought to analyze future-directed thinking in clinical and general populations and to study the psychometric properties and factorial structure of the S-SPT. The EFA conducted for the S-SPT items supported the original structure proposed by MacLeod et al., revealing two factors, namely negative expectancies and positive expectancies. The two factors were weakly and negatively correlated, implying that negative and positive expectancies are two separate and distinct dimensions, but related. CFA supported this structure. The internal consistency coefficients obtained for the two subscales of the S-SPT were excellent, rendering the SPT subscales reliable instruments for the sample used. These results are very similar to the ones reported by other authors (e.g., MacLeod et al., 1996; Meevissen et al., 2011; Peters et al., 2010). Test-retest reliability was good in both GP and CP. Regarding criterion validity, significant correlations have been found in the expected directions between the two subscales of the SPT (NE and PE), and measures of PA and NA, worry, hopelessness, anxiety, and depression. As expected, significant differences have been observed between GP and CP regarding both NE and PE. The effect size observed for the differences in PE was greater than the one observed for NE, reaching a medium-to-large value. This finding is of particular importance for clinical practice, suggesting that positive futuredirected thinking has an important role to play in the psychopathology and 
perhaps treatment of psychological disorders, and thus deserves as much attention, if not more, as negative future-directed thinking.

The two-system view proposed by MacLeod et al. was partially supported by the results obtained. First, the factor analysis conducted for the GP sample revealed two factors, a NA factor and a PA factor. The NA factor had loadings from negative affect, worry, anxiety, depression, and negative expectancies, and the PA factor had loadings from positive affect, hopelessness, and PE. These results largely resemble the ones obtained by MacLeod et al. in their study, with one difference. Although depression was expected to load on both factors, it loaded only on the NA factor and not on the PA factor. The theoretical ground suggests that depression has a strong component of reduced activity of the cognitive-affective system that mediates PA and expectancies for positive outcomes. This is why a higher negative loading on the PA factor was expected for depression. One possible explanation why this did not occur in the present study could be the instrument used to assess depression. ODSIS measures the severity of depression, and levels of avoidance and interference associated with depression, but it does not address core depressive symptoms such as loss of pleasure or interest. It is possible that an instrument that addresses the low PA component of depression would have shown the expected relation. Nevertheless, all the other variables loaded in the expected direction, as predicted by the theoretical body that supports the existence of two underlying cognitive-affective systems. These results corroborate the existing data on the presence of high NA in both anxiety and depression, along with its cognitive correlates (i.e., worry and NE). Moreover, the results 
reinforce the idea that hopelessness and PE are cognitive contents related only to PA, and are not shared with anxiety.

Second, the factor analysis conducted for the CP showed a completely different pattern than the one proposed by MacLeod et al. and the one found in the present study for the GP. The first factor reflected a lack of positive affect (LPA), while the second factor was a negative affect factor (NA). With positive loadings from hopelessness, depression, and NE, and negative loadings from PA and PE, this LPA factor reflects an inverse of the PA factor found for the GP. Considering this, the positive loading from depression on the LPA factor is consistent with the results obtained by MacLeod et al. Although small, this loading suggests that for the CP depression has a component of reduced positive affect. The positive loading from $\mathrm{NE}$ on the LPA factor is unexpected and inconsistent with previous findings, as well as the failure to load on the NA factor. These results could suggest a different pattern of NE in $\mathrm{CP}$, in which NE are more closely related to a lack of PA and to hopelessness rather than to increases of NA. It is not clear, however, why the factor related to PA is more potent than the one related to NA. It could indicate that individuals with a psychological disorder are characterized more by deficiencies in the PA system than in the NA system, or simply that the clinical sample used in the present study presented significantly more depressive or mixed depressive-anxious symptomatology than pure anxious symptomatology. These results are similar to the ones obtained in the study of Beck et al. (2001), conducted with a clinical sample composed primarily of patients with mood disorders and mixed depression-anxiety disorders. The factor analysis in Beck and colleagues' study revealed two factors, a large low 
positive affect/depression factor (loadings from PA, hopelessness, and depression) and a smaller negative affect/anxiety factor (loadings from NA, worry, anxiety, and depression). It appears that for mixed clinical populations, reductions in the PA system are more marked than increases in the NA system.

The results of the regression analyses suggest that $\mathrm{NE}$ and $\mathrm{PE}$ contribute to explaining NA and PA, respectively, in addition to worry and hopelessness. More specifically, in the GP sample, NA scores were significantly predicted by both worry and NE, and PA scores were significantly predicted by both hopelessness and PE. The results for the CP sample differed, NA scores being predicted only by worry. The fact that NE did not explain NA scores could be related to the unusual loading that NE had on the NA factor for the CP (loading on the PA factor, instead of the NA factor). Moreover, regarding PA in clinical populations, although BHS and PE share a significant proportion of variance, PE had a unique relationship with PA in the eating and personality disorders subsample. These findings suggest that specific expectancies towards the future help explain better the relationship of future-directed thinking with the affective dimensions of PA and NA, at least in the case of PE. The fact that PE was the only significant predictor of PA for the eating and personality disorders subsample is novel and unexpected, suggesting that low PA is better explained by a lack of PE towards the future, rather than a more general hopeless attitude towards the future.

The present study comes with limitations. One of them is the heterogeneity of the CP sample. A homogenous CP sample could give more 
insight into the relationship between patterns of future-directed thinking and specific psychological disorders, which in turn could reveal important aspects that, if implemented in a treatment protocol, could improve the treatment response for these disorders. The choice of the depression measure is another limitation of the study. Perhaps if a different instrument had been employed, then the results would have been even more consistent with the two-system view proposed by MacLeod et al.

\section{Conclusions}

The present study contributes to the study of psychopathology by being the first one that explores the two-system cognitive-affective view proposed by MacLeod et al. in a Spanish-speaking population and using a CP. Furthermore, it provides evidence that the S-SPT is a valid and reliable measure for assessing future-directed thinking in GP and CP. The S-SPT will also give the

opportunity to better measure the outcomes of positive activity interventions, which are beginning to show their great potential to improve individuals' wellbeing. Future research should explore the relationship between patterns of future-directed thinking and specific psychological disorders.

\section{References}

Aguilar, E., Hidalgo, M., Cano, R., López, J., Campillo, M., \& Hernández, J. (1995). Estudio prospectivo de la desesperanza en pacientes psicóticos de inicio: Características psicométricas de la escala de 
Desesperanza de Beck en este grupo. Anales de psiquiatría, 2(4), 121125.

Beck, A. T. (1976). Cognitive therapy and the emotional disorders. New York: New American Library.

Beck, A. T., Weissman, A., Lester, D., \& Trexler, L. (1974). The measurement of pessimism: the hopelessness scale. Journal of consulting and clinical psychology, 42(6), 861-865.

Beck, R., \& Perkins, T. S. (2001). Cognitive content-specificity for anxiety and depression: A meta-analysis. Cognitive Therapy and Research, 25(6), 651-663.

Beck, R., Perkins, T. S., Holder, R., Robbins, M., Gray, M., \& Allison, S. H. (2001). The cognitive and emotional phenomenology of depression and anxiety: Are worry and hopelessness the cognitive correlates of NA and PA?. Cognitive Therapy and Research, 25(6), 829-838.

Bentley, K. H., Gallagher, M. W., Carl, J. R., \& Barlow, D. H. (2014). Development and validation of the overall depression severity and impairment scale. Psychological Assessment, 26(3), 815-830.

Clark, D. A., \& Beck, A.T. (1989). Cognitive theory and therapy of anxiety and depression. In P.C. Kendall \& D. Watson (Eds.), Anxiety and depression: Distinctive and overlapping features (pp. 379-411). San Diego: Academic Press.

Clark, D. A., Beck, A. T., \& Brown, G. (1989). Cognitive mediation in general psychiatric outpatients: A test of the cognitive content-specificity hypothesis. Journal of Personality and Social Psychology, 56, 958-964. 
Clark, L. A., \& Watson, D. (1991). Tripartite model of anxiety and depression: Psychometric evidence and taxonomic implications. Journal of Abnormal Psychology, 100, 316-336.

Clark, L. A., Watson, D., \& Mineka, S. (1994). Temperament, personality, and the mood and anxiety disorders. Journal of Abnormal Psychology, 103, 103-116.

Cohen, J. (1988). Statistical power analysis for the behavioral sciences, 2 nd ed. Hillsdale, NJ: Lawrence Earlbaum Associates.

Di Nardo, P. A., Brown, T. A., \& Balow, D. H. (1994). Anxiety Disorders interview schedule for DSM-IV: Liftime version (ADIS-IV-L). New York: Graywind Publications Inc.

First, M. B., Spitzer, R. L., Gibbon, M., \& Williams, J. B.W. (1996). Structured Clinical Interview for DSM-IV Axis I Disorders, Clinician Version (SCIDCV). Washington, D.C.: American Psychiatric Press, Inc.

First, M. B., Gibbon, M., Spitzer, R. L., Williams, J. B. W., Benjamin, L. S. (1997). Structured Clinical Interview for DSM-IV Axis II Personality Disorders, (SCID-II). Washington, D.C.: American Psychiatric Press, Inc.

Hanssen, M. M., Peters, M. L., Vlaeyen, J. W., Meevissen, Y., \& Vancleef, L. M. (2013). Optimism lowers pain: Evidence of the causal status and underlying mechanisms. Pain, 154(1), 53-58.

Horn, J. L. (1965). A rationale and test for the number of factors in factor analysis. Psychometrika, 30(2), 179-185.

MacLeod, A. K., \& Byrne, A. (1996). Anxiety, depression, and the anticipation of future positive and negative experiences. Journal of abnormal psychology, 105(2), 286-289. 
MacLeod, A. K., Byrne, A., \& Valentine, J. D. (1996). Affect, emotional disorder, and future-directed thinking. Cognition \& Emotion, 10(1), 69-86.

MacLeod, A. K., Rose, G. S., \& Williams, J. M. G. (1993). Components of hopelessness about the future in parasuicide. Cognitive Therapy and Research, 17(5), 441-455.

Meevissen, Y., Peters, M. L., \& Alberts, H. J. (2011). Become more optimistic by imagining a best possible self: Effects of a two week intervention.Journal of behavior therapy and experimental psychiatry, 42(3), 371-378.

Meyer, T. J., Miller, M. L., Metzger, R. L., \& Borkovec, T. D. (1990). Development and validation of the Penn State Worry Questionnaire. Behaviour research and therapy, 28(6), 487-495.

Miloyan, B., Pachana, N. A., \& Suddendorf, T. (2014). The future is here: a review of foresight systems in anxiety and depression. Cognition \& emotion, 28(5), 795-810.

Miranda, R., Fontes, M., \& Marroquín, B. (2008). Cognitive content-specificity in future expectancies: Role of hopelessness and intolerance of uncertainty in depression and GAD symptoms. Behaviour Research and Therapy, 46(10), 1151-1159.

Miranda, R., \& Mennin, D. S. (2007). Depression, generalized anxiety disorder, and certainty in pessimistic predictions about the future. Cognitive Therapy and Research, 31(1), 71-82.

Norman, S. B., Hami Cissell, S., Means-Christensen, A. J., \& Stein, M. B. (2006). Development and validation of an overall anxiety severity and impairment scale (OASIS). Depression and anxiety, 23(4), 245-249. 
Peters, M. L., Flink, I. K., Boersma, K., \& Linton, S. J. (2010). Manipulating optimism: Can imagining a best possible self be used to increase positive future expectancies?. The Journal of Positive Psychology, 5(3), 204-211.

Rief, W., Glombiewski, J. A., Gollwitzer, M., Schubö, A., Schwarting, R., \& Thorwart, A. (2015). Expectancies as core features of mental disorders. Current opinion in psychiatry, 28(5), 378-385.

Sandín, B., Chorot, P., Lostao, L., Joiner, T. E., Santed, M.A. \& Valiente, R. M. (1999). Escalas PANAS de afecto positivo y negativo: Validación factorial y convergencia transcultural. Psicothema, 11(1), 37-51.

Sandín, B., Chorot, P., Valiente, R. M., \& Lostao, L. (2009). Validación española del cuestionario de preocupación PSWQ: Estructura factorial y propiedades psicométricas. Revista de psicopatología y psicología clínica, 14(2), 107-122.

Stöber, J. (2000). Prospective cognitions in anxiety and depression: Replication and methodological extension. Cognition and Emotion, 14, 725-729.

Watson, D., Clark, L. A., \& Carey, G. (1988). Positive and negative affectivity and their relation to anxiety and depressive disorders. Journal of Abnormal Psychology, 97, 346-353.

Watson, D., Clark, L. A., \& Tellegen, A. (1988). Development and validation of brief measures of positive and negative affect: The PANAS scales. Journal of Personality and Social Psychology, 54, 1063-1070.

Watson, D., \& Tellegen, A. (1985). Toward a consensual structure of mood. Psychological Bulletin, 98, 219-235. 
Wolfe, F., Smythe, H.A., Yunus, M.B., Bennett, R.M., Bombardier, C., Goldenberg, D.L., ... \& Sheon, R.P. (1990). The American College of Rheumatology 1990 criteria for the classification of fibromyalgia: report of the Multicenter Criteria Committee. Arthritis and Rheumatism, 33(2), $160-172$. 


\section{Assessment of positive affect regulation: validation of}

\section{the Spanish version of the Response to Positive Affect questionnaire in clinical and general samples}

Este artículo ha sido enviado para su publicación en la Revista Assessment. Autores: Molinari, G., Etchemendy, E., Herrero, R., Espinoza, M., Paniagua, D., Feldman, G. C., García-Palacios, A, Baños, R. M., y Botella, C. (submitted).

\section{Abstract}

Emotion regulation has been a topic of interest for clinicians, specially for the importance given to this construct in transdiagnostic approaches for emotional disorders. Research has primarily focused on the regulation of negative emotions rather than positive emotions. The Responses to Positive Affect (RPA) questionnaire is a self-report measure that assesses cognitive response-focused positive emotion regulation. This study examines the psychometric properties of the Spanish adaptation of the RPA in a sample of 1135 volunteers (general population: 735; clinical services: 400). Confirmatory factor analysis supported the three-factor structure: Self-focus, Emotion-focus and Dampening, and its factorial invariance in both subsamples. Correlations with measures of depression and positive functioning supported the validity of the RPA and the distinct nature of emotion and self-focused strategies. Our findings confirmed the incremental validity of the RPA to the most established measure to assess emotion regulation in predicting depression and quality of life. 
Keywords: Emotion regulation, Positive affect, Dampening, Positive

Rumination, Validation 


\section{Introduction}

Emotion regulation comprises processes that influence which emotions we have, when we have them, and how we experience or express these emotions (Gross, 1998). It is characterized by the activation of a goal to modify the emotion-generative process and involves one or more processes to influence emotion generation (Gross, Sheppes, \& Urry, 2011). Emotions can be down-regulated where the goal is to decrease a certain emotion response, maintained where the goal is to prolong a given emotional response, or up-regulated where the goal is to increase an emotional response (Sheppes \& Gross, 2002).

Recently, emotion regulation has been a topic of increasing interest for clinicians and researchers, especially in light of the importance given to this construct in transdiagnostic approaches for emotional disorders (Dillon \& Pizzagalli, 2009; Kring, 2008). From this perspective, disturbances in emotion regulation are associated with emotional disorders and could represent a core aspect in the development and maintenance of psychopathology (Werner \& Gross, 2010).

Existing research on emotion regulation has primarily focused on the regulation of negative emotions rather than positive emotions (Carl, Soskin, Kerns, \& Barlow, 2013), possibly reflecting the relatively greater emphasis given to negative emotions over positive emotions in the characterization of psychological disorders and etiological theories. Generally, most studies investigated the up and down-regulation of negative emotions, and to a lesser extent, the up-regulation of positive emotions, especially since the arrival of 
Positive Psychology and the documented benefits of positive emotions in well-being (Fredrickson \& Joiner, 2002). Down-regulation of positive emotions is an understudied topic in research for emotional disorders. Recently, attention has been drawn to the dampening of positive emotions, not only because of its clinical implications, but also for its impact on wellbeing (Quoidbach, Berry, Hansenne, \& Mikolajczak, 2010). In this sense, studies have showed that dampening positive affect was related to low selfesteem, an increase of rumination on negative affect and depressive symptoms (Bryant, 2003; Nolen-Hoeksema \& Davis, 2004; Wood, Heimpel, Michela, 2003).

The predominance of studies focusing on the regulation of negative emotions is also manifested in the number of instruments developed to measure emotional regulation processes. While there are several instruments to assess regulation processes of negative emotions, the number of instruments oriented to positive emotions is significantly lower (for an extended review see Carl, Soskin, Kerns, \& Barlow, 2013).

In this sense, the Responses to Positive Affect questionnaire (RPA, Feldman, Joormann \& Johnson, 2008) is one of the first self-report measures to assess three cognitive response-focused positive emotion regulation strategies: Self-focused positive rumination (eg. thoughts like "I am achieving everything"), Emotion-focused positive rumination (eg. thoughts about how happy you feel), and Dampening (eg. thoughts like "I don't deserve this"'). While the first two strategies attempt to enhance or maintain positive mood once it is experienced, the dampening strategy focus on decreasing or eliminating the intensity and duration of positive affect. There has been some 
controversies regarding the distinct nature of emotion-focused and selffocused strategies. Some studies have suggested that because of the high correlation of these two factors, they should be considered as one dimension of positive rumination for the sake of conceptual and analytical parsimony (Bijttebier, Raes, Vasey, \& Feldman, 2012; Nelis, Luyckx, Feldman, Bastin, Raes, \& Bijttebier, 2016). However, most of the validations that have been developed so far, have replicated the 3-factor structure of the scale. There are validations of this measure in Dutch (Raes, Daems, Feldman, Johnson \& Van Gucht, 2010), Swedish (Engh \& Olofsson, 2011), Korean (Kim \& Kwon, 2014), Chinese (Yang \& Guo, 2014), and also a version of the RPA for children has been developed (Bijttebier, Raes, Vasey, \& Feldman, 2012).

In terms of the use of this measure for clinical purposes, results indicated that compared with control participants and people with major depressive disorder, individuals with bipolar disorder demonstrated greater emotion-focused rumination to positive affective states (Johnson et al., 2008; Shapero et al., 2015). Moreover, people with bipolar disorder reported more dampening responses to positive affect than did control participants (Edge et al., 2013; Shapero et al., 2015). In community samples, results indicated that current and formerly depressed individuals engage in dampening strategies in response to positive affect (Nelis, Holmes, \& Raes, 2015; Werner-Seidler, Banks, Dunn, \& Moulds, 2013). Similarly, in cross-sectional analyses in nonclinical samples, depressive symptoms were associated with more dampening responses to positive mood states and less positive rumination; whereas differences in self-focused and emotion-focused positive rumination were related to hypomania symptoms (Feldman, Joormann \& Johnson, 2008; 
Nelis et al., 2016). In addition, scales of the RPA have been shown to prospectively predict depression symptoms in non-clinical samples of adults (Raes, Smets, Nelis, \& Schoofs, 2012) and symptoms of depression and hypomania in children (Bijttebier, Raes, Vasey, \& Feldman, 2012).

Although a growing body of literature has begun to demonstrate the differentiated role of positive affect regulation in psychological disorders, there are some important limitations in the generalizability of these findings to broader clinical populations. In a recent review of studies where the RPA has been validated or administered (Nelis et al., 2016), very few examined responses to positive affect among individuals diagnosed with mood disorders via a clinical interview. Little is known about how these strategies function in emotional disorders beyond major depressive disorder or bipolar disorders. Furthermore, none of the studies in this review examined responses to positive affective states among more patients seeking treatment recruited in clinical settings.

The aim of the present study is to test the psychometric properties of the RPA in two Spanish speaking samples: clinical patients and community based adults, and to demonstrate how the scale performs in these two different populations. Although the RPA has been used with clinical patients, its factorial invariance in diverse clinical samples has not been tested. Moreover, we want to further examine its construct validity. Specifically, we sought to replicate previous reported findings assessing the association of the RPA scales with measures of depression (Nelis et al., 2016), positive and negative affect (Raes et al., 2010), and quality of life as a form of psychological well-being (Quoidbach et al., 2010). We also sought to extend 
the existing literature by examining the association of the RPA with the most widely used measure of emotion regulation, the Emotion Regulation Questionnaire (ERQ, Gross \& Josh, 2003), as well as three measures reflecting positive and negative expectancies for the future (hopelessness, optimism, and hope). We hypothesized that the Spanish RPA would evidence the same three factor structure as the original version and adequate internal consistency in both general and clinical samples. Taking into account results from previous research assessing emotion regulation in psychological disorders, we hypothesized that dampening positive emotions would be significantly correlated with distress measures (depression, hopelessness, negative affect) and ERQ suppression scale, and positive rumination would be significantly associated with well-being measures (quality of life, positive affect) and positive expectancies (Nelis et al., 2016; Raes et al., 2010; Quoidbach et al., 2010). A final purpose of this study is to test the incremental validity of this measure. Given the established association between suppression and reappraisal of emotions, as measured with the ERQ, with depression symptoms and quality of life, and the emerging evidence linking dampening of positive emotions with depression and quality of life with positive rumination, it is important to determine if the RPA uniquely explains variance in measures of depression and quality of life. We expect the RPA to predict symptoms of depression and quality of life above and beyond the scales of the ERQ in general and clinical populations. 


\section{Method}

\section{Participants}

The total sample was composed of 1135 volunteers (832 Spanish and 303 Argentinean), 798 women and 337 men. 735 participant (473 women, age: $\mathrm{M}=24.89, S D=8.41$ range $=17-79$ ) comprised the subsample of general population, and 400 participants (325 women, age: $M=32.40, S D=14.69$ range $=18-71$ ) composed the subsample of patients with psychological disorders. 354 patients met criteria for emotional disorder and were recruited from the Psychological Support Service at Universitat Jaume I SAP-(Spain), specialized in emotional disorders, and 46 patients met criteria for eating disorders and were recruited from the Previ Clinical Psychology Centre (Spain), specialized in Eating Disorders and Personality Disorders.

\section{Translation of the RPA}

A native Spanish speaker, who was aware of the objective of the RPA, first translated the RPA to Spanish. Then, a bilingual in Spanish and English, who was not familiar with the RPA, performed a back-translation from Spanish to English. The final version was approved by one of the authors of the original English version of the RPA (G. Feldman).

\section{Measurements}

Responses to Positive Affect questionnaire (RPA; Feldman et al., 2008) is a questionnaire that assesses responses to positive affective states and consists of 17 items. Items are rated on a 4-point scale, ranging from 1 (almost never) to 4 (almost always). The original measure consists of three factor- 
analytically derived scales: Dampening, Self-focused positive rumination, and Emotion-focused positive rumination. Initial psychometric results with the original English version show adequate reliability and validity for the scales (e.g., Feldman et al., 2008). Discriminant validity has been supported in that the scale is uniquely related to risk for hypomania after controlling for other measures of impulsivity and responses to positive affect (Johnson \& Jones, 2009).

Beck Depression Inventory II (BDI-II, Beck, Steer \& Brown, 1996, Spanish version by Sanz, Navarro \& Vázquez, 2003): This inventory includes 21 items evaluating cognitive, behavioral, affective and somatic symptoms of depression in a 4-point scale. Items 1 to 13 assess symptoms that are psychological in nature, while items 14 to 21 assess physical symptoms. In the current sample, internal consistency coefficients was high, Cronbach's alpha, $\alpha=.90$

Beck Hopelessness Scale (BHS, Beck et al., 1974; Spanish version by Aguilar et al., 1995) is a 20 item self-report inventory which reflects negative expectancies in the respondent. The response format is dichotomous, requiring the respondent to state whether each item is either true or false in describing their attitude over the past week. To control for acquiescence, nine items are keyed false and 11 are keyed true. In the current sample, internal consistency coefficients was high, Cronbach's alpha, $\alpha=.80$

Positive and Negative Affect Schedule (PANAS, Watson, Clark \& Tellegen, 1988; Spanish version by Sandin et al. 1999). This is one of the most used self- 
report instruments for measuring positive and negative affect. It includes 20item evaluating positive (10 items) and negative (10 items) affect to be responded in a 5-point scale. In the present study the time-frame used to measure affect was "generally" (on average). In the current sample, internal consistency coefficient was high for both scales, being $\alpha=.90$ for positive scale and $\alpha=.88$ for negative scale.

Hope Scale (HS, Snyder, Irving, \& Anderson, 1991; Spanish version: Espinoza et al., 2016) measures Snyder's cognitive model of hope which defines hope as "a positive motivational state that is based on an interactively derived sense of successful agency (goal-directed energy), and pathways (planning to meet goals)" (Snyder, Irving, \& Anderson, 1991). The adult hope scale contains 12 items, eight items measure Hope state and four items are fillers. Participants respond to each item using a 8-point scale ranging from definitely false to definitely true. In the current sample, internal consistency coefficient was high $\alpha=.88$.

Emotional Regulation Questionnaire (ERQ, Gross \& John, 2003; Spanish version: Rodríguez-Carvajal, Moreno-Jiménez, \& Garrosa, 2006) is a 10-item scale designed to measure respondents' tendency to regulate their emotions in two ways: (1) Cognitive Reappraisal and (2) Expressive Suppression. Respondents answer each item on a 7-point Likert-type scale ranging from 1 (strongly disagree) to 7 (strongly agree). In the current sample, internal consistency coefficient was high for both scales, being $\alpha=.71$ for cognitive reappraisal and $\alpha=.75$ for expressive suppression. 
Quality of Life Index (QLI-Sp, Spanish version by Mezzich, Ruiperez, Pérez, Yoon \& Mahmud, 2000). It consists of 10 items evaluating physical wellbeing, psychological/emotional wellbeing, self-care and independent functioning, occupational functioning, interpersonal functioning, socialemotional support, community and services support, personal fulfillment, spiritual fulfillment, and overall quality of life on a 10-point scale. In the current sample, internal consistency coefficient was high, $\alpha=.92$.

Life Orientation Test-revised (LOT-R; Scheier, Carver \& Bridges, 1994; Spanish version: Perczek, Carver, Price \& Pozo-Kaderman, 2000). This is the most used self-report instrument to assess individual differences in generalized optimism, and it includes 10 items (but 4 of them are fillers) to be responded in a 5-point scale. Cronbach's alpha, $\alpha=.71$

\section{Procedure}

All participants filled out the questionnaires online. A link to the study was published in social networking websites dedicated to disseminate information of ongoing research projects, recent findings, news, courses, etc. Participants from the clinical sample were given access to the online survey. All participants were informed that the study was voluntary and confidential and gave informed consent of their willingness to participate. No monetary compensation was offered to participants. Before the survey was administered, demographic data and information regarding psychological problems were collected for trained psychologist using the MINI International Neuropsychiatric Interview (Lecrubier, et al., 1998). Participants were instructed that they would have to complete 
several psychological measures. In order to evaluate test-retest reliability, part of the sample (100 participants from the GP and 100 from the CP) was contacted 3 months after the first administration of the RPA and asked to complete it again. A total of 119 participants completed the retests (51 from the Clinical and 68 from the General population).

\section{Data analysis}

To study the internal structure of the scale we applied two different techniques: Exploratory and Confirmatory Factor Analysis (EFA and CFA). For this, the total sample $(\mathrm{N}=1135)$ was divided in two independent sample using SPSS. Before the EFA a parallel analysis based on minimum rank factor analysis (Timmerman, \& Lorenzo-Seva, 2011) was conducted to explore the number of factors. The EFA and the parallel analysis were conducted $(n=245)$ using the Factor software, version 10.1 (Lorenzo-Seva, \& Ferrando, 2013). The EFA was based on the matrix of polychoric correlation, Unweighted Least Squares (ULS) as the method for factor extraction and Direct Oblimin as factor rotation. The CFA was conducted $(n=890)$ using the MPlus program, version 7.0. The analysis was based on the polychoric correlation matrix and the Weighted Least Squares Means and Variance adjusted (WLSMV) estimation method under the Theta parameterization. The WLSMV estimator was chosen because the data of the present study were categorical, and simulation studies have shown the superiority of WLSMV estimator compared with maximum likelihood estimator (Beauducel \& Herzberg, 2006). The following recommended goodness-of-fit indices were used: Chisquare $(\chi 2)$, the comparative fit index (CFI), which compares the fit of the 
model to a null model and establishes the absence of relationships among the variables, and the weighted root mean square residual (WRMR). Root Mean Squared Error of Approximation (RMSEA) and its confidence interval (90\% CI) were included. The following criteria were used to indicate the fit of the CFA models to the data: CFI $\geq .90$ and RMSEA $\leq .08$ (Hu \& Bentler, 1999). Three models were tested based on the previous literature: (a) a Unidimensional model; (b) a Two factor model (Dampening and Positive rumination (including Emotion-focus items and Self-Focus items); and (c) a Three Factor model, which represents the three hypothesized factors observed in the original RPA psychometric studies: Dampening, Emotionfocus and Self-Focus. This last model was composed by two related factors (Emotion-focus and Self-Focus) and one independent factor (Dampening). Once the best fitting model was identified, an invariance test (factorial invariance) was performed to evaluate the level of measurement invariance across the general population sample and the clinical sample with patients suffering from psychological disorders. The invariance of the structure, factors loadings, intercepts/thresholds and residual variances were tested following the guidelines presented in Millsap, \& Yun-Tein (2004), Brown (2006) and Dimitrov (2010). To test the invariance level between nested models both the difference between the $\chi^{2}$ statistics and the CFI difference were used. We used both a significant $\Delta \chi^{2}$ and CFI decrease greater than -.01 as a criterion to reject the null hypothesis of invariance (Cheung, \& Rensvold, 2002).

To test the factorial invariance two CFAs were performed in both samples. After the good fit of both factor structures, four invariance models 
were calculated. The first model (M1) aimed to test the Configural Invariance using the following steps: 1) For each factor, the factor loading of one marker variable was fixed. Other factor loadings were freely estimated across groups. 2) Two thresholds were constrained in marker variables and one threshold was constrained in other variables. 3) The unique variances of the first group were fixed as 1 . The unique variances of other groups are freely estimated. 4) The factor covariance matrices (variances and covariances) of all groups were freely estimated. 5) The factor means of the first group were fixed as 0 . The factor means of the other groups were freely estimated. The second model (M2) aimed to test the weak invariance (metric invariance). The model constrained the factor loadings across groups. The third model (M3) aimed to test the strong invariance (scalar invariance). The model constrained the thresholds across groups. The fourth model (M4) aimed to test the strict measurement invariance (uniqueness invariance) constraining the unique variances across groups.

The descriptive statistics of the total score for the RPA, its scales and all measures used in the study were calculated for the entire sample and for sample size type (GP vs. CP). In addition, Student's t-test were calculated to evaluate differences between groups. Internal consistency of the Spanish RPA scales was assessed using Cronbach's alpha coefficient. This coefficient varies from 0 to 1; the higher the value, the better the reliability. Temporal stability of the data, as well as construct validity, was also assessed using Pearson correlation coefficient analysis with measures of depression, hopelessness, emotion regulation, positive and negative affect, optimism, hope and quality 
of life. In order to be able to compare both groups (GP vs CP) $\mathrm{r}^{2}$ scores were transformed using Z-scores (Fisher, 1915, 1921).

Also, the relation between RPA and the ERQ was analyzed. Two separate hierarchical multiple regressions were conducted for each outcome: depression and quality of life, for both populations separately. In each regression analysis, ERQ scales were entered during the first step to control for their potential confounding effects. RPA scales were entered in the second block.

\section{Results}

\section{Exploratory factor analysis of the Spanish version of the RPA}

The results from the parallel analysis suggested two dimensions. The EFA performed was forced to have those two factors. Factor loadings are shown in the Table 1. 
Table 1. RPA factor loadings from the exploratory confirmatory factor analysis

\section{Dampening Positive \\ Rumination}

1. Piensas en lo feliz que te sientes

(Think about how happy you feel)

$-.045$

.545

2. Piensas en lo fuerte que te sientes

(Think about how strong you feel)

.661

3. Piensas en las ganas que tienes de hacer de todo

(Think about how you feel up to doing everything)

4. Notas cómo te sientes lleno de energía

(Notice how you feel full of energy)

5. Saboreas ese momento

(Savor this moment)

6. Piensas: "mi golpe de suerte terminará pronto"

(Think "My streak of luck is going to end soon")

7. Piensas: "no merezco esto"

(Think "I don't deserve this")

8. Piensas en las cosas que podrían ir mal

(Think about things that could go wrong)

9. Piensas en las cosas que no te han salido bien

(Think about things that have not gone well for you)

10. Te dices a ti mismo que estos sentimientos no durarán

(Remind yourself these feelings won't last)

11. Piensas: "esto es demasiado bueno para ser verdad"

(Think "This is too good to be true")

12. Piensas en lo difícil que es concentrarse

(Think about how hard it is to concentrate)

13. Piensas: "la gente pensará que estoy presumiendo"

(Think "people will think I'm bragging")

14. Piensas: "estoy consiguiendo todo"

(Think "I am achieving everything")

15. Piensas: "estoy a la altura de mi potencial" 
16. Piensas en lo orgulloso que te sientes de ti mismo

(Think about how proud you are of yourself)

17. Piensas: "estoy consiguiendo todo lo que tengo que hacer"

(Think "I am getting everything done")

$-.010$

.758

\section{Confirmatory factor analysis of the Spanish version of the RPA}

First, we tested a model with a mono-factorial structure (model 1). The second model tested was the EFA model: a Two-uncorrelated first-order factors model (model 2) that evaluates the following dimensions: 'Dampening' (i.e., the eight items from the Dampening factor as identified by Feldman et al., 2008) and 'Positive Rumination' (i.e., all nine items belonging to the Emotion-focused and Self-focused scales as identified by Feldman et al. (2008) but now loading on a single positive rumination factor). The third model tested was the original solution with 3 first-order factors, obtained by Feldman et al. (2008) in the original English RPA (model 3). The Three-factor model consisted of the following three factors and items: 'Dampening' (eight items), 'Emotion-focused positive rumination' (five items) and 'Self-focused positive rumination' (four items), with the two positive scales correlated.

The Chi-square test for difference testing, the CFI and the RMSEA indices showed a better fit for model 3 over the rest of competing models (see Table 2), and therefore this model was selected to test the factorial invariance. The factor loadings of all RPA items are shown in Figure 1. 
Table 2. Goodness-of-Fit Indexes for the Models comparison of the Spanish RPA

\begin{tabular}{|c|c|c|c|c|c|c|c|c|c|}
\hline \multirow[b]{2}{*}{ Model } & \multirow[b]{2}{*}{$\chi^{2}$} & \multirow[b]{2}{*}{ df } & \multirow[b]{2}{*}{$\begin{array}{c}p \\
(\Delta \chi 2)\end{array}$} & \multirow[b]{2}{*}{ CFI } & \multirow[b]{2}{*}{ TLI } & \multirow[b]{2}{*}{ WRMR } & \multirow[b]{2}{*}{ RMSEA } & \multicolumn{2}{|c|}{$\begin{array}{l}\text { 90\% CI for } \\
\text { RMSEA }\end{array}$} \\
\hline & & & & & & & & $\mathbf{L L}$ & UL \\
\hline Unidimensional & $4640.154^{* *}$ & 119 & & .62 & .56 & 5.37 & .21 & .20 & .21 \\
\hline $\begin{array}{l}\text { 2-correlated } \\
\text { Factors }\end{array}$ & $1371.655^{* *}$ & 118 & $<.001$ & .89 & .88 & 2.71 & .11 & .10 & .11 \\
\hline $\begin{array}{l}\text { 3-Factors, only } \\
\text { two correlated }\end{array}$ & $753.599^{* *}$ & 118 & $<.001$ & .94 & .93 & 2.54 & .08 & .07 & .08 \\
\hline
\end{tabular}

Note: $\chi 2=$ Chi-square fi statistic; $\mathrm{p}(\Delta \chi 2)=$ Chi-square test for difference testing; $\mathrm{CFI}=$ comparative fit index; SRMR = standardized root mean squared residual; WRMR = weighted least squares mean and variance adjusted; $\mathrm{CI}=$ confidence interval; $\mathrm{LL}=$ lower limit; $\mathrm{UL}=$ upper limit. ${ }^{*} \mathrm{p}<.001 ;{ }^{* *} \mathrm{p}<.001$
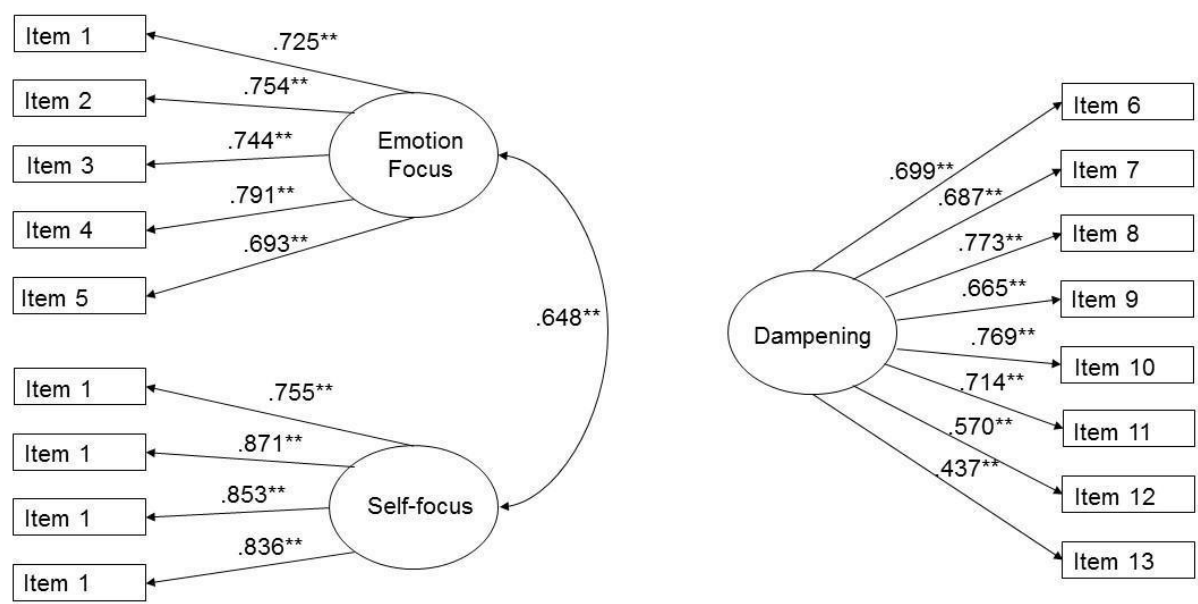

${ }^{* *} p<.001$

Figure 1. Item factor loadings of the RPA from CFA 


\section{Factorial Invariance across groups}

A forward multistage procedure was used to test factorial invariance of the Spanish RPA across GP and CP groups. A good baseline model for both groups was found (see Table 3). Then, four invariance models were calculated: configural invariance, invariance of the factor loadings (metric invariance), invariance of the items thresholds (scalar invariance) and invariance of the the residual variances across both groups (uniqueness invariance) were tested (see Table 4). Multi-sample analysis showed a strict factorial invariance of the scale, with invariant factorial loadings, partially invariant thresholds and invariant item residuals (except items 14, 15 and 17) (Model 4P). Besides, there is invariance of factor variances and covariances (structural invariance).

Table 3. Goodness-of-Fit Indexes for the Baseline Model in Two Groups

90\% CI for RMSEA

\begin{tabular}{cccccccc} 
Group & $\chi^{2}$ & df & CFI & WRMR & RMSEA & LL & UL \\
\hline Clinical & $350.63^{* *}$ & 118 & .94 & 1.67 & .08 & .07 & .09 \\
General & $452.76^{* *}$ & 118 & .95 & 1.85 & .07 & .06 & .08 \\
\hline
\end{tabular}

Note: $\chi 2=$ Chi-square fi statistic; $\mathrm{CFI}=$ comparative fit index; $\mathrm{WRMR}=$ weighted least squares mean and variance adjusted; RMSEA = root mean square error of approximation; $\mathrm{CI}$ = confidence interval; $\mathrm{LL}=$ lower limit; $\mathrm{UL}=$ upper limit. ${ }^{* *} \mathrm{p}<.01$ 
Table 4. Testing for invariance of the Factor Model across two groups

\begin{tabular}{|c|c|c|c|c|c|c|c|}
\hline Model & $\chi^{2}$ & df & Comparison & $p$ & CFI & $\Delta \mathrm{CFI}$ & RMSEA \\
\hline M1 - Configural Invariance & $827.40^{* *}$ & 237 & & & .94 & & .07 \\
\hline $\begin{array}{l}\text { M2 - Metric (Weak) } \\
\text { Invariance }\end{array}$ & $853.06^{* *}$ & 250 & M2-M1 & .09 & .94 & -.001 & .07 \\
\hline $\begin{array}{l}\text { M3 - Scalar (Strong) } \\
\text { Invariance }\end{array}$ & $907.31^{* *}$ & 281 & M3-M2 & .003 & .94 & -.002 & .07 \\
\hline $\begin{array}{l}\text { M3P - Partial Scalar } \\
\text { (Strong) Inv. }\end{array}$ & $901.09^{* *}$ & 280 & M3P-M2 & .19 & .94 & -.001 & .07 \\
\hline M4 - Strict invariance & $943.28^{* *}$ & 297 & M4-M3P & $<.001$ & .94 & -.003 & .07 \\
\hline $\begin{array}{l}\text { M4P - Partial Strict } \\
\text { invariance }\end{array}$ & $923.62^{* *}$ & 294 & M4P-M3P & .04 & .94 & -.001 & .07 \\
\hline
\end{tabular}

Note: $\chi 2=$ Chi-square fi statistic; CFI = comparative fit index; RMSEA = root mean square error of approximation; M1 = configural model; M2 = invariant factor loadings; M3 = invariant factor loadings and invariant thresholds; M3P = invariant factor loadings and partially invariant thresholds (first threshold of item 14 freed); M4 = invariant factor loadings, partially invariant thresholds and free item residuals; M4P = invariant factor loadings, partially invariant thresholds, invariant item residuals (except items 14, 15 and 17).

a. $\triangle \mathrm{CFI}<-.01$ (signal lack of invariance).

$* * \mathrm{p}<.01$

\section{Reliability: Internal consistency and test-retest}

All the scales show excellent values of internal consistency coefficients. Cronbach's alpha was .85 for Emotion-focus, .83 for Dampening, and .85 for Self-focus in the clinical sample; and .79 for Emotion-focus, .80 for Dampening, and .84 for Self-focus in the community sample. Regarding testretest reliability, Pearson correlations revealed moderate stability in the case of dampening ( $\mathrm{r}=.601)$, nevertheless thes respecting other two scales the results obtained show poor reliability $(\mathrm{r}=.482$ for Emotion-Focused and $r=.479$ for Self-Focused). 


\section{Differences between clinical and non-clinical groups}

Table 5 and 6 present the means, standard deviations and ranges of the Spanish RPA scale factors and all the measures used in the study. T-test was used to analyze possible differences between both groups. In terms of emotion regulation, results indicate that clinical population showed higher scores in the Dampening scale and lower scores in the Emotion-focus and Self-focus scales. Moreover, clinical patients used fewer strategies of cognitive reappraisal. General population showed higher scores on positive variables as positive affect, hope, optimism and quality of life, while clinical population were more depressed and presented higher levels of negative affect than community participants. No differences were found in Expressive Suppression and hopelessness between groups. The effect sizes (Cohen's $d$ ) for mean differences in RPA and ERQ scores between clinical and general samples were of small magnitudes, meanwhile differences in positive variables and distress measures were of medium and large magnitudes.

Table 5. Mean, standard deviation and range of the Spanish RPA factors in both groups

\begin{tabular}{|c|c|c|c|c|c|c|c|c|c|c|c|}
\hline & & \multicolumn{8}{|c|}{ CI } & \multicolumn{2}{|c|}{ CI } \\
\hline & & $\mathbf{N}$ & $\mathbf{X}$ & (sd) & LL & UL & $t$ & $p$ & $d$ & LL & UL \\
\hline \multirow{2}{*}{$\begin{array}{c}\text { Emotional } \\
\text { Focus }\end{array}$} & $\mathrm{CP}$ & 400 & 13.97 & 4.03 & 13.57 & 14.37 & - & \multirow{2}{*}{$<.001$} & - & \multirow{2}{*}{.65} & \multirow{2}{*}{1.59} \\
\hline & GP & 735 & 15.09 & 3.42 & 14.84 & 15.34 & 4.71 & & .30 & & \\
\hline \multirow[b]{2}{*}{ Dampening } & $\mathrm{CP}$ & 400 & 16.69 & 5.68 & 16.13 & 17.25 & \multirow[b]{2}{*}{4.65} & \multirow[b]{2}{*}{$<.001$} & \multirow[b]{2}{*}{.29} & \multirow{2}{*}{2.25} & \multirow[b]{2}{*}{-.91} \\
\hline & GP & 735 & 15.11 & 5.02 & 14.75 & 15.47 & & & & & \\
\hline \multirow{2}{*}{ Self-focus } & $\mathrm{CP}$ & 400 & 8.96 & 3.27 & 8.64 & 9.28 & \multirow{2}{*}{$\begin{array}{c}- \\
5.78\end{array}$} & \multirow{2}{*}{$<.001$} & \multirow{2}{*}{$\begin{array}{c}- \\
.34\end{array}$} & \multirow{2}{*}{.70} & \multirow{2}{*}{1.50} \\
\hline & $\mathrm{GP}$ & 735 & 10.06 & 3.28 & 9.82 & 10.30 & & & & & \\
\hline
\end{tabular}

Note: $\mathrm{CP}=$ clinical population; $\mathrm{GP}=$ general population 
Table 6. Mean, standard deviation and range of the ERQ scales, wellbeing and distress measures in both groups

\begin{tabular}{|c|c|c|c|c|c|c|c|c|c|c|}
\hline & \multicolumn{8}{|c|}{ CI } & \multicolumn{2}{|c|}{ CI } \\
\hline & & $\mathbf{X}$ & (sd) & LL & UL & $t$ & $p$ & $d$ & LL & UL \\
\hline \multirow{2}{*}{$\begin{array}{c}\text { Cognitive } \\
\text { Reappraisal }\end{array}$} & $\mathrm{CP}$ & 25.54 & 7.21 & 24.63 & 26.45 & \multirow{2}{*}{-2.13} & \multirow{2}{*}{.034} & \multirow{2}{*}{-.17} & \multirow{2}{*}{.09} & \multirow{2}{*}{2.29} \\
\hline & GP & 26.73 & 6.50 & 26.11 & 27.35 & & & & & \\
\hline \multirow{2}{*}{$\begin{array}{c}\text { Expressive } \\
\text { Suppression }\end{array}$} & $\mathrm{CP}$ & 12.86 & 5.59 & 12.16 & 13.57 & \multirow{2}{*}{-.54} & \multirow{2}{*}{.591} & \multirow{2}{*}{-.04} & \multirow{2}{*}{-.64} & \multirow{2}{*}{1.13} \\
\hline & GP & 13.11 & 5.59 & 12.57 & 13.64 & & & & & \\
\hline \multirow{2}{*}{$\begin{array}{l}\text { Positive } \\
\text { affect }\end{array}$} & $\mathrm{CP}$ & 25.47 & 8.23 & 24.06 & 26.88 & \multirow{2}{*}{-6.47} & \multirow{2}{*}{$<.001$} & \multirow{2}{*}{-.66} & \multirow{2}{*}{3.53} & \multirow{2}{*}{6.63} \\
\hline & GP & 30.55 & 7.04 & 29.91 & 31.19 & & & & & \\
\hline \multirow{2}{*}{$\begin{array}{l}\text { Negative } \\
\text { affect }\end{array}$} & $\mathrm{CP}$ & 23.40 & 7.67 & 22.08 & 24.71 & \multirow{2}{*}{5.44} & \multirow{2}{*}{$<.001$} & \multirow{2}{*}{.56} & \multirow{2}{*}{-5.43} & \multirow{2}{*}{-2.54} \\
\hline & GP & 19.41 & 6.58 & 18.80 & 20.01 & & & & & \\
\hline \multirow[b]{2}{*}{ Depression } & $\mathrm{CP}$ & 18.41 & 11.15 & 16.45 & 20.33 & \multirow[b]{2}{*}{8.97} & \multirow[b]{2}{*}{$<.001$} & \multirow[b]{2}{*}{.97} & \multirow[b]{2}{*}{-11.32} & \multirow[b]{2}{*}{-7.23} \\
\hline & GP & 9.14 & 7.54 & 8.44 & 9.84 & & & & & \\
\hline \multirow{2}{*}{ Hopelesness } & $\mathrm{CP}$ & 3.37 & 2.84 & 2.63 & 4.11 & & & & & \\
\hline & GP & 2.82 & 3.21 & 2.51 & 3.13 & 1.38 & (1) & .18 & -1.35 & .247 \\
\hline & $\mathrm{CP}$ & 44.03 & 10.74 & 42.12 & 45.95 & & & & & \\
\hline Hope & GP & 49.17 & 8.99 & 47.99 & 50.35 & T.J2 & .001 & .02 & 2.03 & 1.00 \\
\hline Quality of & $\mathrm{CP}$ & 60.24 & 16.96 & 55.65 & 64,22 & & & & & \\
\hline Life & GP & 72.61 & 16.20 & 70.45 & 74.78 & 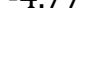 & .001 & 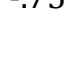 & 1.21 & 17.45 \\
\hline & $\mathrm{CP}$ & 19,81 & 4.62 & 18.96 & 20.66 & & & & & \\
\hline Optimism & GP & 21.36 & 5.17 & 20.76 & 21.97 & -2.95 & .003 & .52 & -0.32 & 2.59 \\
\hline
\end{tabular}

Note: $\mathrm{CP}=$ clinical population; $\mathrm{GP}=$ general population

\section{Correlation analyses}

Correlation coefficients between the Spanish RPA and measures of depression (BDI-II), hopelessness (BHS), positive and negative affect (PANAS), optimism (LOT-R), hope (HS) and quality of life (QLI-Sp) are summarized in Table 7. Also, the correlations between RPA and the ERQ are included. In both groups, there were significant -although small and 
moderate- correlations between Dampening, Emotion-focus and the different measures of wellbeing (QLI, positive affect), future expectancies (optimism, hope, hopelessness) and distress (BDI, negative affect), all of them in the expected direction. Similar findings were observed for ERQ and these RPA scales correlations. Dampening correlated positively to Expressive Suppression scale and negatively to Cognitive Reappraisal. Inversed valence correlations were found between these ERQ scales and Emotion-focused scale. However, in the general population group the associations between Self-focus and three measures (the two ERQ scales and optimism) were nonsignificant. In the case of clinical patients, no significant correlations were detected between Self-focus and three measures: negative affect, quality of life, and the ERQ Expressive Suppression scale.

Table 7. Correlation of Spanish RPA and measures of emotion regulation, depression, affect, future expectancies and quality of life

\begin{tabular}{|c|c|c|c|c|c|c|c|c|c|c|}
\hline $\begin{array}{c}\text { RPA } \\
\text { Subscales }\end{array}$ & & $\begin{array}{c}\text { ERQ- } \\
\text { R }\end{array}$ & $\begin{array}{l}\text { ERQ- } \\
\quad S\end{array}$ & BDI & BHS & PA & NA & LOT & HS & QLI \\
\hline \multirow[t]{2}{*}{ Self-focus } & $\mathrm{CP}$ & $.24^{* *}$ & .11 & $-.40^{* *}$ & $-.39^{* *}$ & $.52^{* *}$ & -.15 & $.35^{* *}$ & $.58^{* *}$ & .27 \\
\hline & GP & .06 & -.10 & $-.23^{* *}$ & $-.19^{* *}$ & $.44^{* *}$ & $-.19^{* *}$ & .08 & $.29^{* *}$ & $.31^{* *}$ \\
\hline \multirow[t]{2}{*}{ Dampening } & $\mathrm{CP}$ & $-.20^{* *}$ & $.24^{* *}$ & $.58^{* *}$ & $.72^{* *}$ & $-.29^{* *}$ & $.54^{* *}$ & & $-.24^{* *}$ & $-.40^{* *}$ \\
\hline & GP & $-.19^{* *}$ & $.22^{* *}$ & $.45^{* *}$ & $.266^{* *}$ & $-.20^{* *}$ & $.40^{* *}$ & $-.29^{* *}$ & $-.33^{* *}$ & $-.30^{* *}$ \\
\hline \multirow{2}{*}{$\begin{array}{l}\text { Emotion- } \\
\text { focus }\end{array}$} & $\mathrm{CP}$ & $.36^{* *}$ & $-.14^{*}$ & $-.39^{* *}$ & $-.47^{* *}$ & $.42^{* *}$ & $-.24^{* *}$ & $.39^{* *}$ & $.49^{* *}$ & $.41^{* *}$ \\
\hline & GP & $.11^{*}$ & $-.28^{* *}$ & $-.22^{* *}$ & $-.20^{* *}$ & $.48^{* *}$ & $-.16^{* *}$ & $.20^{* *}$ & $.40^{* *}$ & $.32^{* *}$ \\
\hline
\end{tabular}

Note: $\mathrm{CP}=$ clinical population; $\mathrm{GP}=$ general population. $\mathrm{ERQ}-\mathrm{R}=$ emotion regulation questionnaire, reappraisal subscale. ERQ-S= emotion regulation questionnaire, suppression subscale. BDI= Beck Depression Inventory. BHS= Beck Hopelessness scale. PA=positive affect. NA=negative affect. LOT= Life orientation test. HS= Hope scale. QLI= Quality of life inventory. Mean computed using Fisher's $r$-to- $z$ transformation. Correlations $\geq .35$ are in bold

$* * \mathrm{p}<.01$

$* \mathrm{p}<.05$ 


\section{Hierarchical regression analyses}

The purpose of these analyses was to test whether the scales of the RPA explained significant amount of variability in depression and quality of life above and beyond the established measure of emotion regulation, the ERQ. In both analyses, reappraisal and suppression scales of the ERQ were entered in block 1 . The three scales of the RPA were simultaneously entered in block 2. In predicting depressive symptoms in clinical patients (see Table 8 ), the RPA predicted $40 \%$ of the variability in symptoms above and beyond ERQ suppression strategy, with dampening predicting greater depression and self-focused positive rumination predicting less depression. When parallel analyses were conducted to predict quality of life, the RPA did not add incremental validity above of the $30 \%$ accounted by ERQ strategies.

In predicting depressive symptoms in general population (see Table 9), data showed that after controlling for variance explained by ERQ scales, dampening predicted $32 \%$ of the variability in symptoms. In the case of quality of life, dampening and self-focused positive rumination accounted for the $29 \%$ of the variance. 
Table 8. Hierarchical regression analysis for RPA subscales and ERQ predicting depression symptoms and quality of life in clinical patients

\begin{tabular}{|c|c|c|c|c|c|}
\hline \multicolumn{6}{|c|}{ Model: Depression } \\
\hline & $R^{2}$ & $\Delta R^{2}$ & B & SE & $\beta$ \\
\hline \multicolumn{6}{|l|}{ Step 1} \\
\hline Constant & & & 23.17 & 3.63 & \\
\hline Reappraisal (ERQ) & .15 & $.14^{* *}$ & -.41 & .12 & $-.30^{* *}$ \\
\hline Suppression (ERQ) & & & .51 & .16 & $.28^{* *}$ \\
\hline \multicolumn{6}{|l|}{ Step 2} \\
\hline Constant & & & 16.45 & 4.87 & \\
\hline Reappraisal (ERQ) & & & -.13 & .11 & -.09 \\
\hline Suppression (ERQ) & & & .28 & .13 & $.15^{*}$ \\
\hline Dampening (RPA) & .43 & $.40^{* *}$ & .83 & .14 & $.44^{* *}$ \\
\hline Self-focus (RPA) & & & -.75 & .31 & $-.20^{* *}$ \\
\hline Emotion-focus (RPA) & & & -.41 & .25 & -.14 \\
\hline
\end{tabular}

Step 1

Constant

$67.39 \quad 7.70$

Reappraisal (ERQ)

$\begin{array}{lllll}.32 & .30^{* *} & .48 & .24 & .23^{*}\end{array}$

Suppression (ERQ)

$\begin{array}{lll}-1.46 \quad .33 & -.51^{* *}\end{array}$

Step 2

Constant

64.6513 .59

Reappraisal (ERQ)

$.35 \quad .26 \quad .17$

Suppression (ERQ)

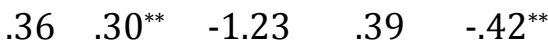

Dampening (RPA)

$\begin{array}{lll}-.41 & .42 & -.12\end{array}$

Self-focus (RPA)

$\begin{array}{lll}-.39 & .95 & -.06\end{array}$

Emotion-focus (RPA)

$.93 \quad .76 \quad .19$

Note: $\mathrm{ERQ}-\mathrm{R}=$ emotion regulation questionnaire, RPA= Responses to positive affect. ${ }^{*} p<.05 ;{ }^{* *} p<.01$ 
Table 9. Hierarchical regression analysis for RPA and ERQ predicting depression symptoms and quality of life in general population

\begin{tabular}{|c|c|c|c|c|c|}
\hline \multicolumn{6}{|c|}{ Model: Depression } \\
\hline & $R^{2}$ & $\Delta R^{2}$ & B & SE & $\beta$ \\
\hline \multicolumn{6}{|l|}{ Step 1} \\
\hline Constant & & & 10.98 & 2.22 & \\
\hline Reappraisal (ERQ) & .25 & $.25^{* *}$ & -.34 & .07 & $-.29^{* *}$ \\
\hline Suppression (ERQ) & & & .62 & .09 & $.44^{* *}$ \\
\hline \multicolumn{6}{|l|}{ Step 2} \\
\hline Constant & & & 11.80 & 3.39 & \\
\hline Reappraisal (ERQ) & & & -.27 & .07 & $-.23^{* *}$ \\
\hline Suppression (ERQ) & & & .49 & .09 & $.34^{* *}$ \\
\hline Dampening (RPA) & .34 & $.32^{* *}$ & .40 & .10 & $.24^{* *}$ \\
\hline Self-focus (RPA) & & & -.27 & .16 & -.11 \\
\hline Emotion-focus (RPA) & & & -.30 & .16 & -.12 \\
\hline \multicolumn{6}{|c|}{ Model: Quality of life } \\
\hline
\end{tabular}

\begin{tabular}{|c|c|c|c|c|c|}
\hline \multicolumn{6}{|l|}{ Step 1} \\
\hline Constant & & & 70.33 & 4.56 & \\
\hline Reappraisal (ERQ) & .19 & $.19^{* *}$ & .57 & .15 & $.24^{* *}$ \\
\hline Suppression (ERQ) & & & -1.08 & .18 & $-.39^{* *}$ \\
\hline \multicolumn{6}{|l|}{ Step 2} \\
\hline Constant & & & 60.39 & 6.87 & \\
\hline Reappraisal (ERQ) & & & .45 & .14 & $.19^{* *}$ \\
\hline Suppression (ERQ) & & & -.82 & .17 & $-.29^{* *}$ \\
\hline Dampening (RPA) & .31 & $.29^{* *}$ & -.59 & .20 & $-.18^{* *}$ \\
\hline Self-focus (RPA) & & & 1.14 & .32 & $.23^{* *}$ \\
\hline Emotion-focus (RPA) & & & .57 & .32 & .12 \\
\hline
\end{tabular}




\section{Discussion}

The present study was conducted to explore the psychometric properties of the RPA on a Spanish-speaking general and clinical population sample. Moreover, we aimed to validate the factorial invariance of the scale to test whether the measure functions differently in clinical and nonclinical samples. We also examined convergent and discriminant validity of the RPA with measures of depression, hopelessness, positive functioning and a widely used scale of emotion regulation.

The adaptation process of the RPA led to the confirmation of the three scales of this questionnaire in the Spanish population: Dampening, Self-focus and Emotion-focus. To test this structure, an EFA and a CFA of the RPA were conducted. Fit indices and factorial invariance analyzes showed that the 3 factor structure of the Spanish RPA was adequate not only for general but also for clinical populations. In this sense, factorial invariance tested (structural invariance) supports the use and comparison of the Spanish RPA outcomes in both populations. Items are measured with the same precision in each group, and therefore, any difference detected between them is only related to group specificities. In addition, the Spanish RPA showed to be a reliable measure in general and clinical samples (Cronbach's alpha ranging from .79 to .85$)$. The measure also exhibited test-retest stability $(r=.48-.60)$ coefficients that are consistent with previously observed values for three month test-retest-reliability of the RPA scales (e.g., $r=.41-.46$ in Bijttebier et al., 2012; $r=.54-.65$ in Raes et al., 2012). 
Regarding construct validity, Dampening scale was positively related to depression, hopelessness and negative affect, and Emotion-focused scale was positively associated to well-being measures (quality of life, optimism, positive affect and hope) in both, clinical and general populations. Results were different in general and clinical populations in Self-focus strategies. This scale did not correlate in a significant manner with optimism (in GP), quality of life and negative affect (in CP). It is of special interest to note that Dampening and Emotion-focused scales also evidenced significant correlations with the ERQ scales, which corroborates its validity. Emotionfocused strategies were positively correlated with cognitive reappraisal and negatively correlated with expressive suppression, whereas dampening strategies were inversely correlated with reappraisal and positively associated with expressive suppression in both samples. However, self-focus strategies only showed significant correlations with ERQ cognitive reappraisal in clinical populations. The inclusion of a battery of measures capturing an expanded range of constructs helps to further distinguish emotion-focus and self-focused positive rumination. Whereas the former is related to a broad array of constructs related to positive emotion and positive expectancies (or their absence in the case of depression and hopelessness), self-focused may capture a more specific process involving self-referential cognitive elaboration triggered by initial positive emotional states. Such an interpretation would be supported by the finding that self-focused positive rumination was more consistently related to measures of hope and hopelessness (which explicitly captures perceptions of personal agency and 
accomplishments) than measures such as optimism or emotional suppression which do not tap address self-concepts directly.

Regarding the emotional regulation strategies used by the clinical and general groups included in this study, it is quite noteworthy that there were significant differences in the strategies employed to regulate affect. Clinical patients used more strategies to dampen positive affect and lower strategies to intensify positive emotions. This is in line with other studies that found that people with bipolar I disorder and depressed individuals reported more dampening responses to positive affect than did control participants (Edge et al., 2013; Werner-Seidler, Banks, Dunn, Moulds, 2013). Clinical population differed from nonclinical samples in the use of reappraisal (changing the way one thinks about potentially emotion-eliciting events) to regulate affective responses (Ray, McRae, Ochsner., \& Gross, 2010) but not in their emotional expression (changing the way one behaviorally responds to emotion-eliciting events). These outcomes highlight the relevance of consider not only the well known construct of reappraisal when distinguishing clinical from general populations, but also RPA strategies, which detect differences between populations with somewhat larger effect sizes than the ERQ scale.

Our findings are consistent with previous research (Feldman et al., 2008; Quoidbach et al., 2010) demonstrating an associations between dampening strategies, positive rumination and depression. Multivariate analyses revealed that clinical patients who endorsed using more dampening strategies and less self-focused positive rumination endorsed more depressive symptoms, above and beyond the variance accounted by suppression and reappraisal strategies. Moreover, these outcomes extend 
previous research about the relation between positive emotion regulation and patients suffering from eating disorders. These results also suggest that it may be valuable for clinicians to assess strategies that patients use to regulate positive affect, and focus not only in the downregulation of positive affect but also in the upregulation strategies, specifically those referred to positive aspects about the self. In general population, the use of dampening strategies was the only predictor of greater levels of depression, after controlling for reappraisal and suppression strategies. This may be particularly important in those positive psychology interventions where reducing depression is a therapeutic focus (Bolier et al., 2013), as dampening or ignoring positive affect may undermine the effectiveness of these interventions. In terms of the promotion of quality of life in general population, less dampening and more self-focus strategies predicted higher levels of quality of life. Surprisingly, RPA strategies did not remain as significant predictors of quality of life in clinical patients after controlling for suppression strategies of emotion regulation. It is possible that common variance across the RPA scale and suppression scale in this population could explain these results.

In sum, our findings confirmed the 3 factor structure of the Spanish RPA and the distinct nature of emotion-focused and self-focused strategies in general and clinical populations in relation to other constructs related to distress, well-being, and expectancies for the future. Although some studies have suggested that they should be considered as one dimension of positive rumination (Nelis et al., 2016), our results indicate that there is value in considering different aspects of positive rumination. In addition to the 
assessment of an expanded range of constructs, the present study also differs from most of previous studies which have considered the relation between both scales in adolescent and student samples (Engh \& Olofsson, 2011, Nelis et al., 2016). Moreover, studies that included patients with bipolar I and major depressive disorder found that dampening and emotion strategies, but not self-focus strategies, were capable of distinguished between clinical and nonclinical groups (Shapero et al., 2015). In the present study which included patients with a broader range of diagnoses, self-focused, emotion-focused and dampening strategies differentiated the clinical from non-clinical samples. These patterns of findings further highlight the relevance of maintaining the positive rumination differentiation to detect possible differences among clinical subgroups. Moreover, our study confirmed the incremental validity of the RPA to one of the most used questionnaires to assess emotional regulation.

These findings emphasize the relevance of including the assessment of specific strategies to regulate positive affect in clinical populations and support the inclusion of positive emotions regulation processes in the understanding of psychological disorders, at least in the case of emotional disorders.

Our study has some limitations. First, different methods were used to collect the study sample. A web-delivered survey was used for collecting the general population sample while clinical patients completed questionnaires in paper. However, we believe this system could improve the data collection, decreasing the possibility of missing or inaccurate information rates, allowing capturing data in real time in the participant's natural environment 
and having the opportunity to obtain samples that are heterogeneous with respect to age, education, income, social class, and nationality (Birnbaum, 2004; Ritter, Lorig, Laurent, \& Matthews, 2004). These advantages are especially significant in validation studies. In addition, this form of data collection has been used in several studies focused on emotional regulation (Goodall, Trejnowska, \& Darling, 2012; Hofmann, Carpenter, \& Curtiss, 2016; Miyamoto, \& Ma, 2011). Second, both general and clinical populations had a majority of women, and there were a small subsample of participants with eating disorders, which it is not possible generalize the findings to this population. Third, further studies with a larger sample of clinical and general participants should corroborate the temporal stability of the scale in both populations.

Our findings are promising and indicate that the Spanish RPA has good reliability and validity properties and is useful for clinical and research purposes. These results are encouraging in order to include this instrument in the psychological evaluation of positive emotion regulation processes. To our knowledge, this is the first study to validate the factorial structure of the RPA in clinical populations.

We believe these findings represent an important contribution to the understanding of emotion regulation processes, specifically of positive emotion regulation. Emotion regulation has been conceptualized as one of the core and transdiagnostic mechanisms in the development and maintenance of psychological disorders (Allen, McHugh, \& Barlow, 2009). The present study offers important additional evidence of the reliability and validity of the RPA which has the advantage of assessing positive emotion 
regulation in terms of both the upregulation of positive emotion, but also the suppression of positive affect. In addition, our study provides a valid instrument for assessing cognitive response style of positive emotion regulation in both general and clinical Spanish-speaking populations.

\section{References}

Allen L.B., McHugh R.K., \& Barlow D.H. Emotional disorders: A unified protocol. In: Barlow DH, editor. Clinical handbook of psychological disorders: A step-by-step treatment manual. 4. New York: Guilford Press; 2008. pp. 216-249.

Barlow, D.H., Allen, L.B., \& Choate, M.L. (2004) Toward a unified treatment for emotional disorders. Behaviour Therapy, 35, 205-230.

Barnes, L. L. B., Harp, D., \& Jung, W. S. (2002). Reliability generalization of scores on the Spielberger State-Trait Anxiety Inventory. Educational and Psychological Measurement, 62, 603- 618.

Beauducel, A., \& Herzberg, P. Y. (2006). On the performance of maximum likelihood versus means and variance adjusted weighted least square estimation in confirmatory factor analysis. Structural Equation Modeling, 13, 186-203.

Beck, A., Weissman, A., Lester, D., Trexler, L. (1994) The measurement of pessimism: The Hopelessness Scale. Journal of Consulting and Clinical Psychology, 42(6), 861-865. http://dx.doi.org/10.1037/h0037562

Beck, A. T., Steer, R. A., \& Brown, G. K. (1996). Manual for the beck depression inventory. The Psychological Corporation. San Antonio, TX. 
Bijttebier, P., Raes, F., Vasey, M. W., \& Feldman, G. C. (2012). Responses to positive affect predict mood symptoms in children under conditions of stress: a prospective study. Journal of Abnormal Child Psychology, 40(3), 381-9. doi:10.1007/s10802-011-9579-2

Birnbaum, M. H. (2004). Human research and data collection via the Internet. Annual Review in Psychology, 55, 803-32. doi:10.1146/annurev.psych.55.090902.141601

Bolier, L., Haverman, M., Westerhof, G.J., Riper, H., Smit, F., \& Bohlmeijer, E. (2013). Positive psychology interventions: a meta-analysis of randomized controlled studies. BMC Public Health, 13, 119. doi:10.1186/1471-2458-13-119

Brown, T. A. (2006). Confirmatory factor analysis for applied research. New York, NY: Guilford Press

Bryant, F.B. (2003) Savoring beliefs inventory (SBI): A scale for measuring beliefs about savouring. Journal of Mental Health, 12, 175-196.

Carl, J. R., Soskin, D. P., Kerns, C., \& Barlow, D. H. (2013). Positive emotion regulation in emotional disorders: A theoretical review. Clinical Psychology Review, 33, 343-360. doi:10.1016/j.cpr.2013.01.003.

Cheung, G. W., \& Rensvold, R. B. (2002). Evaluating goodness-of-fit indexes for testing MI. Structural Equation Modeling, 9(2), 235-55.

Dillon, D. G., \& Pizzagalli, D. A. (2009). Maximizing positive emotions: A translational, transdiagnostic look at positive emotion regulation. In: Kring A, Sloan D, editors. Emotion Regulation and Psychopathology: A Transdiagnostic Approach to Etiology and Treatment (pp. 229-252). New York: The Guilford Press. 
Dimitrov, D. (2010). Testing for Factorial Invariance in the Context of Construct Validation. Measurement and Evaluation in Counseling and Development, 43, 121-149. doi: 10.1177/0748175610373459

Edge, M. D., Miller, C. J., Muhtadie, L., Johnson, S. L., Carver, C. S., Marquinez, N., \& Gotlib, I. H. (2013). People with bipolar I disorder report avoiding rewarding activities and dampening positive emotion. Journal of Affective Disorders, 146(3), 407-13. doi:10.1016/j.jad.2012.07.027

Eisner, L. R., Johnson, S. L., \& Carver, C. S. (2009). Positive affect regulation in anxiety disorders. Journal of Anxiety Disorders, 23, 645-649.

Engh, J., \& Olofsson, M. (2011). Do cognitive responses to how we feel really matter?: a psychometric evaluation and experimental extension of the Responses to Positive Affect questionnaire (RPA). (Student paper). Örebro universitet.

Espinoza, M., Molinari, G., Etchemendy, E., Herrero, R., Botella, C., \& Baños, R. (2016). Understanding Dispositional Hope in General and Clinical Populations. Applied Research in Quality of Life DOI $10.1007 / s 11482-016-9469-4$

Feldman, G. C., Joormann, J., \& Johnson, S. L. (2008). Responses to positive affect: A self-report measure of rumination and dampening. Cognitive Therapy and Research, 32(4), 507-525. doi:10.1007/s10608-0069083-0.

Fisher, R. A. (1915). Frequency distribution of the values of the correlation coefficient in samples of an indefinitely large population. Biometrika 10(4), 507-521. doi:10.2307/2331838. 
Fisher, R. A. (1921). On the 'probable error' of a coefficient of correlation deduced from a small sample. Metron 1, 3-32.

Fredrickson, B.L., \& Joiner, T. (2002) Positive emotions trigger upward spirals toward emotional well-being. Psychological Science, $13,172-175$.

Goodall, K., Trejnowska, A., \& Darling, S. (2012). The relationship between dispositional mindfulness, attachment security and emotion regulation. Personality and Individual Differences, 52(5), 622-626.

Gross, J.J. (1998). The emerging field of emotion regulation: An integrative review. Review of General Psychology, 2, 271-299. doi:10.1037/10892680.2.3.271

Gross, J.J., \& John, O.P. (2003). Individual differences in two emotion regulation processes: Implications for affect, relationships, and wellbeing. Journal of Personality and Social Psychology, 85, 348-362.

Gross, J.J., Sheppes, G., \& Urry, H.L. (2011) Emotion generation and emotion regulation: A distinction we should make (carefully). Cognition and Emotion, 25(5),765-781.

Hofmann, S. G., Carpenter, J., \& Curtiss, J. (2016). Interpersonal emotion regulation questionnaire (IERQ): Scale development and psychometric characteristics. Cognitive Therapy \& Research, 40(3), 341-356. doi:10.1007/s10608-016-9756-2.

Johnson, S.L., \& Jones, S. (2009). Cognitive correlates of mania risk: Are responses to success, positive moods, and manic symptoms distinct or overlapping? Journal of Clinical Psychology, 65, 891-905. 
Johnson, S.L., McKenzie, G., \& McMurrich, S. (2008). Ruminative responses to negative and positive affect among students diagnosed with bipolar disorder and major depressive disorder. Cognitive Therapy and Research, 32, 702-713.

Kim, B.N., \& Kwon, S.M. (2014). Preliminary validation of Korean-Responses to Positive Affect (K-RPA). The Korean Journal of Clinical Psychology, 33, 243-260. http://dx.doi.org/10.15842/kjcp.2014.33.2.002.

Kring, A. M. (2008). Emotion disturbances as transdiagnostic processes in psychopathology. In: Lewis M, Haviland-Jones J, Barrett LF, editors. Handbook of Emotion 3rd ed. (pp. 691-705). New York, NY: Guilford Press.

Lecrubier, Y., Weiller, E., Hergueta, T., Amorim, P., Bonora, L. I., \& Lepine, J. P. Mini-International Neuropsychiatric Interview, English Version. Sheehan \& Lecrubier, Paris, 1998.

Lorenzo-Seva, U., \& Ferrando, P.J. (2013). FACTOR 9.2 A Comprehensive Program for Fitting Exploratory and Semiconfirmatory Factor Analysis and IRT Models. Applied Psychological Measurement, 37(6), 497-498.

Mezzich, J. E., Ruipérez, M. A., Pérez, C., Yoon, G., Liu, J., \& Mahmud, S. (2000). The Spanish version of the quality of life index: presentation and validation. The Journal of nervous and mental disease, 188(5), 301305.

Millsap, R. E., \& Yun-Tein, J. (2004). Assessing Factorial Invariance in Ordered-Categorical Measures. Multivariate Behavioral Research, 39(3), 479-515. 
Miyamoto, Y., \& Ma, X. (2011). Dampening or savoring positive emotions: A dialectical cultural script guides emotion regulation. Emotion, 11(6), 1346.

Nelis, S., Holmes, E., \& Raes, F. (2015). Response styles to positive affect and depression: Concurrent and prospective associations in a community sample. Cognitive Therapy and Research, 39, 480-491. http://dx.doi.org/10.1007/s10608-015-9671-y

Nelis, S., Luyckx, K., Feldman, G., Bastin, M., Raes, F., \& Bijttebier P. (2016). Assessing response styles to positive affect: One or two dimensions of positive rumination in the Responses to Positive Affect questionnaire?. Personality and Individual Differences, 89, 40-46

Nolen-Hoeksema, S., Davis, C.G. (2004) Theoretical and methodological issues in the assessment and interpretation of posttraumatic growth. Psychological Inquiry, 15, 60-64.

Perczek, R., Carver, C. S., Price, A. A., \& Pozo-Kaderman, C. (2000). Coping, mood, and aspects of personality in Spanish translation and evidence of convergence with English versions. Journal of Personality Assessment, 74(1), 63-87.

Raes, F., Daems, K., Feldman, G. C., Johnson, S. L., \& Van Gucht, D. (2010). A psychometric evaluation of the Dutch version of the responses to positive affect questionnaire. Psychologica Belgica, 49(4), 293-310.

Raes, F., Smets, J., Nelis, S., \& Schoofs, H. (2012). Dampening of positive affect prospectively predicts depressive symptoms in non-clinical samples. Cognition \& Emotion, 26, 75-82. 
Ray, R., McRae, K., Ochsner, K., \& Gross, J. (2010). Cognitive Reappraisal of Negative Affect: Converging Evidence From EMG and Self-Report. Emotion, 10, 587-92.

Ritter, P., Lorig, K., Laurent, D., \& Matthews, K. (2004). Internet versus mailed questionnaires: A randomized comparison. Journal of Medical Internet Research, 6(3), e29.

Rodríguez-Carvajal, R., Moreno-Jiménez, B., \& Garrosa, E. (2006). Cuestionario de Regulación Emocional.Versión española. Autorizado por los autores de la versión original en Inglés (Gross y John, 2003). Madrid: Universidad Autónoma de Madrid

Sandin, B., Chorot, P., Lostao, L., Joiner, T. E., Santed, M. \& Valiente, R. M. (1999). Escalas PANAS de afecto positivo y negativo: validación factorial y convergencia transcultural. Psicothema, 11(1), 37-51.

Sanz, J., Navarro, M. E., \& Vázquez, C. (2003). Adaptación española del Inventario para la depresión de Beck-II (BDI-II): Propiedades psicométricas en estudiantes universitarios. Análisis y modificación de conducta, 29(124), 239-288.

Shapero, B.G., Stange, J.P., Goldstein, K.E., Black, C.L., Molz, A.R., Hamlat, E.J., ... Abramson, L.Y. (2015). Cognitive styles in mood disorders: discriminative ability of unipolar and bipolar cognitive profiles. International Journal of Cognitive Therapy, 8, 35-60. http://dx.doi.org/10.1521/ijct.2015.8.1.35.

Scheier, M. F., Carver, C. S., \& Bridges, M. W. (1994). Distinguishing optimism from neuroticism (and trait anxiety, self-mastery, and self-esteem): A 
re-evaluation of the Life Orientation Test. Journal of Personality and Social Psychology, 67, 1063-1078.

Sheppes, G. \& Gross, J.J. (2002). Emotion regulation effectiveness: What works when. In H.A. Tennen and J.M. Suls (Eds.), Handbook of psychology, volume five: Personality and social psychology. New York, NY: Wiley.

Snyder, C. R., Harris, C., Anderson, J. R., Holleran, S. A., Irving, L. M., Sigmon, S. T., ... Harney, P. (1991). The will and the ways: Development and validation of an individual-differences measure of hope. Journal of Personality and Social Psychology, 60(4), 570585. doi:10.1037/0022-3514.60.4.570

Spielberger, C. D., Gorsuch, R., \& Lushene, R. E. (1970). Manual for the statetrait inventory. Consulting Psychologists, Palo Alto, California.

Timmerman, M. E., \& Lorenzo-Seva, U. (2011). Dimensionality assessment of ordered polytomous items with parallel analysis. Psychological Methods, 16, 209-220. doi:10.1037/a0023353

Quoidbach, J., Berry, E.V., Hansenne, M., \& Mikolajczak, M. (2010) Positive emotion regulation and well-being: Comparing the impact of eight savoring and dampening strategies. Personality and Individual Differences, 49(5), 368-373

Werner, K., \& Gross, J.J. (2010). Emotion regulation and psychopathology: A conceptual framework. In A. Kring \& D. Sloan (Eds.), Emotion regulation and psychopathology: A transdiagnostic approach to etiology and treatment (pp. 13-37). New York: Guilford Press. 
Werner-Seidler, A., Banks, R., Dunn, B.D., \& Moulds, M.L. (2013). An investigation of the relationship between positive affect regulation and depression. Behaviour Research and Therapy, 51, 46-56. http://dx.doi.org/10.1016/j.brat.2012.11.001.

Wood, J.V., Heimpel, S.A., Michela, J.L. (2003) Savoring versus dampening: Self-esteem differences in regulating positive affect. Journal of Personality and Social Psychology, 85, 566-580.

Yang, H., \& Guo, W. (2014). Chinese version of the Responses to Positive Affect questionnaire: testing the factor structure, reliability, and validity in a college student sample. Psychological reports, 115(2), 467-484. 


\section{Discusión General}

El objetivo de la presente tesis doctoral ha sido diseñar, desarrollar y evaluar la eficacia de una intervención psicológica apoyada en TICs, orientada a la promoción del optimismo y del afecto positivo en pacientes con FM.

Para ello, en primer lugar, realizamos la validación al español de las distintas escalas para medir las variables principales de resultado de nuestros estudios. De esta manera, validamos la Escala General de Autoeficacia (GSES-12, Bosscher y Smit, 1998), la Tarea de Probabilidad Subjetiva (SPT, MacLeod, 1996) y el Cuestionario de Respuestas al Afecto Positivo (RPA, Feldman, Joormann y Johnson, 2008). Este trabajo fue hecho de manera transversal al diseño de la intervención para evaluar si efectivamente estas escalas presentaban validez y confiabilidad en el idioma español y si permitían su aplicación en el ámbito clínico. Pudimos comprobar que los tres instrumentos de medida presentaron buenas propiedades psicométricas tanto en población general como en población clínica de habla hispana. Esto es importante ya que, por un lado, la auto-eficacia es una de las medidas de resultado más importante en los tratamientos de dolor crónico debido a su asociación negativa con el deterioro funcional, el malestar afectivo y la gravedad del dolor, así como un factor promotor de la mejor adaptación al dolor (Jackson, Wang, Wang y Fan, 2014). Por otro lado, la Tarea de Probabilidad Subjetiva es un cuestionario que mide expectativas de futuro positivas y negativas, y es el instrumento más utilizado, junto con el Test de Optimismo (LOT-R, Scheier, Carver y Bridges, 1994), para evaluar la eficacia de la intervención de Mi Mejor Yo Posible en la inducción de 
optimismo. Por último, el Cuestionario de Respuestas al Afecto Positivo, es quizás el más novedoso para evaluar cómo las personas reaccionan frente a las emociones positivas: si las amplifican o las suprimen. Esta variable resulta fundamental si tenemos en cuenta que se va a realizar un ejercicio que induce afecto positivo y el proceso de regulación de esta emoción puede influir en los resultados de nuestra intervención.

Una vez establecido el protocolo de evaluación, se diseñó el protocolo de intervención. Si bien decidimos utilizar una intervención ya validada en población general, debíamos adaptar y personalizar la intervención de $M i$ Mejor Yo Posible a las características clínicas de los pacientes. Se diseñó una intervención que pudiera ser auto-aplicada, teniendo en cuenta la necesidad de centrarnos tanto en la eficacia como en la adherencia a medio plazo. Para ello, pensamos en las TICs como una herramienta que, por un lado, nos permitiera personalizar y potenciar el ejercicio de imaginación; y, por el otro lado, que nos ofreciera la ventaja de trasladar ese contenido al día a día del paciente y brindar apoyo de manera virtual para promover la motivación y adherencia. Realizamos entrevistas cualitativas con psicólogos especialistas en intervenciones apoyadas en TICs para definir: el diseño del sistema tecnológico para llevar a cabo el ejercicio y de la plataforma online para acceder a la práctica del ejercicio en el hogar; la duración y el tipo de personalización del apoyo a brindar, y la forma en la que debía brindarse dicho apoyo. Decidimos utilizar uno de los módulos de actividades del sistema "EARTH of Wellbeing" (Baños, Etchemendy, Farfallini, GarcíaPalacios, Quero y Botella, 2014), el Libro de la Vida. Este módulo nos permitió contar con una herramienta en la cual los pacientes podían escribir sus 
narrativas, seleccionar imágenes, videos y sonidos personalizados para acompañar su texto, y luego visualizarlo para potenciar su imaginación. Para que pudieran continuar visualizando su ejercicio en casa, utilizamos una plataforma online, "Terapia Emocional Online" (TEO; Quero, Molés, Pérez, Botella y Baños, 2012). TEO es un sistema web que permite la creación de material terapéutico personalizado. Los pacientes podían acceder a este material a través de Internet utilizando una contraseña personal, para visualizar su diario personal con la narrativa y los recursos multimedia que seleccionaron previamente en la sesión de laboratorio. Al finalizar la sesión, podían desplazarse dentro de un entorno virtual (una playa o un entorno forestal) para reflexionar sobre la sesión y su experiencia y seguir visualizando su Mejor Yo Posible. Finalmente, dos veces a la semana, se enviaron SMS al teléfono móvil del paciente con recordatorios para practicar el ejercicio y con refuerzos para que no abandonara la práctica. Este diseño apoyado en TICs y personalizado a las características de los pacientes nos permitió tener en cuenta la eficacia, compromiso y adherencia hacia la intervención.

Después de estas fases preparatorias, nos centramos ya en evaluar la intervención. En primer lugar, llevamos adelante un estudio piloto para poner a prueba la adaptación de la intervención Mi Mejor Yo Posible en pacientes clínicos y utilizando el apoyo de las TICs. Este primer paso fue importante ya que estas intervenciones dirigidas a promover afecto positivo han sido diseñadas y validadas, en su mayoría, en población general (Bolier, Haverman, Westerhof, Riper, Smit y Bohlmeijer, 2013). Por lo tanto, teniendo en cuenta la complejidad y las particularidades que presentan los pacientes 
clínicos, y en especial los pacientes con dolor crónico, este primer estudio nos permitió comprobar la viabilidad de aplicar esta intervención, así como la satisfacción, aceptación y utilidad percibida por parte de las pacientes. Además, si bien se trataba de resultados preliminares, varias de las pacientes alcanzaron un cambio clínicamente significativo en medidas de estado funcional y depresión, y un incremento en la calidad de vida.

Con respecto a este este estudio preliminar, podemos decir que hemos conseguido los objetivos que nos proponíamos y que las hipótesis que nos planteamos se cumplieron parcialmente. Si bien encontramos un aumento en las emociones positivas y en la calidad de vida de la mayoría de las pacientes, así como una disminución en los niveles de depresión, expectativas negativas, afecto negativo, catastrofización e impacto del dolor, el optimismo y las expectativas positivas no se incrementaron en la mayoría de las pacientes. A su vez, muchos de los cambios encontrados no se mantuvieron en el seguimiento a los tres meses. Pero, por otro lado, las pacientes expresaron elevados niveles de satisfacción con la intervención y una opinión muy positiva de su utilidad.

Dado que los resultados fueron prometedores y que la intervención no produjo efectos adversos en el estudio piloto, el siguiente paso fue comprobar la eficacia de esta intervención en un estudio controlado. Por tal razón, las pacientes con FM fueron asignadas aleatoriamente a realizar la intervención de Mi Mejor Yo Posible, o a una intervención control que consistía en registrar sus actividades diarias. En cuanto a los efectos de una única sesión, la intervención de Mi Mejor Yo Posible y el ejercicio de actividades diarias produjeron disminuciones significativas en expectativas 
negativas y aumentos en afecto positivo. Sin embargo, los aumentos en el afecto positivo después de la sesión sólo fueron significativos en la condición intervención. En este caso, vemos que el ejercicio control también produjo beneficios para los pacientes. Esto puede explicarse por diversos factores. Por un lado, puede haber ocurrido que el hecho de reflexionar sobre los acontecimientos ocurridos durante el día haya generado un mayor nivel de conocimiento de metas de actividad alcanzadas. Por lo tanto, podría haber actuado como un simple ejercicio de activación comportamental. Además, es posible que los efectos positivos se deban a la inducción de expectativas (Peerdeman, van Laarhoven, Peters y Evers, 2016). Informar a los pacientes sobre los resultados esperables y hacer hincapié en los efectos positivos previstos podría haber optimizado la eficacia del ejercicio control. Por otra parte, con respecto a la intervención de Mi Mejor Yo Posible, la intervención fue breve, pero cognitivamente desafiante para las pacientes con FM. Es posible que se requiera más tiempo de práctica para obtener efectos sustanciales de este ejercicio, como se sugiere en un meta-análisis reciente de los efectos de las intervenciones basadas en imaginación en dolor (Peerdeman y cols., 2016). Esto, además, tiene sentido si se tienen en consideración los resultados que se encontraron después de un mes de práctica de la intervención.

Durante un mes, las pacientes practicaron ambos ejercicios en casa, de manera autoaplicada, contando únicamente con un apoyo web. Los resultados mostraron que, en las medidas de resultado principales, aquellas pacientes que realizaron la intervención de Mi Mejor Yo Posible redujeron de manera significativa sus niveles de depresión y afecto negativo, y 
aumentaron sus niveles de afecto positivo, en comparación con aquellas pacientes que practicaron la intervención control.

La reducción en la sintomatología depresiva a partir de la práctica del ejercicio de visualización es algo que ya se había demostrado en pacientes clínicos que sufrían de depresión (Pietrowsky y Mikuta, 2012). Por otro lado, la reducción en el afecto negativo es algo que no se había encontrado en estudios previos aplicando el ejercicio de Mi Mejor Yo Posible de manera controlada, aunque éstos habían sido realizados en población general (Meevissen, Peters y Alberts, 2011; Peters, Flink, Boersma y Linton, 2010; Renner, Schwarz, Peters y Huibers, 2014; Sheldon y Lyubomirsky, 2006). Y esta reducción en los niveles de afecto negativo se mantuvo al mes y a los tres meses de seguimiento.

El aumento en los niveles de afecto positivo puede ser especialmente significativo para las pacientes con FM, ya que reportan un efecto positivo significativamente menor que los pacientes con otras enfermedades reumatológicas (Zautra y cols., 2005). Está ampliamente aceptado en la literatura científica que el afecto negativo y el afecto positivo constituyen entidades relacionadas pero independientes, y que afectan al dolor de manera diferenciada (Pressman y Cohen, 2005). En la FM se ha demostrado que el equilibrio afectivo, especialmente el estilo depresivo (alto afecto negativo/ bajo afecto positivo), es predictor de comorbilidad psiquiátrica, gravedad del dolor y estado funcional. Mientras que el estilo saludable (bajo afecto negativo /alto afecto positivo) se relaciona con una menor sintomatología depresiva, menos ansiedad y menor número de síntomas asociados al dolor. 
En cuanto a las expectativas de futuro, tanto la intervención de $M i$ Mejor Yo Posible como la intervención de Actividades Diarias, fueron eficaces en la reducción de expectativas negativas. No encontramos diferencias por condición. Tampoco se produjo un aumento de las expectativas de futuro positivas. Cabe señalar que los estudios previos que sí encontraron cambios en las expectativas futuras se realizaron en población general y estas diferencias podrían explicarse por diferencias en las características de las poblaciones (Meevissen y cols., 2011; Peters y cols., 2010; Renner y cols., 2014; Sheldon y Lyubomirsky, 2006). Futuros estudios que se realicen en diferentes muestras clínicas deberán aclarar estas discrepancias. Además, el cuestionario utilizado mide expectativas futuras específicas (por ejemplo: "Tendrá muchos buenos momentos con amigos" o "Irá muy atrasado en su trabajo") y estandarizadas. Quizás en este tipo de población sea conveniente utilizar medidas de respuesta abierta, como la Tarea de Futuro Personal (MacLeod, Tata, Kentish y Jacobsen, 2010), que además de permitir generar eventos futuros personalizables, permite variar el rango de tiempo.

Sin embargo, sí encontramos un aumento en los niveles de optimismo en la condición intervención a los tres meses de seguimiento, en comparación con la condición control. Debido a que el optimismo es un rasgo disposicional y dimensional, las intervenciones dirigidas a aumentar los niveles de optimismo deben esperar lograr un pensamiento más flexible y optimista de manera gradual (Eichner, Kwon y Marcus, 2014).

En cuanto a las medidas de resultado secundarias, encontramos que las pacientes que recibieron la intervención de Mi Mejor Yo Posible aumentaron sus niveles de autoeficacia mientras que aquellas pacientes que 
recibieron la intervención control los disminuyeron. Parece que la visualización de metas futuras positivas ayudó a las pacientes a aumentar la creencia en su capacidad para llevar a cabo comportamientos específicos (Bandura, 1977). Para las pacientes que sufren FM es difícil establecer objetivos relacionados con actividades que sean positivas y significativas para ellas. El miedo al movimiento, la fatiga generalizada y el estado de ánimo bajo, sumado al dolor, obstaculizan su disposición a realizar actividades valiosas, causando una baja motivación y patrones de actividad evitativos (Esteve y cols., 2016). Este resultado es alentador por dos razones. Por un lado, porque en un estudio de meta-análisis reciente se encontró que los niveles de autoeficacia se asocian de manera significativa con el deterioro funcional, el malestar afectivo y la gravedad del dolor en muestras de dolor crónico, y además representan un factor protector importante de ajuste ante el dolor (Edwards, Dworkin, Sullivan, Turk y Wasan, 2016; Jackson, Wang, Wang y Fan, 2014). Por otro lado, ningún estudio anterior que utilice la intervención de Mi Mejor Yo Posible había tenido en cuenta como medida de resultado la variable de autoeficacia. De esta manera, nuestros hallazgos sugieren que esta intervención podría tener otros efectos que no han sido estudiados y extiende la evidencia científica disponible acerca de los efectos de este ejercicio de visualización. King (2001), quien fuera la creadora del ejercicio de Mi Mejor Yo Posible, ya sugería que escribir acerca de las metas futuras permitiría a los individuos perseguir sus objetivos más eficazmente a través de la visualización de los mismos, de un aumento de la conciencia de sí mismo y de la auto-regulación. Sin embargo, los estudios que han utilizado este ejercicio hasta la fecha no habían incluido una medida capaz de captar 
estos procesos (Loveday, Lovell y Jones, 2016). Además, esto se corresponde con la noción de "Yo futuro" de Erikson (2007), quien sugiere que los posibles "yo" deben ser vistos como concepciones de tener al menos algún grado de agencia en una situación futura. Esta sería la característica fundamental de un "yo futuro", que lo diferenciaría de un mero deseo o esperanza, y además estaría íntimamente relacionado con la sensación de autoeficacia, que es la confianza en mis capacidades para afectar los resultados o metas propuestas.

Los nuevos enfoques en el tratamiento del dolor crónico sugieren que las reducciones en el dolor pueden no ser requisitos para reducir el malestar emocional y promover un mejor funcionamiento (Vowles, Witkiewitz, Levell, Sowden y Ashworth, 2017). Aunque la disminución en los niveles de dolor no era un objetivo primordial en este estudio, la incapacidad causada por el dolor mostró reducciones en los seguimientos en ambas condiciones. Esto puede ser especialmente importante en las intervenciones dirigidas a aumentar el afecto positivo y promover un funcionamiento más positivo, donde el foco de la intervención está puesto en enseñarle al paciente una serie de herramientas psicológicas que lo ayuden a construir una vida significativa a pesar de su dolor.

Ambos ejercicios también fueron eficaces en reducir la catastrofización hacia el dolor y mejorar la calidad de vida. Estos resultados están en línea con estudios previos que indujeron experimentalmente dolor en participantes sanos, y practicaron el ejercicio de Mi Mejor Yo Posible, encontrando una reducción en la catastrofización hacia el dolor (Boselie, Vancleef, Smeets y Peters, 2014; Hanssen, Peters, Vlaeyen, Meevissen y 
Vancleef, 2013). En cuanto al aumento en la calidad de vida, si bien estudios anteriores no incluyeron la calidad de vida como medida de resultado, nuestros resultados sugieren que las técnicas basadas en la visualización serían capaces de mejorar el estado funcional en pacientes con FM. Esto coincide con los hallazgos de estudios que utilizaron técnicas de imaginación guiada en pacientes con enfermedades reumáticas y encontraron mejoras en el bienestar psicológico (Giacobbi, Stabler, Stewart, Jaeschke, Siebert y Kelley, 2015; Menzies, Taylor y Bourguignon, 2006).

Con respecto a este este estudio controlado, podemos decir que hemos conseguido los objetivos que nos proponíamos y que las hipótesis que nos planteamos se cumplieron parcialmente. En cuanto a los efectos de una única sesión, como esperábamos, encontramos un aumento significativo en el afecto positivo en la condición intervención en comparación con la condición control. Además, ambas condiciones obtuvieron una reducción en las expectativas de futuro negativas. Sin embargo, no encontramos cambios significativos en el afecto negativo ni en las expectativas de futuro positivas en ninguna de las dos condiciones.

En cuanto a los efectos de la intervención en la evaluación postintervención, encontramos una disminución significativa en sintomatología depresiva y afecto negativo, y un aumento en los niveles de autoeficacia y afecto positivo en la condición intervención comparado con la intervención control. Ambas condiciones mostraron reducciones en catastrofización hacia el dolor y aumentos en la calidad de vida. Sin embargo, contrario a lo esperado, no se encontraron cambios en las expectativas de futuro ni en los niveles de optimismo. 
Por último, en cuanto al mantenimiento de los resultados a largo plazo, encontramos un aumento en la condición intervención del optimismo y la calidad de vida, y una reducción en los niveles de afecto negativo, en comparación con la condición control. El resto de los cambios no se mantuvieron en el tiempo.

El último paso de la presente tesis doctoral fue analizar las variables mediadoras y moderadoras de la eficacia de la intervención de Mi Mejor Yo Posible en pacientes con FM. Es la primera vez que se estudia cómo una intervención dirigida a promover factores positivos funciona en esta población.

Encontramos que los cambios en el estado funcional de las pacientes con FM estaban mediados por los cambios en los niveles de depresión. Las pacientes que practicaron el ejercicio de imaginación guiada consiguieron mejoras significativas en la sintomatología depresiva en comparación con quienes practicaron el ejercicio control, lo que a su vez generó mejoras en la incapacidad causada por el dolor. No encontramos evidencia de que la condición de tratamiento recibida influyera en el cambio en el impacto del dolor independientemente de su efecto sobre el cambio en los niveles de depresión. Este es un hallazgo importante, ya que implica que los cambios en el estado emocional de las pacientes son necesarios para lograr cambios en el estado funcional. Esto está en línea con los resultados de un estudio reciente que demostró que el estrés mediaba la relación entre una intervención online de terapia cognitivo comportamental y la gravedad del dolor en pacientes con dolor crónico (DasMahapatra, Chiauzzi, Pujol, Los y Trudeau, 2015). 
Los niveles de afecto negativo y positivo no permanecieron como mediadores directos de la discapacidad del dolor. Resultados similares también se han observado en investigaciones previas que evaluaron la asociación entre el rasgo positivo y la severidad del dolor (Finan, Quartana, Smith, 2013; Strand, Kerns, Christie, Haavik-Nilsen, Klokkerud y Finset, 2007). Estos resultados sugieren que, aunque el afecto positivo y el afecto negativo influyen en la adaptación al dolor, esta relación puede ser compleja y no directamente observable con las medidas tradicionales de dolor (Hassett y Finan, 2016).

Los cambios en el afecto positivo y negativo fueron mediadores del efecto de la intervención de Mi Mejor Yo Posible sobre los cambios en los niveles de depresión. Y además, el efecto directo de la intervención sobre la sintomatología depresiva no fue significativo sin la mediación del afecto positivo y negativo. Esto significa que los participantes que recibieron la condición intervención tuvieron mayores reducciones en el afecto negativo y aumentos en el afecto positivo que en la condición de control, lo que condujo a reducciones en la sintomatología depresiva. Estos hallazgos confirman los efectos diferenciados del afecto negativo y positivo sobre la depresión en los síndromes del dolor. Estudios correlacionales previos han encontrado que las asociaciones entre la intensidad del dolor, el afecto negativo y los síntomas depresivos, fueron moderados por el afecto positivo (Thong, Tan y Jensen, 2017). Los pacientes con dolor crónico con un bajo afecto positivo mostraron fuertes asociaciones entre la intensidad del dolor, la depresión y el afecto negativo, mientras que los pacientes con un alto afecto positivo mostraron asociaciones no significativas entre las mismas variables. La importancia de 
nuestro estudio es que es uno de los primeros estudios que confirman causalmente el rol del afecto positivo como un factor protector significativo entre el dolor y variables relacionadas con el dolor, como los niveles de depresión (Reme, 2017).

Además, los cambios en el afecto positivo y negativo fueron mediadores del efecto de la intervención de Mi Mejor Yo Posible sobre los cambios en la calidad de vida de las pacientes con FM. Las pacientes que recibieron la intervención tuvieron una mayor disminución del afecto negativo y un aumento del afecto positivo que quienes recibieron la intervención control, y esto a su vez repercutió en los cambios conseguidos en los niveles de calidad de vida. La evidencia científica ya había encontrado asociaciones entre los niveles de dolor e incapacidad física y un afrontamiento desadaptativo, que a la vez se relacionaban con menores niveles de afecto positivo y mayor presencia de afecto negativo, en pacientes con artritis reumatoide (Zautra y cols., 1995). Sin embargo, es preciso destacar que la práctica del ejercicio de visualización influyó también de manera directa en el cambio en calidad de vida, independientemente de los cambios en el afecto positivo y negativo. Esto podría querer decir que los cambios en la calidad de vida de las pacientes con FM podrían explicarse por una compleja serie de factores que no se reducen simplemente a los cambios en afecto positivo y negativo.

Los cambios conseguidos en autoeficacia no se explicaron por los cambios en el afecto positivo, el afecto negativo ni en la sintomatología depresiva. Futuros estudios podrían incorporar otro tipo de variables, como por ejemplo aquellos factores relacionados con la intervención (por ejemplo: 
dosis de la intervención, frecuencia de práctica y motivación), para explicar los mecanismos de cambio en autoeficacia.

Por último, además de intentar responder a través de qué mecanismos la intervención de Mi Mejor Yo Posible es eficaz, quisimos saber a quién podría serle más o menos útil. Por esa razón, analizamos variables moderadoras de la intervención. Por un lado, tuvimos en cuenta si niveles iniciales de dolor, afecto, auto-eficacia, o calidad de vida influirían en la respuesta al ejercicio. Encontramos que aquellas pacientes que practicaron el ejercicio de visualización y tenían niveles bajos o moderados de autoeficacia, se beneficiaron más en términos de su reducción de la sintomatología depresiva. Los resultados de nuestro estudio son prometedores, ya que la ausencia de un gran número de moderadores puede indicar que una intervención de afecto positivo es eficaz para una amplia variedad de pacientes con FM. Además, los pacientes con FM se caracterizan por bajos niveles de autoeficacia en comparación con otras enfermedades reumatoides, por lo que esta intervención puede ser especialmente adecuada para ellos.

Por otro lado, dado que se trata de una intervención para promover estados emocionales, quisimos saber si los estilos de regulación emocional negativa y positiva, así como un estilo rumiativo, influían en la respuesta a la intervención. En términos de la regulación emocional negativa, encontramos que aquellas pacientes que tienen problemas para concentrarse y realizar tareas mientras experimentan emociones negativas se beneficiaron más del ejercicio de Mi Mejor Yo Posible. Podría decirse que tener que practicar la tarea de visualizar positivamente sus objetivos y metas futuras ayudó a estas pacientes como una mejor estrategia para regular su estado de ánimo 
negativo. En cuanto a la regulación emocional positiva, encontramos que aquellas pacientes que tienen dificultades para centrarse en una emoción positiva para amplificarla, lograron una mayor reducción de sus niveles de depresión a partir de la práctica de la intervención. Parece que la práctica del ejercicio de imaginación actuó como un facilitador para centrarse en la emoción positiva para aquellas pacientes que no tienen una tendencia a usar estrategias para aumentar el afecto positivo.

Finalmente, aquellas pacientes con un estilo rumiativo moderado o elevado que recibieron la intervención de Mi Mejor Yo Posible lograron mayores mejoras en la sintomatología depresiva. La rumiación es un proceso repetitivo en el que los individuos centran su atención en las causas, el contenido y las consecuencias de los estados afectivos y de sus síntomas (Lyubomirsky y Nolen-Hoeksema, 1995). La rumiación sobre las emociones negativas se asocia con el inicio y el curso de la depresión, la ansiedad y los estilos de afrontamiento más pobres en la FM (Malin y Littlejohn, 2015). Más importante aún, el estilo ruminativo es persistente, incluso cuando la sintomatología depresiva mejora (Brinker y Dozois, 2009). Por esta razón, creemos que esta intervención podría ayudar a los pacientes con un estilo rumiativo a cambiar su foco de atención centrado en el contenido negativo (por ejemplo, en el dolor o el estrés diario) hacia un contenido más positivo (por ejemplo: objetivos, metas vitales).

Con respecto a este este estudio acerca de los mecanismos de la intervención, podemos decir que hemos conseguido los objetivos que nos proponíamos y que las hipótesis que nos planteamos se cumplieron parcialmente. Los cambios en los niveles de depresión, mediaron los cambios 
en la incapacidad causada por el dolor en las pacientes que recibieron la intervención. Contrario a lo esperado, los cambios en los niveles de depresión no mediaron los cambios en calidad de vida ni en autoeficacia. En cuanto a los niveles de afecto negativo y positivo, éstos no permanecieron como mediadores directos de la discapacidad causada por el dolor. Por otro lado, los cambios en el afecto positivo y negativo fueron mediadores del efecto de la intervención de Mi Mejor Yo Posible sobre los cambios en los niveles de depresión y de calidad de vida. No encontramos mediadores de los cambios en los niveles de autoeficacia. Según lo esperado en cuanto a las variables moderadoras, aquellas pacientes con niveles bajos o moderados de autoeficacia, con un estilo rumiativo y con problemas en la regulación del afecto positivo y negativo, se beneficiaron más en términos de su reducción de la sintomatología depresiva.

\section{Limitaciones y direcciones futuras}

A pesar de que los resultados encontrados en la presente tesis doctoral son prometedores, varias limitaciones deben ser mencionadas. En primer lugar, es preciso destacar que el tamaño de la muestra utilizada, tanto en el estudio de eficacia como en el estudio de mediadores y moderadores de la intervención, era pequeño. Es necesario replicar estos estudios con muestras más amplias y con diversas poblaciones de dolor crónico para poder corroborar nuestros resultados.

En segundo lugar, es importante señalar que la eficacia de las tecnologías no pudo ser comparada, al no contar con una condición sin tecnologías. Por ello, no es posible conocer el papel diferencial de la tecnología en la implementación de la intervención de Mi Mejor Yo Posible. 
En futuros estudios sería importante contemplar la posibilidad de contar con una condición sin el apoyo de tecnologías para poder evaluar de manera controlada su rol en la potenciación del ejercicio de visualización.

A la luz de los resultados obtenidos en este estudio, un punto importante a destacar es el efecto producido por la condición control, el ejercicio de Actividades Diarias. Las pacientes de ambas condiciones recibieron la misma descripción del estudio, que indicaba que realizar el ejercicio podría tener una influencia positiva en su estado de ánimo. Esta instrucción podría haber influido en los resultados. Se ha demostrado que las expectativas sobre los resultados del tratamiento pueden mejorar o reducir los efectos analgésicos de las intervenciones (Peerdeman y cols., 2016). Sin embargo, el procedimiento se extrajo de estudios anteriores en los que las expectativas no tuvieron ningún efecto sobre los resultados. Es preciso destacar que éstos fueron realizados en población general.

Además, la intervención control está centrada en las últimas 24 horas, a diferencia del ejercicio de Mi Mejor Yo Posible, que está orientado hacia el futuro. Las pacientes que sufren de FM suelen expresar su miedo a pensar sobre el futuro y sus sentimientos de desesperanza hacia lo que el futuro puede traer (Sallinen, Kukkurainen y Peltokallio, 2011). Futuros estudios podrían considerar desarrollar una intervención control que también estuviera centrada en el futuro y controlar así el rol que juega la orientación temporal de la intervención.

Por otro lado, sería importante incluir otras variables de resultado, como pasó en el caso de la autoeficacia, para estudiar el alcance de esta intervención. Y en este punto, no sólo pensar qué variables clínicas 
relevantes medir, sino cómo medirlas. En este sentido, una limitación de nuestros estudios es depender casi exclusivamente de medidas de autoreporte. Los nuevos métodos de evaluación centrados en la evaluación ecológica momentánea a partir de teléfonos móviles pueden ser una herramienta muy útil para la medición del dolor, estado de ánimo y variables relacionadas con el dolor. Y no sólo medirlas de forma aislada, sino poder ver la relación entre las mismas en el día a día y en el entorno natural del paciente. Además, en el caso de introducir una intervención psicológica, nos permitiría observar las distintas trayectorias de cambio y así determinar de manera más precisa los perfiles de pacientes que se beneficiarían más o menos con estas nuevas intervenciones.

Por último, creemos que la intervención de Mi Mejor Yo Posible resulta una herramienta psicológica prometedora. Aún queda mucho por estudiar acerca de sus beneficios. Para ello, mediante métodos de análisis cualitativo creemos que sería interesante realizar un análisis de contenido de las narrativas producidas por las pacientes y comprender mejor cuáles son las metas vitales relevantes para las pacientes que sufren FM y cómo ayudarlas a resignificar ese futuro que muchas veces les parece aterrador.

\section{Conclusiones}

Aunque el papel de los factores positivos como protección frente a los efectos incapacitantes del dolor crónico había sido estudiado previamente, el rol específico de los componentes positivos en los tratamientos psicológicos para el dolor crónico no había sido extraído y probado. Creemos que la presente tesis doctoral es una importante contribución, no sólo a la investigación sobre la eficacia de las intervenciones psicológicas positivas, 
sino también a la investigación de los tratamientos psicológicos para personas que sufren dolor crónico, ayudando a entender cómo una intervención psicológica centrada en la promoción de afecto positivo trabaja en una población especial, los pacientes con FM, ampliando sus datos de eficacia en poblaciones clínicas específicas y aportando conocimiento al papel que los factores psicológicos positivos tienen en la experiencia del dolor.

Además, nuestros hallazgos muestran los efectos específicos de la intervención de Mi Mejor Yo Posible, ayudando a extraer conclusiones sobre la utilidad de incorporar este ejercicio en los protocolos de tratamiento. Por otra parte, nuestro trabajo propone una buena manera de implementar el ejercicio de Mi Mejor Yo Posible integrando las TICs en el sistema de prestación de servicios de salud existente. Asimismo, esta tesis doctoral extiende las conclusiones de trabajos anteriores demostrando que la intervención de Mi Mejor Yo Posible puede tener un efecto sobre los niveles de autoeficacia en pacientes con dolor crónico que han estado experimentando dolor durante aproximadamente 10 años.

Los resultados alcanzados en la presente tesis doctoral nos animan a continuar explorando el uso de intervenciones basadas en imaginería positiva y apoyadas por tecnologías en esta población. Creemos que el manejo de esta condición de dolor crónico necesita adaptar las intervenciones que incluyen múltiples componentes de tratamiento a cada paciente individual, teniendo en cuenta las nuevas intervenciones clínicas que se dirigen a promover recursos positivos (Goodin y Bulls 2013), y la comprensión de que si se trata de una condición crónica, la autogestión y el autocuidado son eventualmente fundamentales. 
Si bien hemos ayudado a responder cómo una de las intervenciones dirigidas a aumentar el afecto positivo y promover el funcionamiento positivo funciona, y qué mecanismos actúan como facilitadores del cambio, aún quedan preguntas por responder. ¿Debemos poner un énfasis principal en el tratamiento de los factores positivos como una vía para mejorar los síntomas del dolor crónico? ¿Debemos primero aliviar los síntomas de malestar para lograr cambios en las medidas de funcionamiento positivo? Las investigaciones futuras deben determinar qué mecanismos específicos se promueven en las intervenciones centradas en el afecto positivo, qué mecanismos comparten, y si se pueden mejorar los tamaños del efecto de estas intervenciones. Las terapias de intervención psicológica para el dolor crónico suelen ser complejas y abordan diferentes objetivos terapéuticos. Tal vez es hora de dar un paso atrás y diseñar y probar intervenciones específicas, para producir cambios en variables determinadas, y luego incluirlas en protocolos de tratamiento.

Además, nuestros resultados extienden estudios previos sobre los moderadores del cambio en los tratamientos del dolor, incluyendo estrategias de regulación emocional como predictores clínicos. Estos resultados contribuyen a la comprensión de las estrategias de regulación emocional en la asociación entre el afecto positivo inducido y la depresión en pacientes con dolor crónico. Nuestros hallazgos sugieren que futuras investigaciones se beneficiarían de la medición de los estilos de regulación del afecto positivo y negativo.

En resumen, estos estudios amplían los hallazgos anteriores sobre las características de los pacientes asociados con la respuesta a las 
intervenciones de tratamiento del dolor. Además, presentan evidencia sobre cómo y quiénes pueden beneficiarse más de una intervención dirigida a aumentar el afecto positivo y promover el funcionamiento positivo en pacientes con FM. Tradicionalmente, estos esfuerzos se habían centrado en las respuestas a los tratamientos basados en la Terapia Cognitivo Comportamental. Se necesita más investigación para avanzar en nuestra comprensión de los mecanismos terapéuticos involucrados en las intervenciones psicológicas para el manejo del dolor crónico.

Desde los modelos biopsicosociales de dolor hacia los modelos actuales centrados en los sistemas de aproximación y de inhibición relacionados con el dolor, todos ellos señalan la importancia de los factores psicosociales en el mantenimiento del dolor crónico. Las relaciones entre las variables cognitivas, afectivas, conductuales y el dolor, parecen ser más complejas de lo que se pensaba originalmente. Los comportamientos, pensamientos y emociones aparecen como agentes causales, pero también como variables de resultado en intervenciones de dolor. Además, estas interacciones pueden ser moduladas por diferencias individuales. Para entender estas interacciones multifacéticas, las intervenciones psicológicas para el tratamiento del dolor crónico deben orientar y evaluar estas diferentes variables asociadas con el dolor, incluyendo los factores positivos y las estrategias de regulación emocional, con el fin de mejorar el manejo psicológico del dolor crónico. Y esta mejora vendrá de la mano de la integración de la investigación y la práctica clínica. 


\section{Referencias Bibliográficas}

Affleck, G., Tennen, H., Zautra, A., Urrows, S., Abeles, M., y Karoly, P. (2001). Women's pursuit of personal goals in daily life with fibromyalgia: a value-expectancy analysis. Journal of Consulting and Clinical Psychology, 69, 587-596.

Alden, A. L., Dale, J. A., y DeGood, D. E. (2001). Interactive effects of the affect quality and directional focus of mental imagery on pain analgesia. Applied Psychophysiology and Biofeedback, 26, 117-126.

Bandura A. (1977). Self-efficacy: Toward a unifying theory of behavioral change. Psychological Review, 84, 191-215.

Baños, R. M., Etchemendy, E., Farfallini, L., García-Palacios, A., Quero, S. y Botella, C. (2014). EARTH of Well-Being System: A pilot study of an Information and Communication Technology-based positive psychology intervention. Journal of Positive Psychology, 9, 482-488.

Bolier, L., Haverman, M., Westerhof, G. J., Riper, H., Smit, F., y Bohlmeijer, E. (2013). Positive psychology interventions: A meta-analysis of randomized controlled studies. BMC Public Health, 13, 119.

Boselie, J. J., Vancleef, L. M., Smeets, T. y Peters, M. L. (2014). Increasing optimism abolishes pain-induced impairments in executive task performance. Pain, 155, 334-340.

Bosscher, R. J. y Smit, J. H. (1998). Confirmatory factor analysis of the General Self Efficacy Scale. Behavior Research and Therapy, 36, 339-343.

Botella, C., Baños, R. M., Guillén Botella, V. (2017). Positive Technologies for improving health and well-being. In Carmel Proctor (Eds.): Positive 
Psychology Interventions in Practice (219-234). Springer International Publishing.

Botella, C., García-Palacios, A., Vizcaíno, Y., Herrero, R., Baños, R. M. y Belmonte, M. (2013). Virtual Reality in the treatment of fibromyalgia: a pilot study. Cyberpsychology, Behavior and Social Networking, 16(3), 215-223.

Botella, C., Riva, G., Gaggioli, A., Wiederhold, B. K., Alcaniz, M. y Baños, R. M. (2012). The present and future of positive technologies. Cyberpsychology Behavior and Social Networking, 15, 78-84.

Brinker, J. K. y Dozois, D. J. (2009). Ruminative thought style and depressed mood. Journal of Clinical Psychology, 65, 1-19.

Carver, C. S., Scheier, M. F. y Segerstrom, S. (2010). Optimism. Clinical Psychology Review, 30, 879-889.

Castells, X., Coscolla, R., Sunyol, R., Cegarra, B., y Comas, N. (2013). “ESTUDI EPIFFAC" Impacto Familiar, Socio-Laboral y Económico de Padecer Fibromialgia.

Disponible

en

http://www.infocop.es/pdf/EstudiEPIFFAC.pdf.

DasMahapatra, P., Chiauzzi, E., Pujol, L. M., Los, C., Trudeau, K. J. (2015). Mediators and Moderators of Chronic Pain Outcomes in an Online SelfManagement Program. The Clinical Journal of Pain, 31, 404-413. doi:10.1097/AJP.0000000000000125.

Davis, M. C., Zautra, A. J. y Smith, B. W. (2004). Chronic pain, stress, and the dynamics of affective differentiation. Journal of Personality, 72, 11331160. 
Edwards, R. R., Dworkin, R. H., Sullivan, M. D., Turk, D. C. y Wasan, A. D. (2016). The Role of Psychosocial Processes in the Development and Maintenance of Chronic Pain. The Journal of Pain, 17, 70-92.

Eichner, K. V., Kwon, P. y Marcus, D. K. (2014). Optimists or optimistic? A taxometric study of optimism. Psychological Assessment, 26, 10561061.

Erikson, M. G. (2007). The meaning of the future: towards a more specific definition of possible selves. Review of General Psychology, 11, 348358.

Esteve, R., Ramírez-Maestre, C., Peters, M. L., Serrano-Ibáñez, E. R., RuízPárraga, G. T., López-Martínez, A. E. (2016). Development and initial validation of the Activity Patterns Scale in patients with chronic pain. The Journal of Pain, 17, 451-461.

Feldman, G. C., Joormann, J., Johnson, S. L. (2008). Responses to Positive Affect: A Self-Report Measure of Rumination and Dampening. Cognitive Therapy and Research, 32, 507-525. doi:10.1007/s10608006-9083-0.

Finan, P. H., y Garland, E. (2015). The role of positive affect in pain and its treatment. The Clinical Journal of Pain, 31, 177-187.

Finan, P. H., Quartana, P. J. y Smith, M. T. (2013). Positive and negative affect dimensions in chronic knee osteoarthritis: effects on clinical and laboratory pain. Psychosomatic Medicine, 75, 463-470.

Finan, P. H., Zautra, A. J. y Davis, M. C. (2009). Daily affect relations in fibromyalgia patients reveal positive affective disturbance. Psychosomatic Medicine, 71, 474-482. 
Flink, I. K., Smeets, E., Bergbom, S. y Peters, M. L. (2015). Happy despite pain: a pilot study of a positive psychology intervention for patients with chronic pain. Scandinavian Journal of Pain, 7, 71-9.

Flor, H. y Turk, D. (2011). Chronic Pain: An Integrated Biobehavioural Approach. Seattle: IASP Press.

Fors, E. A., Sexton, H. y Götestam, K. G. (2002). The effect of guided imagery and amitriptyline on daily fibromyalgia pain: a prospective, randomized, controlled trial. Journal of Psychiatric Research, 36, 179187.

Fredrickson, B. L. (2001). The role of positive emotions in positive psychology. The broaden-and-build theory of positive emotions. The American Psychologist, 56, 218-226.

Gatchel, R.J., Peng, Y.B., Peters, M.L., Fuchs, P.N., \& Turk, D.C. (2007). The biopsychosocial approach

to chronic pain: Scientific advances and future directions. Psychological Bulletin, 133, 581-624.

Gatchel, R.J., Peng, Y.B., Peters, M.L., Fuchs, P.N., \& Turk, D.C. (2007). The biopsychosocial approach

to chronic pain: Scientific advances and future directions. Psychological Bulletin, 133, 581-624.

Gatchel, R.J., Peng, Y.B., Peters, M.L., Fuchs, P.N., \& Turk, D.C. (2007). The biopsychosocial approach

to chronic pain: Scientific advances and future directions. Psychological Bulletin, 133, 581-624. 
Gatchel, R.J., Peng, Y.B., Peters, M.L., Fuchs, P.N., y Turk, D.C. (2007). The biopsychosocial approach to chronic pain: Scientific advances and future directions. Psychological Bulletin, 133, 581-624.

Garcia-Palacios, A., Herrero, R., Belmonte, M. A., Castilla, D., Guixeres, J., Molinari, G., Banos R. M. y Botella, C. (2014). Ecological momentary assessment for chronic pain in fibromyalgia using a smartphone: a randomized crossover study. European Journal of Pain, 18(6), 862872.

Giacobbi, P. R., Stabler, M., Stewart, J., Jaeschke, A. M., Siebert, J.L. y Kelley, G. A. (2015). Guided Imagery for Arthritis and other Rheumatic Diseases: A Systematic Review of Randomized Controlled Trials. Pain Management and Nursing, 16, 792-803.

Glombiewski, J. A., Sawyer, A. T., Gutermann, J., Koenig, K., Rief, W. y Hofmann, S. G. (2010). Psychological treatments for fibromyalgia: A metaanalysis. Pain, 151, 280-295.

Goodin, B. R., y Bulls, H. W. (2013). Optimism and the experience of pain: benefits of seeing the glass as half full. Current Pain and Headache Reports, 17, 329-339.

Goodin, B. R., Glover, T. L., Sotolongo, A., King, C. D., Sibille, K. T., Herbert, M. S., ... Fillingim, R. B. (2013). The association of greater dispositional optimism with less endogenous pain facilitation is indirectly transmitted through lower levels of pain catastrophizing. The Journal of Pain, 14, 126-135.

Gray, J. A. (1990). Brain systems that mediate both emotion and cognition. Cognition and Emotion, 4, 269-288. 
Hanssen, M. M., Peters, M. L., Vlaeyen, J. W. S., Meevissen, Y. M. C. y Vancleef, L. M. G. (2013). Optimism lowers pain: evidence of the causal status and underlying mechanisms. Pain, 154, 53-58.

Hassett, A. L. y Finan, P. H. (2016). The role of resilience in the clinical management of chronic pain. Current Pain and Headache Reports, 20, 39.

Hausmann, L. R. M., Parks, A., Youk, A. O. y Kwoh, C. K. (2014). Reduction of bodily pain in response to an online positive activities intervention. The Journal of Pain, 15, 560-567.

Herrero, R., García-Palacios, A., Castilla, D., Molinari, G. y Botella C. (2014). Virtual Reality for the Induction of Positive Emotions in the Treatment of Fibromyalgia: A Pilot Study over Acceptability, Satisfaction, and the Effect of Virtual Reality on Mood. Cyberpsychology Behavior and Social Networking, 17, 379-84.

Holmes E. A. y Mathews A. (2005). Mental imagery and emotion: A special relationship? Emotion, 5, 489-97.

Holmes, E. A. y Mathews, A. (2010). Mental imagery in emotion and emotional disorders. Clinical Psychology Review, 30, 349-362.

Hood, A., Pulvers, K., Carrillo, J., Merchant, G., y Thomas, M. (2012). Positive traits linked to less pain through lower pain catastrophizing. Personality and Individual Differences, 52, 401-405.

Iddon, J.E., Dickson, J.M y Unwin, J. (2016). Positive Psychological Interventions and Chronic Non-Cancer Pain: A systematic review of the literature. International Journal of Applied Positive Psychology, 125. doi:10.1007/s41042-016-0003-6 
Jackson, T., Wang, Y., Wang, Y. y Fan, H. (2014). Self-efficacy and chronic pain outcomes: A meta-analytic review. The Journal of Pain, 15, 800-814.

Jensen, M. P., Ehde, D. M. y Day, M. A. (2016). The Behavioral Activation and Inhibition Systems: Implications for understanding and treating chronic pain. The Journal of Pain, 17, 529.e1-529.e18. doi: 10.1016/j.jpain.2016.02.001

Jensen, M. P., Tan, G., Chua, S. M. (2015). Pain intensity, headache frequency, and the behavioral activation and inhibition systems. The Clinical Journal of Pain, 31, 1068-1074.

Kamping S, Bomba IC, Kanske P, Diesch E, Flor H. 2013. Deficient modulation of pain by a positive emotional context in fibromyalgia patients. Pain 154:1846-1855

Kamping S, Bomba IC, Kanske P, Diesch E, Flor H. 2013. Deficient modulation of pain by a positive emotional context in fibromyalgia patients. Pain 154:1846-1855

Kamping S, Bomba IC, Kanske P, Diesch E, Flor H. 2013. Deficient modulation of pain by a positive emotional context in fibromyalgia patients. Pain 154:1846-1855

Kamping, S., Bomba, I. C., Kanske, P., Diesch, E., Flor, H. (2013). Deficient modulation of pain by a positive emotional context in fibromyalgia patients. Pain, 154, 1846-1855.

Keefe, F.J., y Wren, A. A. (2013). Optimism and pain: a positive move forward. Pain, 154, 7-8.

Keogh, E., Rosser, B. y Eccleston, C. (2010). e-Health and chronic pain management: current status and developments. Pain, 151, 18-21. 
King, L. A. (2001). The health benefits of writing about life goals. Personality and Social Psychology Bulletin, 27, 798-807.

Lewandowski, W. (2004). Patterning of pain and power with guided imagery. Nursing Science Quarterly, 17, 233-241.

Loveday, P. M., Lovell, G. P. y Jones, C. M. (2016). The Best Possible Selves Intervention: A review of the literature to evaluate efficacy and guide future research. Journal of Happiness Studies. 1-22. doi:10.1007/s10902-016-9824-z

Lyubomirsky, S. y Nolen-Hoeksema, S. (1995). Effects of self-focused rumination on negative thinking and interpersonal problem solving. Journal of Personality and Social Psychology, 69, 176-190.

MacLeod, A. K. (1996). Affect, emotional disorder, and future-directed thinking. Cognition \& Emotion, 10, 69-86.

MacLeod, A. K., Tata, P., Kentish, J. y Jacobsen, H. (1997) Retrospective and Prospective Cognitions in Anxiety and Depression, Cognition \& Emotion, 11, 467-479.

Malin, K. y Littlejohn, G. O. (2015). Rumination modulates stress and other psychological processes in fibromyalgia. European Journal of Rheumatology, 2,143-148. doi.org/10.5152/eurjrheum.2015.0005

Meevissen, Y. M., Peters, M. L. y Alberts, H. J. (2011). Become more optimistic by imagining a best possible self: effects of a two week intervention. Journal of Behavior Therapy and Experimental Psychiatry, 42, 371-378.

Menzies, V., Taylor, A. G. y Bourguignon, C. (2006). Effects of guided imagery on outcomes of pain, functional status, and self-efficacy in persons 
diagnosed with fibromyalgia. Journal of Alternative and Complementary Medicine, 12, 23-30.

Mohr, D. C., Burns, M. N., Schueller, S. M., Clarke, G., y Klinkman, M. (2013). Behavioral intervention technologies: Evidence review and recommendations for future research. General Hospital Psychiatry, 35, 332-338.

Morley, S., Eccleston, C., y Williams, A. (1999). Systematic review and metaanalysis of randomized controlled trials of cognitive behaviour therapy and behaviour therapy for chronic pain in adults, excluding headache. Pain, 80, 1-13.

Morley S, Williams A, Eccleston C. (2013). Examining the evidence of psychological treatments for chronic pain: time for a paradigm shift? Pain, 154, 1929-1931.

Morris, L. D., Louw, Q. A., Grimmer, K. A., Meintjes, E. (2015). Targeting pain catastrophization in patients with fibromyalgia using virtual reality exposure therapy: a proof-of-concept study. Journal of Physical Therapy Science, 27, 3461-3467.

Muller, R., Gertz, K. J., Molton, I. R., Terrill, A. L., Bombardier, C. H., Ehde, D. M. y Jensen, M. P. (2016). Effects of a tailored positive psychology intervention on well-being and pain in individuals with chronic pain and a physical disability: a feasibility trial. The Clinical Journal of Pain, $32,32-44$.

Peerdeman, K. J., Van laarhoven, A. I., Peters, M. L. y Evers, A. W. (2016). An integrative review of the influence of expectancies on pain. Frontiers in Psychology, 7, 1270. 
Peters, M. L., Flink, I. K., Boersma, K., y Linton, S. J. (2010). Manipulating optimism: can imagining a best possible self be used to increase positive future expectancies? Journal of Positive Psychology, 5, 204211.

Pietrowsky, R. y Mikutta, J. (2012). Effects of positive psychology interventions in depressive patients: a randomized control study. Psychology, 3, 1067-1073.

Pressman, S. D. y Cohen, S. (2005). Does positive affect influence health? Psychological Bulletin, 131, 925.

Queiroz, L. P. (2013). Worldwide epidemiology of fibromyalgia. Current Pain and Headache Report, 17, 356.

Quero, S., Molés, M., Pérez, M. A., Botella, C., y Baños, R. M. (2012). An online emotional system to deliver homework assignments for treating adjustment disorders. Journal of CyberTherapy and Rehabilitation, 5, 115-116.

Reme, S.E. (2017). Positive affect could reduce the impact of pain. Scandinavian Journal of Pain, 14, 89-90.

Renner, F., Schwarz, P., Peters, M. L. y Huibers, M. J. (2014). Effects of a best possible self mental imagery exercise on mood and dysfunctional attitudes. Psychiatry Research, 215, 105-110.

Riva, G., Baños, R. M., Botella, C., Mantovani, F., y Gaggioli, A. (2016). Transforming Experience: The Potential of Augmented Reality and Virtual Reality for Enhancing Personal and Clinical Change. Frontiers in Psychiatry, 7, 164. 
Rivera, J., Alegre, C., Ballina, F. J., Carbonell, J., Carmona, L., Castel, B., ... Vidal, J. (2006). Documento de consenso de la Sociedad Española de Reumatología sobre la fibromialgia. Reumatología Clínica, 2, 55-66.

Roditi, D. y Robinson, M. E. (2011). The role of psychological interventions in the management of patients with chronic pain. Psychology Research and Behavior Management, 4, 41-49. doi:10.2147/PRBM.S15375

Sallinen, M., Kukkurainen, M. L. y Peltokallio, L. (2011). Finally heard, believed and accepted-peer support in the narratives of women with fibromyalgia. Patient Education and Counseling, 85, 126-130.

Scascighini, L., Toma, V., Dober-Spielmann, S., y Sprott, H. (2008). Multidisciplinary treatment for chronic pain: A systematic review of interventions and outcomes. Rheumatology, 47, 670-678. doi:10.1093/ rheumatology/ken021

Segerstrom, S. C. (2007). Optimism and resources: Effects on each other and on health over 10 years. Journal of Research in Personality, 41, 772786.

Scheier, M. F., Carver, C. S. y Bridges, M. W. (1994). Distinguishing optimism from neuroticism (and trait anxiety, self-mastery, and self-esteem): A re-evaluation of the Life Orientation Test. Journal of Personality and Social Psychology, 67, 1063-1078.

Sheldon, K. M. y Lyubomirsky, S. (2006). How to increase and sustain positive emotion: the effects of expressing gratitude and visualizing best possible selves. Journal of Positive Psychology, 1, 73-82.

Simm, R., Iddon, J. y Barker, C. (2014). A community pain service solutionfocused pain management programme: delivery and preliminary 
outcome data. British Journal of Pain, 8, 49-56. doi:10.1177 /2049463713507910.

Strand, E.B., Zautra, A.J., Thoresen, M., Ødegård, S., Uhlig, T. y Finset, A. (2006). Positive affect as a factor of resilience in the pain-negative affect relationship in patients with rheumatoid arthritis. Journal of Psychosomatic Research, 60, 477-484.

Strand, E. B., Kerns, R. D., Christie, A., Haavik-Nilsen, K., Klokkerud, M. y Finset, A. (2007). Higher levels of pain readiness to change and more positive affect reduce pain reports - a weekly assessment study on arthritis patients. Pain, 127, 204-213.

Sturgeon, J. A., Zautra, A. J. (2010). Resilience: a new paradigm for adaptation to chronic pain. Current Pain and Headache Reports, 14, 105-112.

Sturgeon, J. A., Zautra, A. J. (2013). Psychological resilience, pain catastrophizing, and positive emotions: perspectives on comprehensive modeling of individual pain adaptation. Current Pain and Headache Reports, 17, 317. doi: 10.1007/s11916-012-0317-4.

Thong, I. S. K. , Tan, G. y Jensen, M. P. (2017). The buffering role of positive affect on the association between pain intensity and pain related outcomes. Scandinavian Journal of Pain, 14, 91-97.

Tooyserkani, M. A., Besharat, M. A. y Koochi, S. (2011). The moderating role of positive and negative affect on the relationship between alexithymia and experience of pain in chronic pain patients. Procedia Social and Behavioral Sciences, 30, 154-158.

Vowles, K. E., Witkiewitz, K., Levell, J., Sowden, G. y Ashworth, J. (2017). Are reductions in pain intensity and pain-related distress necessary? An 
analysis of within-treatment change trajectories in relation to improved functioning following interdisciplinary acceptance and commitment therapy for adults with chronic pain. Journal of Consulting and Clinical Psychology, 85, 87-98.

Wolfe, F., Clauw, D.J., Fitzcharles, M.A, Goldenberg, D.L,, Häuser, W., Katz, R. S., ...Winfield, J. B. (2011). Fibromyalgia criteria and severity scales for clinical and epidemiological studies: a modification of the ACR Preliminary Diagnostic Criteria for Fibromyalgia. The Journal of Rheumatology, 38, 1113-1122.

Zautra, A. J., Burleson, M. H., Smith, C. A., Blalock, S. J., Wallston, K. A., DeVellis, R. F., DeVellis, B. M. y Smith, T. W. (1995). Arthritis and perceptions of quality of life: an examination of positive and negative affect in rheumatoid arthritis patients. Health Psychology, 14, 399-408.

Zautra, A. J., Fasman, R., Reich, J. W., Harakas, P., Johnson, L. M., Olmsted, M. E. y Davis, M. C. (2005). Fibromyalgia: evidence for deficits in positive affect regulation. Psychosomatic Medicine, 67, 147-155.

Zautra, A. J., Johnson, L. M. y Davis, M. C. (2005). Positive affect as a source of resilience for women in chronic pain. Journal of Consulting and Clinical Psychology, 73, 212-220. 


\section{Anexos}




\section{MANUAL DE USO}

\section{"El poder de la} Imaginación"

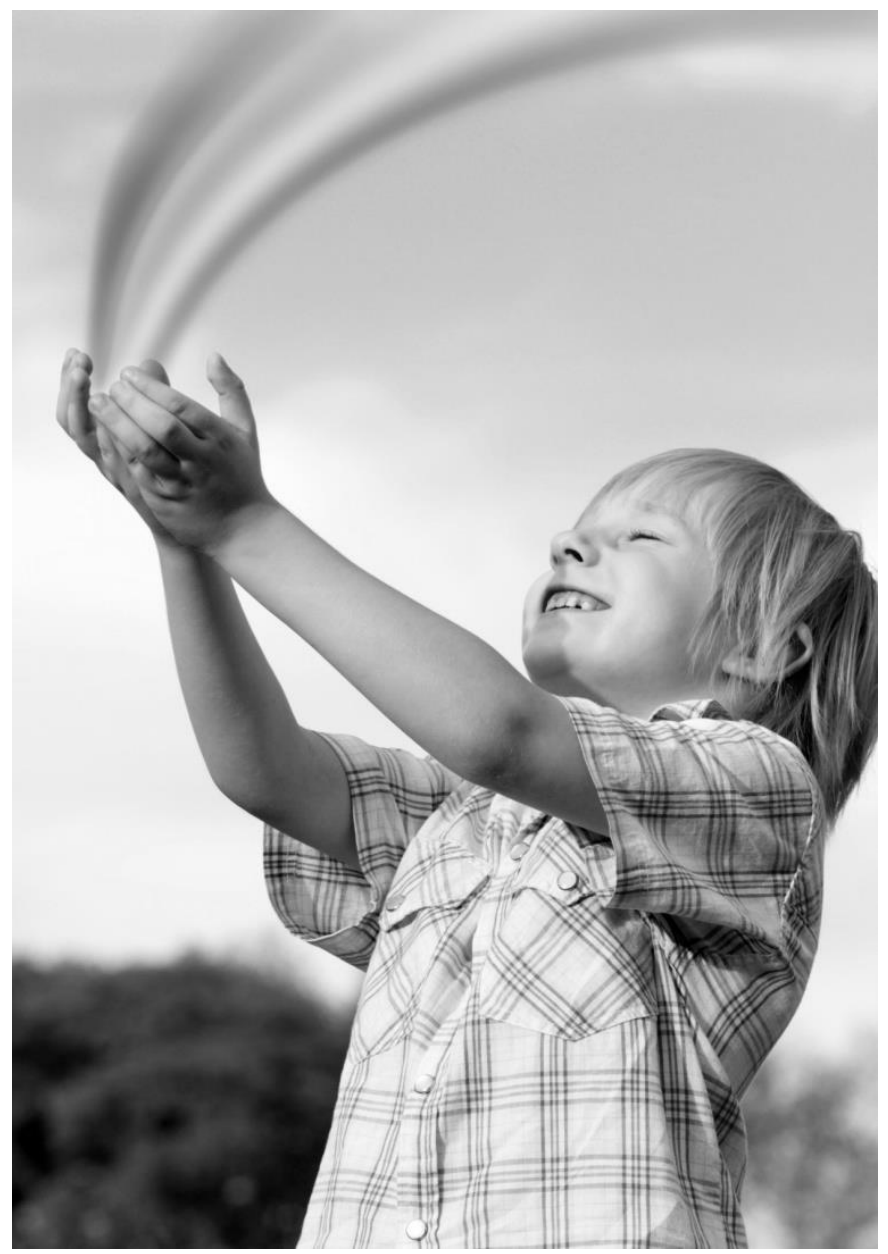

LABPSITEC, 2012. Castellón de la Plana, España. 


\section{¡Bienvenido!}

Muchas gracias por participar en nuestro estudio de investigación "El poder de la Imaginación". Las instrucciones que te brindaremos a continuación, te ayudarán paso a paso a mejorar tus habilidades de visualización.

Es importante que sepas que toda la información es tratada de manera absolutamente confidencial y todo el material que generes a partir del ejercicio que te propondremos será leído únicamente por ti. 


\section{$M i$ “mejor yo"}

Has sido asignado al azar para participar en una condición en la que vas a pensar sobre tu "mejor yo posible". Con este posible mejor "yo" queremos que te imagines a ti mismo en un futuro en el que todo se ha desarrollado de la mejor manera posible. Te has esforzado mucho y has conseguido alcanzar todos los objetivos que te habías planteado en tu vida. Puedes imaginártelo como el hecho de haber conseguido todos tus sueños y de haber desarrollado todas tus potencialidades.

Dentro de un momento, te voy a pedir que pienses en la mejor manera posible en que tu vida podría desarrollarse en 4 ámbitos (personal, social, profesional y de la salud), con el objetivo de dirigir las decisiones que estás tomando en la actualidad. Probablemente nunca has pensado acerca de ti mismo de esta manera, pero las investigaciones sugieren que este método puede tener una influencia positiva en tu estado de ánimo. Queremos animarte a que continúes pensando en ti e imaginándote de esta manera durante las próximas cuatro semanas.

Para poder determinar y guiar la construcción de tu mejor posible "yo", durante los próximos 20 minutos, vas a pensar y a escribir las metas, habilidades y deseos que te gustaría adquirir en un futuro lejano dentro de cada uno de los cuatro ámbitos que hemos mencionado. Tienes que unificarlos en una especie de diario personal. A lo largo de este proceso, piensa en habilidades realistas y en metas/deseos que sean posibles de alcanzar y que te gustaría adquirir o lograr en el futuro. 


\section{Ámbito personal}

Piensa en objetivos que te gustaría conseguir en el terreno de lo personal (por ejemplo unas habilidades físicas y psicológicas determinadas).

\section{Ámbito profesional}

Piensa en objetivos que te gustaría conseguir en el terreno de lo profesional, es decir, relacionados con tu trabajo (por ejemplo un puesto determinado, logros profesionales, nivel de experiencia. También puede ser la adquisición de habilidades, etc.).

\section{Ámbito de las relaciones personales}

Piensa en objetivos que te gustaría adquirir en el terreno de las relaciones con los demás (por ejemplo, relaciones y contacto con tus seres queridos, amigos, colegas. También puede ser el hecho de realizar actividades en grupo dentro de tu entorno social).

\section{Ámbito de la salud}

Piensa en objetivos que te gustaría adquirir en el terreno de tu salud, es decir, relacionados con tu estado físico y psicológico (por ejemplo, llevar adelante hábitos de salud saludables, ser capaz de hacer frente a los problemas de salud que pudieran aparecer, estar activo e implicado en tu vida, etc.) 
Ahora, me gustaría que escribas, de la manera más detallada posible, cuál es tu futuro ideal. Puedes usar las metas que acabas de construir como guía. Cuando describas tus pensamientos, intenta activar todos tus sentidos, emociones y percepciones y haz de todo ello una historia personal.

Para finalizar, repasa en el "Libro de la Vida" lo que has escrito, vuelve a ver las imágenes que has elegido o la música que has seleccionado, e imagínate durante 5 minutos ese "Mejor Yo Posible" que quieres ver realizado en un futuro... 
Te animamos a que continúes pensando en ti e imaginándote de esta manera durante las próximas semanas. Puedes volver a leer lo que has escrito y a mirar los elementos que has utilizado, cuantas veces lo desees. Incluso puedes continuar modificándolos, visualizándolos de otra manera, escribiendo e incluyendo tus propias imágenes y todo lo que desees...

¡No olvides realizar este ejercicio por lo menos 5 minutos al día durante los próximos 30 días!

...Céntrate en ti e imagina tu mejor yo posible... 


\section{MANUAL DE USO}

\section{"El poder de la} Imaginación"

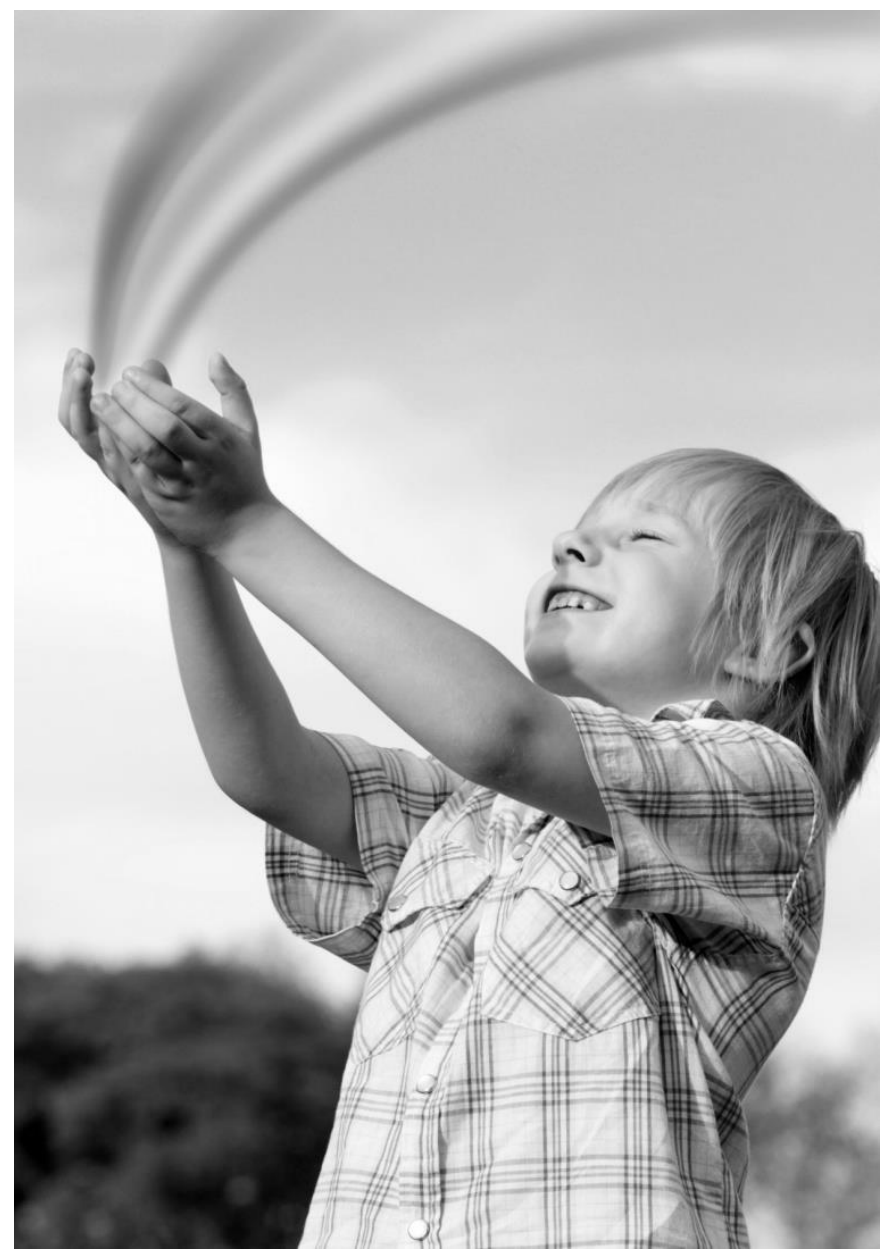




\section{¡Bienvenido!}

Muchas gracias por participar en nuestro estudio de investigación "El poder de la Imaginación". Las instrucciones que te brindaremos a continuación, te ayudarán paso a paso a mejorar tus habilidades de visualización.

Es importante que sepas que toda la información es tratada de manera absolutamente confidencial y todo el material que generes a partir del ejercicio que te propondremos será leído únicamente por ti. 


\section{Mis actividades diarias}

Has sido asignado al azar para participar en una condición en la que vas a prestar mayor atención a las actividades que realizas diariamente en tu vida. Esto quiere decir que vas a pensar más en aquellas actividades de tu vida diaria que normalmente pasan desapercibidas, como por ejemplo, reuniones, clases, conversaciones, pensamientos típicos que tienes durante el día, etc. Utiliza tu agenda de las últimas 24 horas como guía. Este ejercicio te ayudará a identificar más fácilmente áreas problemáticas que puedes tener en tu vida y a actuar para mejorarlas.

Probablemente nunca has pensado acerca de ti mismo de esta manera, pero las investigaciones sugieren que este método puede tener una influencia positiva en tu estado de ánimo. Queremos animarte a que continúes pensando en ti e imaginándote de esta manera durante las próximas cuatro semanas.

Para ayudarte a determinar y guiar en lo que centrarte, trabaja de acuerdo a la siguiente estructura. Piensa en tu agenda de las últimas 24 horas y repásala lentamente. Piensa en las actividades, reuniones, etc. y profundiza en las conversaciones, discusiones, pensamientos o en el estado de ánimo que puedes haber tenido. 
Durante los próximos $\mathbf{2 0}$ minutos te pedimos que escribas tus pensamientos. Cuando describas tus pensamientos, intenta activar todos tus sentidos, sensaciones y percepciones y haz de todo ello una historia personal.

Para finalizar, repasa lo que has escrito, y piensa durante 5 minutos en las actividades que has realizado....

Te animamos a que continúes pensando en las actividades que realizas durante las próximas semanas. Puedes volver a leer lo que has escrito cuantas veces lo desees. Incluso puedes continuar modificándolas ...

¡No olvides realizar este ejercicio por lo menos 5 minutos al día durante los próximos 30 días!

...Continúa pensando en ti e imaginándote de esta manera durante las próximas semanas... 